\title{
jpen
}

AUTARQUIA ASSOCIADA À UNIVERSIDADE DE SÃO PAULO

PROJETO, CONSTRUÇÃO E CARACTERIZAÇÃO DE CÂMARAS DE IONIZAÇÃO PARA UTILIZAÇÃO COMO SISTEMAS PADRÕES

EM FEIXES DE RADIAÇÃO X E GAMA

ANA PAULA PERINI

Tese apresentada como parte dos requisitos para obtenção do Grau de Doutor em Ciências na Área de Tecnologia Nuclear - Aplicações

Orientadora:

Profa. Dra. Linda V. E. Caldas 


\title{
INSTITUTO DE PESQUISAS ENERGÉTICAS E NUCLEARES
}

Autarquia associada à Universidade de São Paulo

\section{PROJETO, CONSTRUÇÃO E CARACTERIZAÇÃO DE CÂMARAS DE IONIZAÇÃO PARA UTILIZAÇÃO COMO SISTEMAS PADRÕES \\ EM FEIXES DE RADIAÇÃO X E GAMA}

\author{
ANA PAULA PERINI
}

Tese apresentada como parte dos requisitos para obtenção do Grau de Doutor em Ciências na Área de Tecnologia Nuclear - Aplicações

Orientadora:

Profa. Dra. Linda V. E. Caldas

Versão Corrigida

Versão Original disponível no IPEN 
Aos meus pais, aos meus irmãos e ao meu noivo Lucio, com muito amor e carinho. 


\section{AGRADECIMENTOS}

À Dra. Linda Caldas, pela orientação, incentivo, dedicação, oportunidades e confiança dedicada a mim durante todo meu projeto de doutorado. Foi muito bom conviver com uma pessoa tão dedicada, amiga, honesta, solidária e prestativa. Agradeço por ter compartilhado comigo seu conhecimento científico e pessoal, que contribuiu de forma significativa para eu me tornar uma pessoa mais experiente e paciente. Muito obrigada por tudo.

Ao Dr. Vitor Vivolo, por sua ajuda no desenvolvimento deste projeto. Sempre se mostrou muito prestativo para sugerir e contribuir de forma significativa durante a realização dos experimentos. Também gostaria de agradecer ao Dr. Vitor por suas contribuições a este trabalho, em meu exame de Qualificação e Seminário de Área.

À Dra. Denise Yanikian Nersissian, do Instituto de Física da Universidade de São Paulo, pelas contribuições a este trabalho, em meu exame de Qualificação e Seminário de Área.

À Dra. Maria da Penha Albuquerque Potiens, pelos ensinamentos e sugestões durante o desenvolvimento deste projeto.

À Dra. Helen J. Khoury e ao Dr. Vagner Cassola do DEN/UFPE, que me ajudaram muito no aprendizado do Código EGSnrc. Também gostaria de agradecer a dedicação e o acolhimento durante minha estada em Recife.

À Dra. Ana Maia, pelas suas contribuições científicas na área de tomografia computadorizada.

Ao Sr. Claudinei T. Cescon, por toda sua atenção e ajuda com a parte de eletrônica.

Ao Sr. Gelson P. dos Santos, que me ajudou com o aprendizado na utilização do irradiador de ${ }^{60} \mathrm{Co}$ e com os padrões de referência do IPEN.

Ao Sr. Marcos Xavier, pelo desenvolvimento das câmaras de ionização tipo lápis.

Ao Dr. Ludwig Büermann, do Laboratório Padrão Primário Alemão PTB, por sua ajuda e sugestões em simulação de Monte Carlo.

Ao Dr. José Maria Fernández-Varea, da Universidade de Barcelona, por sua 
contribuição significativa em simulação de Monte Carlo com o código PENELOPE. Também gostaria de agradecer pelos conselhos e apoio científico dado a este projeto.

À Dra. Åsa Carlson Tedgren da Linköping University, Sweden, por ceder o espectro do irradiador de ${ }^{60}$ Co do Laboratório de Padrões Secundários da Suécia.

A todos da Oficina Mecânica, em especial ao Sr. José Carlos Sabino, pela confecção das câmaras e dos suportes.

À empresa MRA Indústria de Equipamentos Eletrônicos pelo apoio financeiro.

Ao Dr. Paulo R. Costa, do Instituto de Física da Universidade de São Paulo, por ceder o material equivalente ao tecido, bem como todos os detalhes de seu desenvolvimento, para confecção das câmaras de ionização CMETA e CMETG.

À empresa Carbomec - Indústria de Produtos Eletromecânicos Ltda., pela usinagem das peças em grafite.

À empresa Centerflon, pela usinagem das peças de Teflon.

À Sra. Donata C. Zanin, pela sua disponibilidade em resolver problemas administrativos e por sua amizade e carinho nos vários momentos durante o doutorado.

Aos meus pais, José e Marley, e aos meus irmãos Sérgio, Sandra e Rita pela compreensão de ficarmos longe e por todo apoio e incentivo inesgotável sem o qual tudo se tornaria impossível. Valeu, obrigada por tudo!

Ao meu noivo, que sempre esteve do meu lado, nos momentos mais difíceis e também nos mais felizes. Gostaria de agradecer toda sua dedicação, carinho e compreensão durante todo este projeto de doutorado. Suas conversas sobre como solucionar os problemas que surgiam ao longo deste trabalho foram muito valiosas. Muito obrigada por tudo!

Aos amigos do IPEN, Tallyson Alvarenga, Jonas Oliveira da Silva, Christianne Cavinato, Felipe Belonsi, Fernanda Nonato, Daniela Groppo, Maíra Yoshizumi, Mateus Hilário, Patrícia Antônio, Eric Alexandre Brito da Silva, Gustavo Villa e Maria Inês Teixeira, pelos muitos momentos de descontração.

Ao Instituto de Pesquisas Energéticas e Nucleares (IPEN), pela infraestrutura oferecida e pela oportunidade de desenvolver este trabalho. 
À Comissão Nacional de Energia Nuclear, pelo suporte financeiro.

A Deus que sempre esteve do meu lado indicando o melhor caminho e apontando as melhores soluções para todos os problemas que resolvi durante este projeto. Agradeço também por todas as oportunidades concedidas. 
PROJETO, CONSTRUÇÃO E CARACTERIZAÇÃO DE CÂMARAS DE IONIZAÇÃO PARA UTILIZAÇÃO COMO SISTEMAS PADRÕES EM FEIXES DE RADIAÇÃO X E GAMA

\author{
Ana Paula Perini
}

\title{
RESUMO
}

As câmaras de ionização apresentam várias vantagens em comparação com os demais dosímetros: facilidade de uso, dependência energética pequena e excelente precisão. Estas vantagens aliadas ao grande número de exames de radiodiagnóstico e tratamentos radioterápicos motivaram o desenvolvimento deste plano de doutorado. Neste projeto foram desenvolvidas e caracterizadas câmaras de ionização para aplicação em dosimetria de feixes de radiodiagnóstico e em terapia, com boa precisão e desempenho nos testes de caracterização dentro dos limites recomendados internacionalmente. Elas foram construídas de maneira simples com materiais nacionais de baixo custo, para que elas possam ser reproduzidas e aplicadas em laboratórios de calibração. Os projetos das câmaras de ionização desenvolvidas e caracterizadas neste projeto apresentam diferenças relacionadas ao material e configuração geométrica em comparação às câmaras de ionização comerciais disponíveis no mercado. Além do desenvolvimento de câmaras de ionização para serem utilizadas em feixes padrões de radiação X como padrões de trabalho, neste projeto também foram desenvolvidas e caracterizadas experimentalmente e por simulação de Monte Carlo duas câmaras de ionização cavitárias de grafite de placas paralelas, que foram caracterizadas como sistemas padrões de referência para determinação da taxa de kerma no ar de fontes de radiação gama. Comparando a taxa de kerma no ar determinada com o padrão de referência do Laboratório de Calibração do IPEN, uma câmara de ionização tipo Farmer, com os valores de taxa de kerma no ar obtidos com as câmaras de ionização de grafite, as máximas diferenças obtidas foram de apenas 1,7\% e 1,2\% para as câmaras de ionização de grafite G1 e G2, respectivamente. Além disso, estas câmaras de ionização apresentaram fatores de correção próximos de 1,000, que é o ideal para uma câmara de ionização ser caracterizada como um sistema de referência. 


\title{
PROJECT, CONSTRUCTION AND CHARACTERIZATION OF IONIZATION CHAMBERS FOR USE AS STANDARD SYSTEMS IN X AND GAMMA RADIATION BEAMS
}

\begin{abstract}
Ana Paula Perini
ABSTRACT

Ionization chambers present some advantages in relation to other dosimeters: easiness of handling, low energy dependence and high precision. The advantages associated to ionization chambers and the large number of diagnostic radiology exams and therapeutic treatments motivated the development of this project. In this project ionization chambers were developed and characterized to be applied in diagnostic radiology and therapy beam dosimetry, with high precision and performance, in compliance with international recommendations. They were assembled in a simple way, utilizing low-cost national materials, so they can be reproduced and applied at calibration laboratories. The project of these ionization chambers presents some differences in relation to commercial ionization chambers, as the materials utilized and geometrical arrangements. Besides the development of the ionization chambers to be utilized in standard X-ray beam dosimetry as work standard systems, two graphite parallel-plate ionization chambers were developed and characterized to be applied as reference standard systems for determining the air kerma rates of gamma radiation sources. Comparing the air kerma rates determined with the reference standard of the Calibration Laboratory of IPEN, a Farmer ionization chamber, with the values of the air kerma rates obtained with the graphite ionization chambers, the maximum differences obtained were only $1.7 \%$ and $1.2 \%$ for the G1 and G2 graphite ionization chambers, respectively. Moreover, these ionization chambers presented correction factors close to 1.000 , which is ideal for an ionization chamber be characterized as a reference standard system.
\end{abstract}




\section{Sumário}

Lista de Figuras $\quad$ xi

Lista de Tabelas $\quad$ xv

Lista de Siglas $\quad$ xvii

1 Introdução 1

2 Objetivos $\quad 6$

3 Revisão da Literatura $\quad \mathbf{8}$

3.1 Câmaras de ionização utilizadas em radiodiagnóstico convencional e $\mathrm{TC} \ldots \ldots \ldots \ldots \ldots$. . . . . . . . . . . . . . . . 8

3.2 Câmaras de Ionização Utilizadas como Padrões de Referência . . . . . 11

4 Fundamentos Teóricos $\quad \mathbf{1 5}$

4.1 Interações da Radiação com a Matéria . . . . . . . . . . . . . . . . . 15

4.1.1 Efeito Fotoelétrico . . . . . . . . . . . . . . . 15

4.1 .2 Efeito Compton . . . . . . . . . . . . . . . . 16

4.1.3 Espalhamento Compton Coerente ou Efeito Rayleigh . . . . . 17

4.1.4 Produção de Pares . . . . . . . . . . . . . . . . . . . . 17

4.2 Grandezas Dosimétricas . . . . . . . . . . . . . . . . . 18

4.2 .1 Exposição . . . . . . . . . . . . . . . . . . . . . . 18

4.2 .2 Dose Absorvida . . . . . . . . . . . . . . . . . . . . . . 19

4.2 .3 Kerma . . . . . . . . . . . . . . . . . . 19

4.3 Teoria Cavitária . . . . . . . . . . . . . . . . . . . 20

4.3.1 Teoria de Bragg-Gray . . . . . . . . . . . . . . . . . 20

4.3.2 Teoria de Spencer-Attix . . . . . . . . . . . . . . . 21

4.3.3 Teoria de Burlin ou Teoria Cavitária Geral . . . . . . . . . . . 23

4.4 Câmaras de Ionização . . . . . . . . . . . . . . . . . . . . . . . . . . 24

4.4.1 Características Gerais . . . . . . . . . . . . 24

4.5 Tipos de Câmaras de Ionização . . . . . . . . . . . . . . . . . . . . 25

4.5.1 Câmara de Ionização de Ar Livre . . . . . . . . . . . . . . . . . 25

4.5.2 Câmara de Ionização Cavitária . . . . . . . . . . . . . . . . 27

4.5.3 Câmara de Ionização do Tipo Dedal . . . . . . . . . . . . . . 28

4.5.4 Câmara de Ionização de Placas Paralelas . . . . . . . . . . . . 29

4.6 Testes de Caracterização e Controle de Qualidade das Câmaras de

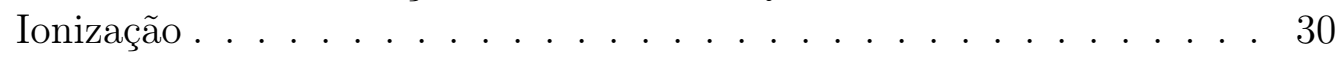

4.6.1 Testes de Estabilidade . . . . . . . . . . . . . . 30 
4.6.2 Teste de Tempo de Estabilização . . . . . . . . . . . . . . . . 31

4.6 .3 Teste de Saturação . . . . . . . . . . . . . . . . . . . . . . . . 31

4.6.4 Teste de Corrente de Fuga . . . . . . . . . . . . . . . . . . 31

4.6.5 Teste de Linearidade de Resposta e Dependência Angular . . . 31

4.6.6 Teste de Dependência Energética . . . . . . . . . . . . . . 32

4.7 Sistema Tandem . . . . . . . . . . . . . . . . . . . . . . 32

4.8 Fatores de Correção Aplicados a Câmaras de Ionização Padrões de

Referência .................... 33

4.8.1 Poder de Freamento . . . . . . . . . . . . . . . . . . . . . 34

4.8.2 Coeficiente de Transferência de Energia Mássico . . . . . . . . 34

4.8.3 Coeficiente de Absorção de Energia Mássico . . . . . . . . . . 34

4.8.4 Fator de Correção de Atenuação e Espalhamento de Fótons na Parede da Câmara de Ionização $\left(\mathrm{k}_{\text {parede }}\right)$. . . . . . . . . 35

4.8.5 Fator de Correção para Falta de Uniformidade Axial $\left(\mathrm{k}_{\mathrm{an}}\right)$. . 35

4.8.6 Fator de Correção para o Espalhamento no Cabo da Câmara

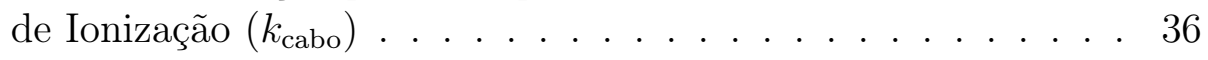

4.8.7 Fator de Correção para o Eletrodo Coletor $\left(k_{\text {elec }}\right)$. . . . . . . 36

4.9 Simulação de Monte Carlo . . . . . . . . . . . . . . . . . . . 37

4.9.1 Aplicações do Método de Monte Carlo . . . . . . . . . . . . . 38

4.9.2 Métodos de Monte Carlo aplicados em Física Médica . . . . . 40

4.9.3 Método de Monte Carlo para o Estudo de Câmaras de Ionização 40

4.10 Calibração de Instrumentos . . . . . . . . . . . . . . . . . . 44

4.10.1 Objetivos e Técnicas da Calibração de Instrumentos . . . . . . 45

4.10 .2 Intercomparação . . . . . . . . . . . . . . . . . . . 46

4.10 .3 Rastreabilidade . . . . . . . . . . . . . . . . . 46

4.10.4 Classificação dos Instrumentos de Medição . . . . . . . . . . . 46

4.10.5 Laboratórios de Padronização . . . . . . . . . . . . . . . . . 47

4.10.6 Sistemas Padrões Utilizados para Medição de Kerma no Ar . . 48

5 Materiais e Métodos $\quad 51$

5.1 Sistemas de Radiação . . . . . . . . . . . . . . . . . . . . . . 51

5.2 Sistemas de Medição . . . . . . . . . . . . . . . . . . . . 52

5.3 Sistemas Auxiliares . . . . . . . . . . . . . . . . . . . 55

5.4 Caracterização Experimental das Câmaras de Ionização . . . . . . . . . 55

5.4 Testes de Estabilidade . . . . . . . . . . . . . 56

5.4.2 Teste de Tempo de Estabilização . . . . . . . . . . . . . . . 56

5.4 .3 Teste de Saturação . . . . . . . . . . . . . . . . . . 56

5.4 .4 Teste de Corrente de Fuga . . . . . . . . . . . . . . 57

5.4.5 Teste de Linearidade de Resposta e Dependência Angular . . . 57

5.4 .6 Teste de Dependência Energética . . . . . . . . . . . . . 58

5.5 Correção das Medições para Condições de Referência de Temperatura e Pressão . . . . . . . . . . . . . . . . . . . . . . . 58

5.6 Caracterização por Simulação de Monte Carlo das Câmaras de Ionização 59

5.6.1 Espectros de Radiação X e de ${ }^{60}$ Co Utilizados nas Simulações 59

5.6.2 Cálculo da Influência dos Componentes das Câmaras de Ionização nas suas Respostas . . . . . . . . . . . . . . . . 60

5.6.3 Determinação dos Fatores de Correção de Câmaras de Ionização 61

5.7 Estimativa das Incertezas . . . . . . . . . . . . . . . . . . 62 
6 Resultados e Discussão: Projeto, Construção e Caracterização Experimental das Câmaras de Ionização

6.1 Projeto e Construção de Câmaras de Ionização em Feixes Padronizados de Radiação X Convencional . . . . . . . . . . . . . . . . . . . . 65

6.2 Caracterização das Câmaras de Ionização CG, CMETG e CMETA em Feixes Padronizados de Radiação X Convencional . . . . . . . . . 71

6.2.1 Curva de Saturação, Efeito de Polaridade e Eficiência de Coleção de Íons . . . . . . . . . . . . . . . . . . . . . . . . . 71

6.2.2 Teste de Estabilidade de Resposta em Curto e Longo Prazos . 72

6.2.3 Tempo de Estabilização . . . . . . . . . . . . . . . . . . . 74

6.2.4 Teste de Corrente de Fuga . . . . . . . . . . . . . . . . . 75

6.2.5 Teste de Linearidade de Resposta . . . . . . . . . . . . . . . . 75

6.2.6 Teste de Dependência Angular . . . . . . . . . . . . . . . . 76

6.2.7 Teste de Dependência Energética . . . . . . . . . . . . . . . 78

6.3 Caracterização de Câmaras de Ionização Tipo Lápis e de Placas Paralelas em Feixes Padronizados de Radiação X para TC . . . . . . . . 80

6.3.1 Curva de Saturação, Efeito de Polaridade e Eficiência de Coleção de Íons . . . . . . . . . . . . . . . . . . . . . . . . . . 81

6.3.2 Teste de Estabilidade de Resposta em Curto e Longo Prazos . 84

6.3 .3 Tempo de Estabilização . . . . . . . . . . . . . . . . . 84

6.3.4 Teste de Corrente de Fuga . . . . . . . . . . . . . . . . 86

6.3.5 Teste de Linearidade de Resposta . . . . . . . . . . . . . . . 86

6.3.6 Teste de Dependência Angular . . . . . . . . . . . . . . . . . 87

6.3.7 Teste de Dependência Energética . . . . . . . . . . . . . . 87

6.3.8 Avaliação do Comprimento Efetivo e da Uniformidade Espacial da Resposta da Câmara de Ionização L2 . . . . . . . . . . 90

6.3.9 Mapeamento do Campo de Radiação X com a Câmara de Ionização L1 . . . . . . . . . . . . . . . . . . . . . . . . . . . . 91

6.4 Projeto e Construção de Câmaras de Ionização de Placas Paralelas como Sistemas Padrões em Feixes de ${ }^{60} \mathrm{Co}$. . . . . . . . . . . . . . . 92

6.5 Caracterização das Câmaras de Ionização G1, G2, CG e PTW (Modelo TN30002) em Feixes de ${ }^{60} \mathrm{Co}$. . . . . . . . . . . . . . . . . . . . 98

6.5.1 Curva de Saturação, Efeito de Polaridade e Eficiência de Coleção de Íons . . . . . . . . . . . . . . . . . . . . . . . . . . . 98

6.5.2 Estabilidade em Curto e Longo Prazos . . . . . . . . . . . . . 99

6.5.3 Linearidade de Resposta . . . . . . . . . . . . . . . . . 100

6.5.4 Corrente de Fuga . . . . . . . . . . . . . . . . . . . . . . 101

6.5.5 Dependência Angular . . . . . . . . . . . . . . . . . . 102

\section{Resultados e Discussão: Avaliação das Câmaras de Ionização por} Simulação de Monte Carlo

7.1 Simulação de Monte Carlo das Câmaras de Ionização L1, L2, PPTC e CG em Feixes Padronizados de Radiação X . . . . . . . . . . . . . . . 104

7.1.1 Estudo da Influência dos Componentes das Câmaras de Ionização L1 e L2 nas suas Respostas . . . . . . . . . . . . . . . . 105

7.1.2 Estudo da Distribuição de Energia no Volume Sensível da Câmara de Ionização CG e a Influência do seu Eletrodo Coletor nas suas Medições . . . . . . . . . . . . . . . . . . . . . . 109 
7.1.3 Estudo da Influência dos Componentes da Câmara de Ionização PPTC na sua Resposta . . . . . . . . . . . . . . . . . . . 112

7.2 Simulação de Monte Carlo das Câmaras de Ionização CG, G1 e G2 em Feixes de ${ }^{60} \mathrm{Co}$. . . . . . . . . . . . . . . . . . . . . . . . . . 1119

7.2.1 Simulação de Monte Carlo para Avaliação do Efeito de Alguns Componentes da Câmara de Ionização CG nas suas Medições

7.2.2 Determinação dos Fatores de Correção das Câmaras de Ionização G1 e G2 pelo Método de Monte Carlo para o Cálculo da Taxa de Kerma no Ar . . . . . . . . . . . . . . . . . . . . 122

8 Conclusões

A Lista de Publicações em Periódicos Decorrentes desta Tese

A.1 Artigos Publicados em Periódicos . . . . . . . . . . . . . . . . 130

A.2 Artigos Aceitos para Publicação . . . . . . . . . . . . . . . . . . . . 131

B Lista de Trabalhos Completos Publicados em Anais de Congressos Decorrentes desta Tese

C Lista de Resumos Publicados em Anais de Congressos Decorrentes desta Tese

D Estimativa do custo de confecção das câmaras de ionização desenvolvidas neste projeto

Referências Bibliográficas 


\section{Lista de Figuras}

4.1 Esquema representativo do efeito fotoelétrico [TAUHATA et al. (2003)]. . . . . . . . . . . . . . . . . . 16

4.2 Esquema representativo do efeito Compton [TAUHATA et al. (2003)]. 17

4.3 Importância relativa dos tipos mais comuns de processos de interação de fótons com a matéria em função da energia do fóton e do número atômico do material. Figura modificada de [ATTIX (2004)]. . . . . . 18

4.4 Desenho esquemático de uma câmara de ionização de ar livre. Os fótons passam através da abertura do diafragma e interagem com o ar presente na câmara de ionização para produzir elétrons secundários $\left(\mathrm{e}_{1}, \mathrm{e}_{2}, \mathrm{e}_{3}\right)$. Uma parte isolada da placa inferior cria uma região de ar de comprimento 1 (tracejada) na qual a carga é coletada e medida como corrente de ionização. Figura modificada de [BURNS e BÜERMANN (2009)] . . . . . . . . . . . . . . 26

4.5 Desenho esquemático de uma câmara de ionização cavitária cilíndrica. Figura modificada de [CHERY e DUXBURY (2009)] . . . . . . . . . 28

4.6 Desenho esquemático de uma câmara de ionização do tipo dedal. . . . 29

4.7 Desenho esquemático de uma câmara de ionização de placas paralelas Figura modificada de [DeWERD e WAGNER (1999)]. . . . . . . . . 30

5.1 Fotos dos sistemas de radiação utilizados neste trabalho. (a) Equipamento de raios X, marca Pantak/Seifert; (b) Irradiador gama, marca Siemens/Gammatron e (c) Fonte de controle de ${ }^{90} \mathrm{Sr}+{ }^{90} \mathrm{Y}$, PTW, modelo 8921. . . . . . . . . . . . . . . . . . . 52

5.2 Fotos dos sistemas padrões de referência do LCI usados neste trabalho. (a) câmara de ionização cilíndrica, Radcal, modelo RC6; (b) câmara de ionização tipo lápis, Radcal, modelo RC3CT e (c) câmara de ionização Farmer, PTW, modelo TN30002. . . . . . . . . . . . . . 54

5.3 Fotos dos eletrômetros usados neste trabalho. (a) eletrômetro PTW, modelo UNIDOS E e (b) eletrômetro Keithley, modelo 6517A. . . . . 55

6.1 (a) Fotografia e (b) diagrama esquemático da câmara de ionização de placas paralelas CG desenvolvida e caracterizada neste projeto. . . . . 65

6.2 Detalhes, com dimensões, dos componentes da câmara de ionização CG: (a) parede, (b) eletrodo coletor, (c) isolante e (d) cabo. . . . . . 67

6.3 Fotografias das câmaras de ionização (a) CMETG e (b) CMETA e (c) esquema das câmaras de ionização CMETG e CMETA desenvolvidas e caracterizadas neste projeto. . . . . . . . . . . . . . . . . 68 
6.4 Detalhes, com dimensões, dos componentes das câmaras de ionização CMETG e CMETA: (a) paredes, (b) janela de entrada, que possui 0,5 $\mathrm{mm}$ de espessura, (c) eletrodo coletor, (d) anel de guarda, (e) isolantes de Teflon (Teflon é marca registrada da DuPont), utilizado entre o anel de guarda e o eletrodo coletor e (f) cabo. . . . . . . . .

6.5 Curvas de saturação obtidas na qualidade de radiação RQR5 para as câmaras de ionização (a) CG, (b) CMETG e (c) CMETA. Os valores das incertezas das medições são menores que $0,1 \%$, imperceptíveis no gráfico da câmara de ionização CG. . . . . . . . . . . . . . . . . . . . 72

6.6 (a) Fonte de controle de ${ }^{90} \mathrm{Sr}+{ }^{90} \mathrm{Y}$ posicionada sobre a câmara de ionização e (b) esquema da câmara de ionização e do suporte de PMMA. 73

6.7 Estabilidade de resposta em longo prazo, utilizando uma fonte de controle de ${ }^{90} \mathrm{Sr}+{ }^{90} \mathrm{Y}$, da resposta das câmara de ionização (a) CG, (b) CMETG e (c) CMETA. As linhas pontilhadas mostram os limites recomendados pela IEC 61674 [IEC (1997)] . . . . . . . . . . . . . .

6.8 Linearidade de resposta na qualidade de radiação RQR5 das câmaras de ionização (a) CG, (b) CMETG e (c) CMETA. Os valores das incertezas das medições são menores que $0,4 \%$ para a câmara $\mathrm{CG}$, imperceptíveis na figura. . . . . . . . . . . . . . . . 76

6.9 Câmara de ionização CG posicionada no goniômetro para realização do teste de dependência angular.

6.10 Dependência angular na qualidade de radiação RQR5 das câmaras de ionização (a) CG, (b) CMETG e (c) CMETA. As linhas pontilhadas representam $\pm 1 / 3$ do limite recomendado pela norma IEC 61674

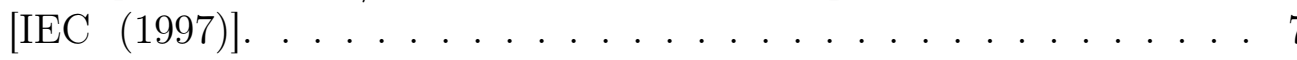

6.11 Curvas Tandem das câmaras de ionização CMETG e CMETA (a) para as qualidades de radiação RQR e (b) para as qualidades de radiação RQA.

6.12 Fotografias das câmaras de ionização tipo lápis (a) L1 e (b) L2 e (c) diagrama esquemático das câmaras de ionização L1 e L2.

6.13 (a) Fotografia da câmara de ionização PPTC e (b) diagrama esquemático da câmara de ionização PPTC.

6.14 Curvas de saturação obtidas na qualidade de radiação RQT9 para as câmaras de ionização (a) L1, (b) L2 e (c) PPTC. Os valores das incertezas das medições são menores que 1,0\%, e, desta forma, imperceptíveis nos gráficos. . . . . . . . . . . . . . . . . .

6.15 Fotografia da fonte de controle de ${ }^{90} \mathrm{Sr}+{ }^{90} \mathrm{Y}$ posicionada sobre a câmara de ionização L1 no suporte de PMMA. . . . . . . . . . . . . . .

6.16 Estabilidade em longo prazo, utilizando a fonte de controle de ${ }^{90} \mathrm{Sr}+{ }^{90} \mathrm{Y}$, da resposta das câmaras de ionização (a) L1, (b) L2 e (c) PPTC. As linhas pontilhadas mostram os limites de $\pm 2,0 \%$ recomendados pela IEC 61674 [IEC (1997)].

6.17 Linearidade de resposta na qualidade de radiação RQT9 das câmaras de ionização (a) L1, (b) L2 e (c) PPTC. Os valores das incertezas das medições são menores que $0,9 \%$ e, desta forma, imperceptíveis nas figuras. . . . . . . . . . . . . . . . . . 87

6.18 Dependência angular na qualidade de radiação RQT9 das câmaras de ionização (a) L1, (b) L2 e (c) PPTC. 
6.19 Resposta da câmara de ionização L2 ao longo de seu eixo na qualidade de radiação RQT9. Todos os valores foram normalizados para a resposta no centro do volume sensível. O sentido positivo indica a direção do conector de BNC. As incertezas foram menores que $0,3 \%$ e, desta forma, imperceptíveis na figura. . . . . . . . . . . . . . 9

6.20 Mapeamento do campo de radiação X com as câmaras de ionização L1 e Farmer nas direções (a) horizontal e (b) vertical. As linhas pontilhadas delimitam 95,0\% do valor medido no centro do campo. As incertezas foram menores que $0,5 \%$ e, desta forma, são imperceptíveis nas figuras. . . . . . . . . . . . . . . . . . . . 92

6.21 Fotografias das câmaras de ionização de grafite (a) G1 e (b) G2 e esquemas das câmaras de ionização (c) G1 e (d) G2 . . . . . . . . . . 94

6.22 Detalhes, com dimensões, dos componentes da câmara de ionização G1: (a) paredes, (b)isolante de Teflon, utilizado para fixar o eletrodo coletor no interior da câmara de ionização, (c)parede superior, (d) eletrodo coletor, e (e) cabo.

6.23 Detalhes, com dimensões, dos componentes da câmara de ionização G2: (a) paredes, (b) parede em detalhes, (c) eletrodo coletor, (d) isolantes de Teflon externos, utilizados para unir as paredes, (e) isolantes de Teflon internos, utilizados para fixar o eletrodo coletor no interior da câmara de ionização e (f) cabo.

6.24 Curvas de saturação obtidas no feixe de ${ }^{60} \mathrm{Co}$ para as câmaras de ionização (a) G1, (b) G2, (c) CG e (d) PTW. Os valores das incertezas das medições são menores que $0,2 \%$, imperceptíveis nas figuras. . . .

6.25 Estabilidade em longo prazo, no feixe de ${ }^{60} \mathrm{Co}$, da resposta das câmaras de ionização (a) G1, (b) G2, (c) CG e (d) PTW. As linhas pontilhadas mostram os limites recomendados pela norma IEC 60731 [IEC (2011)]. . . . . . . . . . . . . . . . . 100

6.26 Linearidade de resposta, obtida no feixe de ${ }^{60} \mathrm{Co}$, para as câmaras de ionização (a) G1 e (b) G2, (c) CG e (d) PTW. Os valores das incertezas das medições são menores que 1,0\%, imperceptíveis nas figuras. . . . . . . . . . . . . . . . . . . . 101

6.27 Dependência angular obtida no feixe de ${ }^{60} \mathrm{Co}$ para as câmaras de ionização (a) G1, (b) G2 e (c) CG e (d) PTW. As linhas pontilhadas mostram os limites recomendados pela IEC 60731 [IEC (2011)]. . . . 103

7.1 Geometria utilizada no arquivo de entrada nas simulações de Monte Carlo com o código PENELOPE da câmara de ionização L1 (a) completa, (b) sem o conector BNC, (c) sem o eletrodo coletor e (d) sem o corpo de PMMA. . . . . . . . . . . . . . . . . . . . 107

7.2 Geometria utilizada no arquivo de entrada nas simulações de Monte Carlo com o código PENELOPE da câmara de ionização L2 (a) completa, (b) sem o conector BNC, (c) sem o eletrodo coletor e (d) sem o corpo de PMMA. . . . . . . . . . . . . . . . . . . . 108

7.3 Geometria da câmara CG utilizada no arquivo de entrada nas simulações de Monte Carlo com o código PENELOPE (a) corte axial e (b) visão frontal. 
7.4 Geometria utilizada no arquivo de entrada nas simulações de Monte Carlo com o código PENELOPE da câmara de ionização CG sem o eletrodo coletor. . . . . . . . . . . . . . . . . . . . 111

7.5 Geometria utilizada no arquivo de entrada nas simulações de Monte Carlo com o código PENELOPE da câmara de ionização PPTC com todos componentes (a) corte axial e (b) corte lateral. . . . . . . . . 113

7.6 Geometria utilizada no arquivo de entrada nas simulações de Monte Carlo com o código PENELOPE da câmara de ionização PPTC (a) sem os cabos, (b) sem o isolante e (c) sem o corpo de PMMA. Os componentes em estudo foram destacados em negrito. . . . . . . . . . 114

7.7 Geometria utilizada no arquivo de entrada nas simulações de Monte Carlo com o código PENELOPE da câmara de ionização PPTC (a) sem eletrodo coletor, (b) sem o anel de guarda e (c) sem os parafusos. Os componentes em estudo foram destacados em negrito. . . . . . . . 115

7.8 Corte axial da geometria da câmara CG utilizada no arquivo de entrada nas simulações de Monte Carlo com o código PENELOPE. . . . 119

7.9 Geometria utilizada no arquivo de entrada nas simulações de Monte Carlo com o código PENELOPE da câmara de ionização CG (a) sem eletrodo coletor, (b) sem isolantes e (c) sem cabo. Os componentes estudados estão destacados em negrito . . . . . . . . . . . . . . 121

7.10 Geometria utilizada no arquivo de entrada nas simulações de Monte Carlo com o código EGSnrc da câmara de ionização G1 e G2 (a) completa, (b) sem eletrodo coletor e (c) sem cabo. Os componentes em estudo estão em negrito. . . . . . . . . . . . . . . . . . . . . . . 123 


\section{Lista de Tabelas}

4.1 Parâmetros de controle da simulação de Monte Carlo com código

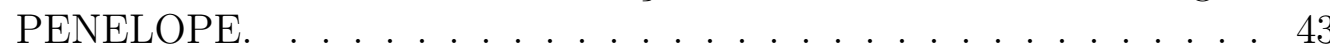

4.2 Bibliotecas do código EGSnrc para obtenção dos fatores de correção envolvidos na determinação da taxa de kerma no ar. . . . . . . . . . . 44

5.1 Características dos feixes padronizados de radiação X para radiodiagnóstico convencional do equipamento Pantak/Seifert, seguindo a recomendação da norma IEC 61267 [IEC (2005)] . . . . . . . . . . . 53

5.2 Características dos feixes padronizados de radiação X para tomografia computadorizada do equipamento Pantak/Seifert, seguindo a recomendação da norma IEC 61267 [IEC (2005)]. . . . . . . . . . . . . 53

5.3 Metodologia adotada na determinação dos fatores de correção das câmaras de ionização de grafite. . . . . . . . . . . . . . . . . . . . 61

6.1 Especificações técnicas das câmaras de ionização CG, CMETG e CMETA. . . . . . . . . . . . . . . 666

6.2 Teste de polaridade e eficiência de coleção de íons das câmaras de ionização CG, CMETG e CMETA. . . . . . . . . . . . . . 73

6.3 Diferença entre as correntes de ionização medidas após $15 \mathrm{~min}$ e 60 min para avaliação do tempo de estabilização para as câmaras de ionização CG, CMETG e CMETA. . . . . . . . . . . . . . . . 75

6.4 Teste de corrente de fuga das câmaras de ionização CG, CMETG e CMETA. . . . . . . . . . . . . . . . . 75

6.5 Coeficientes de calibração e fatores de correção da câmara de ionização CG em feixes diretos de radiodiagnóstico. . . . . . . . . . . . . . 78

6.6 Coeficientes de calibração, fatores de correção e fatores Tandem para as câmaras CMETG e CMETA em feixes de radiodiagnóstico diretos e atenuados. . . . . . . . . . . . . . . . . . . 79

6.7 Especificações técnicas das câmaras de ionização tipo lápis L1 e L2. 81

6.8 Especificações técnicas da câmara de ionização PPTC. . . . . . . . . . . 82

6.9 Teste de polaridade e eficiência de coleção de íons das câmaras de ionização L1, L2 e PPTC. . . . . . . . . . . . . . . . . . . . . . . . . 83

6.10 Diferença entre as correntes de ionização medidas após $15 \mathrm{~min}$ e 60 min, para avaliação do tempo de estabilização das câmaras de ionização L1, L2 e PPTC. . . . . . . . . . . . . . . . . . . . . . 88 86

6.11 Teste de corrente de fuga das câmaras de ionização L1, L2 e PPTC. . 86

6.12 Coeficientes de calibração e fatores de correção da câmara de ionização L1 para as qualidades de radiação de TC. 
6.13 Coeficientes de calibração e fatores de correção da câmara de ionização L2 para as qualidades de radiação de TC. . . . . . . . . . . . . . 89

6.14 Coeficientes de calibração e fatores de correção da câmara de ionização PPTC para as qualidades de radiação de TC . . . . . . . . . . . . . 89

6.15 Coeficientes de calibração e fatores de correção da câmara de ionização Victoreen 660-6 para as qualidades de radiação de TC. . . . . . . 89

6.16 Valores da dependência energética para as câmaras de ionização L1, L2, PPTC e Victoreen 660-6 nas qualidades de radiação de TC. . . . 90

6.17 Especificações técnicas das câmaras de ionização G1 e G2. . . . . . . 95

6.18 Teste de polaridade e eficiência de coleção de íons no feixe de ${ }^{60} \mathrm{Co}$ das câmaras de ionização G1, G2, CG e PTW. . . . . . . . . . . . . . 99

6.19 Corrente de fuga das câmaras de ionização G1, G2, CG e PTW. . . . 102

7.1 Parâmetros de controle da simulação de Monte Carlo com código PENELOPE utilizados neste trabalho. . . . . . . . . . . . . 106

7.2 Fatores de correção experimentais e simulados da câmara de ionização L2 nas qualidades de radiação de TC . . . . . . . . . . . . . . . 106

7.3 Influência dos componentes das câmaras de ionização L1 e L2 na energia depositada em seus volumes sensíveis para a qualidade de radiação RQT9. . . . . . . . . . . . . . . . . . . . . . . . 109

7.4 Distribuição da energia depositada nas três partes distintas do volume sensível da câmara de ionização CG nas qualidades de radiação RQR. 111

7.5 Influência dos componentes da câmara de ionização PPTC na sua resposta utilizando a qualidade de radiação RQT9. . . . . . . . . . 116

7.6 Influência dos componentes da câmara de ionização PPTC constituídos de materiais diferentes na sua resposta. . . . . . . . . . . . 117

7.7 Influência de configurações geométricas diferentes da câmara de ionização PPTC na sua resposta. . . . . . . . . . . . . . . . . . . . . . 118

7.8 Influência dos componentes da câmara de ionização CG na sua resposta, no feixe de ${ }^{60} \mathrm{Co}$, nas três partes distintas do volume sensível. . 122

7.9 Resultados da simulação de Monte Carlo para os termos envolvidos na determinação da taxa de kerma no ar . . . . . . . . . . . . . . . . 124

7.10 Comparação entre os parâmetros utilizados na determinação da taxa de kerma no ar dos protótipos G1 e G2 e da câmara de ionização do BIPM. . . . . . . . . . . . . . . . . . . . . . 125

7.11 Comparação entre os parâmetros utilizados na determinação da taxa de kerma no ar dos protótipos G1 e G2 e da câmara de ionização do PTB. . . . . . . . . . . . . . . . . 125

7.12 Valores da taxa de kerma no ar da fonte de ${ }^{60} \mathrm{Co}$ do LCI determinados com as câmaras de ionização G1, G2 e PTW.

D.1 Estimativa de custo de confecção da câmara de ionização CG. . . . . 140

D.2 Estimativa de custo de confecção das câmaras de ionização CMETG e CMETA. . . . . . . . . . . . . . . . . . . . . . 141

D.3 Estimativa de custo de confecção das câmaras de ionização G1 e G2. . 141 


\section{Lista de Siglas}

BIPM Bureau International des Poids et Mesures

CG Câmara de ionização de placas paralelas de PMMA grafitado com volume sensível de $6,3 \mathrm{~cm}^{3}$

CMETA Câmara de ionização de placas paralelas, com janela de entrada de material equivalente ao tecido e eletrodo coletor de alumínio, com volume sensível de $2,3 \mathrm{~cm}^{3}$

CMETG Câmara de ionização de placas paralelas, com janela de entrada e eletrodo coletor de material equivalente ao tecido, com volume sensível de $2,3 \mathrm{~cm}^{3}$

CNEN Comissão Nacional de Energia Nuclear

G1 Câmara de ionização de placas paralelas de grafite com volume sensível de $9,4 \mathrm{~cm}^{3}$

G2 Câmara de ionização de placas paralelas de grafite com volume sensível de $6,4 \mathrm{~cm}^{3}$

IAEA International Atomic Energy Agency

IEC International Electrotechnical Commission

INMETRO Instituto Nacional de Metrologia, Qualidade e Tecnologia

IPEN Instituto de Pesquisas Energéticas e Nucleares

L1 Câmara de ionização tipo lápis com volume sensível de $0,34 \mathrm{~cm}^{3}$

L2 Câmara de ionização tipo lápis com volume sensível de $3,40 \mathrm{~cm}^{3}$

LCI Laboratório de Calibração de Instrumentos, IPEN/CNEN

LNMRI Laboratório Nacional de Metrologia das Radiações Ionizantes

NIST National Institute of Standards and Technology, EUA

NPL National Physical Laboratory, Inglaterra

NRC National Research Council, Canadá

OMS Organização Mundial de Saúde

PMMA Polimetil-metacrilato 
PPTC Câmara de ionização de placas paralelas para TC, com janela de entrada de mylar e eletrodo coletor de grafite, e volume sensível de $3,2 \mathrm{~cm}^{3}$

PTB Physikalisch-Technische Bundesantstalt, Alemanha

PTW Physikalisch-Technische Werkstätten, Alemanha

PVC Cloreto de Polivinila

SI Sistema Internacional de Unidades

TC Tomografia computadorizada

VIM Vocabulário Internacional de Metrologia 


\section{Capítulo 1}

\section{Introdução}

Um fator extremamente importante relacionado ao uso de radiação ionizante aplicada à medicina é a determinação da dose recebida pelo paciente. Em procedimentos diagnósticos como: exames de raios $\mathrm{X}$, medicina nuclear, tomografia computadorizada (TC), por exemplo, o conhecimento da dose recebida pelo paciente é importante para otimização da qualidade da imagem e para fins de proteção radiológica. A preocupação com a proteção radiológica justifica-se pelo fato de que as exposições resultantes de procedimentos relacionados a radiodiagnóstico são responsáveis pela maior contribuição da utilização da radiação na população mundial, e as exposições relacionadas a exames de TC correspondem a $34 \%$ da dose coletiva total [UNSCEAR (2008)].

Estudos recentes apontam para os riscos de doses elevadas em exames de TC e radiologia convencional. Em uma série de reportagens, no jornal The New York Times, apresentou-se o caso de uma criança que desenvolveu eritemas no rosto, devido à alta exposição durante um exame de TC [BOGDANICH (2009a)]. Em outros casos, pacientes sofreram com a morte de células epiteliais, responsáveis pelo crescimento do cabelo. Nestes casos, a morte das células corresponde a uma faixa circular, ao redor da cabeça, seguindo a orientação e posição do feixe de raios X utilizado nos exames de TC [BOGDANICH (2009b)]. Até o momento, os riscos a longo prazo destas exposições à radiação são desconhecidas, e os resultados podem aparecer décadas após as irradiações. 
No Brasil, foram realizados alguns estudos no Hospital das Clínicas de Porto Alegre, sobre as doses em pacientes submetidas a exames de raios X. Os dados indicam que em diversas ocasiões os pacientes são expostos a doses muito altas de radiação, devido à exposição por muito tempo aos equipamentos ou repetições de exames, muitas vezes desnecessários [BACELAR et al. (2011); HOFF et al. (2011)].

Estes casos não são isolados, mas apenas alguns exemplos que destacam os efeitos nocivos que exames de diagnóstico podem trazer se não forem adotadas medidas de controle e segurança mais específicos. Este tipo de exposição à população é devido em grande parte a dois motivos: falta de um nível de referência, e desconhecimento por parte das equipes médicas dos danos à exposição durante exames de diagnóstico médico por imagem, como os exames de TC e de radiologia convencional.

Além da aplicação de radiações ionizantes em procedimentos diagnósticos, também é possível observar sua utilização em terapia para o tratamento de tumores. Neste caso, uma dose elevada chega ao tumor, e a eficácia do tratamento dependerá da dose liberada ao paciente, com uma incerteza de no máximo 5\% [IAEA (2004)]. Existem três áreas responsáveis por manter as incertezas pequenas associadas ao tratamento radioterapêutico: dosimetria, planejamento do caso e tratamento do paciente. A dosimetria envolve as seguintes questões: comissionamento dos equipamentos e fontes de tratamento, cálculo de dose e problemas relacionados aos equipamentos.

A dosimetria das radiações ionizantes exige a utilização de instrumentação especializada, com o projeto e desempenho destes instrumentos atendendo à necessidade da situação clínica. O uso destes instrumentos para deteç̧ão da radiação e a interpretação dos resultados fornecidos por eles requer a utilização de técnicas especializadas. Além disso, existem requisitos especiais para calibração destes instrumentos para que suas medições sejam rastreáveis a padrões nacionais ou internacionais.

Existem diversos tipos de dosímetros que podem ser aplicados em dosimetria de radiodiagnóstico e terapia, como câmaras de ionização, detectores cintiladores, semicondutores e detectores de estado sólido [DeWERD e WAGNER (1999); PODGORSAK (2005)]. A câmara de ionização é o tipo de detector de radiação 
mais utilizado para dosimetria em radiodiagnóstico e terapia, geralmente porque ela é robusta, fácil de utilizar, apresenta alta precisão e uma dependência energética pequena dentro de um amplo intervalo de energias.

As câmaras de ionização são feitas em diferentes configurações para aplicações específicas. O tipo de câmara de ionização mais comumente utilizado para dosimetria em radiodiagnóstico para medida de exposição é de placas paralelas [DeWERD e WAGNER (1999)]. Este tipo de câmara de ionização tem uma construção relativamente simples e apresenta um desempenho bastante satisfatório para medidas dosimétricas em radiodiagnóstico. Também existem câmaras de ionização mais específicas, dependendo da aplicação. Por exemplo, o tipo de câmara de ionização utilizada para dosimetria em feixes de TC é cilíndrica alongada, denominada câmara de ionização tipo lápis. Esta câmara de ionização possui normalmente $100 \mathrm{~mm}$ de comprimento do volume sensível, e ela pode ser usada para realizar medidas diretamente no ar ou em objetos simuladores. Um tipo de câmara de ionização muito utilizada em medições dosimétricas rotineiras para controle de qualidade de feixes em radioterapia é do tipo cilíndrica (dedal). O tipo mais comum de câmara de ionização dedal é câmara de ionização Baldwin-Farmer, projetada por Farmer e produzida por Baldwin, que tem um volume sensível de $0,6 \mathrm{~cm}^{3}$ [PODGORSAK (2005)].

Outro tipo de câmara de ionização, muito empregada como sistema padrão primário para determinação de kerma no ar, é a câmara de ionização cavitária de grafite. Este tipo de dosímetro é bastante utilizado como padrão de kerma no ar para feixes de ${ }^{60} \mathrm{Co}$ e ${ }^{137} \mathrm{Cs}$ em diferentes laboratórios padrões primários, como: PhysikalischTechnische Bundesanstalt (PTB) [BÜERMANN e BURNS (2009)], National Institute of Standards and Technology (NIST) [MINNITI e CZAP (2011)] e Bureau International des Poids et Mesures (BIPM) [BURNS et al. (2007)]. Estas câmaras de ionização apresentam diferentes configurações geométricas e diferentes volumes sensíveis, pois cada laboratório é responsável pelo desenvolvimento, caracterização e manutenção de seus próprios sistemas padrões primários. 
A principal motivação no desenvolvimento deste projeto está relacionada a quatro fatores: o grande número de exposições à radiação relacionadas a exames de radiodiagnóstico, a dose elevada recebida pelos pacientes submetidos a exames de TC, as vantagens apresentadas pelas câmaras de ionização em relação aos demais dosímetros e a inexistência de um laboratório padrão primário na América Latina para calibração de dosímetros em feixes de ${ }^{60} \mathrm{Co}$.

Este projeto tem como objetivos o desenvolvimento e a caracterização de câmaras de ionização para aplicação em dosimetria de radiodiagnóstico (raios X convencional e TC) e em terapia, com boa precisão, desempenho nos testes de caracterização dentro dos limites recomendados internacionalmente, e construídas de maneira simples com materiais nacionais de baixo custo, para que elas possam ser reproduzidas e aplicadas em laboratórios de calibração. Além destas características, os projetos das câmaras de ionização desenvolvidas apresentam diferenças em relação às câmaras de ionização comerciais. Estas diferenças são relacionadas ao material utilizado na construção das câmaras de ionização e, também, à disposição geométrica dos componentes que as constituem.

A principal vantagem no desenvolvimento de uma câmara de ionização, para um laboratório de calibração, como é o caso do Laboratório de Calibração de Instrumentos do IPEN (LCI), está relacionada ao conhecimento de todas as configurações (dimensões e materiais) do dosímetro. Esta informação é de extrema importância para determinação de fatores de correção ou influência dos diferentes materiais e componentes na resposta fornecida pela câmara de ionização, pelo método de Monte Carlo. Além disso, o desenvolvimento de um dosímetro pode ser planejado para ser de fácil construção, utilizando materiais facilmente encontrados no mercado nacional, tornando-se uma boa opção para aplicação em laboratórios de calibração.

Além do desenvolvimento de câmaras de ionização para serem utilizadas em feixes padrões de radiação $\mathrm{X}$, como padrões de trabalho, este projeto também teve como meta o desenvolvimento, a caracterização experimental e por simulação de Monte Carlo de duas câmaras de ionização cavitárias de grafite, para atuação como 
sistemas de referência para determinação do kerma no ar da fonte de ${ }^{60}$ Co do LCI. O desenvolvimento deste tipo de dosímetro é muito importante, pois a pesquisa e a construção de um sistema padrão de referência (primário/secundário) é o passo inicial para o avanço tecnológico e aumento da autonomia do país na área de calibração de detectores de radiação, uma vez que cada país é responsável pelo projeto, construção, caracterização e manutenção de seus próprios dosímetros padrões de referência. 


\section{Capítulo 2}

\section{Objetivos}

O objetivo principal deste projeto é o desenvolvimento de câmaras de ionização como sistemas padrões em feixes de radiação X e gama. Este trabalho tem como objetivos específicos:

- Caracterização experimental e por simulação de Monte Carlo de duas câmaras de ionização tipo lápis com diferentes volumes sensíveis nas qualidades de radiação de TC;

- Caracterização experimental e por simulação de Monte Carlo de uma câmara de ionização de placas paralelas em feixes de radiação de TC;

- Desenvolvimento e caracterização experimental de duas câmaras de ionização de placas paralelas construídas usando material equivalente ao tecido, caracterizadas em feixes de radiação $\mathrm{X}$ convencional;

- Desenvolvimento e caracterização experimental e por simulação de Monte Carlo de uma câmara de ionização de placas paralelas construída usando polimetil-metacrilato (PMMA), caracterizada em feixes de radiação X convencional e em feixes de ${ }^{60} \mathrm{Co}$;

- Desenvolvimento e caracterização experimental e por simulação de Monte Carlo de duas câmaras de ionização cavitárias de placas paralelas de grafite caracterizadas em feixes de ${ }^{60} \mathrm{Co}$ para atuação como sistemas padrões de 
referência em feixes de ${ }^{60} \mathrm{Co}$;

- Determinação da taxa de kerma no ar da fonte de ${ }^{60}$ Co do LCI com as câmaras de ionização cavitárias de grafite desenvolvidas neste projeto. 


\section{Capítulo 3}

\section{Revisão da Literatura}

Este capítulo apresenta uma breve descrição de alguns trabalhos relevantes encontrados na literatura relacionados à utilização de câmaras de ionização em radiodiagnóstico convencional e TC. Além disso, também serão descritos alguns trabalhos em que os autores fazem uso de câmaras de ionização como sistemas padrões de referência para a determinação da taxa de kerma no ar de feixes de ${ }^{60} \mathrm{Co}$.

\subsection{Câmaras de ionização utilizadas em radiodiag- nóstico convencional e TC}

Desde a descoberta dos raios X por Wilhelm Conrad Röentgen, há mais de 100 anos, o uso de raios $\mathrm{X}$ para radiodiagnóstico tem crescido muito. Com isto, também aumentou-se a preocupação com os riscos advindos das doses dos exames de diagnóstico. O primeiro método de determinação de dose foi o eritema induzido pela radiação. Em 1908, Paul-Ulrich Villard propôs uma nova técnica para determinação de dose que se baseava na ionização gerada no ar em condições normais de temperatura e pressão. Este conceito de determinação de dose foi adotado no Segundo Congresso Internacional de Radiologia em 1928 e tem sido utilizado na dosimetria em medicina desde sua criação [DeWERD e WAGNER (1999)].

Com o advento de diferentes tecnologias, novos dosímetros foram desenvolvidos e utilizados em dosimetria das radiações. Um dos tipos de dosímetros muito utilizados em radiodiagnóstico é a câmara de ionização. O tipo de câmara de ionização mais 
comumente utilizada para dosimetria em radiodiagnóstico é a de placas paralelas, e o estudo deste tipo de câmara de ionização começou há vários anos e se estende até os dias de hoje. Em 1964, GREENING e INST (1964) estudaram as características relacionadas à saturação de câmaras de ionização de placas paralelas. Neste artigo foi deduzida uma expressão para o cálculo da eficiência de coleção de íons em termos da separação dos eletrodos, produção de taxa de íons, tensão de polarização, coeficiente de recombinação e mobilidade dos íons. Em 1983, FALLONE e PODGOSRSAK (1983) definiram uma nova expressão analítica para descrever a curva de saturação de câmaras de ionização de placas paralelas. Em 1989, ALBUQUERQUE e CALDAS (1989) desenvolveram duas novas câmaras de ionização de placas paralelas para dosimetria em radiodiagnóstico: uma câmara de ionização com eletrodo coletor de alumínio e outra com eletrodo coletor de grafite. A câmara de ionização com eletrodo coletor de grafite apresentou uma qualidade metrológica excelente, comparável com os padrões secundários existentes no LCI.

Em 1991, CALDAS (1991) desenvolveu um sistema Tandem de câmaras de ionização de placas paralelas para determinação da energia efetiva de campos de radiação X. Em 2003, COSTA e CALDAS (2003) desenvolveram um tipo especial de câmara de ionização de placas paralelas para controle de qualidade em diagnóstico e mamografia. Esta câmara de ionização consiste de uma câmara de ionização de dupla face com eletrodos coletores de materiais diferentes para constituir um sistema Tandem. Este sistema apresentou um desempenho adequado nos programas de controle da qualidade em equipamentos de diagnóstico e de mamografia, na verificação da constância da qualidade dos feixes, dispensando a utilização de absorvedores ou de qualquer outro tipo de arranjo especial, como no caso da técnica convencional.

A partir da década de 2000, a simulação de Monte Carlo foi incorporada ao estudo experimental de câmaras de ionização de placas paralelas em radiodiagnóstico. Em 2007, RUSSA et al. (2007) investigaram experimentalmente e computacionalmente o fator de correção de temperatura e pressão para câmaras de ionização de placas paralelas utilizadas em radiodiagnóstico. 
O tipo de câmara de ionização utilizada em dosimetria em TC é a câmara de ionização tipo lápis, que foi introduzida no mercado no final da década de 70. A partir desta época alguns artigos foram publicados trazendo informações sobre este tipo de câmara de ionização. Um dos primeiros artigos que introduziram a câmara de ionização tipo lápis para dosimetria em TC foi publicado por JUCIUS e KAMBIC (1977). Neste trabalho eles apresentaram uma comparação de três dosímetros empregados em dosimetria de TC: filme dosimétrico, dosímetro termoluminescente e câmaras de ionização tipo lápis. Uma conclusão importante apresentada por eles é que a câmara de ionização tipo lápis fornece leitura imediata possibilitando a análise rápida dos resultados, o que não é possível com o emprego das técnicas TL e de filmes dosimétricos.

Em 1979, PAVLICEK et al. (1979) estudaram três aspectos relevantes de uma câmara de ionização tipo lápis: calibração em função da qualidade de radiação, propriedade de responder a irradiações de volumes parciais e a resposta ao longo do comprimento da câmara de ionização. Quanto ao primeiro aspecto, a câmara de ionização tipo lápis apresentou uma dependência energética pequena para energias ente $35 \mathrm{keV}$ e $160 \mathrm{keV}$. Quanto ao segundo aspecto, a resposta da câmara de ionização é diretamente proporcional ao volume irradiado. Em relação ao terceiro aspecto, na região central da câmara de ionização sua resposta não varia mais de $2 \%$ e nas suas extremidades a resposta da câmara de ionização cai por cerca de $90 \%$ da leitura na região central.

Em 2005, MAIA e CALDAS (2005) desenvolveram um novo tipo de câmara de ionização para ser aplicada em dosimetria de feixes de TC em laboratórios de calibração. Esta câmara de ionização é do tipo placas paralelas e apresentou resultados excelentes nos testes de caracterização. Levando em consideração os resultados obtidos com esta câmara de ionização, foi concluído que ela apresenta potencial para ser utilizada como um padrão de referência em laboratórios de calibração em feixes padrões de TC. 


\subsection{Câmaras de Ionização Utilizadas como Padrões de Referência}

As câmaras de ionização são importantes não só para a detecção de radiação, mas também para se obter uma medição precisa da dose absorvida em diversos campos. Elas são consideradas instrumentos de referência em radioterapia clínica, tanto para medições de dose absoluta como relativa. Quando as câmaras de ionização são usadas como instrumentos de referência, elas podem constituir um sistema padrão primário.

Para desenvolver e manter um sistema padrão primário, foram criados os laboratórios padrões primários que são responsáveis por uma série de tarefas, como o desenvolvimento de metodologias e instrumentos padrões, calibração de padrões secundários, elaboração de normas e unificação de métodos de calibração.

A maioria dos laboratórios padrões primários utilizam como sistemas padrões primários para raios X de energias baixas e médias câmaras de ionização de ar livre. Como instrumento de medição, as câmaras de ionização de ar livre constituem o fundamento para avaliação absoluta da exposição. Nos dias de hoje, as câmaras de ionização de ar livre de placas paralelas ainda são as mais usadas nos laboratórios de padronização. Entretanto, as câmaras de ar livre têm aplicação prática em feixes de raios X com energias entre $10 \mathrm{keV}$ e $300 \mathrm{keV}$ [ATTIX (2004)]. A partir deste fato, foi necessária a construção de outro tipo de câmara de ionização que servisse como padrão primário em feixes de fótons com energias mais altas, a chamada câmara de ionização cavitária de grafite, cujo princípio de operação se baseia na teoria de Bragg-Gray [ATTIX (2004)].

Antes da utilização da câmara cavitária para feixes de altas energias, foram feitas várias tentativas para a utilização de câmaras de ionização de ar livre para medir exposição em feixes de radiação gama do ${ }^{137} \mathrm{Cs}$ e ${ }^{60} \mathrm{Co}$ [WYCKOFF (1960)]. Porém, já na década de 1930, GRAY (1936) iniciou seus estudos para utilização de câmaras cavitárias para este mesmo propósito. Em 1964, tanto as câmaras de ar livre quanto as câmaras cavitárias passaram a ser usadas como padrões para exposição no intervalo de energia de 0,5 MeV (raios X) até poucos MeV (raios gama) [ICRU (1964)]. 
Com a utilização destes dois tipos de câmaras de ionização, percebeu-se que as câmaras cavitárias eram mais fáceis de usar e também tinham as menores incertezas. Observando isto, LOEVINGER (1977) publicou um trabalho sobre a utilização de câmaras de ar livre para medições de exposição, apresentando suas limitações para energias altas. O início das comparações internacionais de padrões primários de exposição foi descrita em 1977 por KEMP (1977). Neste documento, Kemp relatou que a primeira comparação internacional de câmaras cavitárias como sistemas padrões primários de exposição em fótons de energias altas foi realizada nos anos de 1959 e 1960. A primeira comparação direta de sistemas padrões de exposição para radiação gama de ${ }^{60} \mathrm{Co}$, organizada pelo BIPM, ocorreu em 1971 [NIATEL et al. (1975)]. Mais recentemente, em 2002, BÜERMANN e CSETE (2003) publicaram um documento que trouxe uma revisão detalhada do desenvolvimento e das características de padrões primários de kerma no ar utilizados nos laboratórios padrões primários.

Existem diversos laboratórios padrões primários no mundo e, portanto, diferentes sistemas são utilizados como padrões primários de kerma no ar. Na grande maioria deles, as câmaras de ionização de ar livre são utilizadas para raios X de energias baixas e médias, e as câmaras cavitárias para energias mais elevadas. Este é o caso dos laboratórios BIPM, PTB, Australian Radiation Protection and Nuclear Safety Agency (ARPANSA) e o National Research Council (NRC).

Além de câmaras de ionização, outro sistema padrão primário foi desenvolvido nos últimos 20 anos, o calorímetro, que é considerado um padrão primário para dose absorvida na água. Existem vários trabalhos publicados que explicam seu funcionamento e suas aplicações [GUNN (1964); ROOS e KLASSEN (1996); SEUNTJENS e PALMANS (1999)]. Alguns laboratórios primários que fazem uso do calorímetro, como sistema padrão primário para dose absorvida na água, são: BIPM, NRC, NIST e National Physical Laboratory (NPL).

Para o caso de câmaras de ionização cavitárias, utilizadas como sistemas padrões primários de kerma no ar, é necessária a determinação de fatores de correção para o 
cálculo do kerma ou taxa de kerma no ar. Inicialmente, estes fatores foram calculados por meio de experimentos e equações matemáticas por BOUTILLON e NIATEL (1973). Neste trabalho, eles descreveram a parte experimental e os cálculos realizados para determinação de alguns fatores de correção para uma câmara cavitária de grafite. A partir destes estudos experimentais percebeu-se que em alguns casos ficava impossível a determinação de diversos fatores de correção por meio da realização de experimentos. Portanto, na década de 1980, foram feitas as primeiras tentativas para simular câmaras de ionização cavitárias com a intenção de determinar os seus fatores de correção [ROGERS (2006)]. O primeiro trabalho publicado neste sentido foi feito por NATH e SCHULZ (1981), onde eles desenvolveram um código de Monte Carlo "caseiro" para simular a resposta de uma câmara em feixes de ${ }^{60}$ Co. A partir daí, foram desenvolvidos vários códigos de Monte Carlo, com rotinas bem específicas para o estudo de câmaras de ionização, como é o caso do Electron Gamma Shower (EGSnrc) e o PENetration and Energy LOss of Positron and Electrons (PENELOPE), que são os dois tipos mais utilizados na caracterização de câmaras de ionização.

O código PENELOPE está constantemente sendo aplicado ao estudo de câmaras de ionização. Vários trabalhos estão sendo realizados na análise das câmaras de ionização utilizando este código. Em 2006, SEMPAU e ANDREO (2006) publicaram um trabalho que ajuda aos usuários do código PENELOPE a configurá-lo para uso em cálculos com excelente precisão e tempo de simulação baixo. Também em 2006, SEMPAU et al. (2006) determinaram alguns fatores de correção para qualidades de feixes de elétrons para três câmaras de ionização comerciais de placas paralelas utilizando o código PENELOPE. BURNS (2006) também fez uso deste código para determinar a taxa de kerma no ar usando câmaras de ionização cavitárias como sistemas padrões de kerma no ar.

O código EGSnrc também tem sido muito aplicado para a caracterização de câmaras de ionização e existem vários trabalhos publicados que comprovam isto. ROGERS e KAWRAKOW (2003) utilizaram o código EGSnrc para obter diversos 
fatores de correção para padrões primários de kerma no ar. Eles concluíram que a utilização deste código é muito confiável para a determinação dos fatores de correção necessários para determinação da taxa de kerma no ar.

Em outro trabalho, também foi utilizado o código EGSnrc por BÜERMANN e BURNS (2007). Neste caso, eles calcularam as taxas de kerma no ar usando uma câmara de ar livre e uma câmara cavitária em feixes de raios X de potenciais médios de $300 \mathrm{kV}$ a $400 \mathrm{kV}$. Para o cálculo destas taxas de kerma no ar foi utilizado o código EGSnrc na determinação das razões entre os poderes de freamento do grafite e do ar, e também do fator de correção para a parede da câmara de ionização cavitária.

Em 2008, WULFF et al. (2008) determinaram o fator de correção da qualidade do feixe e fatores de correção de perturbação para uma câmara de ionização comercial, tipo Farmer, modelo NE2571, em feixes de fótons de energias altas, com o código de Monte Carlo EGSnrc. Deste trabalho, foi possível concluir que a determinação dos fatores de correção para a qualidade do feixe utilizando o método de Monte Carlo apresentou uma concordância excelente com os resultados experimentais.

Mais recentemente, em 2013, ERAZO e LALLENA (2013) calcularam os fatores de correção de perturbação para a mesma câmara de ionização utilizada no trabalho de WULFF et al. (2008), porém eles utilizaram o código de Monte Carlo PENELOPE. A comparação entre os resultados dos fatores de correção de perturbação mostram boa concordância com os dois códigos de Monte Carlo. O fator de correção de perturbação global obtido por ERAZO e LALLENA (2013), com o código de Monte Carlo PENELOPE, apresentou uma diferença de apenas 0,4\% em relação ao fator de perturbação determinado por WULFF et al. (2008), com o código de Monte Carlo EGSnrc. 


\section{Capítulo 4}

\section{Fundamentos Teóricos}

Este capítulo apresenta uma breve descrição de alguns conceitos que foram muito importantes para o desenvolvimento deste projeto.

\subsection{Interações da Radiação com a Matéria}

A interação da radiação com a matéria, no intervalo de energias que inclui as radiações X e gama, pode ocorrer de diferentes maneiras: com o átomo, com os elétrons atômicos, ou ainda com o núcleo. Porém, a radiação pode também não interagir com a matéria. Neste caso, a radiação atravessa distâncias consideráveis em um meio material sem modificá-lo e sem se modificar. A penetrabilidade das radiações $\mathrm{X}$ e gama é maior que a das partículas carregadas; sendo assim, a probabilidade de interação dependerá muito do valor de sua energia.

Nesta seção serão apresentados os principais modos de interação da radiação com a matéria no intervalo de energias incluindo as radiações $\mathrm{X}$ e gama.

\subsubsection{Efeito Fotoelétrico}

O efeito fotoelétrico é caracterizado pela transferência total de energia da radiação X ou gama a um único elétron orbital, que será expelido com uma energia cinética $E_{c}$ bem definida; um esquema representativo deste efeito é mostrado na Figura 4.1. A energia cinética desse elétron será a diferença entre a energia do fóton incidente e a energia de ligação do elétron ao átomo, como mostra a Equação 4.1. 


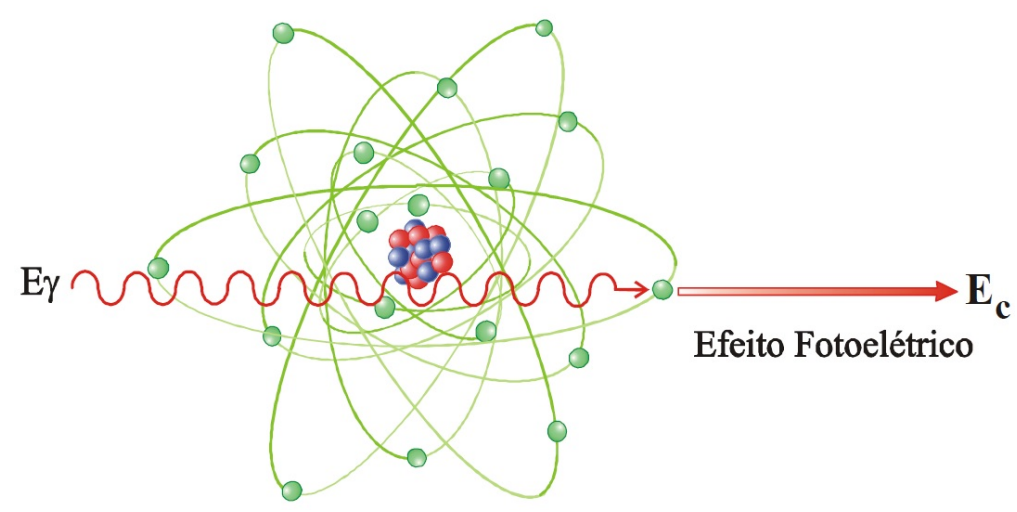

Figura 4.1: Esquema representativo do efeito fotoelétrico [TAUHATA et al. (2003)].

$$
E_{c}=h \nu-B_{e}
$$

onde $h$ é a constante de Plank, $\nu$ é a frequência da radiação e $B_{e}$ é a energia de ligação do elétron orbital.

O efeito fotoelétrico é predominante para energias baixas e para elementos químicos de número atômico $(Z)$ elevado. A probabilidade de ocorrência do efeito fotoelétrico aumenta com $\left(Z^{4}\right)$ e decresce rapidamente com o aumento da energia. A energia mínima do fóton para que o processo fotoelétrico ocorra deve ser igual ou maior que a energia de ligação do elétron no átomo [ATTIX (2004)]. Porém, com o aumento desta energia de ligação, a probabilidade decresce. Sendo assim, a probabilidade de interação por efeito fotoelétrico será máxima quando a energia do fóton for igual à energia de ligação do elétron no átomo [ATTIX (2004); TAUHATA et al. (2003)].

\subsubsection{Efeito Compton}

O efeito Compton é caracterizado pelo espalhamento de um fóton por um elétron de baixa energia de ligação. Neste caso, há transferência de parte da energia e do momento do fóton para o elétron, e um fóton com a energia restante é espalhado em outra direção. Um esquema representativo deste efeito é mostrado na Figura 4.2. Quando a energia de ligação dos elétrons orbitais se torna desprezível face à energia do fóton incidente, a probabilidade de ocorrência de espalhamento Compton 
aumenta de forma considerável.

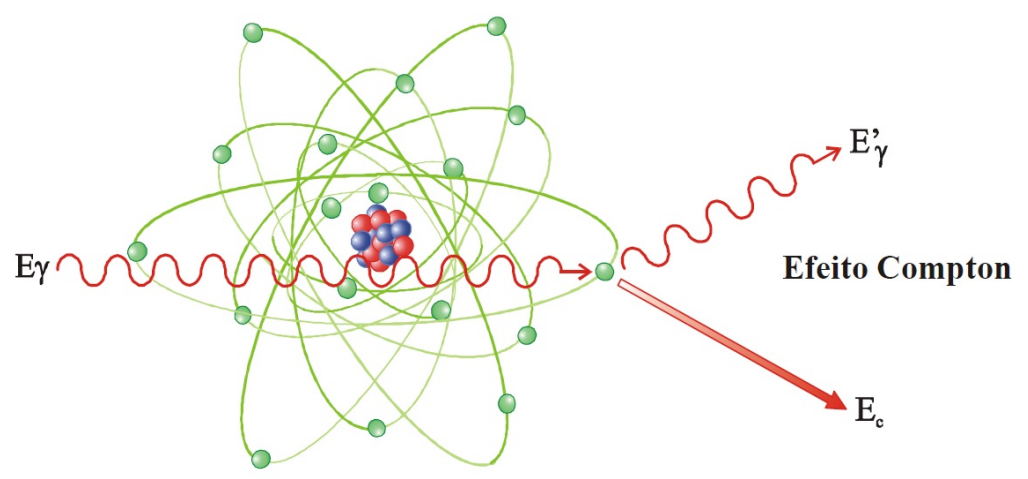

Figura 4.2: Esquema representativo do efeito Compton [TAUHATA et al. (2003)].

\subsubsection{Espalhamento Compton Coerente ou Efeito Rayleigh}

O efeito Rayleigh ocorre quando fótons de baixas energias interagem com elétrons com energia de ligação alta. Neste caso, o fóton interage com a matéria desviandose de sua trajetória inicial, de modo que ele não sofra variação em sua energia [JOHNS e CUNNINGHAM (1983)]. O efeito Rayleigh tem maior probabilidade de ocorrência para fótons de baixas energias e para valores altos de $Z$.

\subsubsection{Produção de Pares}

Uma das formas predominantes de absorção de radiação eletromagnética de alta energia é a produção de pares. Para que este processo ocorra, um fóton com energia mínima de 1,022 MeV colide com um núcleo, cedendo toda sua energia para o núcleo e dando origem a um par de partículas, o par partícula/antíparcula - elétron $\left(e^{-}\right) /$pósitron $\left(e^{+}\right)$[ATTIX (2004)].

Observando os tipos mais comuns de interação de radiação com a matéria, podese observar que o efeito fotoelétrico é predominante com fótons de energia suficientemente baixa. À medida que a energia do fóton aumenta, o efeito Compton se torna predominante. Acima da energia de alguns $\mathrm{MeV}$, a produção de pares passa a ser a principal forma de interação de fótons com a matéria, como mostra a Figura 4.3. 


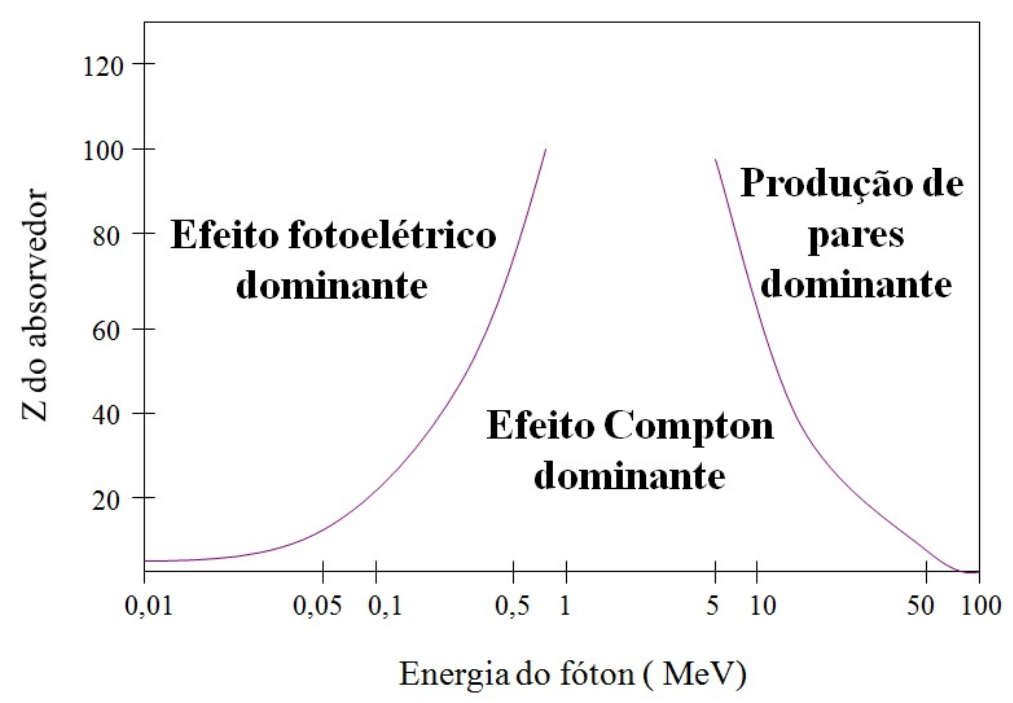

Figura 4.3: Importância relativa dos tipos mais comuns de processos de interação de fótons com a matéria em função da energia do fóton e do número atômico do material. Figura modificada de [ATTIX (2004)].

\subsection{Grandezas Dosimétricas}

Desde o início da utilização das radiações ionizantes, percebeu-se a necessidade de quantificar a radiação que interagia com o meio que ela atravessava. À medida que as pesquisas foram se desenvolvendo, houve um considerável aumento no conhecimento sobre as interações da radiação com a matéria e sobre os efeitos biológicos causados por elas.

Com a intenção de quantificar a radiação que interage em um determinado meio, várias grandezas relacionadas à dosimetria das radiações foram definidas pela International Commission on Radiation Units and Measurements (ICRU) e pela International Commission on Radiological Protection (ICRP). As grandezas dosimétricas de relevância em dosimetria das radiações relacionadas com o presente trabalho são: kerma, exposição e dose absorvida. Estas grandezas foram apresentadas e definidas na Publicação ICRU (1998).

\subsubsection{Exposição}

A grandeza exposição $(X)$ é definida como o quociente de $d Q$ por $d m$, onde $d Q$ é o valor absoluto de todas as cargas elétricas dos íons de um mesmo sinal, produzidas no ar quando todos os elétrons liberados pelos fótons em uma determinada massa 
de ar $d m$ são completamente freados (Equação 4.2) [ICRU (1998)].

$$
X=\frac{d Q}{d m}
$$

A unidade da grandeza exposição no Sistema Internacional de Unidades (SI) é coulomb por kilograma $\left[\mathrm{C} \cdot \mathrm{kg}^{-1}\right]$, e sua unidade antiga é o Roentgen $(1 \mathrm{R}=$ $\left.2,58 \cdot 10^{-4} \mathrm{C} \cdot \mathrm{kg}^{-1}\right)$.

A grandeza exposição apresenta como uma limitação o fato de que ela é definida para fótons que interagem somente no ar.

\subsubsection{Dose Absorvida}

A grandeza dose absorvida é definida como o quociente de $d \bar{E}$ por $d m$, onde $d \bar{E}$ é a energia média cedida pela radiação ionizante à matéria de massa dm (Equação 4.3) [ICRU (1998)].

$$
D=\frac{d \bar{E}}{d m}
$$

A unidade da grandeza dose absorvida no SI é joule por kilograma [ $\mathrm{J}^{\mathrm{kg}}{ }^{-1}$ ] ou gray (Gy). Esta grandeza foi definida para suprir as limitações da grandeza exposição, uma vez que ela é válida para qualquer tipo de radiação ionizante e para qualquer meio absorvedor.

\subsubsection{Kerma}

Quando não é possível medir a grandeza dose absorvida, mede-se a grandeza física kerma. A grandeza kerma $(K)$ é definida como o quociente de $d E_{\text {tr }}$ por $d m$, onde $d E_{\text {tr }}$ é a soma das energias cinéticas iniciais de todas as partículas ionizantes eletricamente carregadas liberadas pelas partículas ionizantes sem carga, como fótons e nêutrons, em um material de massa dm (Equação 4.4) [ICRU (1998)].

$$
K=\frac{d E_{\mathrm{tr}}}{d m}
$$


A unidade da grandeza kerma no SI é joule por kilograma $\left[\mathrm{J}_{\mathrm{kg}}{ }^{-1}\right]$ ou gray (Gy). Esta grandeza é válida somente para radiação indiretamente ionizante (radiação gama, X e de nêutrons). A grande vantagem da grandeza kerma é que ela é independente da complexidade do transporte de energia pelas partículas secundárias carregadas.

Em condições de equilíbrio eletrônico e quando a radiação de freamento puder ser desprezada, o kerma será igual à dose absorvida no ar [ICRU (1980)].

\subsection{Teoria Cavitária}

Para medir a dose absorvida em um meio é necessário introduzir um instrumento sensível à radiação (dosímetro) dentro deste meio. Na maioria dos casos, os dosímetros diferem em número atômico e densidade dos meios onde eles são inseridos criando, assim, cavidades nesses meios. A teoria da cavidade relaciona a dose absorvida no volume sensível do dosímetro com a dose absorvida no meio que contém o dosímetro [PODGORSAK (2005)]. As cavidades são classificadas em três tipos: pequenas, intermediárias e grandes, em comparação com o alcance dos elétrons presentes no meio. Por exemplo, se o alcance dos elétrons presentes no meio é muito maior que as dimensões da cavidade, a cavidade é classificada como pequena. O tipo de teoria a ser utilizada depende do tamanho da cavidade, quando comparado com o alcance dos elétrons presentes no meio. Existem vários modelos de teoria cavitária que serão brevemente discutidos neste texto. Uma revisão com mais detalhes e explicações foi relatada por ATTIX (2004) e por PODGORSAK (2005).

\subsubsection{Teoria de Bragg-Gray}

A teoria cavitária de Bragg-Gray foi a primeira teoria cavitária desenvolvida para fornecer a relação entre a dose absorvida em um dosímetro e a dose absorvida no meio contendo o dosímetro [PODGORSAK (2005)].

Por meio de suas observações e estudos sobre a ionização provocada por radiação gama, Gray derivou um "Princípio de Equivalência". Este princípio afirmava que "a 
energia perdida pelos elétrons na cavidade, por unidade de volume, é $1 / \rho$ vezes a energia perdida pela radiação gama, por unidade de volume do sólido", onde $1 / \rho$ representa a razão entre os poderes de freamento dos elétrons na cavidade e no meio.

A relação de Bragg-Gray, que é o princípio de Equivalência, é dada pela Equação 4.5:

$$
D_{\text {meio }}=\left(\frac{1}{(L / \rho)_{\text {meio }}^{\text {cav }}}\right) D_{\text {cav }}
$$

onde $D_{\text {meio }}$ e $D_{\text {cav }}$ representam a dose absorvida no meio e na cavidade, respectivamente, e $(L / \rho)_{\text {meio }}^{\text {cav }}$ é a razão entre os poderes de freamento de massa da cavidade e do meio.

As condições para aplicação da teoria cavitária de Bragg-Gray são [PODGORSAK (2005)]:

- A cavidade deve ser pequena quando comparada com o alcance das partículas carregadas incidentes sobre ela, de modo que sua presença não perturbe a fluência de partículas carregadas no meio;

- A dose absorvida na cavidade é depositada somente pelas partículas carregadas que a atravessam, ou seja, as interações que ocorrem na cavidade são consideradas insignificantes e, portanto, são ignoradas.

A relação de Bragg-Gray não levou em conta a produção dos raios delta que depositam energia fora do volume de interesse, considerando que toda energia perdida pelos elétrons é dissipada localmente. Este problema foi resolvido com as teorias cavitárias que surgiram posteriormente.

\subsubsection{Teoria de Spencer-Attix}

Spencer e Attix desenvolveram teorias que levaram em consideração os raios delta no cálculo da energia depositada na cavidade e também consideraram as diferenças de número atômico dos materiais. 
A teoria de Spencer-Attix baseia-se nas seguintes suposições:

- O espectro de elétrons presente na cavidade é aquele característico do meio, ou seja, a cavidade é considerada como sendo infinitesimal;

- A energia do elétron gasta na produção do Bremsstrahlung é considerada desprezível;

- As interações de fótons que geram elétrons na cavidade são consideradas desprezíveis.

Para levar em conta os raios delta, Spencer e Attix introduziram uma energia de corte $\Delta$, abaixo da qual as transferências de energia são consideradas dissipativas. Nesta teoria, o tamanho da cavidade está relacionado à energia de corte, que é escolhida como a energia média de elétrons que possuem alcances projetados suficientes apenas para atravessarem a cavidade. O espectro de elétrons formado ao redor da cavidade é dividido da seguinte forma [ATTIX (2004)]:

- Elétrons que possuem energia $T \geq \Delta$. Neste caso, os elétrons podem transportar energia e possuem energia suficiente para atravessarem a cavidade;

- Elétrons que possuem energia $\mathrm{T}<\Delta$. Neste caso, os elétrons têm alcance zero, ou seja, eles perdem sua energia no ponto de formação, sendo assim, estes elétrons não penetram na cavidade.

Para a Teoria de Spencer-Attix, a razão dos poderes de freamento apresentada na Equação 4.5 torna-se (Equação 4.6):

$$
(L / \rho)_{\text {meio }}^{\text {cav }}=\frac{1}{T_{0}} \int_{\Delta}^{T_{0}} \frac{R_{\text {meio }}\left(T_{0}, T\right)}{(L / \rho)_{\text {meio }}(T)}(L / \rho)_{\text {cav }}(T, \Delta) d T
$$

onde $R_{\text {meio }}\left(T_{0}, T\right)$ é a razão do fluxo total de elétrons no meio, incluindo os raios delta e o fluxo de elétrons primários, e $(L / \rho)_{c a v}(T, \Delta)$ é o poder de freamento restrito de massa da cavidade. 


\subsubsection{Teoria de Burlin ou Teoria Cavitária Geral}

Tanto a teoria cavitária de Bragg-Gray quanto a teoria de Spencer-Attix consideraram as cavidades como sendo infinitesimais e, consequentemente, o espectro de elétrons nelas é totalmente característico do meio. Esta foi a limitação apresentada nestas teorias, pois na prática as cavidades não são infinitesimais.

No caso de se ter uma cavidade grande (dimensões maiores que o alcance dos elétrons gerados no meio), a dose absorvida na cavidade é considerada totalmente proveniente dos elétrons gerados pelos fótons na cavidade e proporcional ao coeficiente de absorção de energia mássico $\left(\mu_{\mathrm{en}} / \rho\right)_{\text {cav }}$ do material da cavidade. A dose absorvida no meio é proporcional ao coeficiente de absorção de energia mássico $\left(\mu_{\mathrm{en}} / \rho\right)_{\text {meio }}$ do meio, e pode ser escrita como (Equação 4.7):

$$
D_{\text {meio }}=\left[\frac{\left(\mu_{\text {en }} / \rho\right)_{\text {meio }}}{\left(\mu_{\text {en }} / \rho\right)_{\text {cav }}}\right] D_{\text {cav }}
$$

Geralmente as cavidades apresentam tamanho intermediário (dimensões comparáveis ao alcance dos elétrons) e o espectro presente na cavidade é constituído de elétrons gerados tanto no meio quanto na cavidade. Burlin em 1966 foi o primeiro pesquisador a propor uma teoria que considerou a atenuação dos elétrons gerados no meio e o correspondente aumento de elétrons gerados na cavidade. Esta teoria foi denominada Teoria Cavitária Geral e a expressão para ela é formulada como (Equação 4.8):

$$
D_{\text {meio }}=\left[d(L / \rho)_{\text {meio }}^{\text {cav }}+(1-d) \frac{\left(\mu_{\mathrm{en}} / \rho\right)_{\mathrm{cav}}}{\left(\mu_{\mathrm{en}} / \rho\right)_{\text {meio }}}\right]^{-1} D_{\text {cav }}
$$

onde $d$ é um fator que depende do tamanho da cavidade e representa o quanto o fluxo de elétrons gerados no meio é, em média, atenuado na cavidade.

A teoria cavitária de Burlin se baseia nas seguintes condições [PODGORSAK (2005)]:

- O meio em torno da cavidade e o meio da cavidade são homogêneos;

- Existe um campo elétrico homogêneo em todo lugar do meio e da cavidade; 
- Existe equilíbrio eletrônico em todos os pontos do meio e da cavidade;

- O espectro de elétrons secundários é igual no meio e na cavidade.

\subsection{Câmaras de Ionização}

No início da utilização de raios X para diagnóstico e terapia, surgiram várias tentativas para tentar medir radiação ionizante com base em efeitos biológicos e químicos. Por exemplo, os efeitos da radiação sobre emulsões fotográficas, mudanças da cor de alguns componentes químicos e vermelhidão da pele das pessoas estavam relacionados com a quantidade de radiação absorvida. Entretanto, estes efeitos eram pouco entendidos naquela época e forneciam apenas uma estimativa da dose de forma muito precária [KHAN (2009)].

Com o avanço na tecnologia e na pesquisa, iniciou-se o processo de desenvolvimento de diversos tipos de detectores de radiação, que tornaram a estimativa da dose mais confiável e segura. Entre os diversos tipos de detectores desenvolvidos, a câmara de ionização é um tipo de dosímetro bastante confiável e utilizado em laboratórios de calibração e hospitais para dosimetria de feixes de radiação de equipamentos de diagnóstico e terapia [PODGORSAK (2005)].

\subsubsection{Características Gerais}

Dos detectores de radiação mais antigos, as câmaras de ionização são ainda um dos mais utilizados nas áreas de radioterapia e radiodiagnóstico, para determinação da dose de radiação. As câmaras de ionização são detectores de radiação a gás. O funcionamento é baseado na coleção de todas as cargas criadas pela ionização direta no gás por meio da aplicação de um campo elétrico, que precisa ser suficientemente grande para coletar todos os íons gerados pela passagem da radiação e, ao mesmo tempo, deve ser o ideal para gerar a multiplicação de íons. As câmaras de ionização apresentam diversas formas e tamanhos, dependendo das especificações de seu uso, mas elas em geral devem apresentar as seguintes propriedades [ATTIX (2004); KHAN (2009)]: 
- Devem possuir a mínima variação em sua sensibilidade de resposta em um grande intervalo de energia;

- Devem possuir volumes adequados para possibilitar medições em um intervalo de interesse de exposição. A sensibilidade de resposta é diretamente proporcional ao volume sensível da câmara de ionização;

- Devem possuir a mínima variação em sua sensibilidade de resposta em relação à direção da radiação incidente;

- Devem ser calibradas utilizando um padrão de referência para cada intervalo de energia de radiação de interesse;

- Devem apresentar a mínima perda possível por recombinação iônica.

\subsection{Tipos de Câmaras de Ionização}

Existem vários tipos de câmaras de ionização; a seguir serão listados os principais tipos e características, com suas respectivas aplicações.

\subsubsection{Câmara de Ionização de Ar Livre}

A câmara de ionização de ar livre ou câmara de ionização padrão é um instrumento empregado na medida de exposição de acordo com sua definição (apresentada na seção 4.2.1). Um esquema da câmara de ionização de ar livre é mostrado na Figura 4.4. Existem diferentes modelos de câmaras de ionização de ar livre que são empregadas nos laboratórios de padronização primária, mas na maioria dos casos elas são câmaras de ionização de placas paralelas [ATTIX (2004)].

Os principais elementos que compõem uma câmara de ionização de ar livre de placas paralelas, como mostrado na Figura 4.4, são: um diafragma e um par de placas paralelas separadas por uma distância $d$. Entre as placas existe um campo elétrico, produzido pela aplicação de uma tensão de polarização em uma das placas, enquanto a outra é mantida aterrada. Uma parte isolada da placa inferior, denominada eletrodo coletor, é conectada a um eletrômetro para realização das medições e 


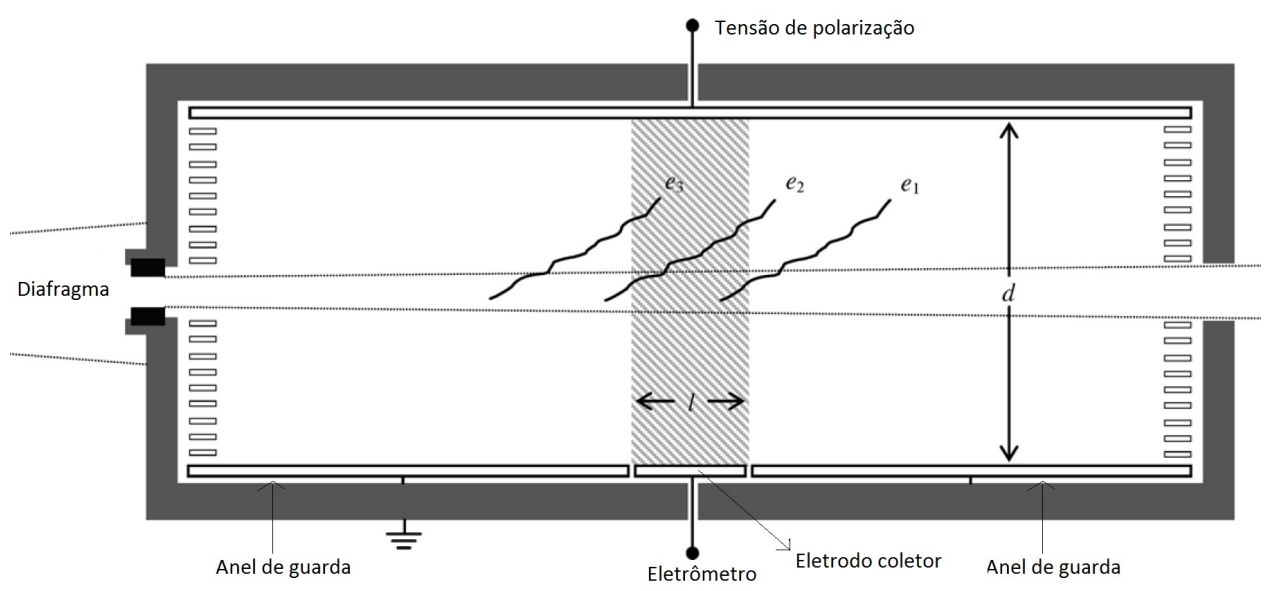

Figura 4.4: Desenho esquemático de uma câmara de ionização de ar livre. Os fótons passam através da abertura do diafragma e interagem com o ar presente na câmara de ionização para produzir elétrons secundários $\left(e_{1}, e_{2}, e_{3}\right)$. Uma parte isolada da placa inferior cria uma região de ar de comprimento l (tracejada) na qual a carga é coletada e medida como corrente de ionização. Figura modificada de [BURNS e BÜERMANN (2009)].

o restante da placa inferior, separado do eletrodo coletor por um material isolante, é o anel de guarda. O anel de guarda é responsável por manter a uniformidade do campo elétrico na região de coleção de íons. O eletrodo coletor e as linhas do campo elétrico definem uma região de comprimento l (área sombreada da Figura 4.4), na qual a carga é coletada [BURNS e BÜERMANN (2009)].

A medição de exposição utilizando uma câmara de ar livre está relacionada ao princípio de equilíbrio eletrônico. À medida que a energia dos fótons aumenta, é necessário que as dimensões da câmara também aumentem, de modo que os critérios adequados para a medição operacional da grandeza exposição sejam obedecidos. Com o aumento da energia, as câmaras de ar livre precisam ser cada vez maiores; assim, existe um limite de energia para que ela possa ser utilizada. A partir de fótons com energia superior a $300 \mathrm{keV}$ surgem problemas técnicos relacionados com o tamanho da câmara de ionização, pois ela deveria possuir um tamanho muito grande, equivalente ao tamanho de uma sala de tratamento radioterápico, por exemplo, para se obter equilíbrio eletrônico. As câmaras de ar livre são bastante utilizadas para medidas de exposição, com grande precisão, para radiação gama e X com energias abaixo de $300 \mathrm{keV}$. 


\subsubsection{Câmara de Ionização Cavitária}

As câmaras de ionização cavitárias medem o kerma no ar, fazendo uso da teoria cavitária de Bragg-Gray [PODGORSAK (2005)]. As câmaras de ionização cavitárias existem em diferentes variedades. Elas consistem basicamente de um gás, geralmente ar, contido em uma cavidade na qual um campo elétrico é estabelecido para coletar os íons formados pela radiação. Estas câmaras substituem as câmaras de ar livre para energia de fótons superior a $300 \mathrm{keV}$ para atuação como padrão primário nas medições de exposição em feixes de fótons. A câmara cavitária apresenta algumas vantagens em relação à câmara de ar livre [ATTIX (2004)]:

- Pode apresentar um projeto compacto, mesmo para uso em altas energias, visto que o alcance de elétrons secundários em material sólido é muito menor que o alcance no ar, sendo isto o que impossibilita a construção de câmaras de ar livre para feixes de radiação de energias altas;

- Ela pode medir campos de radiação multidirecionais, enquanto a câmara de ar livre mede somente campos unidirecionais alinhados para passarem perpendicularmente à abertura da câmara;

- Utilizando a teoria cavitária é possível determinar a dose absorvida em qualquer material da parede da câmara;

- Pode ser feita de diferentes formas, para possibilitar a medida de dose de partículas carregadas, nêutrons e fótons;

- A cavidade de gás pode ser fina e achatada para medir dose na superfície de simuladores.

As câmaras de ionização cavitárias podem ser cilíndricas, esféricas, planas e de placas paralelas. Também há câmaras de ionização cavitárias de extrapolação; neste caso, o volume sensível pode variar por meio da utilização de um parafuso micrométrico. Um desenho esquemático de uma câmara de ionização cavitária cilíndrica é mostrado na Figura 4.5. 


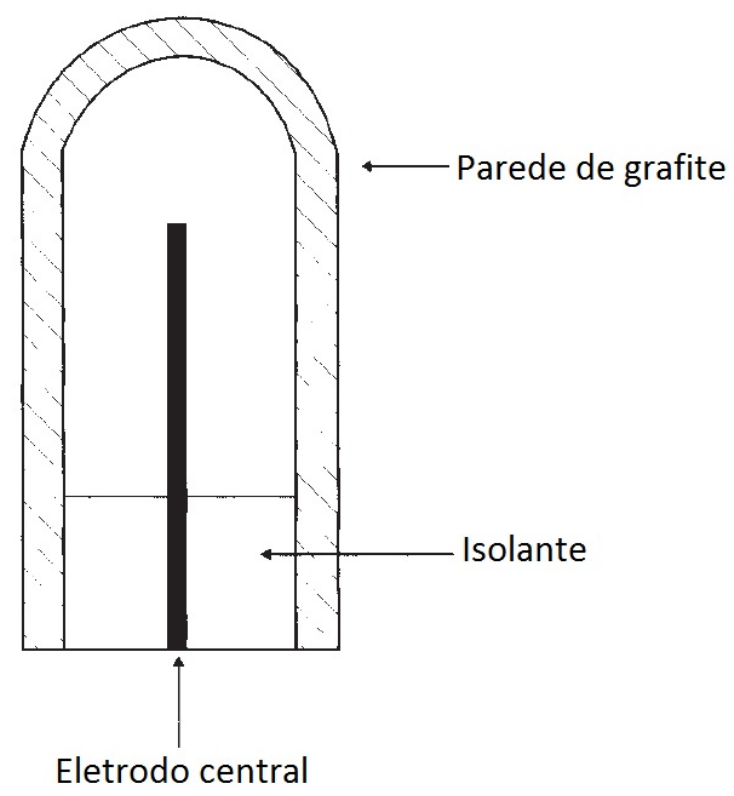

Figura 4.5: Desenho esquemático de uma câmara de ionização cavitária cilíndrica. Figura modificada de [CHERY e DUXBURY (2009)].

Para calibrar as câmaras cavitárias em campos de radiação acima de 2 MV, são utilizadas capas de equilíbrio eletrônico de várias espessuras de grafite ou poliestireno. Para as medições em um simulador, as câmaras cavitárias são geralmente utilizadas sem as capas de equilíbrio eletrônico, pois neste caso o próprio material do simulador permite que o equilíbrio eletrônico seja estabelecido [KASE et al. (1986)].

\subsubsection{Câmara de Ionização do Tipo Dedal}

As medições dosimétricas rotineiras na área de radioterapia geralmente são feitas usando-se câmaras de ionização do tipo dedal, pois estas câmaras são de fácil manuseio e transporte e, além disso, são versáteis. A câmara de ionização tipo dedal é constituída de uma parede sólida condutora que delimita um volume de ar e no centro deste volume está inserido um eletrodo para coletar os íons formados no ar, como mostrado na Figura 4.6. Sua construção é caracterizada pela espessura do material da parede, sua forma, seu volume e o gás utilizado.

A forma da câmara de ionização depende da quantidade e da qualidade de radiação a ser medida. Geralmente, seu volume sensível varia entre $0,1 \mathrm{~cm}^{3}$ e $1,0 \mathrm{~cm}^{3}$; além disso, seu comprimento interno é, na maioria dos casos, menor que $25 \mathrm{~mm}$ e o diâmetro interno menor que $7 \mathrm{~mm}$. O material que constitui a parede da câmara 


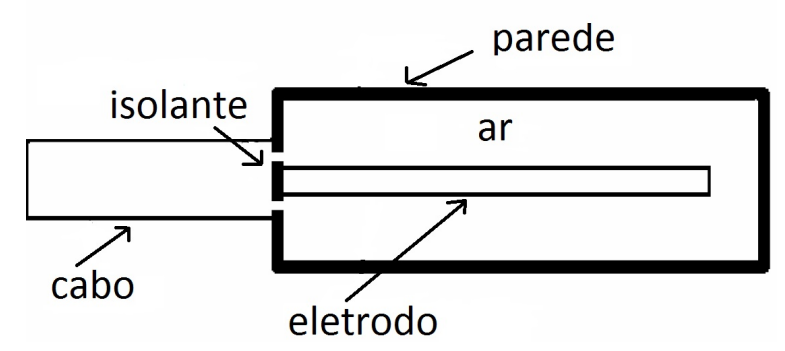

Figura 4.6: Desenho esquemático de uma câmara de ionização do tipo dedal.

de ionização dedal deve possuir número atômico pequeno (material equivalente ao ar ou tecido), e sua espessura deve ser menor do que $0.1 \mathrm{~g} / \mathrm{cm}^{2}$ [PODGORSAK (2005)].

As câmaras de ionização dedal de paredes finas são utilizadas como câmaras cavitárias para fótons de energias médias, utilizando-se uma capa de equilíbrio eletrônico, que é geralmente feita de PMMA [CAMPOS (1982)]. Esta capa impede que os elétrons gerados fora da câmara de ionização penetrem no seu volume sensível.

A câmara de ionização tipo dedal é bastante utilizada em medições dosimétricas rotineiras para controle de qualidade em feixes de radioterapia. O tipo mais comum de câmara de ionização dedal é câmara de ionização Farmer, projetada por Farmer e produzida por Baldwin, que tem um volume sensível de $0,6 \mathrm{~cm}^{3}$ [PODGORSAK (2005)].

\subsubsection{Câmara de Ionização de Placas Paralelas}

As câmaras de ionização de placas paralelas, como o próprio nome sugere, são constituídas por duas placas paralelas que formam as paredes e eletrodos da câmara de ionização. Estas paredes são revestidas com um material condutor, geralmente grafite, e são separadas por alguns milímetros de ar, delimitando o volume sensível da câmara de ionização [CHERY e DUXBURY (2009)]. As câmaras de ionização de placas paralelas são bastante utilizadas em programas de controle de qualidade, nível radiodiagnóstico. Um esquema deste tipo de câmara de ionização é mostrado na Figura 4.7.

As câmaras de ionização de placas paralelas são recomendadas para dosimetria de feixes em radioterapia com raios $\mathrm{X}$ de energias baixas e intermediárias, e tam- 


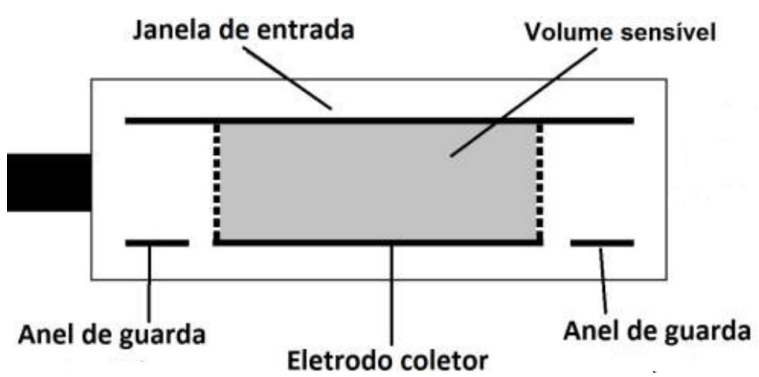

Figura 4.7: Desenho esquemático de uma câmara de ionização de placas paralelas Figura modificada de [DeWERD e WAGNER (1999)].

bém para elétrons de energias altas [ALMOND et al. (1999); IAEA (1997, 2004); MA et al. (2001)]

\subsection{Testes de Caracterização e Controle de Quali- dade das Câmaras de Ionização}

Alguns testes aplicados a câmaras de ionização são definidos e quantificados segundo recomendações internacionais [IEC (2011, 1997)]. Estes testes têm como objetivo verificar se a câmara de ionização está operando corretamente e também para verificar quantitativamente possíveis variações no valor medido pela câmara de ionização ao ser submetida a diferentes condições ambientais, elétricas e de irradiação. No texto a seguir serão descritos os principais testes para caracterização e controle de qualidade que são aplicados a câmaras de ionização, de acordo com a International Electrotechnical Commission [IEC (2011, 1997)]:

\subsubsection{Testes de Estabilidade}

Existem dois testes de estabilidade: estabilidade a curto prazo (teste de repetitividade) e estabilidade a longo prazo (teste de reprodutibilidade). Segundo a definição fornecida pelo Vocabulário Internacional de Termos Fundamentais e Gerais de Metrologia, VIM [INMETRO (2012)], repetitividade é "o grau de concordância entre os resultados de medições sucessivas de um mesmo mensurando efetuadas sob as mesmas condições de medição" e reprodutibilidade é "o grau de concordância entre os resultados das medições de um mesmo mensurando efetuadas sob condições variadas de medição". 
Os testes de repetitividade e reprodutibilidade avaliam a constância das respostas medidas com uma câmara de ionização. Para estes testes são utilizadas, na maioria dos casos, fontes de controle e um suporte para se obter reprodutibilidade geométrica do posicionamento da câmara de ionização em relação à fonte de controle.

\subsubsection{Teste de Tempo de Estabilização}

O teste de tempo de estabilização verifica o tempo necessário para que a resposta da câmara de ionização se torne estável após a aplicação da tensão de operação.

\subsubsection{Teste de Saturação}

O teste de saturação é realizado para se determinar em qual tensão a câmara de ionização deve ser operada. Esta tensão aplicada à câmara de ionização deve ser suficiente para coletar todos os íons primários gerados pela radiação incidente no volume sensível [ATTIX (2004)].

\subsubsection{Teste de Corrente de Fuga}

O teste de corrente de fuga avalia a corrente oriunda do detector, cabos, conexões ou do eletrômetro que não é produzida por ionização no volume sensível da câmara de ionização.

\subsubsection{Teste de Linearidade de Resposta e Dependência An- gular}

O teste de linearidade de resposta avalia se a relação entre a taxa de kerma no ar e a corrente de ionização apresentada pela câmara de ionização é linear. O resultado para este teste é dado pelo coeficiente de correlação obtido do ajuste linear das medições obtidas. O teste de dependência angular avalia a resposta da câmara de ionização em função do ângulo de incidência da radiação. Na maioria dos casos, as câmaras de ionização apresentam dependência angular devido à sua geometria ou à sua construção [KASE et al. (1986)]. 


\subsubsection{Teste de Dependência Energética}

O teste de dependência energética tem o objetivo de estudar a resposta da câmara de ionização em feixes de energias diferentes. Para este teste deve-se calibrar a câmara de ionização em feixes padrões de radiações. A variação da resposta da câmara de ionização deve ser determinada pela sua calibração.

\subsection{Sistema Tandem}

O sistema tandem é um sistema há bastante tempo conhecido e utilizado em dosimetria termoluminescente [GORBICS e ATTIX (1968); KENNEY e CAMERON (1963); ROSA e NETTE (1988); SPURNY et al. (1973)]. Este sistema consiste de dois dosímetros termoluminescentes individuais, com dependências energéticas diferentes, tornando possível a determinação da energia efetiva de um campo de radiação desconhecido. Este sistema é utilizado para calcular as energias efetivas das radiações gama e X para feixes não unidirecionais e também para determinar a energia efetiva de radiação em material sólido [ROSA (1981)].

O cálculo da energia efetiva utilizando este sistema consiste na utilização da razão entre os valores das respostas ou dos fatores de calibração dos dosímetros e, quanto maior esta razão, mais exato será o valor da energia efetiva encontrada [POTIENS (1999)]. A exatidão do sistema tandem está relacionada à precisão inerente dos dosímetros usados para compor o sistema tandem e de suas dependências energéticas.

A utilização do sistema tandem com câmaras de ionização está em constante desenvolvimento no LCI [ALBUQUERQUE (1990); COSTA (2003); MAIA (2005); VIVOLO (2006)]. Neste caso, as câmaras de ionização utilizadas para compor o sistema tandem devem ser aparentemente iguais, porém com eletrodos coletores compostos de materiais distintos, pois isto irá proporcionar diferentes dependências energéticas para formação do sistema tandem.

A utilização do sistema tandem com câmaras de ionização para determinação da energia efetiva é bastante prático e simples, pois basta realizar medições com as 
duas câmaras de ionização sem a utilização de materiais absorvedores e outros aparatos para determinação da energia efetiva, como é feito pelo método convencional. Portanto, este método permite a verificação periódica da energia efetiva de sistemas de raios $\mathrm{X}$, otimizando, assim, a dosimetria de feixes e o controle de qualidade dos equipamentos de raios $\mathrm{X}$.

\subsection{Fatores de Correção Aplicados a Câmaras de Ionização Padrões de Referência}

A determinação de fatores de correção aplicados a câmaras de ionização é muito importante quando se necessita caracterizar uma câmara de ionização como um padrão de referência. Por exemplo, a caracterização de padrões primários para kerma no ar em feixes de ${ }^{60} \mathrm{Co}$, geralmente câmaras de ionização cavitárias de grafite de diferentes configurações geométricas, está relacionada ao estudo de fatores de correção. Eles são parte fundamental na equação para determinação do kerma no ar $\left(K_{\text {ar }}\right)$, como mostra a Equação 4.9 [ROGERS e KAWRAKOW (2003)]:

$$
K_{\mathrm{ar}}=\frac{Q_{\mathrm{gas}}}{m_{\mathrm{ar}}\left(1-\bar{g}_{\mathrm{ar}}\right)}\left(\frac{W}{e}\right)_{\mathrm{ar}}\left(\frac{\bar{L}}{\rho}\right)_{\mathrm{ar}}^{\mathrm{parede}}\left(\frac{\bar{\mu}_{\mathrm{en}}}{\rho}\right)_{\text {parede }}^{\mathrm{ar}} \times \prod k_{i}(\mathrm{~Gy})
$$

onde $Q_{\text {gas }}$ é a carga produzida no volume de ar de massa $m_{\mathrm{ar}}, \bar{g}_{\mathrm{ar}}$ é a fração de energia que é dissipada fora da cavidade devido à radiação Bremsstrahlung produzida na cavidade, $W$ é a energia média gasta por um elétron de carga $e$ para produzir um

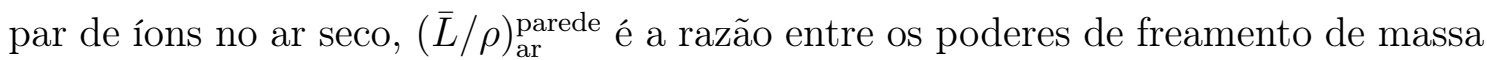

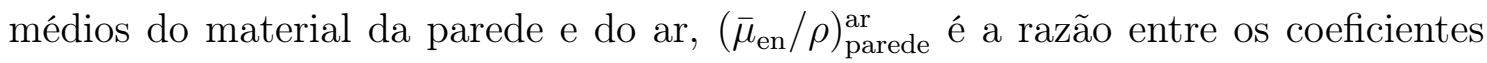
médios de absorção de energia mássico do ar e do material da parede e $k_{i}$ são os fatores de correção: $k_{\text {parede }}$ é o fator de correção de atenuação e espalhamento de fótons na parede da câmara, $k_{\text {an }}$ é o fator de correção para a falta de uniformidade axial devido à natureza puntiforme da fonte, enquanto a teoria assume um feixe

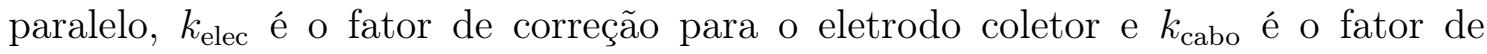
correção para o cabo.

Uma breve definição dos termos envolvidos na Equação 4.9 será apresentada no 
texto a seguir. Os principais fatores de correção serão também brevemente discutidos. Uma explicação mais detalhada é dada por ROGERS e KAWRAKOW (2003) e por BÜERMANN e BURNS (2009).

\subsubsection{Poder de Freamento}

Quando a partícula interage com um meio, para cada interação que ela sofre, sua energia cinética diminui de uma quantidade $d E$. Esta perda está relacionada ao tipo de partícula, a sua energia cinética e ao meio de interação. A composição dos possíveis valores de $d E$, ponderados pela probabilidade de ocorrência de cada tipo de interação, dá como resultado uma grandeza conhecida como poder de freamento $(L)$. Esta grandeza representa a perda média de energia por unidade de caminho em um determinado meio. Assim, a taxa de perda de energia pode ser expressa por (Equação 4.10) [ATTIX (2004)]:

$$
L=-\frac{d E}{d x}
$$

\subsubsection{Coeficiente de Transferência de Energia Mássico}

O coeficiente de transferência de energia mássico, $\mu_{\mathrm{k}} / \rho$, de um material, para partículas não carregadas, é dado por [SHANI (2001)]:

$$
\left(\frac{\mu_{\mathrm{k}}}{\rho}\right)=\frac{1}{\rho d l} \frac{d E}{E}
$$

Unidade: $\mathrm{m}^{2} / \mathrm{kg}^{-1}$,

sendo $d E / E$ a fração de energia radiante incidente que é transferida para a energia cinética das partículas carregadas pelas interações, percorrendo a distância $d l$ do material de densidade $\rho$.

\subsubsection{Coeficiente de Absorção de Energia Mássico}

O coeficiente de absorção de energia mássico, $\mu_{\mathrm{en}} / \rho$, de um material, para partículas não carregadas, é dado por [SHANI (2001)]: 


$$
\left(\frac{\mu_{\mathrm{en}}}{\rho}\right)=\left(\frac{\mu_{\mathrm{k}}}{\rho}\right)(1-g)
$$

Unidade: $\mathrm{m}^{2} / \mathrm{kg}^{-1}$,

sendo $g$ a fração de energia das partículas carregadas que é liberada em processos radiativos, isto é, é a fração de energia gasta como radiação no material.

\subsubsection{Fator de Correção de Atenuação e Espalhamento de Fótons na Parede da Câmara de Ionização ( $\left.k_{\text {parede }}\right)$}

Este fator está relacionado ao fato de que a densidade do fluxo e a distribuição de energia dos fótons em um ponto de medição livre no ar será alterado devido à atenuação causada pela presença da parede da câmara de ionização e à radiação espalhada que é produzida em seu interior. Este fator é calculado experimentalmente adicionando-se sucessivas capas na câmara de ionização e por meio do uso da extrapolação linear obtém-se a resposta da câmara de ionização em uma parede de espessura zero [BOUTILLON e NIATEL (1973)].

$\mathrm{O}$ fator $\mathrm{k}_{\text {parede }}$ pode ser também calculado pelo método de Monte Carlo. Quando se utiliza este código, este fator é a razão entre a dose determinada na cavidade de ar, considerando a ausência de atenuação e espalhamento na parede da câmara, e a dose determinada na cavidade de ar, com atenuação e espalhamento presentes. Utilizando o código EGSnrc, este fator é calculado usando a biblioteca CAVRZnrc [ROGERS et al. (2011)].

Atualmente, o fator de correção da parede é calculado com simulação de Monte Carlo, visto que as incertezas associadas a este fator são bem menores com o uso da simulação em comparação com experimentos.

\subsubsection{Fator de Correção para Falta de Uniformidade Axial $\left(\mathrm{k}_{\mathrm{an}}\right)$}

Considerando um detector ideal e uma fonte puntiforme de fótons, a resposta fornecida por este detector deve seguir a lei do inverso do quadrado da distância. Na prática, a distribuição radial e axial de fótons depende do tamanho finito da fonte, 
espalhamento em diversas regiões, forma e tamanho do detector, além da distância da fonte em relação ao detector. A correção para este efeito inclui a falta de uniformidade radial e axial. Entretanto, a falta de uniformidade radial, em distâncias comuns de calibração, é ignorada. O fator $k_{a n}$ é uma correção para a falta de uniformidade axial no campo de fótons ao longo da linha entre a fonte e o centro geométrico da cavidade [BIELAJEW (1990)], e este fator é dado por [ROGERS e KAWRAKOW (2003)]:

$$
k_{\text {an }}=\frac{\left(D_{\text {gas }} k_{\text {parede }}\right)^{\text {paralelo }}}{\left(D_{\text {gas }} k_{\text {parede }}\right)^{\text {puntiforme }}}
$$

sendo $D_{\text {gas }}$ a dose calculada na cavidade de ar, para um feixe incidente paralelo e para um feixe incidente de uma fonte puntiforme.

\subsubsection{Fator de Correção para o Espalhamento no Cabo da Câmara de Ionização $\left(k_{\text {cabo }}\right)$}

O cabo da câmara de ionização é parcialmente irradiado pelo feixe incidente de fótons e deve, portanto, causar um aumento na resposta da câmara de ionização devido aos fótons espalhados. Este fator de correção pode ser determinado experimentalmente utilizando-se um cabo "falso" posicionado no lado oposto ao cabo verdadeiro [BÜERMANN e BURNS (2009)]. Atualmente, este fator de correção é determinado por meio de simulação de Monte Carlo, como sendo a razão entre a resposta da câmara de ionização sem o cabo e a resposta da câmara de ionização completa.

\subsubsection{Fator de Correção para o Eletrodo Coletor $\left(k_{\text {elec }}\right)$}

O eletrodo coletor também tem uma influência sobre as leituras realizadas por uma câmara de ionização, embora muito pequena. Este fator de correção é complicado de ser determinado experimentalmente. A determinação do fator de correção para o eletrodo coletor pode ser realizada por meio da comparação da resposta da câmara de ionização para eletrodos coletores similares, porém feitos de materiais diferentes. Em 1983, KRISTENSEN (1983) comparou a resposta de duas câmaras 
de ionização cilíndricas, uma com eletrodo coletor de grafite e outra com eletrodo de alumínio. O resultado mostrou que o eletrodo coletor de diâmetro de 1,35 mm de alumínio aumentou a resposta da câmara de ionização em 0,8\% quando comparada com a resposta da câmara de ionização com eletrodo coletor de grafite de mesmo diâmetro.

Atualmente, o fator de correção para o eletrodo coletor da câmara de ionização tem sido investigado utilizando simulação de Monte Carlo [MA e NAHUM (1993); MUIR e ROGERS (2011)]. Neste caso, o fator de correção do eletrodo coletor é determinado como a razão entre a dose no volume sensível da câmara de ionização sem o eletrodo coletor $\left(D_{\mathrm{ch}}\right)$ e a dose no volume sensível com a presença do eletrodo coletor $\left(D_{\text {ch }}^{\text {elec }}\right)$ (Equação 4.14).

$$
k_{\text {elec }}=\frac{D_{\text {ch }}}{D_{\text {ch }}^{\text {elec }}}
$$

\subsection{Simulação de Monte Carlo}

Desde a publicação do artigo de revisão de RAESIDE (1976), onde os princípios do método de Monte Carlo e suas primeiras aplicações em Física Médica foram descritas, o número de publicações neste campo do conhecimento utilizando simulações de Monte Carlo para o transporte de radiação aumentaram de forma significativa. Depois disso, ROGERS (2006) fez um levantamento do número de publicações nas revistas Physics in Medicine and Biology e Medical Physics relacionadas com simulação de Monte Carlo nos últimos 50 anos. Ele observou que houve um aumento significativo de artigos envolvendo simulação de Monte Carlo a partir da década de 90, principalmente devido a melhorias na capacidade de processamento e armazenamento de dados dos computadores e a criação de softwares com ferramentas específicas para diferentes aplicações. Atualmente, é possível encontrar sistemas de planejamento radioterápico comerciais que empregam simulação de Monte Carlo [CYGLER et al. (2004)].

O transporte de radiação na matéria tem sido bastante discutido desde o começo 
do século XX. Hoje sabe-se que fótons, elétrons e pósitrons que penetram na matéria podem sofrer múltiplas interações. Nestas interações, a energia é transferida para os átomos e moléculas do material e partículas secundárias serão produzidas. Portanto, a partir de uma partícula de energia alta origina-se uma cascata de partículas.

O estudo do transporte de radiação foi inicialmente baseado na equação de Boltzmann, que pode ter uma solução bastante complexa, dependendo do problema analisado. Em 1950, quando já era possível ter acesso aos computadores, os métodos de simulação de Monte Carlo foram desenvolvidos como uma alternativa para o estudo do transporte de radiação. O método de Monte Carlo fornece uma simulação detalhada, onde todas as interações realizadas por uma partícula são simuladas em sucessão cronológica, fornecendo os mesmos resultados que uma solução rigorosa da equação de transporte [SALVAT et al. (2003)].

No código de Monte Carlo, o processo físico é simulado diretamente, sem a necessidade de descrever as equações matemáticas que representam o comportamento do sistema, sendo que o único requisito necessário é que o processo físico possa ser descrito por funções de densidades de probabilidade. Uma vez que as funções de densidades de probabilidade são conhecidas, a simulação de Monte Carlo é realizada por meio da amostragem aleatória destas funções. O resultado desejado é obtido por meio da estimativa do valor médio das grandezas observadas, durante um determinado número de simulações (tentativas ou histórias) [YORIAZ (2009)].

A característica essencial do método de Monte Carlo é o uso de técnicas de amostragem para a determinação da solução de um problema físico. Em contraste, os métodos numéricos convencionais partem de modelos matemáticos do sistema físico, por meio da discretização de equações diferenciais, resolvendo um conjunto de equações algébricas, que muitas vezes são bastante complexas e difíceis de se obter uma solução [YORIAZ (2009)].

\subsubsection{Aplicações do Método de Monte Carlo}

A utilização da simulação de Monte Carlo se dá em praticamente todas as áreas do conhecimento, desde a investigação fundamental em diversos domínios científi- 
cos e tecnológicos, até as aplicações das radiações ionizantes nas áreas da saúde, agricultura e na indústria.

O método de Monte Carlo é um método relativamente simples e pode ser aplicado para resolução de problemas de diferentes níveis de complexidade. A principal aplicação de Monte Carlo, hoje em dia, é resolver problemas complexos de transporte de radiação que não podem ser modelados computacionalmente usando métodos determinísticos ou quando medições experimentais são impraticáveis.

A simulação de Monte Carlo é uma ferramenta essencial para descrever o transporte de radiação ionizante. Em particular, simulações de Monte Carlo são muito utilizadas para se estudar um grande número de aplicações médicas, porque é um método barato, seguro e pode fornecer informações muito difíceis ou, às vezes, impossíveis de se obter experimentalmente (determinados fatores de correção de câmaras de ionização, fatores de perturbação em dosimetria, etc).

Entre as principais aplicações do método de Monte Carlo em física médica destacam-se [ROGERS (2006); YORIAZ (2009)]:

- Cálculo de dose e de outras grandezas de interesse, relacionadas ao tratamento de câncer por radiação, com fontes externas ou internas;

- Avaliação de dose em procedimentos diagnósticos;

- Estudo da qualidade de imagens médicas;

- Determinação dos fatores de correção de dosímetros utilizados como sistemas padrões primários;

- Avaliação da resposta de novos tipos de detectores utilizados em dosimetria;

- Avaliação da influência dos componentes e dos materiais constituintes de novos dosímetros em suas respostas;

- Desenvolvimento de sistemas de planejamento e cálculo de distribuição de dose na área de terapia de captura de nêutrons (BNCT) por meio de modelos computacionais baseados no método de Monte Carlo. 


\subsubsection{Métodos de Monte Carlo aplicados em Física Médica}

Os códigos de Monte Carlo mais comumente aplicados em problemas relacionados com Física Médica são: EGSnrc, PENELOPE, Monte Carlo $N$-Particle Transport Code (MCNP) e GEometry ANd Tracking (GEANT) [ROGERS (2006)]. O código EGSnrc é um código que compreende várias bibliotecas para diferentes aplicações em Física Médica. Sua principal aplicação é na determinação de fatores de correção de câmaras de ionização utilizadas como padrões primários [ROGERS (2006)]. O código PENELOPE oferece um pacote de geometria flexível que permite uma simulação bastante detalhada do problema a ser estudado [SALVAT et al. (2003)]. O código MCNP é mantido por um grupo no Laboratório Nacional de Los Alamos, EUA, e apresenta muitas aplicações além da Física Médica, pois ele foi desenvolvido originalmente para estudar o transporte de nêutrons e fótons para cálculos com reatores. A grande vantagem deste código é o seu pacote de geometria que permite a criação de geometrias bastante complexas [ROGERS (2006)]. O código GEANT é um código desenvolvido para aplicações em física de partículas. Este código pode simular diversos tipos de partículas (nêutrons, prótons, pions, etc). Atualmente, o código GEANT tem sido aplicado para cálculos em física da radioterapia [CARRIER et al. (2004)] e também ele serve de base para ferramenta de simulação GATE para aplicações em Medicina Nuclear em PET e SPECT [JAN et al. (2004)].

\subsubsection{Método de Monte Carlo para o Estudo de Câmaras de Ionização}

Particularmente, em dosimetria das radiações, onde alguns experimentos são muito difíceis de realizar com um grau de precisão adequado, e onde muitos fatores de correção utilizados para determinação da taxa de kerma no ar não podem ser medidos diretamente por meio de experimentos, a utilização da simulação de Monte Carlo vem ganhando um espaço cada vez maior.

Nos tempos atuais, a técnica de Monte Carlo tem um papel importante em dosimetria das radiações envolvendo câmaras de ionização [ROGERS (2006)]. Com 
a utilização do código de Monte Carlo, o cálculo dos fatores de correção tornouse mais preciso e confiável, tornando as incertezas do cálculo de kerma no ar e dose absorvida na água cada vez menores. Com isto, muitos laboratórios padrões primários passaram a utilizar o Método de Monte Carlo para analisar os fatores de correção de suas câmaras de ionização padrões primários, como é o caso do BIPM e PTB, entre vários outros.

A maioria dos laboratórios de metrologia internacionais e nacionais determinavam os fatores de correção de seus padrões experimentalmente. Por exemplo, o fator de correção da parede, como dito anteriormente, era calculado adicionando-se sucessivas capas na câmara de ionização e por meio do uso da extrapolação linear obtinha-se a resposta da câmara de ionização numa parede de espessura zero. Com o advento dos vários códigos de Monte Carlo, estes fatores de correção e outros passaram a ser calculados de maneira mais confiável. Além disso, em 2003, um trabalho de BÜERMANN et al. (2003) mostrou que existem inconsistências na utilização da extrapolação linear para o cálculo do fator de correção da parede e eles indicaram a viabilidade e a confiabilidade do uso dos métodos de Monte Carlo para a determinação de diversos fatores de correção.

Com o objetivo de simular uma câmara de ionização e encontrar alguns fatores de correção, NATH e SCHULZ (1981), como já dito anteriormente, desenvolveram um código de Monte Carlo para atender às suas necessidades. Este foi um ponto interessante na utilização da simulação de Monte Carlo em dosimetria com câmaras de ionização. A partir daí, a utilização de códigos de Monte Carlo vem crescendo e aperfeiçoando-se muito rapidamente. Hoje existem diferentes códigos de Monte Carlo para simular o transporte de radiação com aplicação em dosimetria.

Dentre os diferentes tipos de códigos de Monte Carlo, com aplicação em dosimetria, o código PENELOPE e EGSnrc destacam-se no estudo de câmaras de ionização.

O código PENELOPE é distribuído gratuitamente pela International Atomic Energy Agency (IAEA) e é bastante utilizado para simular o transporte de elétrons, 
fótons e pósitrons. O código de simulação PENELOPE é composto por quatro arquivos escritos em linguagem computacional FORTRAN com as seguintes definições das subrotinas utilizadas na simulação [SALVAT et al. (2003, 2008)]:

PENELOPE.f: subrotinas responsáveis pelo transporte das partículas simuladas;

PENGEOM.f: subrotinas que controlam a geometria da simulação;

TIMER.f: subrotinas que controlam o tempo de simulação;

PENVARED.f: subrotinas que executam os métodos de redução variacional.

Além destas subrotinas, o código consta de um programa MATERIAL.f que gera os arquivos de dados de seção de choque dos materiais.

Para desenvolver uma simulação com o código PENELOPE, deve-se editar um arquivo FORTRAN, usuário.f, com as chamadas das subrotinas PENELOPE.f, PENGEON.f, PENVARED.f e TIMER.f, o que proporcionará o gerenciamento da simulação como um todo, e criando, com esses cinco arquivos escritos em linguagem computacional FORTRAN, um arquivo usuário.exe.

A simulação começa com a execução do arquivo usuário.exe, que buscará as informações fornecidas no arquivo de entrada (entrada.in), informações da geometria (geometria.geo), e informações de seção de choque dos materiais usados na simulação por meio do arquivo material.mat.

O arquivo de entrada, entrada.in, contém as seguintes informações: tipo e energia da partícula, abertura e posição da fonte de radiação, parâmetros de controle da simulação, número de partículas e tempo da simulação. Neste arquivo também são definidos os nomes dos arquivos de geometria e material. Os parâmetros de controle da simulação, responsáveis pela exatidão e desempenho da simulação, são descritos na Tabela 4.1.

O código EGSnrc é um código de Monte Carlo distribuído gratuitamente. Este código é usado para simulação do transporte de elétrons e fótons por meio de uma geometria arbitrária. O intervalo de energia para sua aplicação é de $1 \mathrm{keV}$ até $10 \mathrm{GeV}$. 
Tabela 4.1: Parâmetros de controle da simulação de Monte Carlo com código PENELOPE.

\begin{tabular}{|c|c|}
\hline Parâmetro de Controle & Definição \\
\hline$E_{\mathrm{ABS}}$ & $\begin{array}{l}\text { Valor da energia máxima que uma partícula, } \\
\text { carregada ou não, pode possuir antes de } \\
\text { ser absorvida, finalizando o processo } \\
\text { de transporte desta partícula e iniciando } \\
\text { o transporte de uma nova partícula. }\end{array}$ \\
\hline$C_{1}$ & $\begin{array}{c}\text { Parâmetro relacionado com a deflexão } \\
\text { angular média produzida por múltiplo } \\
\text { espalhamento entre duas colisões fortes } \\
\text { consecutivas de uma partícula carregada. } \\
\text { Este valor deve ser suficientemente } \\
\text { pequeno para permitir a simulação o } \\
\text { mais detalhada possível. }\end{array}$ \\
\hline$C_{2}$ & $\begin{array}{c}\text { Parâmetro relacionado a perda fracional } \\
\text { máxima de energia permitida entre eventos } \\
\text { de colisão forte de uma partícula carregada. } \\
\text { Deve ser definido para permitir a amostragem } \\
\text { correta do alcance entre eventos de } \\
\text { colisões fortes. }\end{array}$ \\
\hline$W_{\mathrm{CC}}$ & $\begin{array}{l}\text { Energia máxima perdida por partícula } \\
\text { carregada em colisões fortes. }\end{array}$ \\
\hline$W_{\mathrm{CR}}$ & $\begin{array}{l}\text { Energia máxima perdida por partícula } \\
\text { carregada em perdas radiativas fortes. }\end{array}$ \\
\hline
\end{tabular}

Este código é considerado um dos métodos mais precisos para simulação do transporte de radiação [ROGERS et al. (2011)].

No código EGSnrc existe uma variedade de parâmetros que devem ser definidos para cada simulação. Entre estes parâmetros, os mais importantes são: energia de corte para partículas carregadas $\left(E_{\mathrm{ECUT}}\right)$ e energia de corte para fótons $\left(P_{\mathrm{ECUT}}\right)$ [ROGERS et al. (2011)]. A energia de corte é um parâmetro necessário na simulação, pois é necessário parar o transporte de partículas para uma determinada energia. O transporte de uma partícula cessa se a energia da partícula for menor que o valor da energia de corte.

O transporte de partículas no código EGSnrc também é controlado pelo pacote PEGS4. Este pacote é uma interface onde o usuário pode criar bibliotecas de poderes de freamento e seções de choque para qualquer elemento, composição ou mistura para uma determinada faixa de energia. Este pacote é preparado previamente pelo 
usuário por meio da utilização de programas internos no EGS4. No decorrer das simulações, o programa principal chama os dados das seções de choque contidas no PEGS4 com a finalidade de verificar e classificar os possíveis eventos das partículas em cada seção do meio.

O código EGSnrc inclui um grupo de bibliotecas desenvolvidas para cálculos bem específicos [ROGERS et al. (2011)], como os fatores de correção utilizados para determinação de taxa de kerma no ar (Tabela 4.2).

Tabela 4.2: Bibliotecas do código EGSnrc para obtenção dos fatores de correção envolvidos na determinação da taxa de kerma no ar.

\begin{tabular}{cc}
\hline Biblioteca & Descrição \\
\hline CAVRZnrc & $\begin{array}{c}\text { Utilizada para calcular a dose total em uma região } \\
\text { (ou regiões) definida como uma cavidade em uma } \\
\text { superfície cilíndrica; e também usada para calcular } \\
\text { alguns fatores de correção como o } k_{\text {parede }}\end{array}$ \\
\hline SPRRZnrc & $\begin{array}{c}\text { Usada para calcular a razão dos poderes de freamento } \\
\text { entre o meio, definido no arquivo de entrada, e o ar, } \\
\text { para cada região criada na simulação. }\end{array}$ \\
\hline DOSRZnrc & $\begin{array}{c}\text { Usada para calcular a dose em regiões individuais } \\
\text { dentro de uma superfície cilíndrica. }\end{array}$ \\
\hline Código $g$ & $\begin{array}{c}\text { Usado para calcular a fração de energia que é } \\
\text { dissipada fora da cavidade devido à radiação } \\
\text { Bremsstrahlung produzida na cavidade. }\end{array}$ \\
\hline
\end{tabular}

\subsection{Calibração de Instrumentos}

A calibração de um detector de radiação é parte fundamental no controle de qualidade de qualquer medição ou serviço que utilize radiações ionizantes. Por exemplo, câmaras de ionização utilizadas em radiodiagnóstico ou radioterapia precisam ser calibradas periodicamente para garantir que sua utilização seja confiável. Para que uma câmara de ionização seja calibrada é necessária a utilização de um sistema padrão. Este sistema padrão, juntamente com uma técnica de calibração associada, permitirá a determinação dos coeficientes de calibração para os diferentes intervalos de energia e tipos de radiação para os quais se pretende utilizar a câmara de ionização em questão. A partir dos coeficientes de calibração determinados no procedimento de calibração, pode-se obter a taxa de dose absorvida ou taxa de kerma no ar num 
feixe de radiação similar àquele no qual a câmara de ionização foi calibrada.

\subsubsection{Objetivos e Técnicas da Calibração de Instrumentos}

O procedimento de calibração de instrumentos com radiações ionizantes apresenta os seguintes objetivos [IAEA (2000)]:

- Garantir que o detector esteja funcionando de modo adequado para o uso pretendido;

- Ajustar o detector, se possível, melhorando a precisão nas medidas;

- Realizar testes que envolvem a resposta do detector em função da energia, direção da incidência, efeitos ambientais, etc.;

- Fornecer informações aos usuários dos detectores quanto às suas características.

Existem duas técnicas básicas usadas em procedimentos de calibração [IAEA (1994)]: uso de campos de radiação com propriedades bem definidas, técnica usada para calibração de detectores portáteis, e uso de campos de radiação com propriedades menos bem conhecidas (técnica da substituição), técnica usada para calibração de dosímetros clínicos e detectores para uso em feixes de radiodiagnóstico.

Na técnica de campos conhecidos, o campo de radiação pode ser definido pelo conhecimento de certos parâmetros de uma fonte padrão ou pela medição com um sistema padrão secundário. Neste caso, não é necessária a utilização de um instrumento padrão nos serviços rotineiros de calibração de instrumentos. O procedimento de calibração é feito posicionando-se o instrumento a ser calibrado no campo de radiação e comparando-se o valor medido deste instrumento com o valor previamente conhecido da intensidade do feixe de radiação em termos da grandeza em questão.

Na técnica de substituição, um instrumento de referência é colocado no campo de radiação; em seguida, o detector a ser calibrado substitui o instrumento de referência. Os dois instrumentos devem ocupar exatamente a mesma posição no feixe 
de radiação e a calibração é feita comparando-se as medições fornecidas pelos dois instrumentos.

\subsubsection{Intercomparação}

A intercomparação é um termo relacionado à calibração e é realizada para comparar o desempenho de instrumentos de mesma classificação. A intercomparação permite assegurar a qualidade das medições de cada laboratório de metrologia, e pode ser nacional ou internacional.

Um exemplo de intercomparação realizado periodicamente envolve dois laboratórios brasileiros de metrologia, o LCI e o Laboratório Nacional de Metrologia das Radiações Ionizantes (LNMRI/IRD), que é o Laboratório Padrão Secundário do Brasil, reconhecido e apoiado pela Agência Internacional de Energia Atômica (IAEA) e pela Organização Mundial da Saúde (OMS), seguindo a cadeia hierárquica de rastreabilidade. Este tipo de intercomparação oferece grandes benefícios como a determinação dos coeficientes de calibração e ainda a troca de experiência entre os pesquisadores de diferentes laboratórios.

\subsubsection{Rastreabilidade}

O conceito de rastreabilidade é definido no VIM [INMETRO (2012)] como: "propriedade dum resultado de medição pela qual tal resultado pode ser relacionado a uma referência através duma cadeia ininterrupta e documentada de calibrações, cada uma contribuindo para a incerteza de medição".

Para se obter uma cadeia de rastreabilidade é necessária a obtenção de um conjunto contínuo de comparações que asseguram que o resultado de uma medição, ou o valor de um padrão, se relaciona com as referências de nível mais elevado, terminando no nível padrão primário.

\subsubsection{Classificação dos Instrumentos de Medição}

De acordo com o VIM [INMETRO (2012)] os instrumentos de medição são classificados em: 
Padrão Internacional: "padrão de medição reconhecido pelos signatários dum acordo internacional, tendo como propósito a sua utilização mundial";

Padrão Nacional: "padrão de medição reconhecido por uma entidade nacional para servir dentro dum Estado ou economia, com base para atribuir valores a outros padrões de grandezas de mesma natureza";

Padrão Primário: "padrão de medição estabelecido com auxílio dum procedimento de medição primário ou criado como um artefato, escolhido por convenção";

Padrão Secundário: "padrão de medição estabelecido por intermédio duma calibração com referência a um padrão de medição primário duma grandeza da mesma natureza";

Padrão de Referência: "padrão de medição estabelecido para a calibração de outros padrões de grandezas de mesma natureza numa dada organização ou num dado local";

Padrão de Trabalho: "padrão de medição que é utilizado rotineiramente para calibrar ou controlar instrumentos de medição ou sistemas de medição";

Padrão Itinerante: "padrão de medição, algumas vezes de construção especial, destinado para ser transportado entre diferentes locais";

Dispositivo de Transferência: "dispositivo utilizado como intermediário para comparar padrões";

Padrão Intrínseco: "padrão baseado numa propriedade intrínseca reprodutível dum fenômeno ou duma substância".

\subsubsection{Laboratórios de Padronização}

Existem dois tipos de laboratórios de padronização: laboratório de padronização primária (Primary Standard Dosimetry Laboratory - PSDL) e laboratório de padro- 
nização secundária (Secondary Standard Dosimetry Laboratory - SSDL), segundo uma classificação da IAEA (1994).

Os laboratórios de padronização primária são responsáveis por manter os sistemas padrões primários, ou seja, os sistemas de mais alta qualidade metrológica. Além disso, estes laboratórios devem desenvolver, manter e aperfeiçoar os sistemas padrões primários, além de oferecer serviços de calibração de sistemas padrões secundários. Um laboratório de padronização primária participa do sistema internacional de medição por meio de comparações com o BIPM. No Brasil não há laboratório padrão primário para calibração de instrumentos.

Os laboratórios de padronização secundária devem oferecer serviços de calibração de instrumentos. Estes laboratórios devem possuir pelo menos um padrão secundário para cada intervalo de energia (e tipo de radiação) para o qual o serviço de calibração é oferecido. No Brasil, o laboratório padrão secundário é o LNMRI, no Instituto de Radioproteção e Dosimetria, Comissão Nacional de Energia Nuclear, localizado no Rio de Janeiro. Existem ainda os laboratórios de padronização regionais, tais como os de São Paulo, Belo Horizonte, Rio de Janeiro e Recife, que oferecem serviços de calibração de instrumentos.

\subsubsection{Sistemas Padrões Utilizados para Medição de Kerma no Ar}

Os laboratórios de padronização primária possuem diferentes tipos de sistemas padrões. Cada laboratório é responsável pelo desenvolvimento e pela caracterização de seu próprio sistema padrão. Existem diversos laboratórios primários no mundo e, portanto, diferentes sistemas padrões. A seguir serão listados alguns laboratórios primários com seus respectivos sistemas padrões para cada intervalo de energia.

O Bureau International des Poids et Mesures é um laboratório de padronização primária localizado na França. Neste laboratório são utilizadas três câmaras de ionização diferentes para cada intervalo de energia e tipo de radiação. Para radiação X de energias baixas, que compreende potenciais de $10 \mathrm{kV}$ a $50 \mathrm{kV}$, o sistema padrão utilizado é uma câmara de ionização de ar livre com volume sensível de 1,2004 cm³ . 
Para radiação $\mathrm{X}$ de energias médias, que compreende potenciais de $100 \mathrm{kV}$ a $250 \mathrm{kV}$, o sistema padrão primário utilizado também é uma câmara de ionização de ar livre, porém com volume sensível de 4,6554 $\mathrm{cm}^{3}$. O sistema padrão utilizado para medição de kerma no ar em campos de radiação gama é uma câmara cavitária de placas paralelas de grafite com volume sensível de $6,8344 \mathrm{~cm}^{3}$. Para a determinação da dose absorvida na água é utilizada a mesma câmara de ionização para medição de kerma, porém quando colocada na água ela é inserida em um suporte de PMMA [BIPM (2013)].

O Physikalisch-Technische Bundesanstalt, localizado na Alemanha, é um laboratório de padronização primária que tem como sistemas padrões primários de kerma no ar para radiação $\mathrm{X}$, com potenciais entre $7,5 \mathrm{kV}$ e $400 \mathrm{kV}$, as seguintes câmaras de ionização de ar livre: a câmara de ionização de placas paralelas PK100 (7,5kV - 150 kV), a câmara de ionização cilíndrica FK $(30$ kV - 300 kV) e a câmara de ionização de placas paralelas PK400 $(50 \mathrm{kV}-400 \mathrm{kV})$. Para radiação gama $\left({ }^{60} \mathrm{Co}\right.$ e ${ }^{137} \mathrm{Cs}$ ) o sistema padrão de kerma no ar é um conjunto composto por três câmaras de ionização cavitárias de grafite. A primeira câmara de ionização cavitária é cilíndrica, denominada HRK-1, com volume sensível de $0,5539 \mathrm{~cm}^{3}$; a segunda câmara também é cilíndrica, denominada HRK-2, com um volume sensível de 1,5190 $\mathrm{cm}^{3}$; e a terceira é uma câmara cavitária de placas paralelas, denominada HRK-3, com volume sensível de $6,138 \mathrm{~cm}^{3}$ [PTB (2013)].

O laboratório padrão primário NIST é localizado nos Estados Unidos da América. Neste laboratório existem duas câmaras de ionização de ar livre de placas paralelas que são utilizadas para a determinação de kerma no ar para radiação X [LAITANO (1998); O'BRIEN e LAMPERTI (2000)]. Uma das câmaras de ionização é para radiação $\mathrm{X}$ de energias baixas, com potenciais entre $8 \mathrm{kV}$ e $50 \mathrm{kV}$ e a outra para radiação $\mathrm{X}$ de energias intermediárias, com potenciais entre $50 \mathrm{kV}$ e $300 \mathrm{kV}$. O sistema padrão utilizado para medida de kerma no ar para radiação gama é um conjunto de câmaras cavitárias de grafite [SELTZER e BERGSTROM (2003)].

O National Physical Laboratory, laboratório padrão primário da Inglaterra, tam- 
bém possui, como sistema padrão primário para radiação $\mathrm{X}$ de energias baixas e intermediárias, câmaras de ionização de ar livre [O'BRIEN e LAMPERTI (2000)]. Para a determinação de kerma no ar para radiação gama são utilizadas três câmaras de ionização cavitárias [NPL (2013)].

Outro laboratório de padronização primária é o ARPANSA, localizado na Austrália. Este laboratório possui dois sistemas padrões para kerma no ar para radiação $\mathrm{X}$. Para radiação $\mathrm{X}$ de energias médias, com potenciais entre $50 \mathrm{kV}$ e $300 \mathrm{kV}$, o sistema padrão é uma câmara de ar livre e para radiação X de energias baixas, com potenciais entre $20 \mathrm{kV}$ e $50 \mathrm{kV}$, também é uma câmara de ionização de ar livre de volume sensível menor. O sistema padrão para medição de kerma no ar em campos de radiação gama $\left({ }^{60} \mathrm{Co}\right)$ é uma câmara de ionização cavitária de placas paralelas de grafite com volume sensível de $6,8470 \mathrm{~cm}^{3}$ [ARPANSA (2013)].

O National Research Council também é um laboratório de padronização primária, localizado no Canadá, e seus sistemas padrões primários para padrões de kerma no ar para radiação X são duas câmaras de ionização de ar livre. A câmara de ar livre menor é usada para raios $\mathrm{X}$ com potencial de até $80 \mathrm{kV}$ e a maior para raios $\mathrm{X}$ com potencial de até $300 \mathrm{kV}$. O sistema padrão primário para radiação gama do ${ }^{60}$ Co é uma câmara de ionização cavitária com paredes de grafite [NRC (2013)].

Além destes laboratórios existem outros, onde cada um tem seu próprio sistema de padronização primária de acordo com suas possibilidades, aplicações e oferta de serviços de calibração. 


\section{Capítulo 5}

\section{Materiais e Métodos}

Neste trabalho foram utilizados alguns sistemas de radiação, algumas câmaras de ionização comerciais e outras desenvolvidas neste projeto, além de acessórios para a realização das medições. Toda a infraestrutura utilizada no desenvolvimento deste projeto estava disponível no LCI.

\subsection{Sistemas de Radiação}

Os seguintes sistemas de radiação foram utilizados na caracterização das câmaras de ionização:

- Equipamento de raios X, marca Pantak/Seifert, modelo ISOVOLT 160HS, operando entre $5 \mathrm{kV}$ e $160 \mathrm{kV}$, utilizado para calibração de detectores de radiação: Figura 5.1(a);

- Fonte de radiação gama de ${ }^{60} \mathrm{Co}$ (Siemens/Gammatron II S80), utilizada para calibração de dosímetros clínicos: Figura 5.1(b);

- Fonte de controle de ${ }^{90} \mathrm{Sr}+{ }^{90} \mathrm{Y}$, Physikalisch-Technische Werkstätten (PTW), modelo 8921, com atividade nominal de $33 \mathrm{MBq}$, 1994, utilizada nos testes de controle de qualidade (estabilidade de resposta) das câmaras de ionização: Figura 5.1(c). 


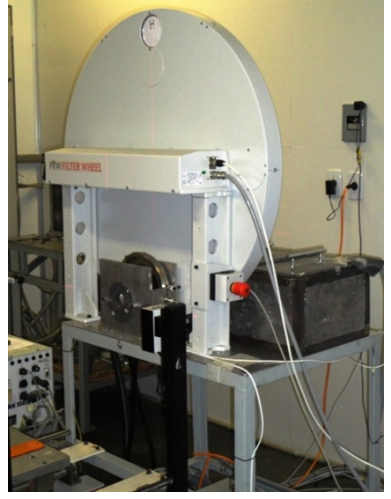

(a)

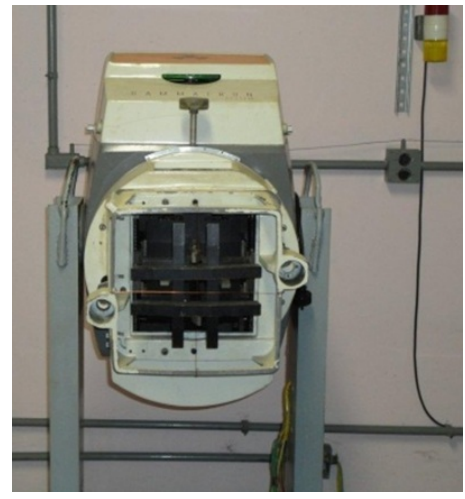

(b)

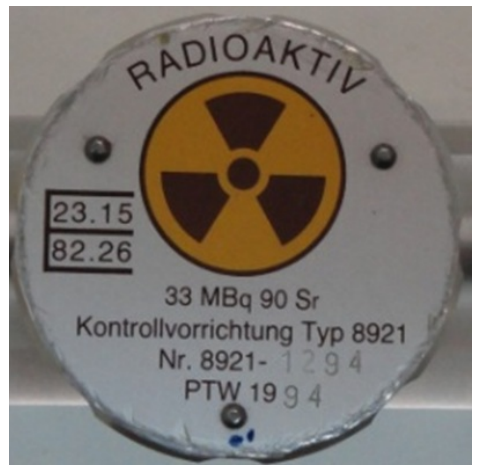

(c)

Figura 5.1: Fotos dos sistemas de radiação utilizados neste trabalho. (a) Equipamento de raios X, marca Pantak/Seifert; (b) Irradiador gama, marca Siemens/Gammatron e (c) Fonte de controle de ${ }^{90} \mathrm{Sr}+{ }^{90} \mathrm{Y}, \mathrm{PTW}$, modelo 8921.

No equipamento de radiação X, Pantak/Seifert, algumas qualidades de feixes de radiação específicas de radioterapia, radiodiagnóstico convencional, mamografia e radioproteção estão implantadas, de acordo com as recomendações internacionais. A Tabela 5.1 mostra as características dos feixes padronizados de radiação X para radiodiagnóstico convencional de acordo com a norma IEC 61267 [IEC (2005)]. A Tabela 5.2 mostra as características dos feixes padronizados para tomografia computacional, de acordo com a norma IEC 61267 [IEC (2005)]. Para implantar estes feixes padronizados foram utilizadas câmaras de ionização padrões secundários com rastreabilidade ao Laboratório Padrão Primário Alemão PTB. Para o estabelecimento dos feixes padronizados de radiação X para radiodiagnóstico convencional foi utilizada a câmara de ionização cilíndrica, Radcal, modelo RC6 e no caso dos feixes de TC foi utilizada a câmara de ionização tipo lápis, Radcal, modelo RC3CT.

\subsection{Sistemas de Medição}

Os sistemas de medição utilizados neste projeto foram:

- Câmaras de ionização tipo lápis com diferentes volumes sensíveis caracterizadas neste projeto nas qualidades de radiação de TC;

- Câmara de ionização de placas paralelas caracterizada nas qualidades de TC; 
Tabela 5.1: Características dos feixes padronizados de radiação X para radiodiagnóstico convencional do equipamento Pantak/Seifert, seguindo a recomendação da norma IEC 61267 [IEC (2005)].

\begin{tabular}{|c|c|c|c|}
\hline $\begin{array}{l}\text { Qualidade } \\
\text { da } \\
\text { Radiação }\end{array}$ & $\begin{array}{c}\text { Tensão } \\
\text { do Tubo } \\
(\mathrm{kV})\end{array}$ & $\begin{array}{c}\text { Camada } \\
\text { Semirredutora } \\
(\mathrm{mmAl})\end{array}$ & $\begin{array}{c}\text { Taxa de Kerma } \\
\text { no Ar } \\
(\mathrm{mGy} / \mathrm{min})\end{array}$ \\
\hline \multicolumn{4}{|c|}{ Feixes Diretos } \\
\hline RQR3 & 50 & 1,78 & $21,60 \pm 0,18$ \\
\hline $\mathrm{RQR} 5^{\dagger}$ & 70 & 2,58 & $37,88 \pm 0,32$ \\
\hline RQR8 & 100 & 3,97 & $67,45 \pm 0,54$ \\
\hline RQR10 & 150 & 6,57 & $120,01 \pm 1,02$ \\
\hline \multicolumn{4}{|c|}{ Feixes Atenuados } \\
\hline RQA3 & 50 & 3,8 & $3,46 \pm 0,01$ \\
\hline $\mathrm{RQA} 5^{\dagger}$ & 70 & 6,8 & $3,45 \pm 0,01$ \\
\hline RQA8 & 100 & 10,1 & $5,93 \pm 0,02$ \\
\hline RQA10 & 150 & 13,3 & $13,48 \pm 0,03$ \\
\hline
\end{tabular}

${ }^{\dagger}$ Qualidade de referência do LCI.

Tabela 5.2: Características dos feixes padronizados de radiação X para tomografia computadorizada do equipamento Pantak/Seifert, seguindo a recomendação da norma IEC 61267 [IEC (2005)].

\begin{tabular}{|c|c|c|c|}
\hline $\begin{array}{l}\text { Qualidade } \\
\text { da } \\
\text { Radiação }\end{array}$ & $\begin{array}{l}\text { Tensão } \\
\text { do Tubo } \\
\quad(\mathrm{kV})\end{array}$ & $\begin{array}{c}\text { Camada } \\
\text { Semirredutora } \\
(\mathrm{mmAl})\end{array}$ & $\begin{array}{c}\text { Taxa de Kerma } \\
\text { no Ar } \\
(\mathrm{mGy} / \mathrm{min})\end{array}$ \\
\hline RQT8 & 100 & 6,90 & $22,0 \pm 0,33$ \\
\hline $\mathrm{RQT}^{\dagger}$ & 120 & 8,40 & $34,0 \pm 0,51$ \\
\hline RQT10 & 150 & 10,1 & $57,0 \pm 0,86$ \\
\hline
\end{tabular}

- Câmaras de ionização de placas paralelas construídas usando material equivalente ao tecido, caracterizadas nas qualidades de radiação X convencional;

- Câmara de ionização de placas paralelas construída usando PMMA, caracterizadas nas qualidades de radiação X convencional e em feixes de ${ }^{60} \mathrm{Co}$;

- Câmaras de ionização cavitárias de grafite construídas e caracterizadas para atuação como sistemas de referência em feixes de ${ }^{60} \mathrm{Co}$;

- Câmaras de ionização padrões secundários: câmara de ionização cilíndrica, 
Radcal, modelo RC6, com volume sensível de $6 \mathrm{~cm}^{3}$ (para as qualidades de radiação RQR e RQA), câmara de ionização tipo lápis, Radcal, modelo RC3CT, com volume sensível de $3 \mathrm{~cm}^{3}$ (para as qualidades de radiação de TC) e câmara de ionização Farmer, PTW, modelo TN30002, com volume sensível de 0,6 cm (para a fonte de ${ }^{60} \mathrm{Co}$ ). Estas câmaras de ionização, utilizadas como padrões de referência do LCI, são apresentadas na Figura 5.2. As câmaras de ionização Radcal RC6 e RC3CT possuem rastreabilidade ao Laboratório Padrão Primário da Alemanha PTB. A câmara de ionização Farmer é calibrada no LNMRI, e possui rastreabilidade ao Laboratório Padrão Primário da França BIPM;

- Câmara de ionização tipo lápis Victoreen, modelo 660-6;

- Câmara de ionização Farmer, PTW, modelo TN30011-1;

- Eletrômetros PTW, modelo UNIDOS E, e Keithley, modelo 6517A, apresentados na Figura 5.3.

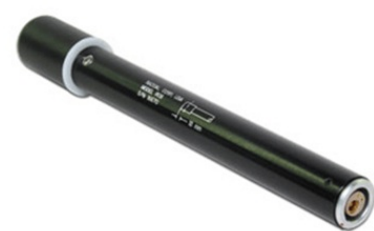

(a)

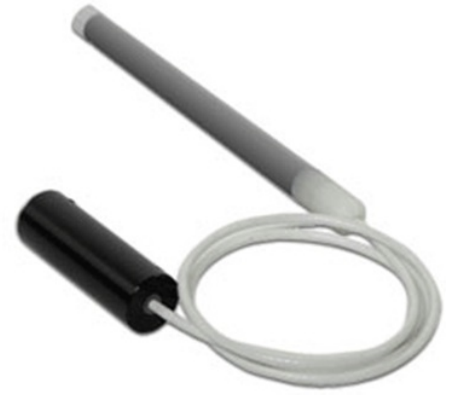

(b)

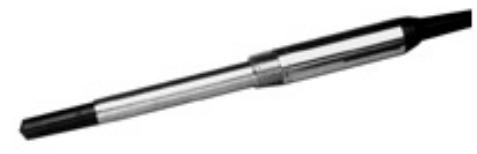

(c)

Figura 5.2: Fotos dos sistemas padrões de referência do LCI usados neste trabalho. (a) câmara de ionização cilíndrica, Radcal, modelo RC6; (b) câmara de ionização tipo lápis, Radcal, modelo RC3CT e (c) câmara de ionização Farmer, PTW, modelo TN30002. 


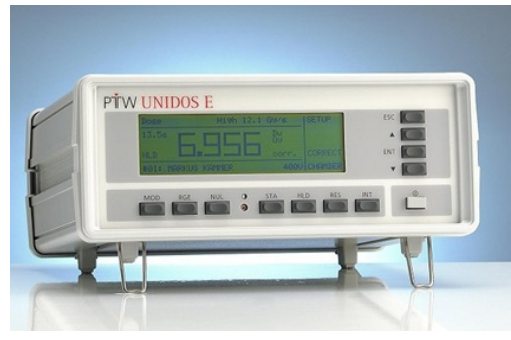

(a)

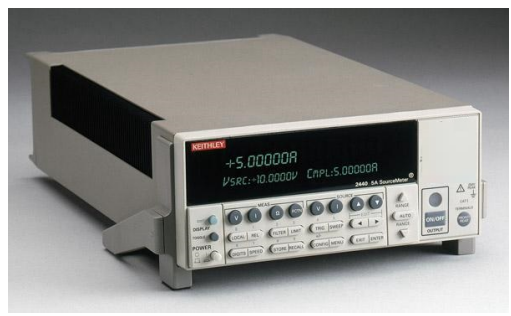

(b)

Figura 5.3: Fotos dos eletrômetros usados neste trabalho. (a) eletrômetro PTW, modelo UNIDOS E e (b) eletrômetro Keithley, modelo 6517A.

\subsection{Sistemas Auxiliares}

Os sistemas auxiliares utilizados no desenvolvimento e caracterização das câmaras de ionização foram:

- Termômetros, higrômetros e barômetros para monitoramento das condições ambientais (temperatura, umidade e pressão atmosférica) dos laboratórios onde foram realizadas as medições com as câmaras de ionização;

- Sistemas de ar condicionado e desumidificadores de ambiente;

- Goniômetro, OPTRON, modelo GN1 200, para os testes de dependência angular;

- Códigos de Monte Carlo EGSnrc e PENELOPE;

- Diferentes tipos de materiais para confecção das câmaras de ionização desenvolvidas neste projeto.

\subsection{Caracterização Experimental das Câmaras de Ionização}

Para a realização dos testes de caracterização experimentais das câmaras de ionização estudadas neste trabalho foram utilizadas duas normas da International Electrotechnical Commission: IEC (1997) e IEC (2011). A metodologia empregada em cada teste será descrita a seguir: 


\subsubsection{Testes de Estabilidade}

O teste de estabilidade em curto prazo foi feito obtendo-se dez medições consecutivas com a câmara de ionização exposta a uma fonte de controle sob condições geométricas reprodutíveis. O resultado obtido do desvio padrão das dez medições é comparado com os limites fornecidos pelas recomendações da norma IEC 60731 [IEC (2011)] aplicada à câmara de ionização utilizada em radioterapia ou com a norma IEC 61674 [IEC (1997)] aplicada à câmara de ionização utilizada em radiodiagnóstico. Para câmaras utilizadas em radiodiagnóstico, o desvio padrão não deve exceder $1 \%$ e para radioterapia o limite é $0,3 \%$, quando se utiliza uma fonte de controle.

O teste de estabilidade em longo prazo foi realizado avaliando-se os resultados obtidos nos testes de estabilidade em curto prazo em função do tempo. O desvio aceitável para feixes de radiodiagnóstico é de 2\% [IEC (1997)] e para feixes de radioterapia é de 0,5\% [IEC (2011)].

\subsubsection{Teste de Tempo de Estabilização}

Este teste foi realizado observando as respostas das câmaras de ionização nos intervalos de tempo de 15, 30, 45 e 60 min após as câmaras de ionização serem polarizadas. Segundo a norma IEC 61674 [IEC (1997)], a resposta da câmara de ionização não deve diferir de $\pm 2 \%$ nestes intervalos de tempo estudados para câmaras de ionização caracterizadas em feixes de radiodiagnóstico. Para câmaras de ionização utilizadas em feixes de ${ }^{60} \mathrm{Co}$, a diferença no valor da corrente de ionização no intervalo de tempo de 15 min em relação à corrente de ionização no intervalo de tempo de 60 min pode ser no máximo $\pm 0,5 \%$ [IEC (2011)].

\subsubsection{Teste de Saturação}

O teste de saturação foi feito variando-se a tensão aplicada à câmara de ionização; para tanto, a resposta da câmara de ionização foi medida para diferentes tensões, em passos de $\pm 50 \mathrm{~V}$. Com os resultados obtidos neste teste, foi possível determinar 
o efeito de polaridade e a eficiência de coleção de íons da câmara de ionização. O efeito de polaridade $\left(k_{\text {pol }}\right)$ foi calculado por meio da Equação 5.1 [IAEA (2004)]:

$$
k_{\mathrm{pol}}=\frac{\left|M_{+}\right|+\left|M_{-}\right|}{2 M}
$$

onde $\left|M_{+}\right|$e $\left|M_{-}\right|$são as medições realizadas com as polaridades positiva e negativa, respectivamente, e $M$ é a medição realizada com a tensão aplicada rotineiramente.

O teste de eficiência na coleção de íons $\left(k_{\mathrm{s}}\right)$ foi estimado pelo método de duas tensões, dado pela Equação 5.2, onde são obtidas as medições $\left(M_{1}, M_{2}\right)$ em duas tensões diferentes $\left(V_{1}, V_{2}\right)$ [IAEA (2004)].

$$
k_{\mathrm{s}}=\frac{\left(V_{1} / V_{2}\right)^{2}-1}{\left(V_{1} / V_{2}\right)^{2}-M_{1} / M_{2}}
$$

\subsubsection{Teste de Corrente de Fuga}

Este teste foi feito medindo-se a variação na leitura da câmara de ionização antes e/ou depois da irradiação. Neste trabalho, a carga foi coletada durante 20 min antes e 20 min após uma irradiação com a fonte de controle ou com a fonte de ${ }^{60} \mathrm{Co}$. Segundo recomendações internacionais, a corrente de fuga antes e após a irradiação não deve exceder 5,0\% da menor medição obtida durante um intervalo de tempo de irradiação de pelo menos 1 min [IEC (1997)]. Para câmaras utilizadas em radioterapia este limite é de $0,5 \%$ do valor da corrente de ionização obtida durante as medições [IEC (2011)].

\subsubsection{Teste de Linearidade de Resposta e Dependência An- gular}

O teste de linearidade de resposta para câmaras de ionização caracterizadas em feixes de radiodiagnóstico foi feito variando-se a corrente no tubo para obtenção de diferentes taxas de kerma. Os valores das taxas de kerma no ar foram determinados utilizando-se as câmaras de ionização de referência do LCI. Para as câmaras de ionização caracterizadas em feixes de ${ }^{60} \mathrm{Co}$, a linearidade foi estudada como a carga 
coletada em função da dose absorvida no feixe de ${ }^{60} \mathrm{Co}$.

O teste de dependência angular foi feito rotacionando-se a câmara de ionização em torno do seu eixo, utilizando-se um goniômetro comercial. Segundo as normas internacionais, o valor medido em cada ângulo para uma câmara em feixes de radiodiagnóstico não deve exceder 3,0\% do valor medido em 0 [IEC (1997)] e este valor deve ser de apenas 0,5\% para câmaras usadas em radioterapia [IEC (2011)].

\subsubsection{Teste de Dependência Energética}

Para a realização do teste de dependência energética foi utilizado um sistema de radiação com feixes padronizados e uma câmara de ionização padrão (calibrada), juntamente com seu certificado de calibração. O coeficiente de calibração [MEGHZIFENE e SHORTT (2002)] foi determinado por meio da Equação 5.3:

$$
N=\frac{M^{*} \times k_{\mathrm{T}, \mathrm{P}}^{*} \times k_{\mathrm{c}}^{*}}{M \times k_{\mathrm{T}, \mathrm{P}}}
$$

onde: $M$ é a média das medições obtidas; $k_{\mathrm{T}, \mathrm{P}}$ é o termo de correção para temperatura e pressão de referência; $k_{\mathrm{c}}$ é o coeficiente de calibração da câmara padrão $\mathrm{e}^{*}$ significa que o termo é referente ao sistema padrão de referência.

O valor da dependência energética foi determinado como a razão entre o maior e o menor coeficiente de calibração, em porcentagem.

\subsection{Correção das Medições para Condições de Re- ferência de Temperatura e Pressão}

As câmaras de ionização geralmente não são seladas; sendo assim, o ar contido em suas cavidades é o mesmo do ambiente. Diante deste fato, é necessário fazer correção das leituras obtidas com as câmaras de ionização para as condições ambientais de referência. As câmaras de ionização desenvolvidas e caracterizadas neste trabalho não são seladas. Isto significa que elas sofrem a influência do meio e suas características internas são as mesmas do ambiente externo. Para levar em consideração este fato, são necessárias correções nas medições para a influência da temperatura e 
pressão. A correção é dada pela Equação 5.4 [IAEA (2007)].

$$
k_{\mathrm{T}, \mathrm{P}}=\frac{273,2+T}{273,2+T_{0}}\left(\frac{P_{0}}{P}\right)
$$

onde $T_{0}$ e $P_{0}$ são a temperatura de referência $\left(20^{\circ} \mathrm{C}\right)$ e a pressão de referência $(101,3 \mathrm{kPa})$, respectivamente.

\subsection{Caracterização por Simulação de Monte Carlo das Câmaras de Ionização}

Nesta seção será apresentada a metodologia empregada na realização das simulações de Monte Carlo. Serão discutidos os espectros utilizados nas simulações e os métodos adotados para se determinar a influência dos componentes das câmaras de ionização nas suas respostas. Além disso, também será apresentada a metodologia para a determinação dos fatores de correção das câmaras de ionização de grafite.

\subsubsection{Espectros de Radiação X e de ${ }^{60}$ Co Utilizados nas Si- mulações}

Como as câmaras de ionização simuladas neste trabalho foram todas desenvolvidas no LCI, todas as suas dimensões são conhecidas, permitindo, assim, uma simulação mais realista. Os espectros utilizados nas simulações não foram medidos no LCI devido principalmente a dois fatores: falta de acesso aos dados dos equipamentos de irradiação e também devido ao fato do LCI não ter um espectrômetro apropriado para medir espectros no intervalo de energia da fonte de ${ }^{60} \mathrm{Co}$.

Os espectros de radiodiagnóstico convencional e de TC foram fornecidos pelo Laboratório Padrão Primário da Alemanha PTB [BÜERMANN (2012)]. Estes espectros foram adquiridos no $\mathrm{PTB}$ em um equipamento de raios $\mathrm{X}$ da marca Yxlon que opera até $450 \mathrm{kV}$, a uma distância de 100,0 $\mathrm{cm}$ do ponto focal do tubo de raios $\mathrm{X}$, mesma distância utilizada neste trabalho nos experimentos e simulações de Monte Carlo. Embora os equipamentos de raios X do LCI e do PTB não são do mesmo fabricante e existem algumas diferenças entre suas respectivas filtrações, os 
valores de camada semirredutora são similares e seguem recomendações da norma IEC 61267 [IEC (2005)].

No caso da fonte de ${ }^{60} \mathrm{Co}$, o espectro foi fornecido pelo Laboratório Secundário da Suécia [TEDGREN et al. (2010)]. Neste laboratório há uma fonte de ${ }^{60} \mathrm{Co}$ similar à presente no LCI. A fonte de ${ }^{60}$ Co do Laboratório da Suécia é da marca Siemens, modelo Gammatron 1, mesmo fabricante da fonte de ${ }^{60} \mathrm{Co}$ presente no LCI. Além disso, NEVES et al. (2013), avaliaram previamente o espectro do Laboratório da Suécia comparando os resultados da simulação com experimentos. Para esta comparação, foi utilizada uma câmara de ionização tipo lápis e capas de equilíbrio eletrônico de diferentes espessuras. A comparação foi feita por meio da avaliação da energia depositada no volume sensível da câmara de ionização, utilizando-se experimento e simulação de Monte Carlo. A máxima diferença entre o experimento e a simulação foi de apenas $0,8 \%$, mostrando uma excelente concordância entre os resultados. Verificando isto, o espectro do Laboratório da Suécia foi utilizando nas simulações onde a fonte de ${ }^{60} \mathrm{Co}$ foi empregada no presente trabalho.

\subsubsection{Cálculo da Influência dos Componentes das Câmaras de Ionização nas suas Respostas}

Neste trabalho, todas as simulações para estudar a influência dos componentes das câmaras de ionização nas suas respostas foram feitas utilizando o código de Monte Carlo PENELOPE. Optou-se pelo uso do código PENELOPE, porque ele oferece um pacote de geometria flexível que permite desenvolver geometrias bastante complexas, como por exemplo, a geometria de um conector BNC de uma câmara de ionização. O tally, utilizado para especificar o que o usuário quer que seja escrito nos dados de saída, adotado nas simulações com o código PENELOPE, foi o tally energy deposition.

Nas simulações de Monte Carlo, as câmaras de ionização foram inseridas em um universo contendo ar para simular as interações da radiação nas camadas de ar que circundam as câmaras de ionização. A influência dos componentes da câmara de ionização na sua resposta foi determinada como a razão entre a dose no volume 
sensível da câmara de ionização sem o componente estudado e a dose com a câmara completa. Para o estudo da influência de diferentes materiais e diferentes configurações geométricas da câmara de ionização na sua resposta, calculou-se a razão entre a dose no volume sensível da câmara de ionização com diferentes materiais ou configurações geométricas e a dose com a câmara de ionização em sua configuração original.

\subsubsection{Determinação dos Fatores de Correção de Câmaras de Ionização}

Os fatores de correção de câmaras de ionização geralmente são determinados utilizando o código de Monte Carlo EGSnrc, que é específico para determinação de fatores de correção para sistemas padrões primários. A Tabela 5.3 apresenta como cada fator de correção relacionado à determinação de taxa de kerma no ar, definidos na seção de Fundamentos Teóricos (Equação 4.9), foi obtido. Os valores de $\left(1-\bar{g}_{\text {ar }}\right)^{-1},(\bar{L} / \rho)_{\text {ar }}^{\text {parede }},\left(\bar{\mu}_{\text {en }} / \rho\right)_{\text {ar }}^{\text {parede }}, k_{\text {parede }}$ e $k_{\text {an }}$ foram obtidos diretamente por meio das bibliotecas do EGSnrc. No caso dos fatores de correção $k_{\text {cabo }}$ e $k_{\text {elec }}$, eles foram obtidos utilizando o código cavity/EGSnrc, pois não existe uma biblioteca que forneça o valor diretamente. Neste caso, os valores destes fatores de correção foram obtidos como a razão entre a dose no volume sensível da câmara de ionização sem o eletrodo coletor, ou sem o cabo, e a dose com a câmara completa.

Tabela 5.3: Metodologia adotada na determinação dos fatores de correção das câmaras de ionização de grafite.

\begin{tabular}{cc}
\hline Fator de Correção & Metodologia Adotada \\
\hline$\left(\bar{\mu}_{\text {en }} / \rho\right)_{\text {ar }}^{\text {parede }}$ & Biblioteca DOSRZnrc do código EGSnrc \\
$\left(1-\bar{g}_{\text {ar }}\right)^{-1}$ & Biblioteca código $g$ do código EGSnrc \\
$(\bar{L} / \rho)_{\text {ar }}^{\text {parede }}$ & Biblioteca SPRRZnrc do código EGSnrc \\
$k_{\text {an }}$ & Biblioteca CAVRZnrc do código EGSnrc \\
$k_{\text {parede }}$ & Biblioteca CAVRZnrc do código EGSnrc \\
$k_{\text {elec }}$ & cavity/EGSnrc \\
$k_{\text {cabo }}$ & cavity/EGSnrc \\
\hline
\end{tabular}




\subsection{Estimativa das Incertezas}

As incertezas foram estimadas utilizando-se as definições das incertezas tipo A e tipo B, definidas nas referências [ABNT (2003); ISO (1995)].

As incertezas tipo A são associadas à análise estatística de uma série de observações [ISO (1995)], enquanto as incertezas tipo B são obtidas por outros meios diferentes da análise estatística [ISO (1995)], como por exemplo: informação obtida a partir de um certificado de calibração dos instrumentos (termômetro e barômetro), distância da calibração, espessura dos filtros e informação obtida a partir de limites deduzidos de experiência pessoal [INMETRO (2012)].

Neste trabalho foram utilizadas médias aritméticas $(\bar{x})$ de séries de medições em mesmas condições e desvios padrões experimentais da média $\left(\delta_{\bar{x}}\right)$, de modo que os valores obtidos são: $\bar{x} \pm \delta_{\bar{x}}$.

A média aritmética é dada pela Equação 5.5:

$$
\bar{x}=\frac{1}{N} \sum_{i=1}^{N} x_{i}
$$

e os desvios-padrões experimentais da média são dados pela Equação 5.6:

$$
\delta_{\bar{x}}=\sqrt{\frac{1}{N(N-1)} \sum_{i=1}^{N}\left(x_{i}-\bar{x}\right)^{2}}
$$

onde $N$ é o número de medições realizadas para um mesmo experimento.

Neste trabalho, para o cálculo das incertezas advindos dos experimentos, utilizouse a incerteza expandida combinada. A partir das incertezas tipo A e tipo B, determinou-se a incerteza combinada, dada pela raiz quadrada da soma dos quadrados de todas as incertezas. Para se determinar a incerteza expandida, multiplicou-se o valor obtido da incerteza combinada por um fator de abrangência $k$ igual a 2 .

Os resultados obtidos com as simulações de Monte Carlo levaram em consideração apenas as incertezas do Tipo A. Estes resultados também são afetados pelas incertezas do Tipo B, e isto se deve principalmente a dois fatores: simplificações nas 
geometrias adotadas nas simulações e limitações nos modelos de interações físicas implementados nos códigos de Monte Carlo. Conforme HUBBELL (2006), as limitações nos modelos físicos advêm principalmente das diferenças entre as diferentes tabulações para as seções de choque, que podem chegar a até 2,0\% para energias baixas. A desconsideração das incertezas do tipo B, nos resultados das simulações, não implicaram de forma significativa nos valores de incertezas finais, uma vez que somente respostas normalizadas foram comparadas [PERINI et al. (2013)]. 


\section{Capítulo 6}

\section{Resultados e Discussão: Projeto, Construção e Caracterização Experimental das Câmaras de Ionização}

Nesta seção serão apresentados o desenvolvimento das câmaras de ionização e sua caracterização, segundo as recomendações das normas IEC 61674 [IEC (1997)] e IEC 60731 [IEC (2011)], em feixes de radiação X e em feixes de ${ }^{60}$ Co. Foram desenvolvidas três câmaras de ionização com aplicação em feixes de radiação X convencional, como padrões de trabalho, sendo que uma delas também foi caracterizada em feixes de ${ }^{60}$ Co. Além destas câmaras de ionização, duas câmaras de ionização tipo lápis e uma câmara de ionização de placas paralelas foram caracterizadas em feixes de radiação X de TC. Foram também desenvolvidas duas câmaras de ionização de grafite caracterizadas em feixes de ${ }^{60} \mathrm{Co}$ como sistemas de referência.

Os resultados relacionados à aplicação do Método de Monte Carlo às câmaras de ionização serão apresentadas no Capítulo 7.

Os trabalhos relacionados ao desenvolvimento desta tese são listados nos Apêndices $\mathrm{A}, \mathrm{B}$ e $\mathrm{C}$.

A estimativa de custo para confecção das câmaras de ionização desenvolvidas neste trabalho é apresentada no Apêndice D. 


\subsection{Projeto e Construção de Câmaras de Ionização em Feixes Padronizados de Radiação X Conven- cional}

Foram projetadas, construídas e caracterizadas três câmaras de ionização de placas paralelas em feixes padronizados de radiação X para radiodiagnóstico convencional. Nesta seção será apresentado o projeto das câmaras de ionização com as dimensões e os materiais empregados em sua construção.

O primeiro protótipo construído, denominado câmara de ionização CG, foi feito utilizando-se uma construção homogênea, com o mesmo material (PMMA grafitado) para parede e eletrodo coletor. Uma fotografia e um esquema da câmara de ionização são mostrados na Figura 6.1. As especificações técnicas da câmara de ionização CG são apresentadas na Tabela 6.1. As dimensões de todos os componentes da câmara de ionização CG são mostrados na Figura 6.2.

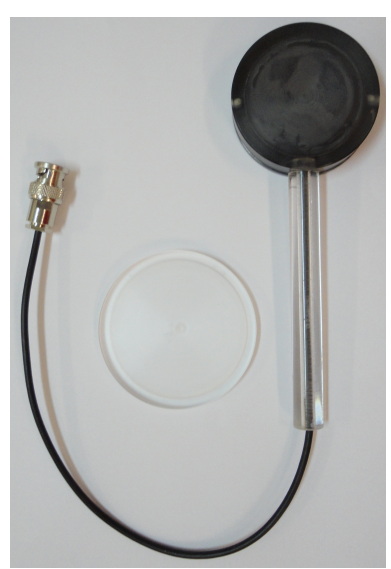

(a)

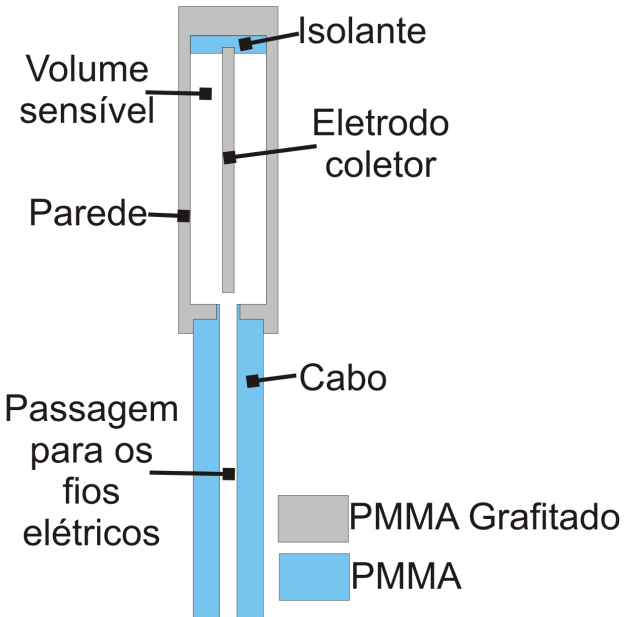

(b)

Figura 6.1: (a) Fotografia e (b) diagrama esquemático da câmara de ionização de placas paralelas $C G$ desenvolvida e caracterizada neste projeto.

O segundo protótipo desenvolvido foi um conjunto de duas câmaras de ionização de paredes feitas de material equivalente ao tecido, desenvolvido e cedido pelo Instituto de Física da Universidade de São Paulo [COSTA (2012)], e com eletrodos coletores de materiais diferentes. Uma câmara de ionização tem eletrodo coletor de material equivalente ao tecido grafitado (CMETG) e a outra tem eletrodo coletor 
Tabela 6.1: Especificações técnicas das câmaras de ionização CG, CMETG e CMETA.

\begin{tabular}{ccc}
\hline & \multicolumn{2}{c}{ Dimensões / Especificações } \\
\cline { 2 - 3 } Características & Câmara de Ionização & Câmaras de Ionização \\
CMETG e CMETA \\
\hline Altura externa $(\mathrm{mm})$ & 16,97 & 8,50 \\
Diâmetro externo $(\mathrm{mm})$ & 56,03 & 56,00 \\
Diâmetro interno $(\mathrm{mm})$ & 46,01 & 46,00 \\
Espessura de parede $(\mathrm{mm})$ & 2,00 & 0,50 \\
Diâmetro do eletrodo & 42,00 & 32,00 \\
coletor (mm) & 2,00 & 1,00 \\
Espessura do eletrodo & & Material equivalente \\
coletor (mm) & PMMA grafitado na & ao tecido \\
Material da parede & superfície interna & Material equivalente ao \\
Material do eletrodo & PMMA grafitado & tecido grafitado/Alumínio \\
coletor & & BNC com pino banana/ \\
Tipo de conector & 6,3 & BNC triaxial \\
Volume sensível (cm $\left.{ }^{3}\right)$ & & 2,3 \\
\hline
\end{tabular}

de alumínio (CMETA). A fotografia das câmaras e um diagrama esquemático são apresentados na Figura 6.3 e as especificações técnicas são listadas na Tabela 6.1. 


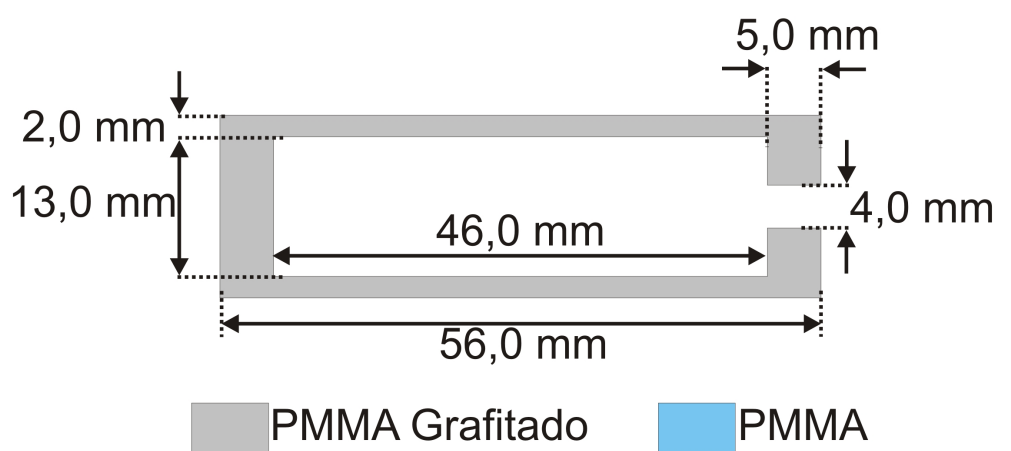

(a)

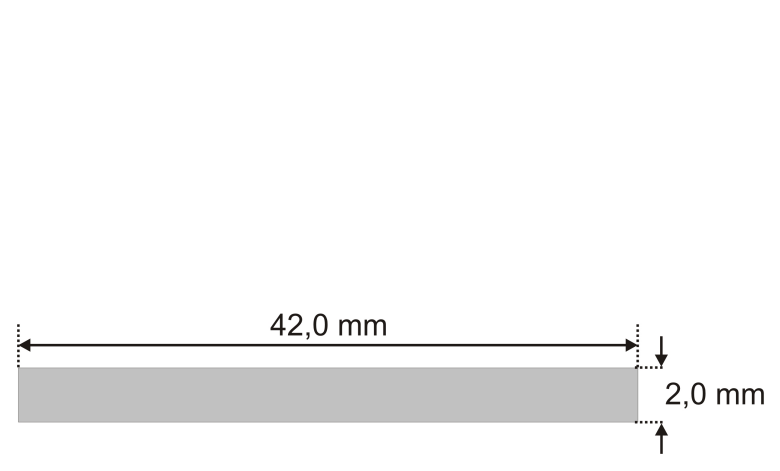

(b)

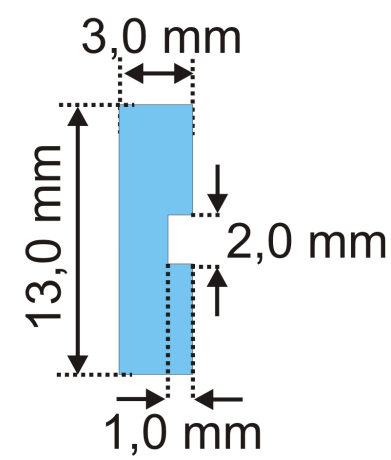

(c)

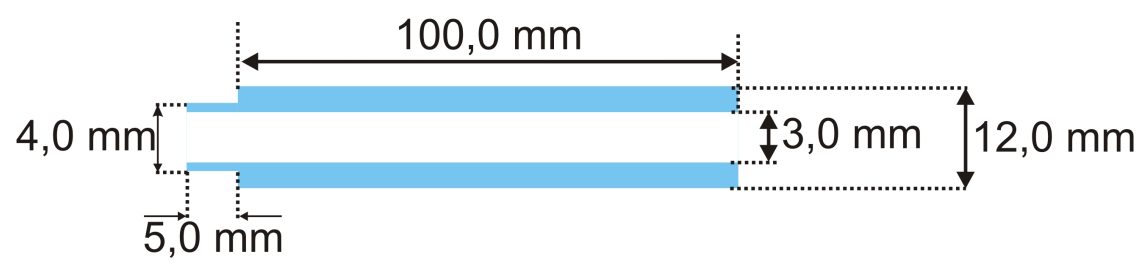

(d)

Figura 6.2: Detalhes, com dimensões, dos componentes da câmara de ionização $C G$ : (a) parede, (b) eletrodo coletor, (c) isolante e (d) cabo. 


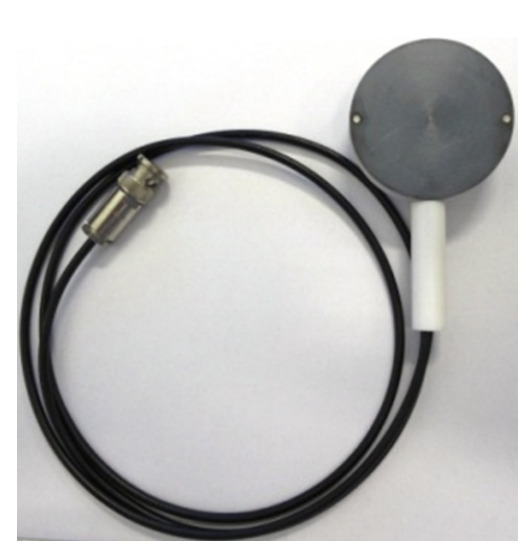

(a)

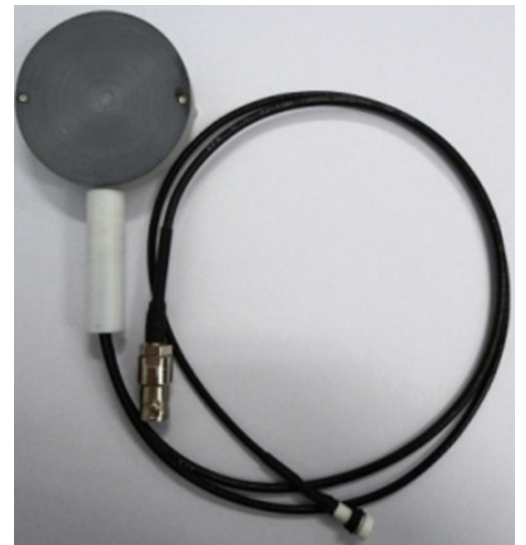

(b)

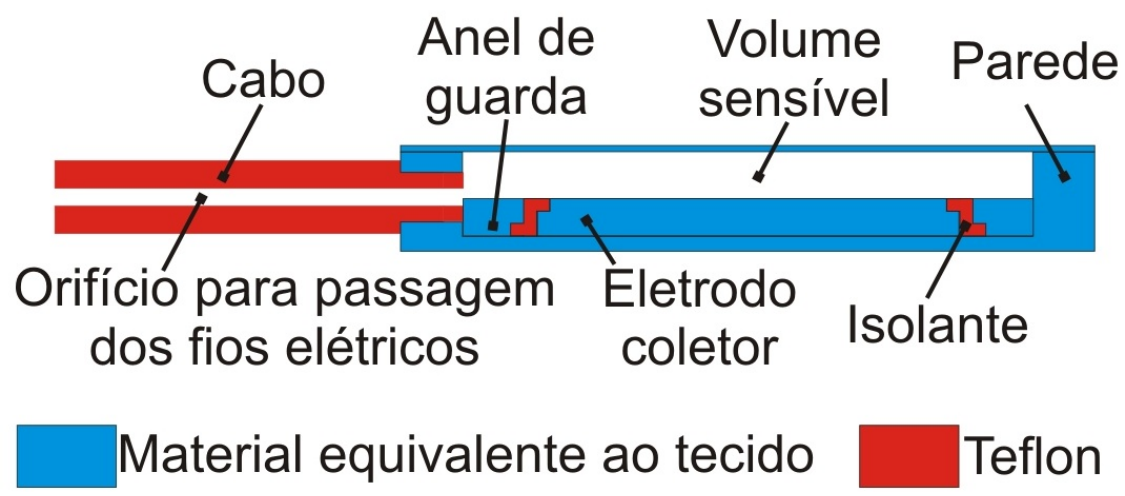

(c)

Figura 6.3: Fotografias das câmaras de ionização (a) CMETG e (b) CMETA e (c) esquema das câmaras de ionização CMETG e CMETA desenvolvidas e caracterizadas neste projeto.

O esquema dos componentes destas câmaras de ionização, com as medidas, é mostrado na Figura 6.4 


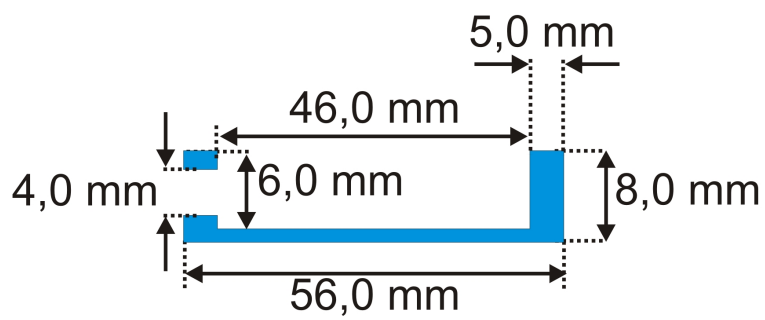

Material equivalente ao tecido Teflon

(a)

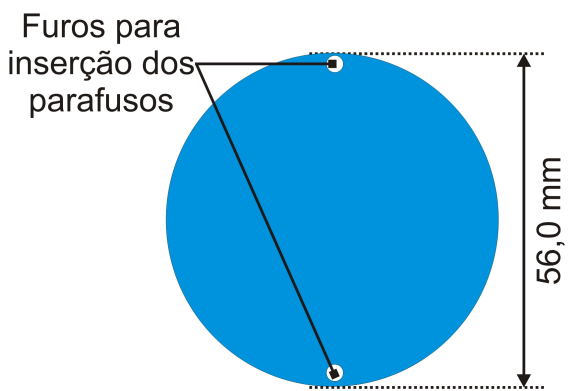

(b)

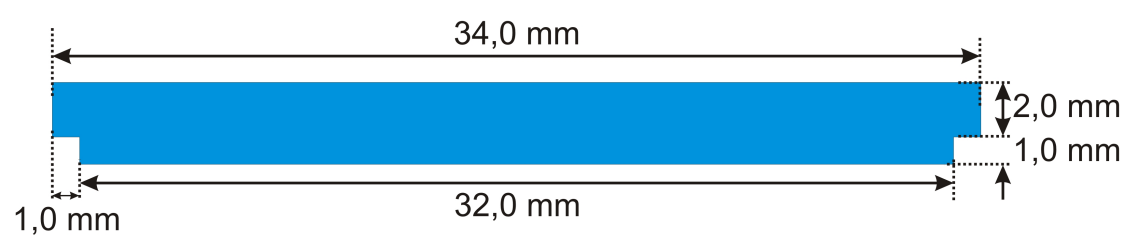

(c)

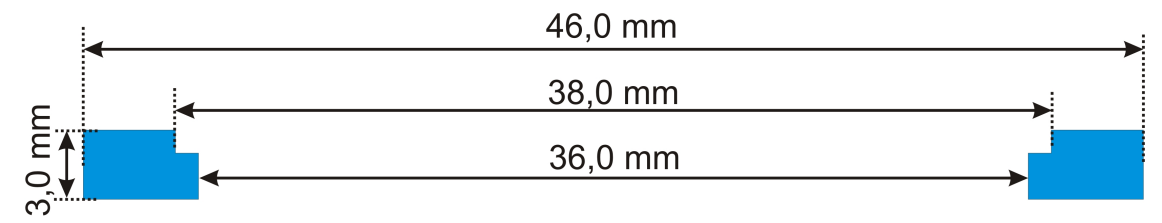

(d)

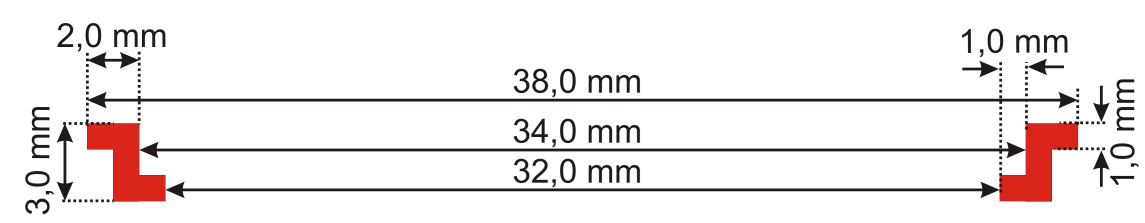

(e)

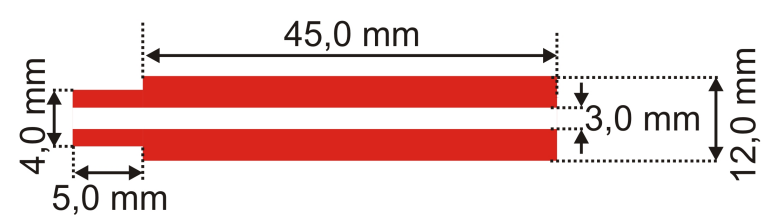

(f)

Figura 6.4: Detalhes, com dimensões, dos componentes das câmaras de ionização CMETG e CMETA: (a) paredes, (b) janela de entrada, que possui 0,5 $\mathrm{mm}$ de espessura, (c) eletrodo coletor, (d) anel de guarda, (e) isolantes de Teflon (Teflon é marca registrada da DuPont), utilizado entre o anel de guarda e o eletrodo coletor e (f) cabo.

O método adotado para a determinação da composição química do material equivalente ao tecido utilizado no desenvolvimento das câmaras de ionização seguiu o procedimento desenvolvido originalmente por Hermann e colaboradores [HERMANN et al. (1985, 1986)]. Este método fornece as proporções que devem 
ser combinadas do material base e de dois aditivos para produzir um material com coeficiente de atenuação igual ao do tecido simulado em duas energias específicas [COSTA (2012)].

Portanto, se $\mu_{1}(E)$ é o coeficiente de atenuação linear do material base em uma dada energia $E, \mu_{2}(E)$ e $\mu_{3}(E)$ são os coeficientes de atenuação lineares dos aditivos 1 e 2 , respectivamente, em uma mesma energia, e $\mu_{\mathrm{T}}(E)$ é o coeficiente linear do tecido a ser simulado, pode-se definir o seguinte sistema de equações lineares (Equação 6.1).

$$
\left\{\begin{array}{l}
q_{1} \mu_{1}\left(E_{1}\right)+q_{2} \mu_{2}\left(E_{1}\right)+q_{3} \mu_{3}\left(E_{1}\right)=\mu_{T}\left(E_{1}\right) \\
q_{1} \mu_{1}\left(E_{2}\right)+q_{2} \mu_{2}\left(E_{2}\right)+q_{3} \mu_{3}\left(E_{2}\right)=\mu_{T}\left(E_{2}\right) \\
q_{1}+q_{2}+q_{3}=1
\end{array}\right.
$$

Nas equações lineares, as energias $E_{1}$ e $E_{2}$ são escolhidas arbitrariamente em um intervalo de energias de interesse e os valores $q_{i}$ representam as frações de volume de cada componente do material. Portanto, as frações de massa necessárias para serem combinadas na mistura podem ser obtidas usando as densidades individuais de seus componentes, $\rho_{i}$, utilizando a Equação 6.2:

$$
p_{i}=\frac{\rho_{i} q_{i}}{\sum_{i} \rho_{i} q_{i}}
$$

O coeficiente de atenuação linear equivalente ao tecido pode ser estimado utilizando os resultados da implementação do sistema linear de equações (Equação 6.3).

$$
\mu(E)=q_{1} \cdot \mu_{1}(E)+q_{2} \cdot \mu_{2}(E)+q_{3} \cdot \mu_{3}(E)
$$

Um grupo de materiais poliméricos e aditivos foram estudados e testados por Kimura e colaboradores [KIMURA et al. (2011)] no Instituto de Física da Universidade de São Paulo. O coeficiente de atenuação de cada material foi obtido utilizando-se o programa XCOM [NIST (2013)]. As possíveis combinações dos materiais foram avaliadas levando-se em consideração as suas propriedades químicas.

Um programa computacional foi desenvolvido pelo IFUSP [ COSTA (2012)] 
para calcular o sistema de equações lineares de cada combinação possível, considerando o intervalo de energias de $5 \mathrm{keV}$ a $150 \mathrm{keV}$. Estes cálculos geraram frações de volume e massa de cada componente destes materiais. O material equivalente ao tecido utilizado para fazer as câmaras de ionização é a combinação de polietileno $\left(\mathrm{C}_{2} \mathrm{H}_{4}\right)$, carbonato de cálcio $\left(\mathrm{CaCO}_{3}\right)$ e Tyrin $\left(\mathrm{C}_{2} \mathrm{H}_{3} \mathrm{Cl}\right)$ com densidades mássicas de $0,93 \mathrm{~g} / \mathrm{cm}^{3}, 2,83 \mathrm{~g} / \mathrm{cm}^{3}$ e $0,46 \mathrm{~g} / \mathrm{cm}^{3}$, respectivamente. Uma combinação apropriada destes materiais resultou em um material equivalente ao tecido com uma resposta adequada para absorção de radiação no intervalo de energia de $5 \mathrm{keV}$ até $150 \mathrm{keV}$.

As frações de massa de cada material foram pesadas em uma balança calibrada (Marte, modelo AY220) e os materiais foram cuidadosamente selecionados e misturados. O processo de polimerização foi feito em uma máquina extrusora com temperaturas internas no intervalo de $120-130^{\circ} \mathrm{C}$. As amostras foram produzidas em discos com diâmetro de $130 \mathrm{~mm}$ e espessura de $10 \mathrm{~mm}$.

\subsection{Caracterização das Câmaras de Ionização CG, CMETG e CMETA em Feixes Padronizados de Radiação X Convencional}

As três câmaras de ionização foram caracterizadas de acordo com a norma IEC 61674 [IEC (1997)], utilizando o equipamento de raios X para todos os testes de caracterização, com exceção do teste de estabilidade que foi feito utilizando-se a fonte de controle de ${ }^{90} \mathrm{Sr}+{ }^{90} \mathrm{Y}$.

\subsubsection{Curva de Saturação, Efeito de Polaridade e Eficiência de Coleção de Íons}

No teste de saturação, a tensão de polarização aplicada às câmaras de ionização CG, CMETG e CMETA foi variada entre $-400 \mathrm{~V}$ e $+400 \mathrm{~V}$, em passos de $50 \mathrm{~V}$. As curvas de saturação, obtidas para as três câmaras de ionização na qualidade de radiação RQR5 (Tabela 5.1), são mostradas na Figura 6.5. O efeito de polaridade e a eficiência de coleção de íons foram obtidos também por meio dos dados das curvas de saturação. O efeito de polaridade foi determinado por meio da Equação 5.1 e 
a eficiência de coleção de íons, utilizando a Equação 5.2; os resultados são listados na Tabela 6.2. O valor máximo do efeito de polaridade para todo o intervalo de tensão estudado ficou dentro do limite máximo de $1,0 \%$ recomendado pela norma IEC 60731 [IEC (2011)]. Para $V_{1}=+200 \mathrm{~V}$ e $\mathrm{V}_{2}=+100 \mathrm{~V}$, a eficiência de coleção de íons foi melhor que 99,99\%, para as três câmaras de ionização. Com base nestes resultados, a tensão de operação escolhida e utilizada em todos os testes foi $+100 \mathrm{~V}$, para as três câmaras de ionização.

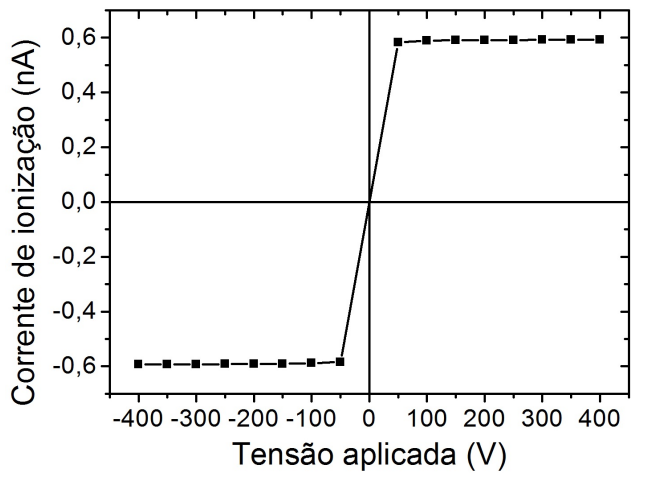

(a)

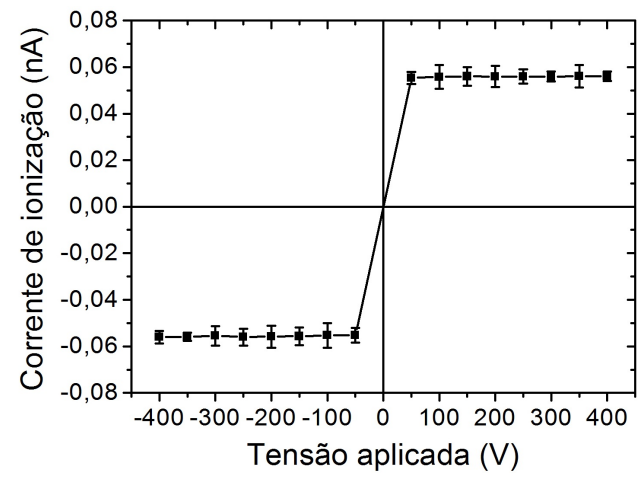

(b)

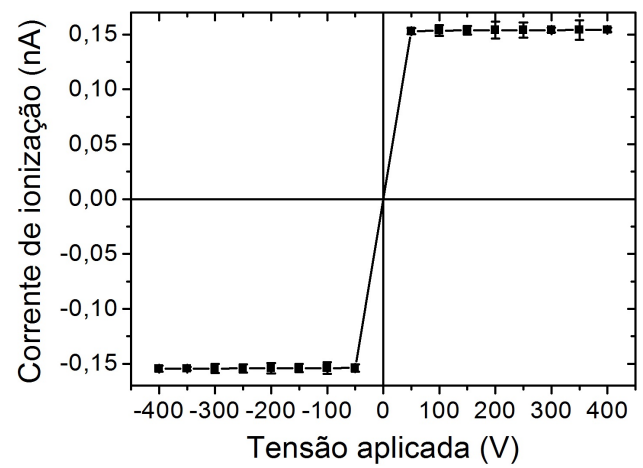

(c)

Figura 6.5: Curvas de saturação obtidas na qualidade de radiação RQR5 para as câmaras de ionização (a) CG, (b) CMETG e (c) CMETA. Os valores das incertezas das medições são menores que 0,1\%, imperceptíveis no gráfico da câmara de ionização $C G$.

\subsubsection{Teste de Estabilidade de Resposta em Curto e Longo Prazos}

Para a realização do teste de estabilidade das câmaras de ionização CG, CMETG e CMETA foi utilizada a fonte de controle de ${ }^{90} \mathrm{Sr}+{ }^{90} \mathrm{Y}$ e um suporte de PMMA para se obter medições reprodutíveis, como mostra a Figura 6.6. No teste de estabi- 
Tabela 6.2: Teste de polaridade e eficiência de coleção de ions das câmaras de ionização $C G, C M E T G$ e CMETA.

\begin{tabular}{ccc}
\hline $\begin{array}{c}\text { Câmara de } \\
\text { Ionização }\end{array}$ & $\begin{array}{c}\text { Efeito de } \\
\text { Polaridade }\end{array}$ & $\begin{array}{c}\text { Eficiência de Coleção } \\
\text { de Íons }\end{array}$ \\
\hline CG & Máximo de $0,11 \%$ & Maior que $99,99 \%$ \\
CMETG & Máximo de $0,40 \%$ & Maior que $99,99 \%$ \\
CMETA & Máximo de $0,10 \%$ & Maior que $99,99 \%$ \\
\hline
\end{tabular}

lidade em curto prazo foram efetuadas 10 medições consecutivas da carga coletada durante 1,0 min. Foram realizadas várias séries de medições, sendo que os desvios padrões máximos das medições foram $0,2 \%, 0,5 \%$ e $0,4 \%$ para as câmaras de ionização CG, CMETG, CMETA, respectivamente. Os valores obtidos estão dentro do limite máximo recomendado de 1,0\% [IEC (1997)].

Para cada conjunto de medições no teste de estabilidade a curto prazo, foi calculado um valor médio. Uma análise dos valores médios foi realizada ao longo do tempo para se obter o teste de estabilidade em longo prazo. Os gráficos de estabilidade em longo prazo são apresentados na Figura 6.7. É possível observar que a máxima variação está dentro do limite permitido de 2,0\% para dosímetros utilizados em radiodiagnóstico [IEC (1997)].

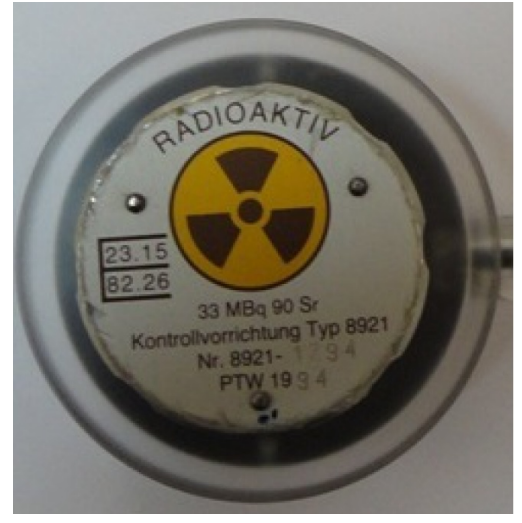

(a)

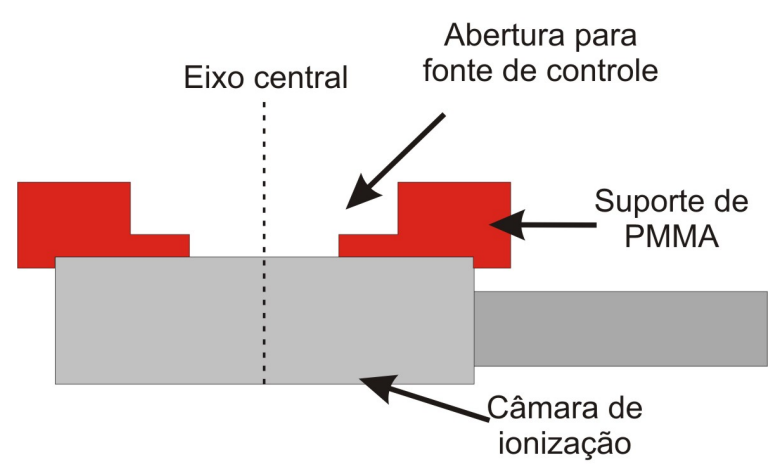

(b)

Figura 6.6: (a) Fonte de controle de ${ }^{90} \mathrm{Sr}+{ }^{90} \mathrm{Y}$ posicionada sobre a câmara de ionização e (b) esquema da câmara de ionização e do suporte de PMMA. 


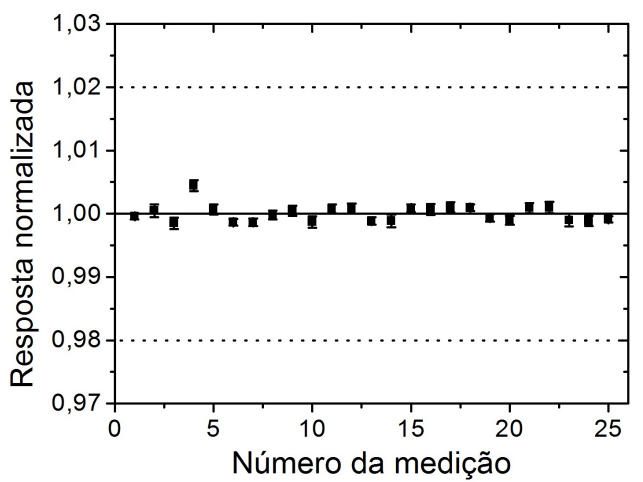

(a)

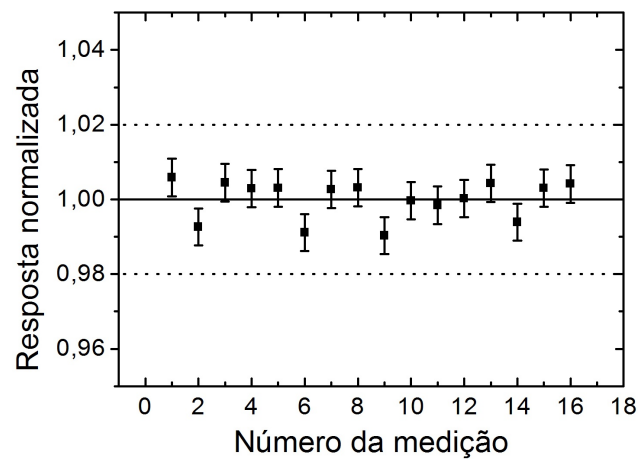

(b)

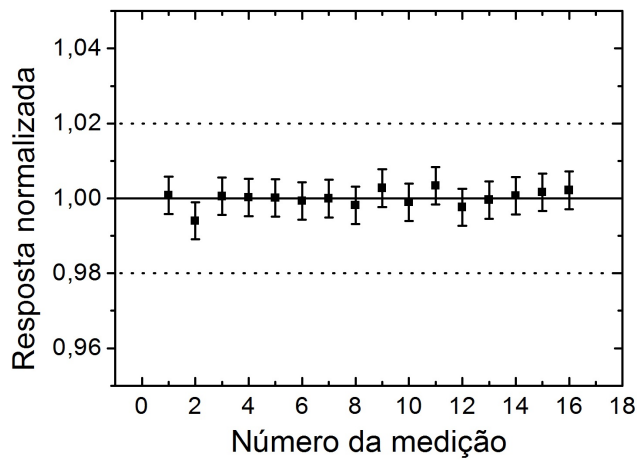

(c)

Figura 6.7: Estabilidade de resposta em longo prazo, utilizando uma fonte de controle de ${ }^{90} \mathrm{Sr}+{ }^{90} \mathrm{Y}$, da resposta das câmara de ionização (a) CG, (b) CMETG e (c) CMETA. As linhas pontilhadas mostram os limites recomendados pela IEC 61674 [IEC (1997)].

\subsubsection{Tempo de Estabilização}

O teste de tempo de estabilização é utilizado para se determinar o tempo mínimo necessário para que a câmara de ionização alcance o equilíbrio com as condições de temperatura, pressão e umidade, após ser polarizada. Na realização deste teste, as câmaras de ionização CG, CMETG e CMETA foram polarizadas com a tensão de +100 V e a corrente de ionização foi medida após $15 \mathrm{~min}, 30 \mathrm{~min}, 45 \mathrm{~min}$ e $60 \mathrm{~min}$.

A fonte de controle de ${ }^{90} \mathrm{Sr}+{ }^{90} \mathrm{Y}$ foi posicionada no suporte de PMMA sobre cada câmara de ionização (Figura 6.6). A corrente de ionização medida após um intervalo de tempo de 15 min foi comparada com a corrente de ionização medida após um intervalo de tempo de 60 min e as diferenças entre os valores de corrente de ionização nestes intervalos de tempo, em porcentagem, obtidas para as câmaras de ionização, são mostradas na Tabela 6.3. Segundo a norma IEC 61674 [IEC (1997)], a variação entre as correntes de ionização medidas após 15 min e após 60 min deve 
ser no máximo $\pm 2,0 \%$. Os resultados da Tabela 6.3 mostram que as câmaras de ionização CG, CMETG e CMETA obedeceram ao limite recomendado pela norma IEC 61674 [IEC (1997)]. O tempo de estabilização utilizado neste trabalho para estas câmaras de ionização foi de 15 min.

Tabela 6.3: Diferença entre as correntes de ionização medidas após 15 min e 60 min para avaliação do tempo de estabilização para as câmaras de ionização CG, CMETG e CMETA.

\begin{tabular}{cc}
\hline Câmara de Ionização & Diferença (\%) \\
\hline CG & $0,45 \%$ \\
CMETG & $0,40 \%$ \\
CMETA & $0,50 \%$ \\
\hline
\end{tabular}

\subsubsection{Teste de Corrente de Fuga}

A corrente de fuga foi avaliada durante um intervalo de 20 min antes e depois de uma irradiação. Neste caso, a corrente de fuga antes ou após as irradiações não ultrapassou 1,0\% e, portanto, está dentro do limite recomendado de 5,0\% [IEC (1997)]. Os valores máximos de corrente de fuga são mostrados na Tabela 6.4.

Tabela 6.4: Teste de corrente de fuga das câmaras de ionização CG, CMETG e CMETA.

\begin{tabular}{ccc}
\hline Câmara de & \multicolumn{2}{c}{ Corrente de Fuga } \\
\cline { 2 - 3 } Ionização & Pré-irradiação & Pós-irradiação \\
\hline CG & Máximo de $0,30 \%$ & Máximo de $0,39 \%$ \\
CMETG & Máximo de $0,52 \%$ & Máximo de $0,60 \%$ \\
CMETA & Máximo de $0,72 \%$ & Máximo de $0,79 \%$ \\
\hline
\end{tabular}

\subsubsection{Teste de Linearidade de Resposta}

O teste de linearidade de resposta das câmaras de ionização CG, CMETG e CMETA foi realizado na qualidade de radiação RQR5. Este teste foi feito variandose a corrente no tubo de raios $\mathrm{X}$ de $2 \mathrm{~mA}$ a $25 \mathrm{~mA}$ para obtenção de diferentes taxas de kerma. Os valores das taxas de kerma no ar foram determinados, utilizando-se a câmara Radcal, modelo RC6. A Figura 6.8 apresenta a variação nas respostas das câmaras de ionização, normalizadas para a medição obtida com uma corrente 
nominal de $2 \mathrm{~mA}$, em função da taxa de kerma no ar. Foi aplicado um ajuste linear às curvas e foram obtidos os coeficientes de correlação iguais a 0,999 para as câmaras de ionização CG e CMETG e igual a 1,000 para a câmara de ionização CMETA.

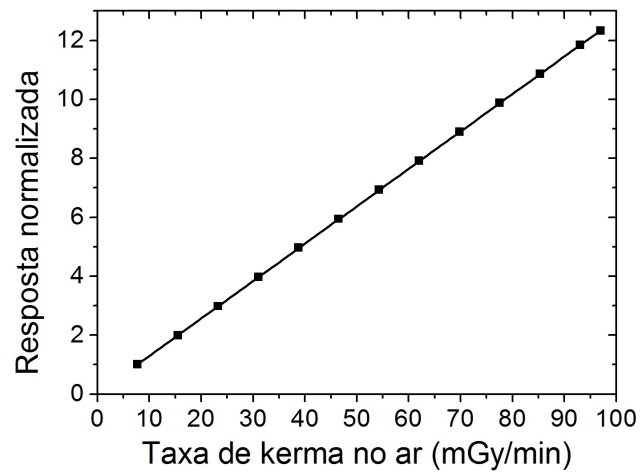

(a)

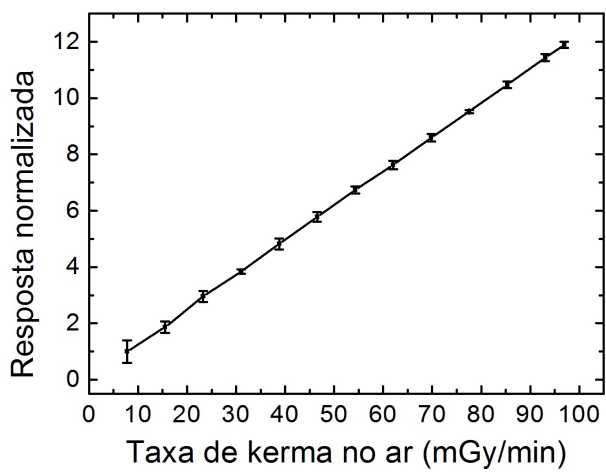

(b)

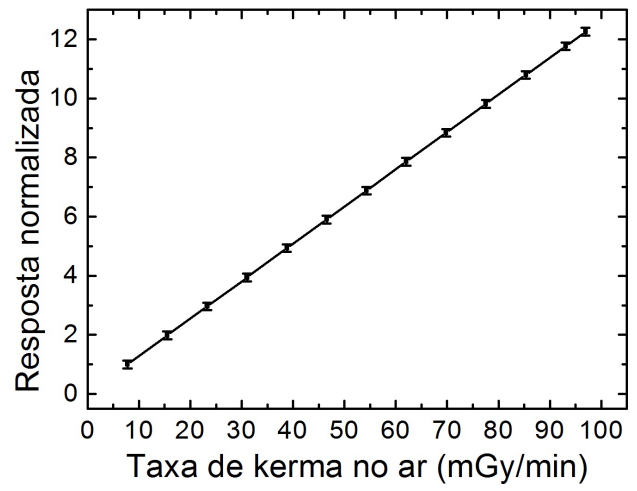

(c)

Figura 6.8: Linearidade de resposta na qualidade de radiação $R Q R 5$ das câmaras de ionização (a) CG, (b) CMETG e (c) CMETA. Os valores das incertezas das medições são menores que 0,4\% para a câmara $C G$, imperceptíveis na figura.

\subsubsection{Teste de Dependência Angular}

No teste dependência angular, cada câmara de ionização foi rotacionada em torno de seu eixo de $-5^{\circ}$ a $+5^{\circ}$, em passos de $1^{\circ}$, utilizando-se um goniômetro e um suporte de PMMA (Figura 6.9), na qualidade de radiação RQR5. As máximas variações obtidas para este teste foram $0,2 \%, 0,4 \%$ e $0,5 \%$ em relação à posição $0^{\circ}$ para as câmaras de ionização CG, CMETG e CMETA, respectivamente, como mostra a Figura 6.10, portanto dentro do limite recomendado de 3,0\% [IEC (1997)]. 


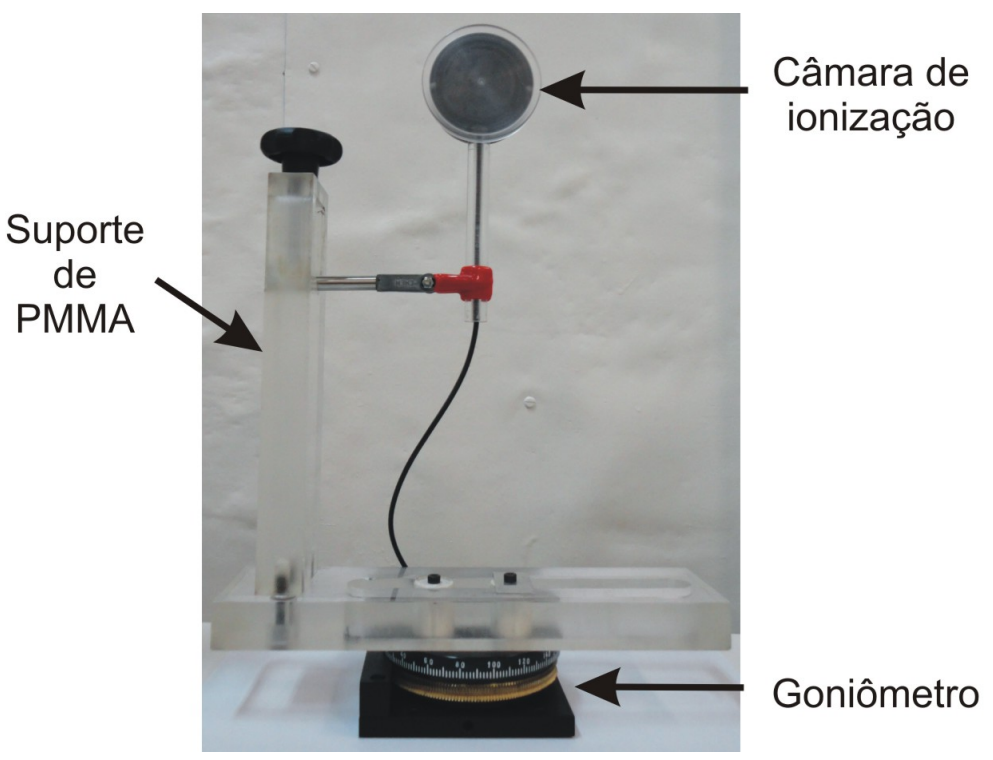

Figura 6.9: Câmara de ionização CG posicionada no goniômetro para realização do teste de dependência angular.

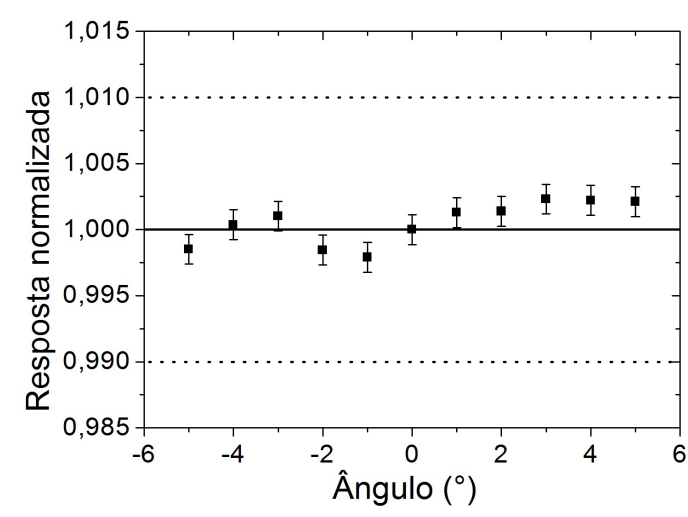

(a)

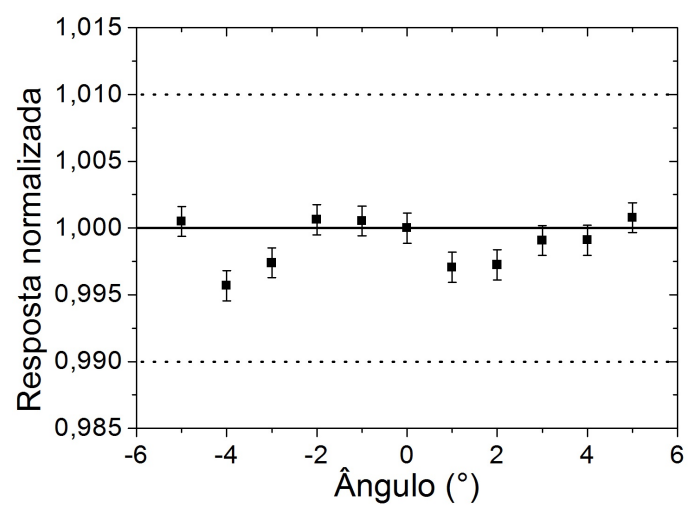

(b)

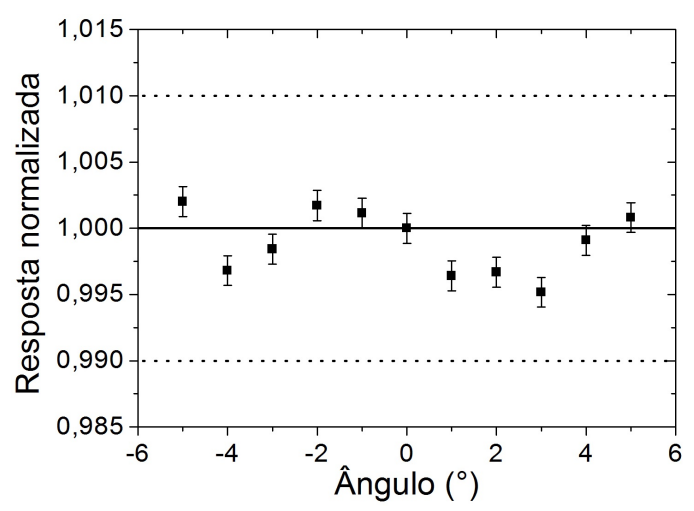

(c)

Figura 6.10: Dependência angular na qualidade de radiação $R Q R 5$ das câmaras de ionização (a) CG, (b) CMETG e (c) CMETA. As linhas pontilhadas representam $\pm 1 / 3$ do limite recomendado pela norma IEC 61674 [IEC (1997)]. 


\subsubsection{Teste de Dependência Energética}

As câmaras de ionização foram calibradas para as qualidades de radiação de radiodiagnóstico, utilizando como sistema padrão a câmara de ionização Radcal RC6. Os coeficientes de calibração foram determinados usando-se a Equação 5.3. Os fatores de correção foram obtidos dividindo-se os coeficientes de calibração de cada qualidade de radiação pelo coeficiente de calibração da qualidade de radiação de referência para feixes diretos (RQR5) e atenuados (RQA5). A dependência energética para a câmara de ionização CG foi de 4,7\% para as qualidades RQR, portanto dentro do limite de 5,0\% recomendado pela norma IEC 61674 [IEC (1997)]. Os coeficientes de calibração e os fatores de correção da câmara de ionização CG são apresentados na Tabela 6.5. Como a câmara de ionização CG tem sua parede muito espessa (2 mm), a dependência energética para feixes atenuados não foi avaliada.

Como as câmaras de ionização CMETG e CMETA foram feitas com as mesmas dimensões, porém com eletrodos coletores de materiais diferentes, elas apresentaram dependências energéticas diferentes e, assim foi montado um sistema Tandem com estas duas câmaras de ionização. Os fatores Tandem foram determinados como a razão entre os coeficientes de calibração da câmara CMETG e os coeficientes de calibração da câmara CMETA. Os resultados obtidos são mostrados na Tabela 6.6. A câmara de ionização CMETG apresentou uma dependência energética de apenas 2,5\% para feixes diretos e 4,8\% para feixes atenuados. A dependência energética da câmara de ionização CMETA foi 5,5\% para feixes diretos e 9,9\% para feixes atenuados.

Tabela 6.5: Coeficientes de calibração e fatores de correção da câmara de ionização CG em feixes diretos de radiodiagnóstico.

\begin{tabular}{ccc}
\hline $\begin{array}{c}\text { Qualidade de } \\
\text { Radiação }\end{array}$ & $\begin{array}{c}\text { Coeficiente de Calibração } \\
\left(\times \mathbf{1 0}^{5} \mathbf{G y} / \mathbf{C}\right)\end{array}$ & $\begin{array}{c}\text { Fator de } \\
\text { Correção }\end{array}$ \\
\hline RQR3 & $9,993 \pm 0,081$ & $1,018 \pm 0,014$ \\
RQR5 & $9,747 \pm 0,079$ & $1,000 \pm 0,016$ \\
RQR8 & $9,653 \pm 0,085$ & $0,991 \pm 0,015$ \\
RQR10 & $9,523 \pm 0,082$ & $0,977 \pm 0,015$ \\
\hline
\end{tabular}


Tabela 6.6: Coeficientes de calibração, fatores de correção e fatores Tandem para as câmaras CMETG e CMETA em feixes de radiodiagnóstico diretos e atenuados.

\begin{tabular}{|c|c|c|c|c|c|}
\hline \multirow[b]{3}{*}{$\begin{array}{c}\text { Qualidade } \\
\text { da } \\
\text { Radiação }\end{array}$} & \multicolumn{4}{|c|}{ Câmara de Ionização } & \multirow[b]{3}{*}{$\begin{array}{c}\text { Fator } \\
\text { Tandem }\end{array}$} \\
\hline & \multicolumn{2}{|c|}{ CMETG } & \multicolumn{2}{|c|}{ CMETA } & \\
\hline & $\begin{array}{c}\text { Coeficiente } \\
\text { de } \\
\text { Calibração } \\
\left(10^{6} \mathrm{~Gy} / \mathrm{C}\right)\end{array}$ & $\begin{array}{c}\text { Fator } \\
\text { de } \\
\text { Correção }\end{array}$ & $\begin{array}{c}\text { Coeficiente } \\
\text { de } \\
\text { Calibração } \\
\left(10^{6} \mathrm{~Gy} / \mathrm{C}\right)\end{array}$ & $\begin{array}{c}\text { Fator } \\
\text { de } \\
\text { Correção }\end{array}$ & \\
\hline \multicolumn{6}{|c|}{ Feixes diretos } \\
\hline RQR 3 & $9,978 \pm 0,060$ & $1,020 \pm 0,010$ & $4,464 \pm 0,016$ & $1,026 \pm 0,010$ & $2,235 \pm 0,016$ \\
\hline RQR 5 & $9,785 \pm 0,078$ & $1,000 \pm 0,011$ & $4,353 \pm 0,013$ & $1,000 \pm 0,008$ & $2,248 \pm 0,019$ \\
\hline RQR 8 & $9,734 \pm 0,071$ & $0,995 \pm 0,011$ & $4,291 \pm 0,010$ & $0,986 \pm 0,007$ & $2,268 \pm 0,017$ \\
\hline RQR 10 & $9,733 \pm 0,074$ & $0,995 \pm 0,011$ & $4,216 \pm 0,013$ & $0,969 \pm 0,008$ & $2,308 \pm 0,019$ \\
\hline \multicolumn{6}{|c|}{ Feixes atenuados } \\
\hline RQA 3 & $9,325 \pm 0,051$ & $1,043 \pm 0,009$ & $4,734 \pm 0,015$ & $1,056 \pm 0,005$ & $1,970 \pm 0,025$ \\
\hline RQA 5 & $8,942 \pm 0,060$ & $1,000 \pm 0,009$ & $4,484 \pm 0,018$ & $1,000 \pm 0,006$ & $1,994 \pm 0,031$ \\
\hline RQA 8 & $8,880 \pm 0,050$ & $0,993 \pm 0,009$ & $4,384 \pm 0,017$ & $0,978 \pm 0,006$ & $2,025 \pm 0,028$ \\
\hline RQA 10 & $8,924 \pm 0,064$ & $0,998 \pm 0,010$ & $4,264 \pm 0,021$ & $0,951 \pm 0,006$ & $2,093 \pm 0,038$ \\
\hline
\end{tabular}

As curvas Tandem, apresentadas na Figura 6.11, mostraram que existe uma variação adequada entre os coeficientes de calibração em função da camada semirredutora. A partir disto, as câmaras CMETG e CMETA podem ser usadas para constituir um sistema Tandem para verificar periodicamente as camadas semirredutoras e, assim, fazer parte do sistema de controle de qualidade de equipamentos de raios X.

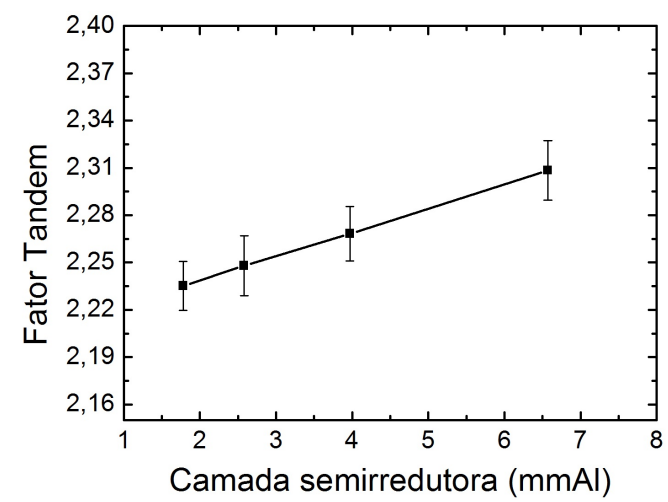

(a)

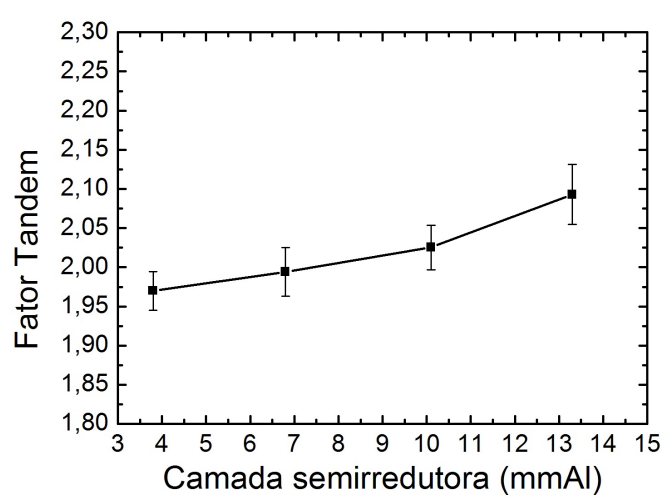

(b)

Figura 6.11: Curvas Tandem das câmaras de ionização CMETG e CMETA (a) para as qualidades de radiação $R Q R$ e (b) para as qualidades de radiação $R Q A$. 


\subsection{Caracterização de Câmaras de Ionização Tipo Lápis e de Placas Paralelas em Feixes Padroni- zados de Radiação X para TC}

As câmaras de ionização tipo lápis, caracterizadas neste projeto em feixes padronizados de radiação X para $\mathrm{TC}$, possuem algumas diferenças relacionadas às suas configurações e aos seus materiais constituintes, que as diferenciam das câmaras de ionização comerciais. As fotografias e o diagrama esquemático das câmaras de ionização, com comprimento de 1,0 cm e com volume sensível de $0,34 \mathrm{~cm}^{3}$ (L1) e com comprimento de 10,0 cm e com volume sensível de 3,4 cm³ (L2), são apresentadas na Figura 6.12 e suas especificações técnicas são listadas na Tabela 6.7. Neste projeto, a câmara de ionização L1 foi aplicada para mapeamento de campo de radiação X e a câmara de ionização L2 foi caracterizada em feixes de TC para aplicação em laboratório de calibração como um padrão de trabalho.

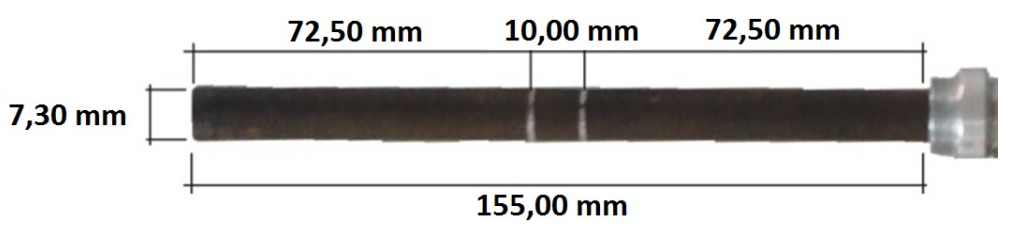

(a)

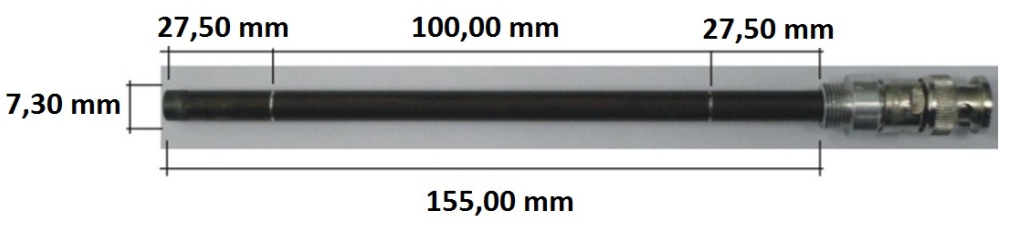

(b)

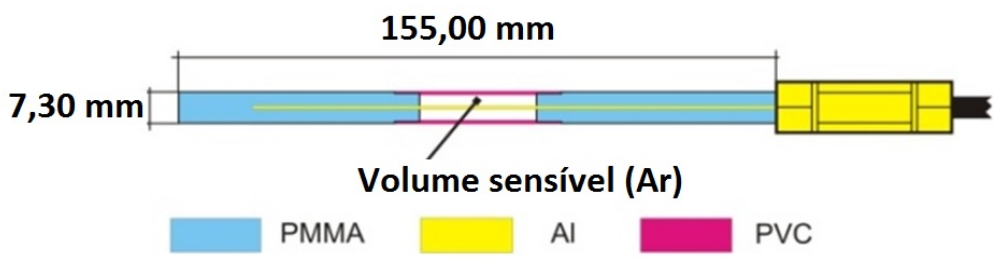

(c)

Figura 6.12: Fotografias das câmaras de ionização tipo lápis (a) L1 e (b) L2 e (c) diagrama esquemático das câmaras de ionização L1 e L2.

A câmara de ionização de placas paralelas, caracterizada neste projeto em feixes padronizados de radiação X para TC, foi desenvolvida por MAIA e CALDAS 
Tabela 6.7: Especificações técnicas das câmaras de ionização tipo lápis L1 e L2.

\begin{tabular}{|c|c|c|}
\hline \multirow{2}{*}{ Características } & \multicolumn{2}{|c|}{ Especificações } \\
\hline & L1 & L2 \\
\hline $\begin{array}{l}\text { Material do eletrodo } \\
\text { coletor central }\end{array}$ & \multicolumn{2}{|c|}{ Alumínio } \\
\hline Material da parede & \multicolumn{2}{|c|}{$\begin{array}{c}\text { PVC com uma } \\
\text { camada de grafite }\end{array}$} \\
\hline $\begin{array}{c}\text { Diâmetro do eletrodo } \\
\text { coletor central }\end{array}$ & \multicolumn{2}{|c|}{$1,22 \mathrm{~mm}$} \\
\hline $\begin{array}{l}\text { Diâmetro do interior da } \\
\text { câmara de ionização }\end{array}$ & \multicolumn{2}{|c|}{$6,72 \mathrm{~mm}$} \\
\hline Espessura da parede & \multicolumn{2}{|c|}{$0,26 \mathrm{~mm}$} \\
\hline Comprimento do volume sensível & $1,0 \mathrm{~cm}$ & $10,0 \mathrm{~cm}$ \\
\hline Volume sensível & $0,34 \mathrm{~cm}^{3}$ & $3,40 \mathrm{~cm}^{3}$ \\
\hline
\end{tabular}

(2005). Esta câmara de placas paralelas será chamada no texto de PPTC. No artigo de MAIA e CALDAS (2005), a câmara de ionização PPTC foi caracterizada em feixes padrões de radiodiagnóstico apresentados na norma IEC 61267 [IEC (1994)]. É importante notar que esta norma não apresentava qualidades de radiação específicas para TC. As qualidades padrões específicas para TC foram apresentadas na nova norma IEC 61267 [IEC (2005)]. Neste projeto, a câmara de ionização PPTC foi caracterizada utilizando-se os feixes padrões de TC, seguindo as recomendações da norma IEC (2005). Uma fotografia e um desenho esquemático da câmara de ionização PPTC são apresentados na Figura 6.13 e suas especificações técnicas são listadas na Tabela 6.8 .

\subsubsection{Curva de Saturação, Efeito de Polaridade e Eficiência de Coleção de Íons}

As curvas de saturação das câmaras de ionização L1, L2 e PPTC (Figura 6.14) foram obtidas variando-se a tensão aplicada de $-400 \mathrm{~V}$ a $+400 \mathrm{~V}$, em passos de $50 \mathrm{~V}$, utilizando um intervalo de coleta de carga de $15 \mathrm{~s}$. Este teste foi feito utilizando-se a qualidade de diagnóstico RQT9 (Tabela 5.2) estabelecida no equipamento de raios X do LCI. 


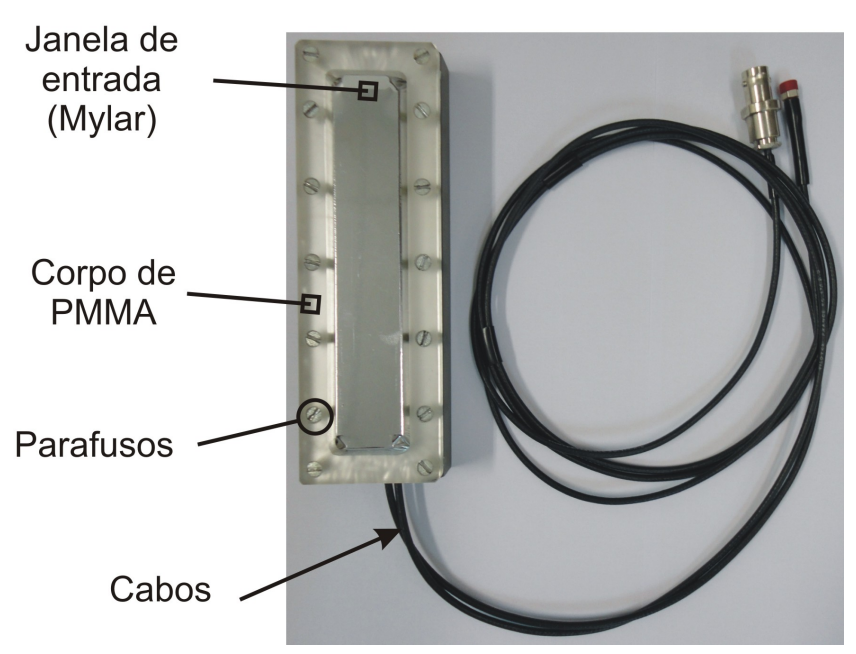

(a)

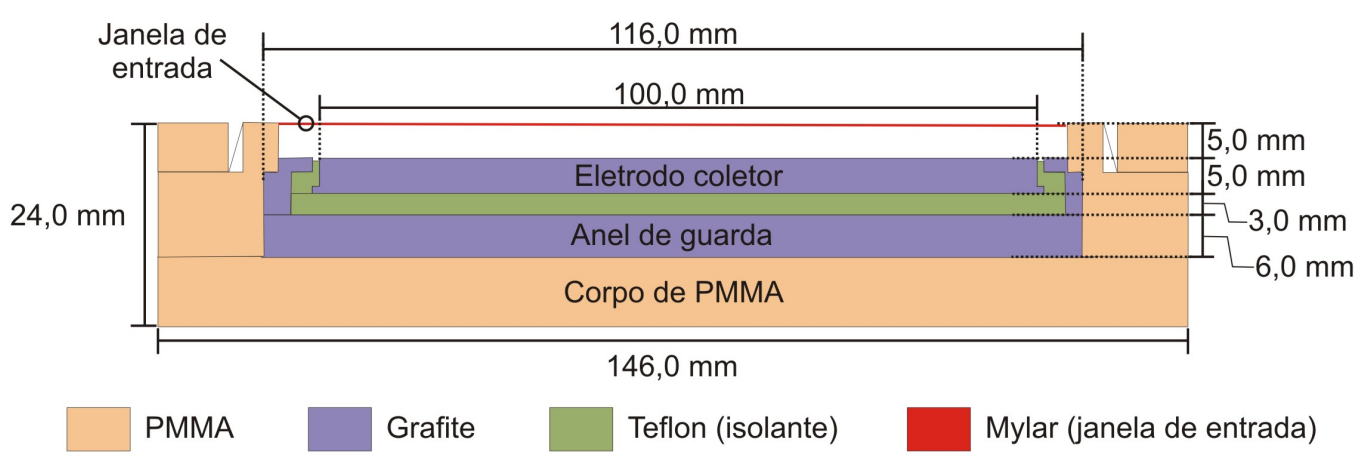

(b)

Figura 6.13: (a) Fotografia da câmara de ionização PPTC e (b) diagrama esquemático da câmara de ionização PPTC.

Tabela 6.8: Especificações técnicas da câmara de ionização PPTC.

\begin{tabular}{cc}
\hline Características & Dimensões/Especificações \\
\hline Material do eletrodo coletor & Grafite \\
Material da janela de entrada & Mylar \\
Diâmetro externo & $146,0 \mathrm{~mm}$ \\
Material do isolante & Teflon \\
Comprimento do volume sensível & $100,0 \mathrm{~mm}$ \\
Tipo de conector & BNC e banana \\
Volume sensível & $3,2 \mathrm{~cm}^{3}$ \\
\hline
\end{tabular}

O efeito de polaridade foi determinado com a Equação 5.1. Os resultados obtidos foram listados na Tabela 6.9 e todos eles estão dentro do limite recomendado de 1,0\% [IEC (2011)]. A eficiência de coleção de íons foi calculada com a Equação 5.2, utilizando-se as tensões $V_{1}=+200 \mathrm{~V}$ e $V_{2}=+100 \mathrm{~V}$. Neste caso, a eficiência de cole- 


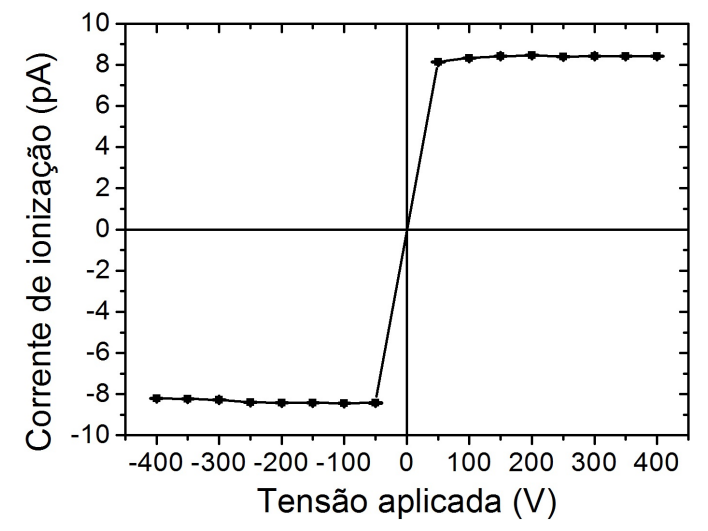

(a)

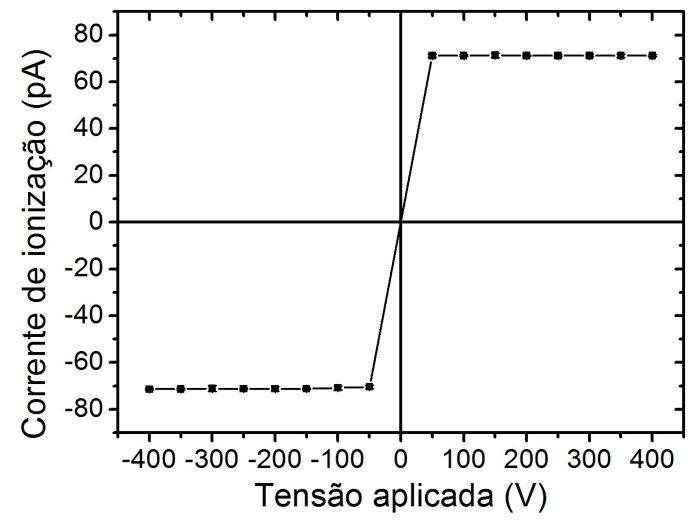

(b)

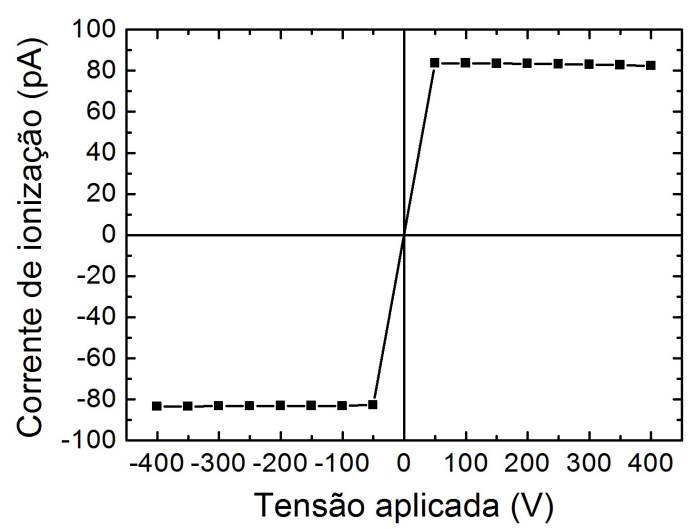

(c)

Figura 6.14: Curvas de saturação obtidas na qualidade de radiação RQT9 para as câmaras de ionização (a) L1, (b) L2 e (c) PPTC. Os valores das incertezas das medições são menores que 1,0\%, e, desta forma, imperceptíveis nos gráficos.

ção de íons foi melhor que 99,99\% para as três câmaras de ionização (Tabela 6.9). A tensão de operação utilizada em todos os testes de caracterização para as três câmaras de ionização foi escolhida como $+100 \mathrm{~V}$.

Tabela 6.9: Teste de polaridade e eficiência de coleção de ions das câmaras de ionização L1, L2 e PPTC.

\begin{tabular}{ccc}
\hline $\begin{array}{c}\text { Câmara de } \\
\text { Ionização }\end{array}$ & $\begin{array}{c}\text { Efeito de } \\
\text { Polaridade }\end{array}$ & $\begin{array}{c}\text { Eficiência de Coleção } \\
\text { de Îons }\end{array}$ \\
\hline L1 & Máximo de 0,90\% & Maior que 99,99\% \\
L2 & Máximo de 0,60\% & Maior que 99,99\% \\
PPTC & Máximo de 0,23\% & Maior que 99,99\% \\
\hline
\end{tabular}




\subsubsection{Teste de Estabilidade de Resposta em Curto e Longo Prazos}

O teste de estabilidade das câmaras de ionização L1, L2 e PPTC foi feito utilizando-se uma fonte de controle e um suporte de PMMA construído para este tipo de câmara de ionização tipo lápis, como mostra a Figura 6.15. No teste de estabilidade de resposta em curto prazo foram efetuadas 10 medições consecutivas da carga coletada durante 1,0 min. As máximas variações no teste de estabilidade em curto prazo foram 0,7\%, 0,2\% e 0,28\% para as câmaras L1, L2 e PPTC, respectivamente.

Os testes de estabilidade em longo prazo foram realizados por meio dos testes em curto prazo ao longo do tempo. Para cada série de medições realizadas no teste em curto prazo, foi calculado um valor médio. Para se determinar a estabilidade em longo prazo, estes valores médios foram analisados ao longo do tempo. Como pode ser observado na Figura 6.16, as variações máximas estão dentro do limite recomendado de 2,0\% [IEC (1997)], para o teste de estabilidade em longo prazo.

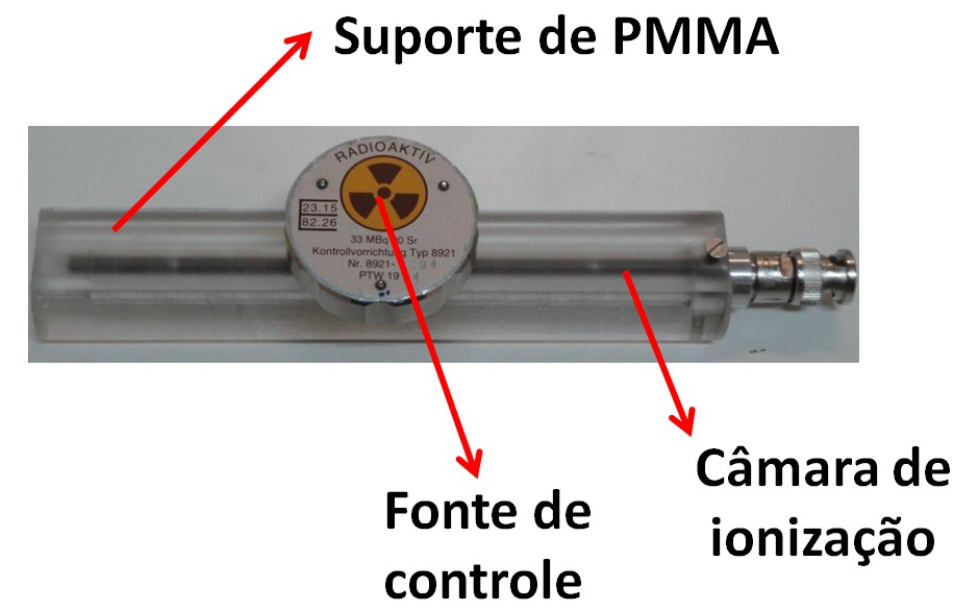

Figura 6.15: Fotografia da fonte de controle de ${ }^{90} S r+{ }^{90} Y$ posicionada sobre a câmara de ionização L1 no suporte de PMMA.

\subsubsection{Tempo de Estabilização}

Na realização do teste de estabilização, as câmaras de ionização L1, L2 e PPTC foram polarizadas com a tensão de $+100 \mathrm{~V}$ e a corrente de ionização foi medida após $15 \min , 30 \mathrm{~min}, 45 \min$ e $60 \mathrm{~min}$.

Para a realização deste teste, a fonte de controle de ${ }^{90} \mathrm{Sr}+{ }^{90} \mathrm{Y}$ foi posicionada 


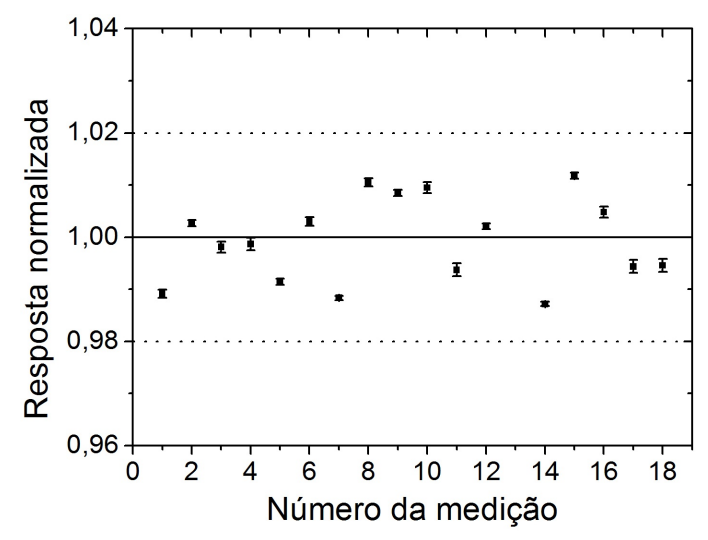

(a)

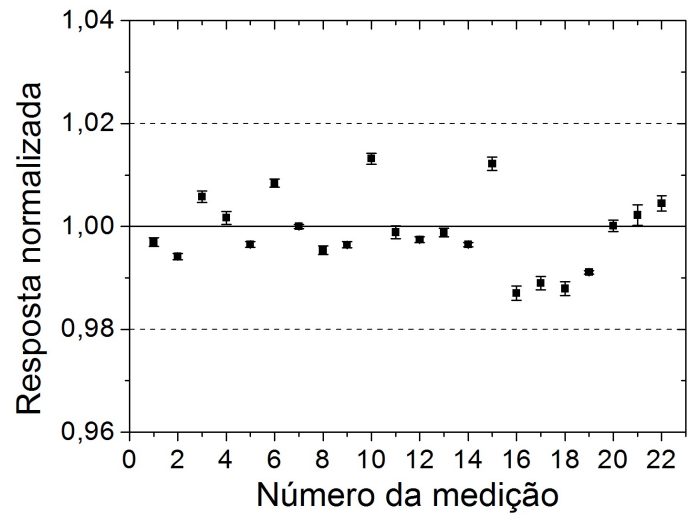

(b)

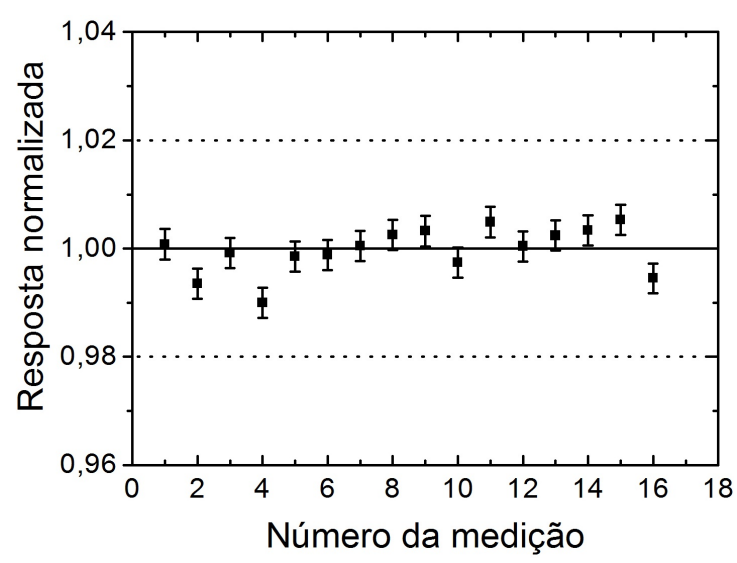

(c)

Figura 6.16: Estabilidade em longo prazo, utilizando a fonte de controle de ${ }^{90} \mathrm{Sr}^{90} \mathrm{Y}$, da resposta das câmaras de ionização (a) L1, (b) L2 e (c) PPTC. As linhas pontilhadas mostram os limites de $\pm 2,0 \%$ recomendados pela IEC 61674 [IEC (1997)].

no suporte de PMMA sobre a câmara de ionização (Figura 6.15). A corrente de ionização medida após 15 min foi comparada com a corrente de ionização medida após 60 min e as diferenças entre os valores de corrente nestes intervalos de tempo, em porcentagem, obtidas para as câmaras de ionização, são mostradas na Tabela 6.10. Segundo a norma IEC 61674 [IEC (1997)], a variação entre as correntes de ionização medidas após 15 min e após 60 min deve ser no máximo $\pm 2,0 \%$. Os resultados da Tabela 6.10 mostram que as câmaras de ionização L1, L2 e PPTC obedeceram ao limite recomendado pela IEC 61674 [IEC (1997)]. O tempo de estabilização utilizado neste trabalho para estas câmaras de ionização foi de 15 min. 
Tabela 6.10: Diferença entre as correntes de ionização medidas após 15 min e 60 min, para avaliação do tempo de estabilização das câmaras de ionização L1, L2 e PPTC.

\begin{tabular}{cc}
\hline $\begin{array}{c}\text { Câmara de } \\
\text { Ionização }\end{array}$ & $\begin{array}{c}\text { Diferença } \\
(\boldsymbol{\%})\end{array}$ \\
\hline L1 & $0,35 \%$ \\
L2 & $0,40 \%$ \\
PPTC & $0,30 \%$ \\
\hline
\end{tabular}

\subsubsection{Teste de Corrente de Fuga}

A corrente de fuga foi avaliada durante um intervalo de 20 min antes e depois de uma irradiação. Os valores máximos de corrente de fuga obtidos são mostrados na Tabela 6.11. Como pode ser observado, para as três câmaras de ionização, a corrente de fuga antes ou após as irradiações não ultrapassou o limite de 5\% [IEC (1997)].

Tabela 6.11: Teste de corrente de fuga das câmaras de ionização L1, L2 e PPTC.

\begin{tabular}{ccc}
\hline Câmara de & \multicolumn{2}{c}{ Corrente de Fuga } \\
\cline { 2 - 3 } Ionização & Pré-irradiação & Pós-irradiação \\
\hline L1 & Máximo de $0,07 \%$ & Máximo de $0,19 \%$ \\
L2 & Máximo de $0,06 \%$ & Máximo de $0,30 \%$ \\
PPTC & Máximo de $0,07 \%$ & Máximo de $0,15 \%$ \\
\hline
\end{tabular}

\subsubsection{Teste de Linearidade de Resposta}

Utilizando-se a qualidade de radiação de referência para TC (RQT9), o teste de linearidade das câmaras de ionização L1, L2 e PPTC foi realizado, variando-se a corrente no tubo de raios $\mathrm{X}$ de $2 \mathrm{~mA}$ a $25 \mathrm{~mA}$ para obtenção de diferentes taxas de kerma. Os valores das taxas de kerma no ar foram determinados utilizando-se a câmara Radcal, modelo RC3CT. A Figura 6.17 apresenta a variação nas respostas das câmaras de ionização, normalizadas para a medição obtida com uma corrente nominal de $2 \mathrm{~mA}$, em função da taxa de kerma no ar. Foi aplicado um ajuste linear às curvas e foram obtidos os coeficientes de correlação igual a 0,999 para a câmara de ionização L1 e igual a 1,000 para as câmaras de ionização L2 e PPTC. 


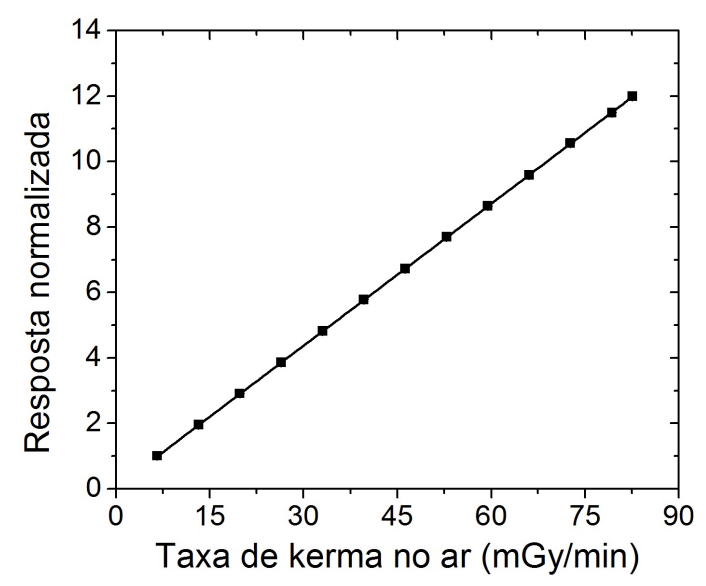

(a)

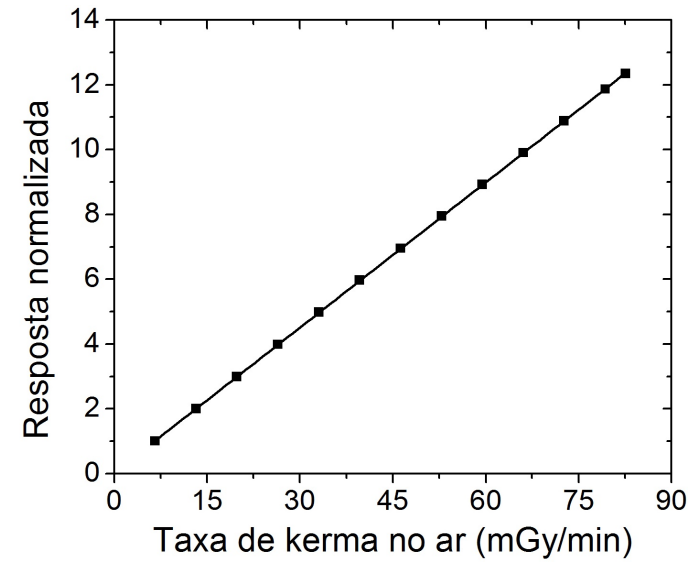

(b)

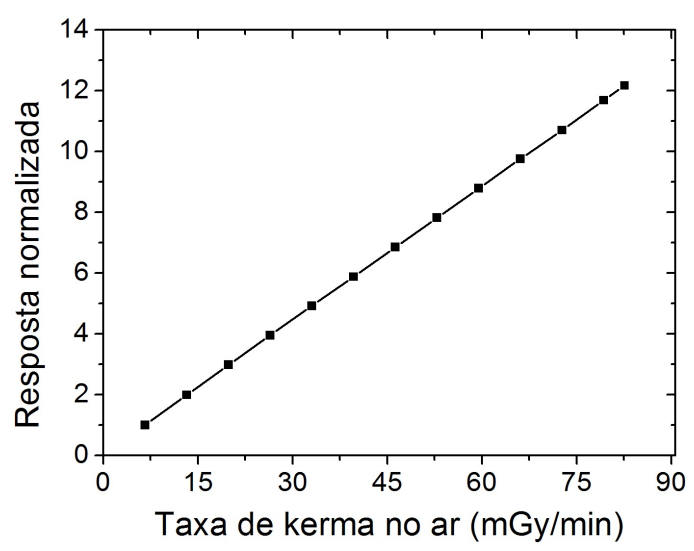

(c)

Figura 6.17: Linearidade de resposta na qualidade de radiação RQT9 das câmaras de ionização (a) L1, (b) L2 e (c) PPTC. Os valores das incertezas das medições são menores que $0,9 \%$ e, desta forma, imperceptiveis nas figuras.

\subsubsection{Teste de Dependência Angular}

No teste de dependência angular, cada uma das câmaras de ionização foi rotacionada em torno de seu eixo de $-180^{\circ}$ a $+180^{\circ}$, em passos de $30^{\circ}$, utilizando-se o goniômetro (Seção 5.3), na qualidade de radiação RQT9. As máximas variações obtidas para este teste foram $0,9 \%, 0,8 \%$ e $0,4 \%$ em relação à posição $0^{\circ}$ para as câmaras de ionização L1, L2 e PPTC, respectivamente, como mostra a Figura 6.18, portanto, dentro do limite recomendado de 3,0\% [IEC (1997)].

\subsubsection{Teste de Dependência Energética}

A variação da resposta das câmaras de ionização L1, L2, PPTC e para a câmara de ionização tipo lápis comercial, Victoreen 660-6, com a energia efetiva do feixe de 


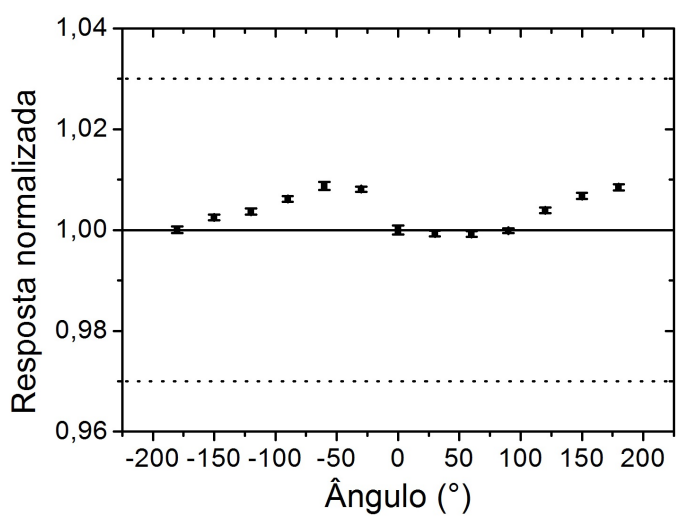

(a)

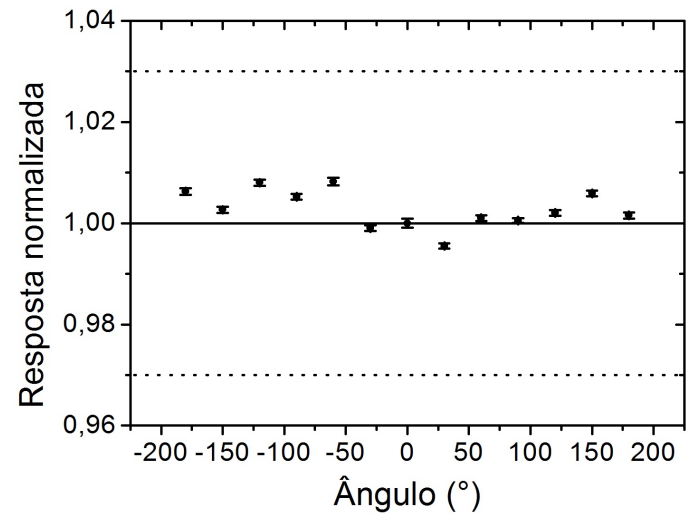

(b)

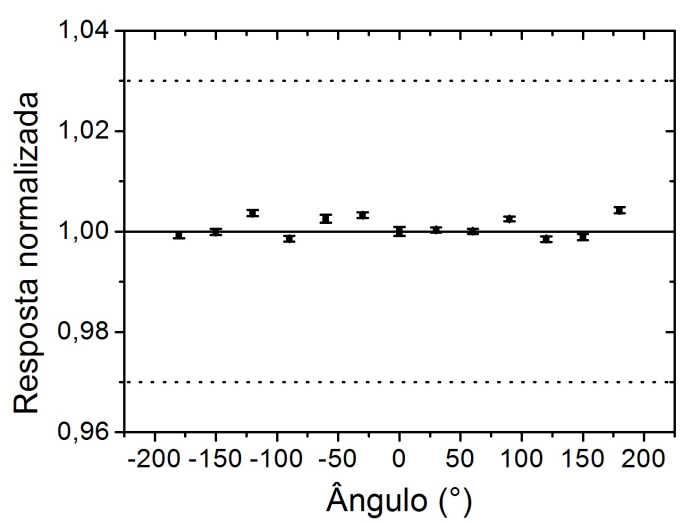

(c)

Figura 6.18: Dependência angular na qualidade de radiação RQT9 das câmaras de ionização (a) L1, (b) L2 e (c) PPTC.

radiação incidente foi estudada utilizando-se as qualidades de radiação, nível TC, listadas na Tabela 5.2. As câmaras de ionização foram calibradas pelo método de substituição, em relação à câmara de ionização de referência Radcal RC3CT. Segundo recomendações internacionais [IEC (1997)], a variação da dependência energética deve estar dentro de $\pm 5,0 \%$ com relação à qualidade de referência, que neste caso é a qualidade de radiação RQT9. As Tabelas 6.12, 6.13, 6.14 e 6.15 mostram os coeficientes de calibração e os fatores de correção das câmaras de ionização L1, L2, PPTC e Victoreen 660-6, respectivamente, nas qualidades de TC.

O valor da dependência energética foi determinado como a razão entre o maior e o menor coeficiente de calibração, em porcentagem. 
Tabela 6.12: Coeficientes de calibração e fatores de correção da câmara de ionização L1 para as qualidades de radiação de TC.

\begin{tabular}{ccc}
\hline $\begin{array}{c}\text { Qualidade de } \\
\text { Radiação }\end{array}$ & $\begin{array}{c}\text { Coeficiente de Calibração } \\
(\mathbf{m G y} / \mathbf{p C})\end{array}$ & $\begin{array}{c}\text { Fator de } \\
\text { Correção }\end{array}$ \\
\hline RQT8 & $0,0759 \pm 0,0011$ & $0,9899 \pm 0,0209$ \\
RQT9 & $0,0767 \pm 0,0011$ & $1,0000 \pm 0,0212$ \\
RQT10 & $0,0768 \pm 0,0011$ & $1,0016 \pm 0,0213$ \\
\hline
\end{tabular}

Tabela 6.13: Coeficientes de calibração e fatores de correção da câmara de ionização L2 para as qualidades de radiação de TC.

\begin{tabular}{ccc}
\hline $\begin{array}{c}\text { Qualidade de } \\
\text { Radiação }\end{array}$ & $\begin{array}{c}\text { Coeficiente de Calibração } \\
\left(\times \mathbf{1 0}^{7} \mathbf{G y} / \mathbf{C}\right)\end{array}$ & $\begin{array}{c}\text { Fator de } \\
\text { Correção }\end{array}$ \\
\hline RQT8 & $7,515 \pm 0,068$ & $0,979 \pm 0,021$ \\
RQT9 & $7,678 \pm 0,066$ & $1,000 \pm 0,021$ \\
RQT10 & $7,879 \pm 0,065$ & $1,026 \pm 0,019$ \\
\hline
\end{tabular}

Tabela 6.14: Coeficientes de calibração e fatores de correção da câmara de ionização PPTC para as qualidades de radiação de TC.

\begin{tabular}{ccc}
\hline $\begin{array}{c}\text { Qualidade de } \\
\text { Radiação }\end{array}$ & $\begin{array}{c}\text { Coeficiente de Calibração } \\
\left(\times \mathbf{1 0}^{7} \mathbf{G y} / \mathbf{C}\right)\end{array}$ & $\begin{array}{c}\text { Fator de } \\
\text { Correção }\end{array}$ \\
\hline RQT8 & $6,714 \pm 0,074$ & $1,020 \pm 0,015$ \\
RQT9 & $6,581 \pm 0,066$ & $1,000 \pm 0,014$ \\
RQT10 & $6,687 \pm 0,066$ & $1,016 \pm 0,014$ \\
\hline
\end{tabular}

Tabela 6.15: Coeficientes de calibração e fatores de correção da câmara de ionização Victoreen 660-6 para as qualidades de radiação de TC.

\begin{tabular}{ccc}
\hline $\begin{array}{c}\text { Qualidade de } \\
\text { Radiação }\end{array}$ & $\begin{array}{c}\text { Coeficiente de Calibração } \\
\left(\times \mathbf{1 0}^{7} \mathbf{G y} / \mathbf{C}\right)\end{array}$ & $\begin{array}{c}\text { Fator de } \\
\text { Correção }\end{array}$ \\
\hline RQT8 & $8,297 \pm 0,091$ & $1,008 \pm 0,015$ \\
RQT9 & $8,235 \pm 0,082$ & $1,000 \pm 0,014$ \\
RQT10 & $8,153 \pm 0,081$ & $0,990 \pm 0,014$ \\
\hline
\end{tabular}


Tabela 6.16: Valores da dependência energética para as câmaras de ionização L1, LQ, PPTC e Victoreen 660-6 nas qualidades de radiação de TC.

\begin{tabular}{cc}
\hline Câmara de & $\begin{array}{c}\text { Dependência Energética } \\
\text { Ionização }\end{array}$ \\
\hline L1 & 1,2 \\
L2 & 4,6 \\
PPTC & 2,0 \\
Victoreen $660-6$ & 1,8 \\
\hline
\end{tabular}

Os resultados da dependência energética (Tabela 6.16) mostram que a câmara de ionização L1 apresentou uma variação menor em sua resposta com a mudança de energia do feixe de raios $\mathrm{X}$ incidente. Contudo, as três câmaras de ionização apresentaram uma dependência energética dentro do limite recomendado pela norma IEC 61674 [IEC (1997)] de $\pm 5,0 \%$.

A partir dos resultados obtidos nos testes de caracterização das câmaras de ionização L1, L2 e PPTC pode-se afirmar que elas podem ser utilizadas como padrões de trabalho, e têm desempenho comparável com a câmara de ionização comercial avaliada neste projeto (Victoreen 660-6).

\subsubsection{Avaliação do Comprimento Efetivo e da Uniformidade Espacial da Resposta da Câmara de Ionização L2}

O comprimento efetivo de uma câmara de ionização tipo lápis é definido pela norma IEC 61674 [IEC (1997)] como "a largura à meia-altura do gráfico da resposta da câmara de ionização em função da distância ao longo do eixo do detector". A uniformidade espacial da resposta da câmara tipo lápis é definida como a região em que a resposta da câmara tem uma variação máxima de 3,0\% em sua resposta.

Seguindo as recomendações da norma IEC 61674 [IEC (1997)], um diafragma com abertura de 2,0 $\mathrm{mm}$ foi colocado a uma distância de 4,0 cm da câmara L2, e ela foi movida ao longo de seu eixo de $-5,1 \mathrm{~cm}$ até $+5,1 \mathrm{~cm}$ em relação ao seu centro. A resposta da câmara de ionização em função da distância ao longo de seu eixo é mostrada na Figura 6.19. Este teste mostrou que o comprimento efetivo da câmara de ionização é 0,6\% menor que seu comprimento ativo $(10,0 \mathrm{~cm})$. 
Devido ao comprimento do volume sensível da câmara de ionização L1 ser muito pequeno, não foi possível realizar este teste de avaliação do comprimento efetivo e da uniformidade espacial da resposta desta câmara de ionização.

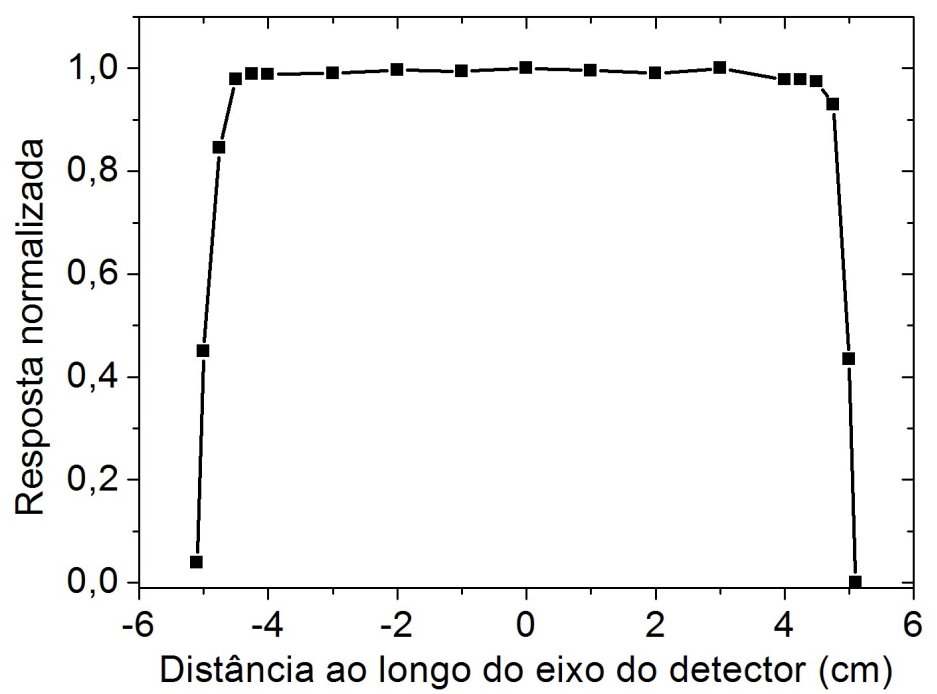

Figura 6.19: Resposta da câmara de ionização L2 ao longo de seu eixo na qualidade de radiação RQT9. Todos os valores foram normalizados para a resposta no centro do volume sensivel. O sentido positivo indica a direção do conector de BNC. As incertezas foram menores que 0,3\% e, desta forma, imperceptiveis na figura.

\subsubsection{Mapeamento do Campo de Radiação X com a Câmara de Ionização L1}

Como a câmara de ionização L1 tem o comprimento do volume sensível pequeno (10,0 mm), ela foi avaliada quanto à possibilidade de sua aplicação em mapeamento de campos de radiação X.

A qualidade de radiação de referência para TC RQT9 foi utilizada neste teste. Os passos para o mapeamento do campo nas direções vertical e horizontal foram de 1,0 cm; e para cada posição foram feitas 10 medições. Os resultados para o mapeamento nas direções horizontal e vertical são mostrados nas Figuras 6.20(a) e 6.20(b), respectivamente.

O limite do campo de radiação é definido pela posição em que a resposta obtida pelo detector de radiação é aproximadamente $95,0 \%$ do valor medido no centro do campo de radiação [ISO (1996)]. Sendo assim, o tamanho do campo medido foi definido com as seguintes dimensões: 12,0 cm na direção horizontal e 12,0 cm na 


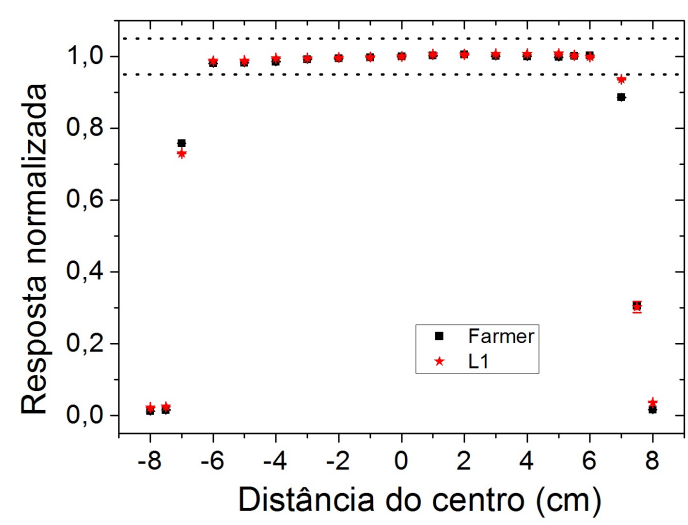

(a)

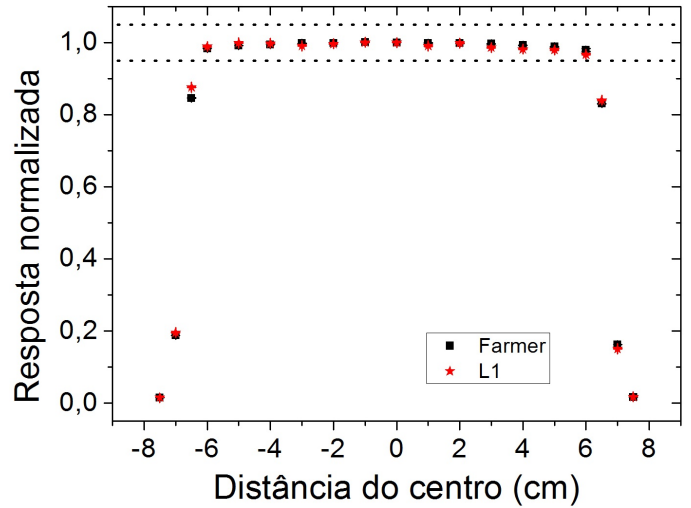

(b)

Figura 6.20: Mapeamento do campo de radiação $X$ com as câmaras de ionização L1 $e$ Farmer nas direções (a) horizontal e (b) vertical. As linhas pontilhadas delimitam 95,0\% do valor medido no centro do campo. As incertezas foram menores que $0,5 \%$ e, desta forma, são imperceptiveis nas figuras.

direção vertical.

Para se avaliar os resultados do mapeamento do campo, a resposta da câmara L1 foi comparada com a de uma câmara comercial Farmer, PTW, modelo TN30011-1. As variações máximas obtidas, na região homogênea do campo, foram de 0,98\% na direção horizontal e de 1,25\% na direção vertical, como mostram as Figuras 6.20(a) e 6.20(b), respectivamente. As pequenas diferenças obtidas no mapeamento de campo, realizado com as câmaras de ionização L1 e Farmer, mostram que a câmara de ionização L1 tem potencial para ser aplicada em mapeamento de campos de radiação X.

\subsection{Projeto e Construção de Câmaras de Ionização de Placas Paralelas como Sistemas Padrões em Feixes de ${ }^{60} \mathrm{Co}$}

Foram desenvolvidas e caracterizadas duas câmaras de ionização de grafite, com dimensões e volumes sensíveis diferentes, em feixes de ${ }^{60} \mathrm{Co}$. A câmara de ionização com volume sensível de $9,4 \mathrm{~cm}^{3}$ será chamada no texto de G1 e a com volume sensível de $6,4 \mathrm{~cm}^{3}$ será denominada G2. Estas câmaras de ionização foram construídas e caracterizadas apenas para uso em laboratórios de calibração como sistemas de referência (primário/secundário). A principal motivação no desenvolvimento de duas câmaras de ionização diferentes foi avaliar a influência das dimensões e das 
configurações destas câmaras, experimentalmente e por simulação de Monte Carlo. Também, como elas serão utilizadas como sistemas de referência, a taxa de kerma no ar pode ser calculada como a média entre os valores obtidos com as duas câmaras de ionização. Esta técnica, de calcular a média dos resultados, é adotada por alguns laboratórios padrões primários, como é o caso do PTB [ALLISY-ROBERTS et al. (2005)].

Além das câmaras de ionização de grafite, a câmara de ionização CG, anteriormente caracterizada nas qualidades de radiação X, foi avaliada também no feixe de ${ }^{60} \mathrm{Co}$. Neste caso, foi utilizada uma capa de equilíbrio eletrônico de PMMA de 2,0 mm de espessura, completando a espessura necessária, já que a câmara de ionização tem uma parede de $2,0 \mathrm{~mm}$.

A câmara de ionização Farmer, PTW, modelo TN30002, número de série 272, com volume sensível de $0,6 \mathrm{~cm}^{3}$, que é o padrão de referência para feixes de ${ }^{60} \mathrm{Co}$ do LCI, também foi avaliada nos testes de caracterização, pois ela é utilizada atualmente para determinar a taxa de kerma no ar da fonte de ${ }^{60}$ Co do LCI. O valor de taxa de kerma no ar, obtido utilizando-se esta câmara de ionização, foi comparado com o valor da taxa de kerma no ar determinado com as câmaras de ionização de grafite.

As câmaras de ionização de placas paralelas de grafite foram desenvolvidas utilizando-se grafite como material da parede e eletrodo coletor, e Teflon como material isolante. Utilizou-se grafite, pois ele apresenta propriedades de interações da radiação com a matéria (espalhamento e absorção) muito semelhantes ao ar, tornando-o um excelente material para a determinação de dose absorvida no ar. As fotos das câmaras de ionização são apresentadas nas Figuras 6.21(a) e 6.21(b) e os diagramas esquemáticos são mostrados nas Figuras 6.21(c) e 6.21(d) para as câmaras de ionização G1 e G2, respectivamente. As especificações destas câmaras são listadas na Tabela 6.17. 


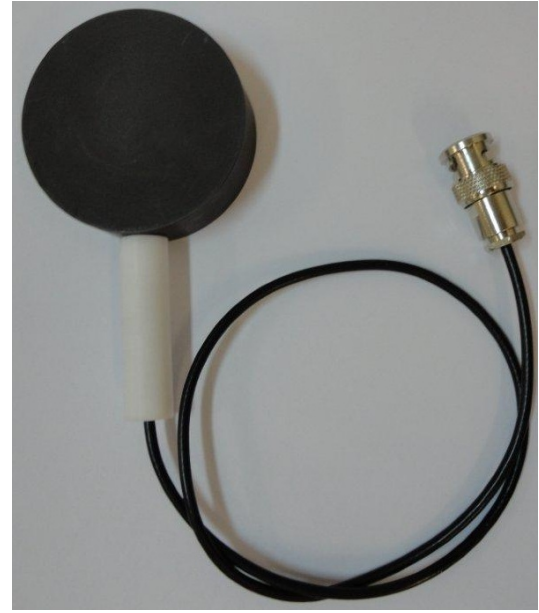

(a)

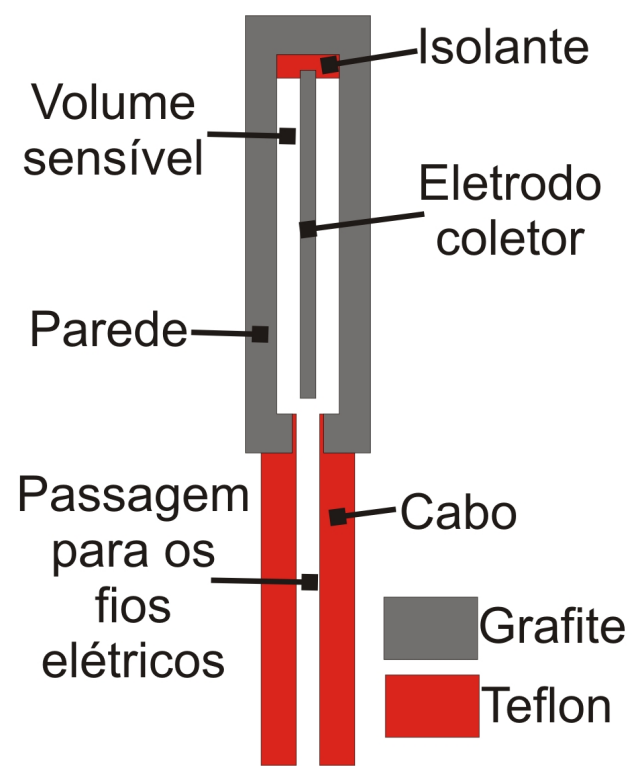

(c)

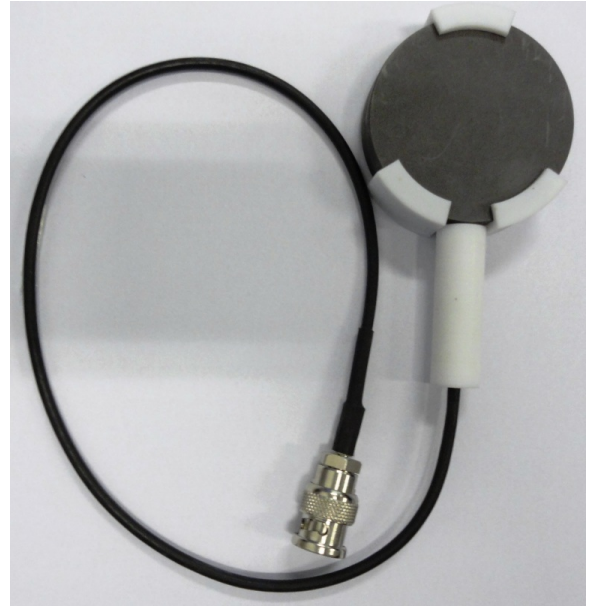

(b)

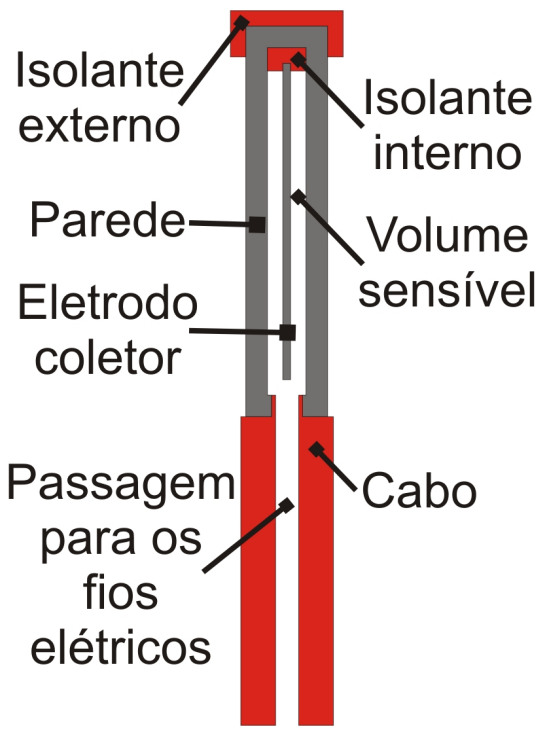

(d)

Figura 6.21: Fotografias das câmaras de ionização de grafite (a) G1 e (b) G2 e esquemas das câmaras de ionização (c) G1 e (d) G2. 
Tabela 6.17: Especificações técnicas das câmaras de ionização G1 e G2.

\begin{tabular}{ccc}
\hline Características & \multicolumn{2}{c}{ Especificações/Dimensões } \\
\cline { 2 - 3 } & G1 & G2 \\
\hline Densidade do grafite $\left(\mathrm{g} / \mathrm{cm}^{3}\right)$ & 1,77 & 1,77 \\
Pureza do grafite $(\%)$ & $99,5^{\dagger}$ & $99,5^{\dagger}$ \\
Espessura da parede $(\mathrm{mm})$ & 4,0 & 2,8 \\
Diâmetro interno $(\mathrm{mm})$ & 46,0 & 45,0 \\
Diâmetro externo $(\mathrm{mm})$ & 56,0 & 50,6 \\
Diâmetro do eletrodo coletor $(\mathrm{mm})$ & 42,0 & 41,0 \\
Espessura do eletrodo coletor $(\mathrm{mm})$ & 2,0 & 1,0 \\
Tipo de conector & $\mathrm{BNC}$ & $\mathrm{BNC}$ \\
Volume sensível $\left(\mathrm{cm}^{3}\right)$ & 9,4 & 6,4 \\
\hline
\end{tabular}

Os detalhes dos componentes da câmara de ionização G1 são mostrados na Figura 6.22 e da câmara de ionização G2 são mostrados na Figura 6.23. 


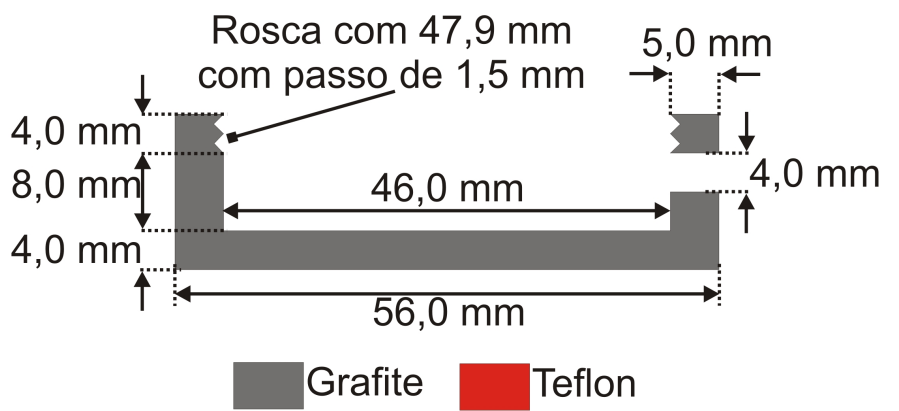

(a)

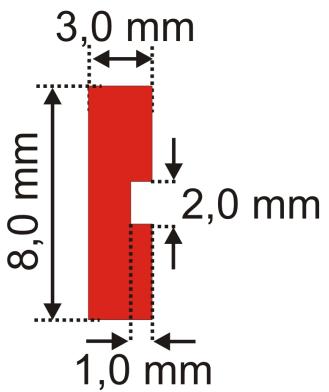

(b)

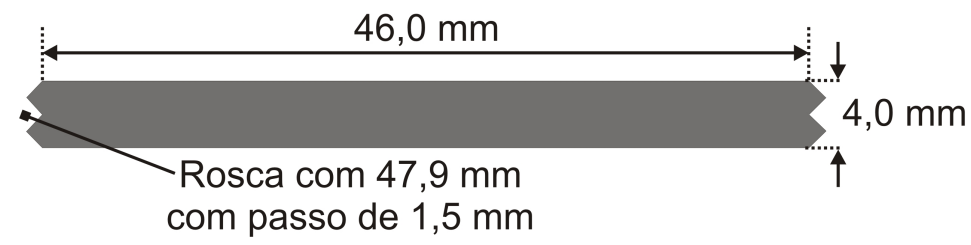

(c)

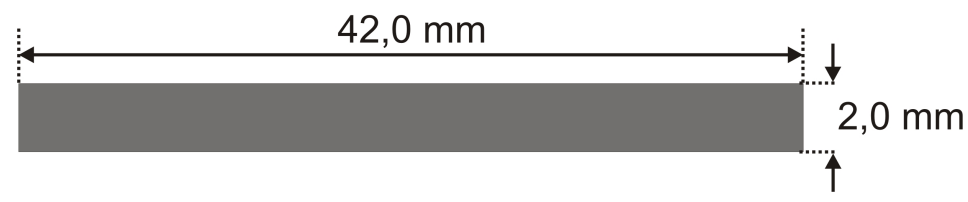

(d)

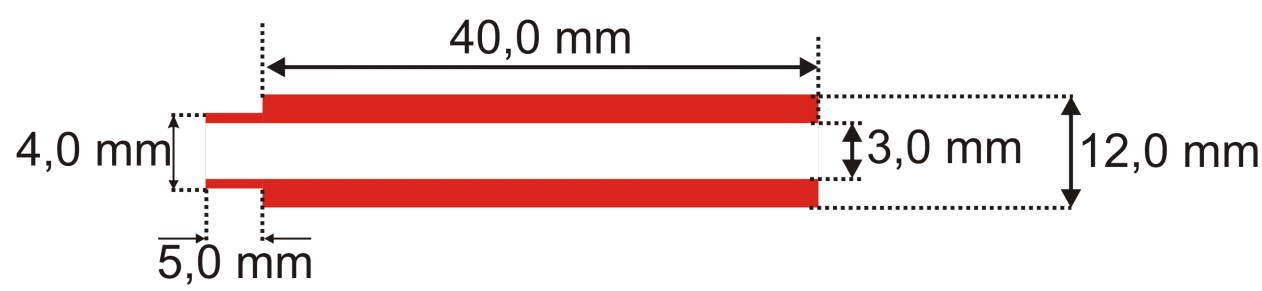

(e)

Figura 6.22: Detalhes, com dimensões, dos componentes da câmara de ionização G1: (a) paredes, (b)isolante de Teflon, utilizado para fixar o eletrodo coletor no interior da câmara de ionização, (c)parede superior, (d) eletrodo coletor, e (e) cabo. 


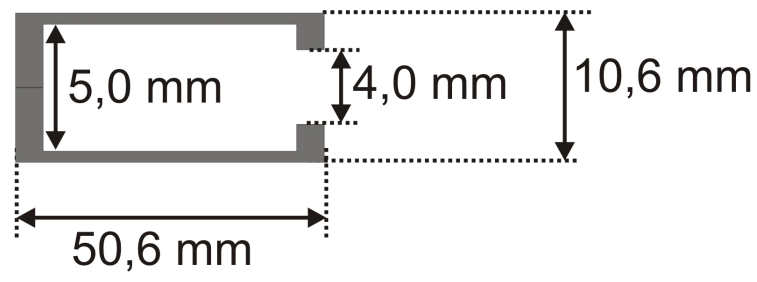

Grafite

$$
\text { Teflon }
$$

(a)

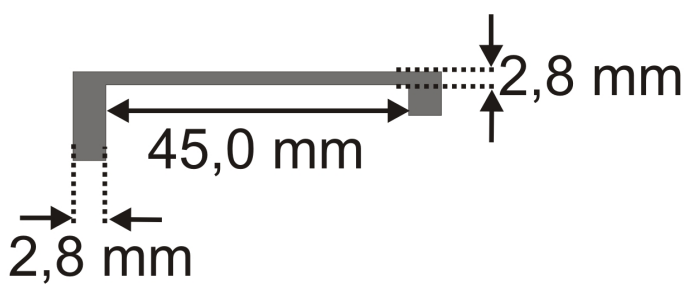

(b)

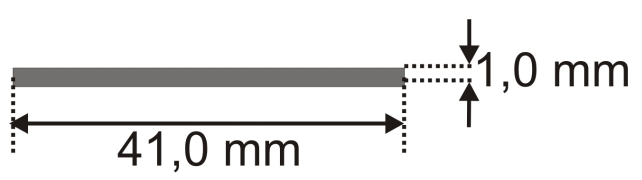

(c)

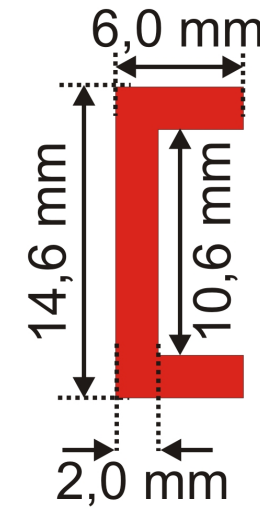

(d)

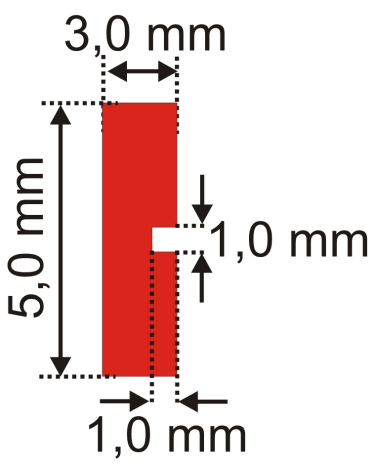

(e)

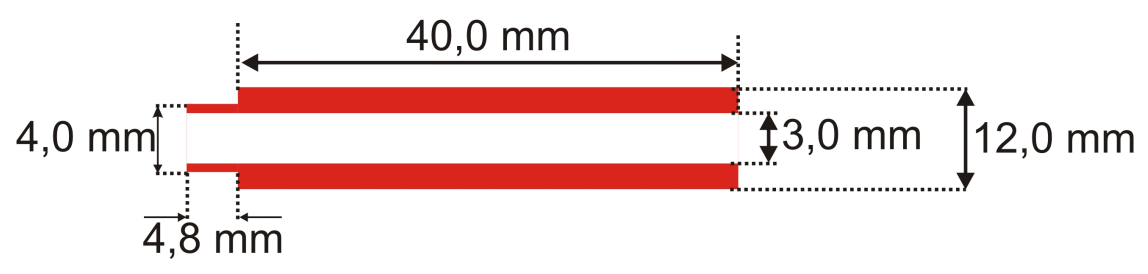

(f)

Figura 6.23: Detalhes, com dimensões, dos componentes da câmara de ionização G2: (a) paredes, (b) parede em detalhes, (c) eletrodo coletor, (d) isolantes de Teflon externos, utilizados para unir as paredes, (e) isolantes de Teflon internos, utilizados para fixar o eletrodo coletor no interior da câmara de ionização e (f) cabo. 


\subsection{Caracterização das Câmaras de Ionização G1, G2, CG e PTW (Modelo TN30002) em Feixes de ${ }^{60} \mathrm{Co}$}

Vários testes de caracterização propostos na norma IEC 60731 [IEC (2011)] foram aplicados às câmaras de ionização G1, G2, CG e PTW no feixe de ${ }^{60}$ Co.

\subsubsection{Curva de Saturação, Efeito de Polaridade e Eficiência de Coleção de Íons}

No teste de saturação foi variada a tensão aplicada às câmaras de ionização de -400 V até $+400 \mathrm{~V}$, em passos de $50 \mathrm{~V}$. Como pode ser observado na Figura 6.24, para todas as tensões testadas não ocorreu nenhuma diferença significativa nas respostas das câmaras de ionização G1, G2, CG e PTW. Para o caso das quatro câmaras de ionização, a tensão de operação escolhida foi +100 V. O efeito de polaridade e a eficiência de coleção de íons foram determinados com as Equações 5.1 e 5.2, respectivamente e os valores obtidos são apresentados na Tabela 6.18. Os efeitos de polaridade máximos ficaram dentro do limite recomendado de 1,0\% [IEC (2011)] e a eficiência de coleção de íons foi melhor que 99,99\% para as quatro câmaras de ionização. 


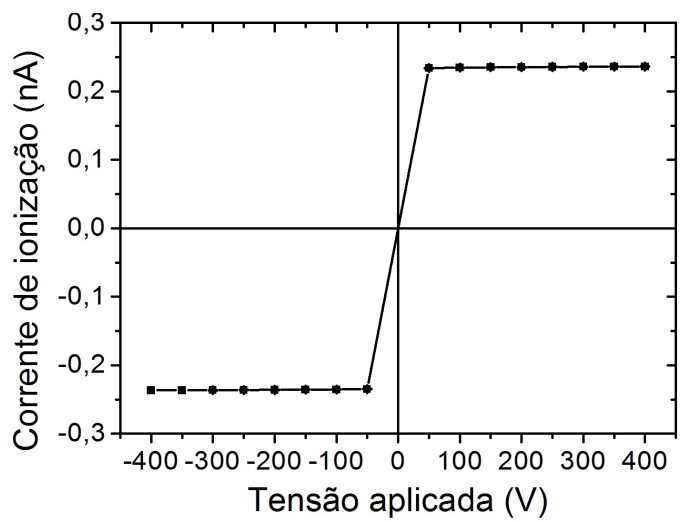

(a)

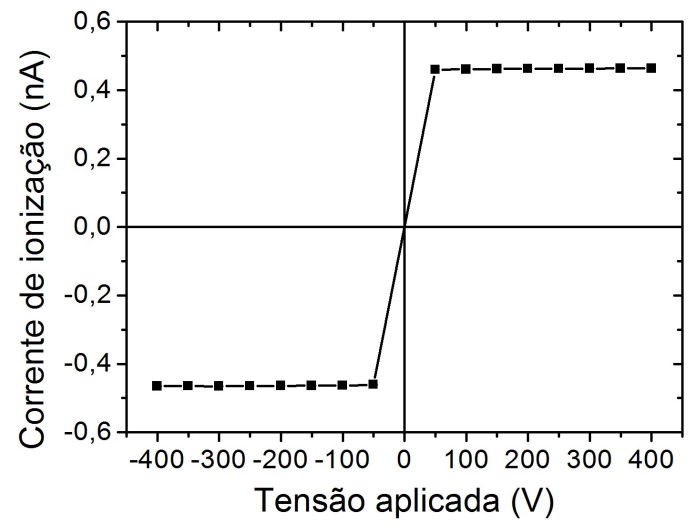

(c)

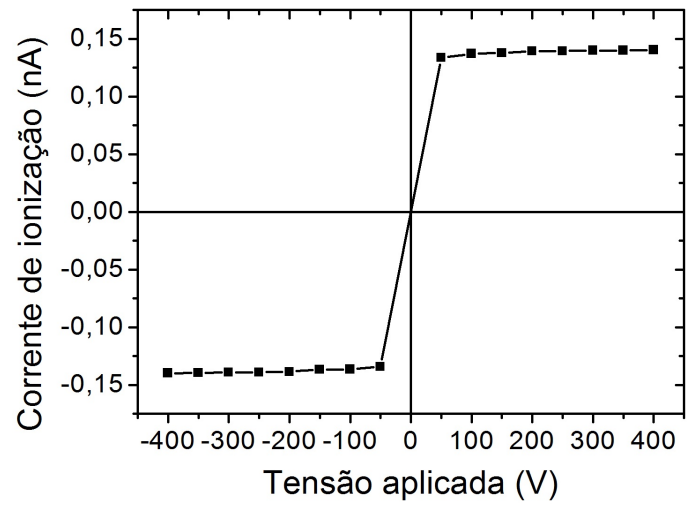

(b)

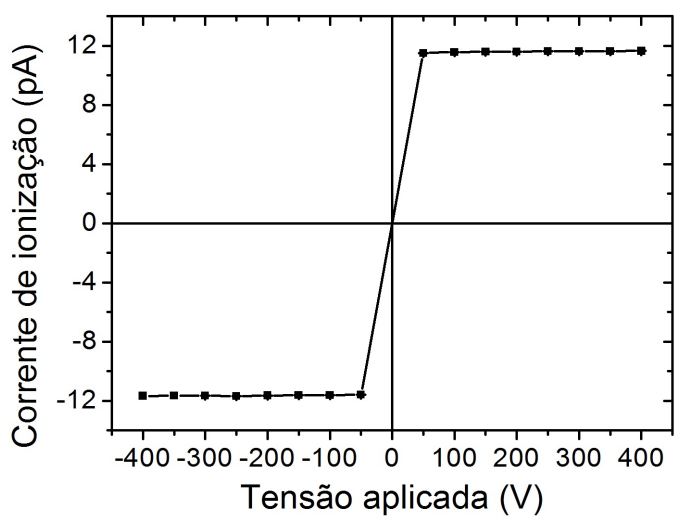

(d)

Figura 6.24: Curvas de saturação obtidas no feixe de ${ }^{60}$ Co para as câmaras de ionização (a) G1, (b) G2, (c) CG e (d) PTW. Os valores das incertezas das medições são menores que 0,2\%, imperceptiveis nas figuras.

Tabela 6.18: Teste de polaridade e eficiência de coleção de ions no feixe de ${ }^{60}$ Co das câmaras de ionização G1, G2, CG e PTW.

\begin{tabular}{ccc}
\hline $\begin{array}{c}\text { Câmara de } \\
\text { Ionização }\end{array}$ & $\begin{array}{c}\text { Efeito de } \\
\text { Polaridade }\end{array}$ & $\begin{array}{c}\text { Eficiência de } \\
\text { Coleção de Íons }\end{array}$ \\
\hline G1 & Máximo de 0,30\% & Maior que 99,99\% \\
G2 & Máximo de 0,49\% & Maior que 99,99\% \\
CG & Máximo de 0,41\% & Maior que 99,99\% \\
PTW & Máximo de 0,40\% & Maior que 99,99\% \\
\hline
\end{tabular}

\subsubsection{Estabilidade em Curto e Longo Prazos}

A estabilidade das câmaras de ionização foi monitorada durante 9 meses. Neste teste, as câmaras foram expostas ao feixe de ${ }^{60} \mathrm{Co}$, sob condições reprodutíveis de medições. Foram realizadas dez medições de carga em cada teste de estabilidade 
em curto prazo. As variações máximas observadas foram 0,20\%, 0,25\%, 0,09\% e 0,12\% para as câmaras de ionização G1, G2, CG e PTW, respectivamente, todas dentro do limite recomendado de 0,3\% [IEC (2011)]. A estabilidade em longo prazo é mostrada na Figura 6.25. Como pode ser observado, a variação máxima para este teste ficou dentro do limite de 0,5\% [IEC (2011)] para as câmaras de ionização G1, G2, CG e PTW, modelo TN30002.

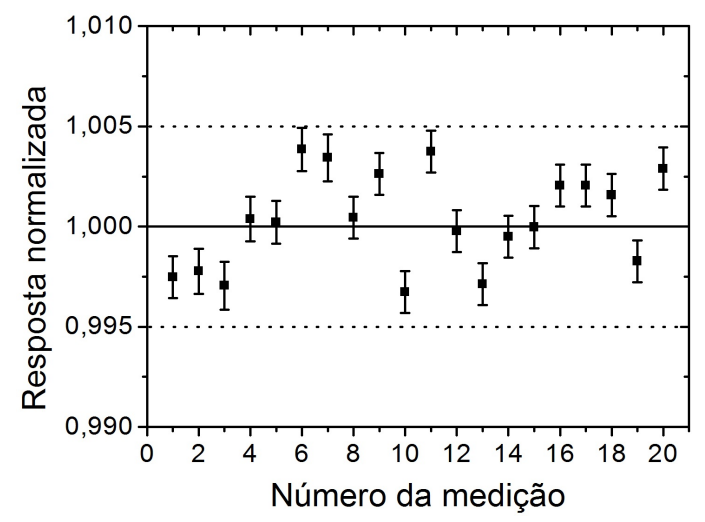

(a)

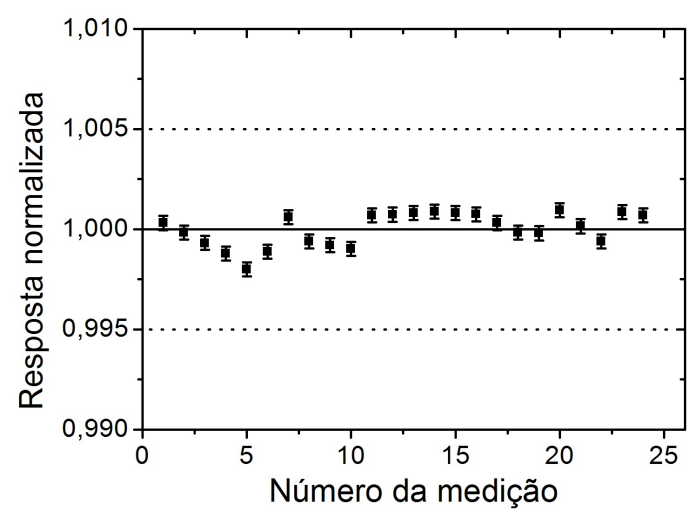

(c)

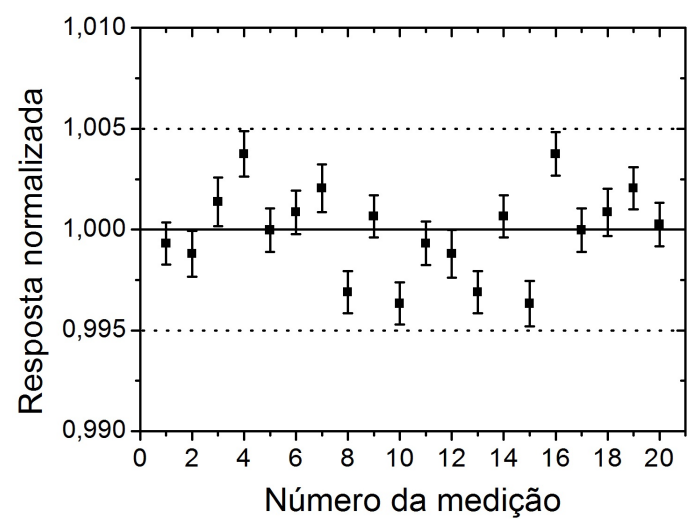

(b)

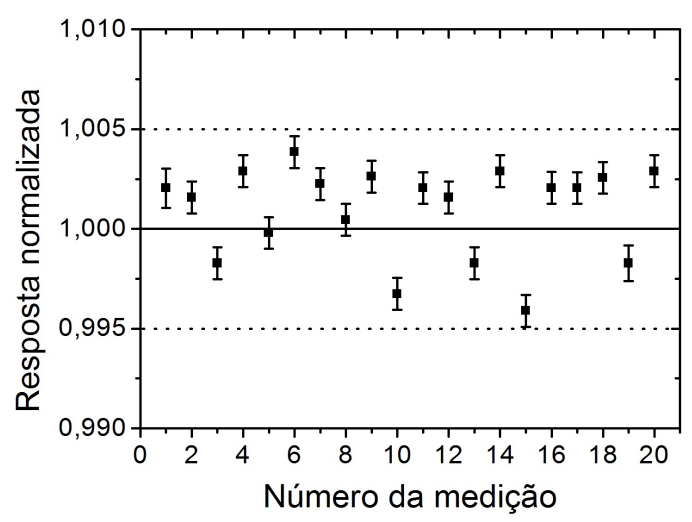

(d)

Figura 6.25: Estabilidade em longo prazo, no feixe de ${ }^{60}$ Co, da resposta das câmaras de ionização (a) G1, (b) G2, (c) CG e (d) PTW. As linhas pontilhadas mostram os limites recomendados pela norma IEC 60731 [IEC (2011)].

\subsubsection{Linearidade de Resposta}

A linearidade de resposta das câmaras de ionização G1, G2, CG e PTW foi estudada como a carga coletada em função da dose absorvida no feixe de ${ }^{60} \mathrm{Co}$. As câmaras de ionização apresentaram um comportamento linear, como pode ser observado na Figura 6.26, com coeficientes de correlação iguais a 1,000 para as 
quatro câmaras de ionização.

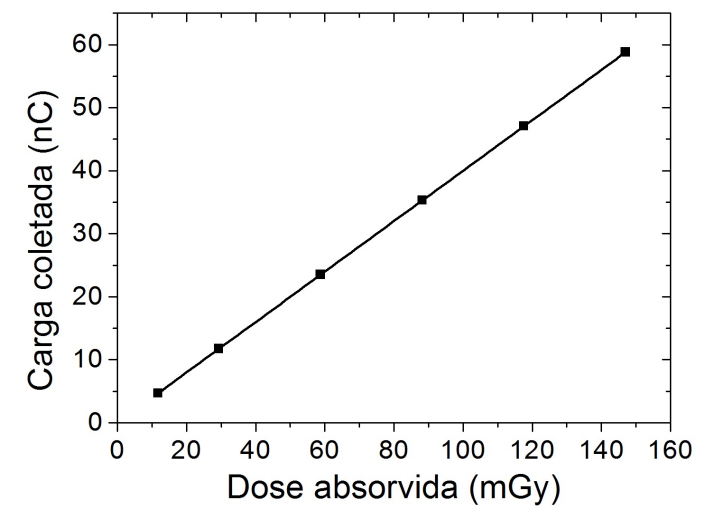

(a)

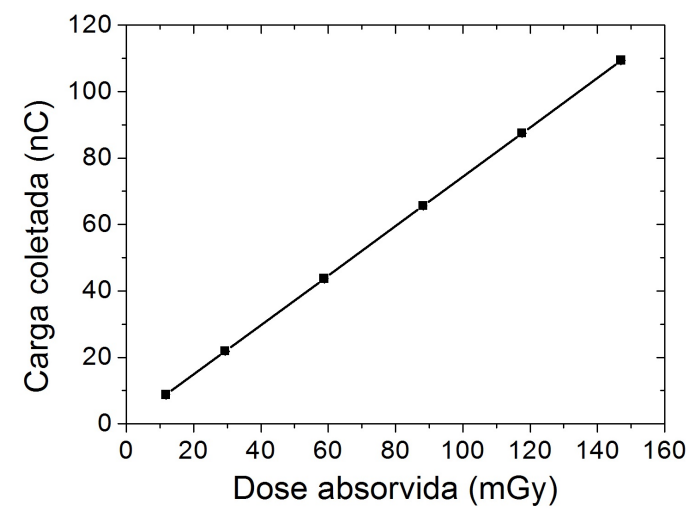

(c)

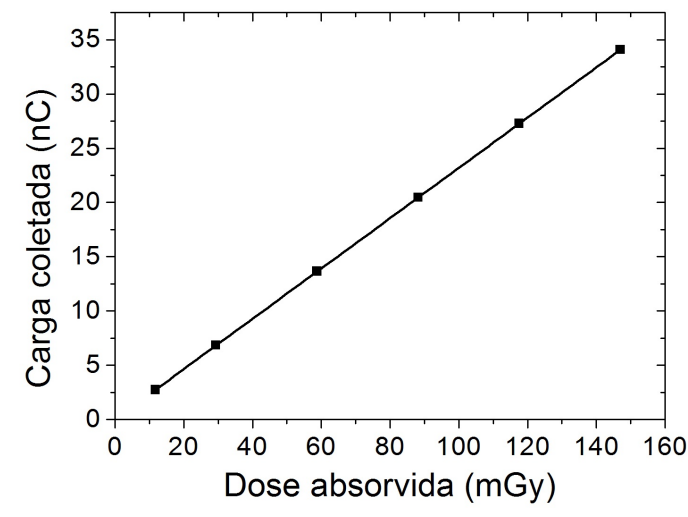

(b)

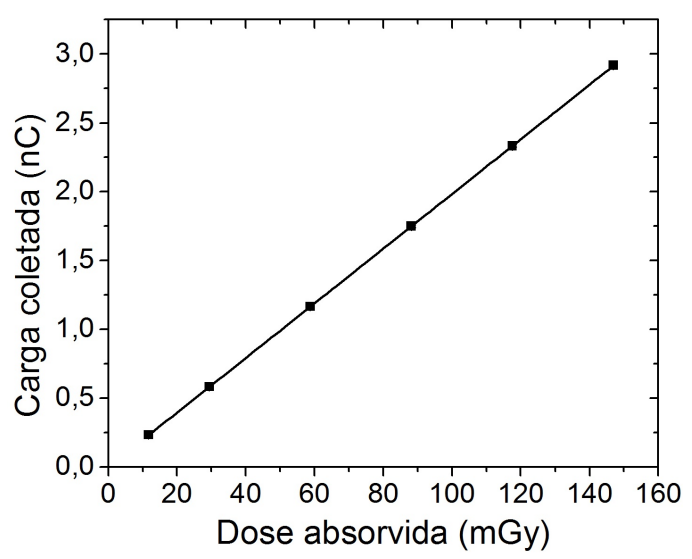

(d)

Figura 6.26: Linearidade de resposta, obtida no feixe de ${ }^{60}$ Co, para as câmaras de ionização (a) G1 e (b) G2, (c) CG e (d) PTW. Os valores das incertezas das medições são menores que 1,0\%, imperceptiveis nas figuras.

\subsubsection{Corrente de Fuga}

A corrente de fuga das câmaras de ionização G1, G2, CG e PTW foi avaliada antes e após as irradiações no feixe de ${ }^{60} \mathrm{Co}$ e os resultados obtidos neste teste são listados na Tabela 6.19. De acordo com a norma IEC 60731 [IEC (2011)], o limite máximo recomendado para este teste é $0,5 \%$ da corrente de ionização durante as irradiações; sendo assim, a resposta das quatro câmaras de ionização ficou dentro deste limite. 
Tabela 6.19: Corrente de fuga das câmaras de ionização G1, G2, CG e PTW.

\begin{tabular}{ccc}
\hline Câmara de & \multicolumn{2}{c}{ Corrente de Fuga } \\
\cline { 2 - 3 } Ionização & Pré-irradiação & Pós-irradiação \\
\hline G1 & Máximo de $0,36 \%$ & Máximo de $0,44 \%$ \\
G2 & Máximo de $0,39 \%$ & Máximo de $0,43 \%$ \\
CG & Máximo de $0,30 \%$ & Máximo de $0,39 \%$ \\
PTW & Máximo de $0,34 \%$ & Máximo de $0,40 \%$ \\
\hline
\end{tabular}

\subsubsection{Dependência Angular}

O teste de dependência angular das câmaras de ionização G1, G2, CG e PTW foi feito rotacionando as câmaras de ionização em torno do seu eixo de $-5^{\circ}$ até $+5^{\circ}$, em passos de $1^{\circ}$, e os resultados são apresentados na Figura 6.27. Este teste foi feito utilizando-se o goniômetro (Seção 5.3). As variações máximas, obtidas nas respostas das câmaras de ionização em relação à posição $0^{\circ}$, foram $0,2 \%$ para as duas câmaras de ionização (G1 e G2), 0,3\% para a câmara de ionização CG e 0,1\% para a câmara de ionização PTW, portanto dentro do limite recomendado de 0,5\% [IEC (2011)]. 


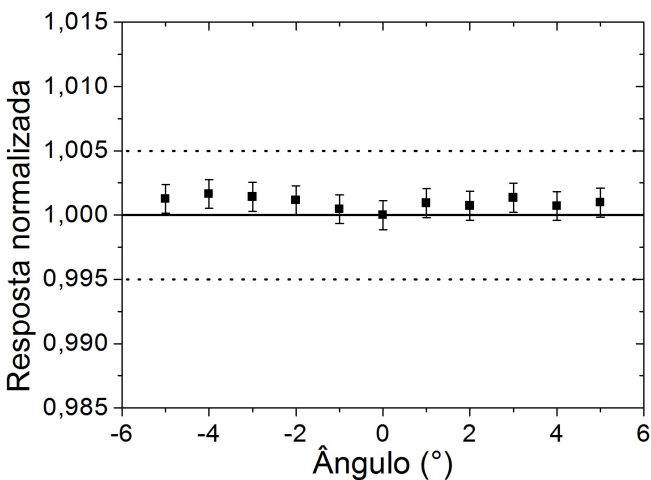

(a)

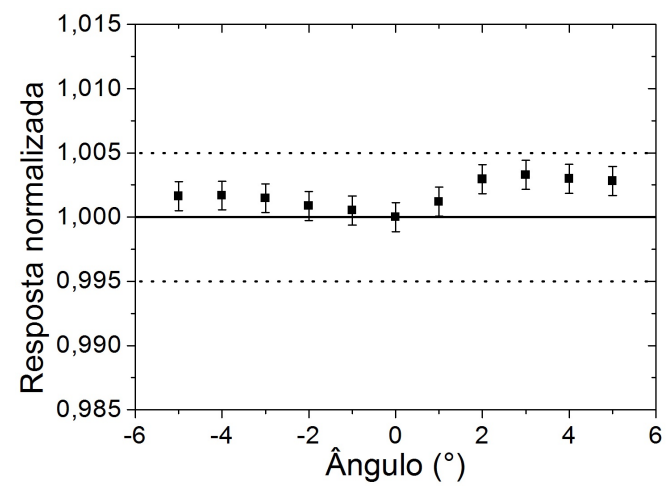

(c)

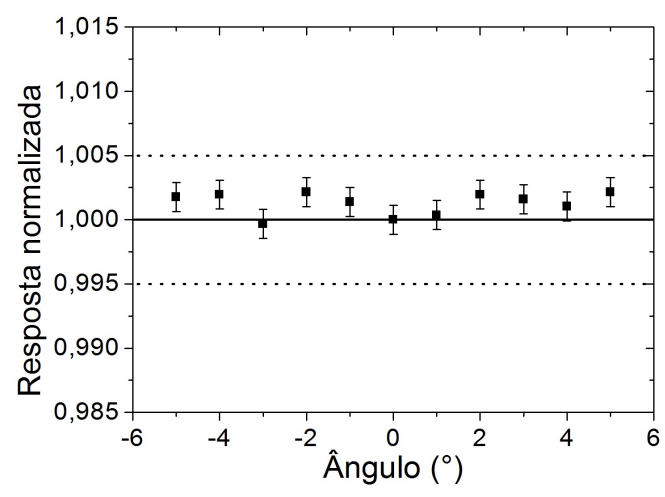

(b)

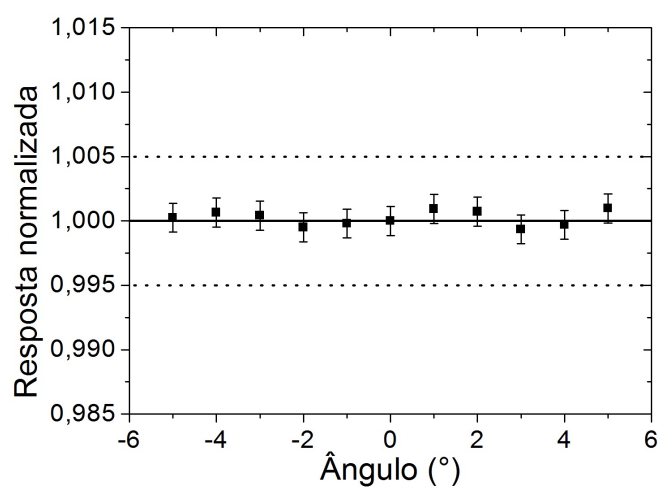

(d)

Figura 6.27: Dependência angular obtida no feixe de ${ }^{60}$ Co para as câmaras de ionização (a) G1, (b) G2 e (c) CG e (d) PTW. As linhas pontilhadas mostram os limites recomendados pela IEC 60731 [IEC (2011)]. 


\section{Capítulo 7}

\section{Resultados e Discussão: Avaliação das Câmaras de Ionização por Simulação de Monte Carlo}

Neste capítulo são apresentadas as simulações de Monte Carlo que foram empregadas para determinar a influência dos diversos componentes das câmaras de ionização L1, L2, PPTC e CG, utilizadas em radiodiagnóstico convencional e TC nas suas respostas. Para as câmaras de ionização de grafite G1 e G2, as simulações foram utilizadas para determinar os fatores de correção com o objetivo da obtenção das taxas de kerma no ar de feixes de ${ }^{60} \mathrm{Co}$.

\subsection{Simulação de Monte Carlo das Câmaras de Io- nização L1, L2, PPTC e CG em Feixes Padro- nizados de Radiação $\mathrm{X}$}

O primeiro estudo aplicando a técnica de Monte Carlo foi para avaliar a utilização do espectro de radiação X fornecido pelo PTB, para representar as qualidades de radiação X do LCI nas simulações. O código de Monte Carlo foi utilizado para determinar os fatores de correção do teste de dependência energética da câmara de ionização L2. Estes fatores de correção foram comparados com os fatores obtidos experimentalmente. Após a comparação dos resultados, observou-se uma boa concordância entre eles; sendo assim, o espectro do PTB foi adotado durante as simulações. O código de Monte Carlo foi utilizado para se determinar a influência de alguns componentes das câmaras de ionização L1, L2 e PPTC nas suas respostas. 
A câmara CG foi simulada para estudar a distribuição de energia em seu volume sensível e a influência do eletrodo coletor na sua resposta nas qualidades de radiodiagnóstico convencional.

\subsubsection{Estudo da Influência dos Componentes das Câmaras de Ionização L1 e L2 nas suas Respostas}

Para estudar a aplicação dos espectros do PTB para representar os espectros do LCI nas simulações de Monte Carlo, foi proposta uma comparação entre resultados experimentais e simulação. O experimento escolhido foi a dependência energética de uma câmara de ionização tipo lápis em feixes padrões de TC. Os fatores de correção obtidos experimentalmente foram comparados com os valores obtidos nas simulações.

A câmara de ionização L2 foi calibrada experimentalmente utilizando a câmara padrão secundário Radcal RC3CT e as qualidades de radiação X de TC. A dependência energética também foi avaliada com simulação de Monte Carlo utilizando-se o código PENELOPE, pois ele é mais apropriado que o código EGSnrc para modelar geometrias mais complexas, como o conector BNC. Os parâmetros de simulação utilizados em todos os estudos com o código de Monte Carlo PENELOPE são listados na Tabela 7.1. Durante as simulações, para a determinação dos fatores de correção do teste de dependência energética, foram utilizados dois espectros, um do PTB [BÜERMANN (2012)] e um obtido por meio do software SpekCalc [POLUDNIOWSKI et al. (2009)]. Este software gerou o espectro de acordo com as características do equipamento de raios X do LCI. A Tabela 7.2 mostra os fatores de correção obtidos experimentalmente (Tabela 6.13) e com a simulação.

As diferenças máximas obtidas entre o resultado experimental e da simulação foram de 2,8\% (RQT10) e 2,9\% (RQT8) para o espectro do PTB e do SpekCalc, respectivamente. Porém, considerando que: (1) o sistema de referência utilizado para estabelecer as qualidades de radiação de radiodiagnóstico convencional e de TC no LCI foi calibrado no PTB e (2) as qualidades de radiação do PTB e do LCI foram estabelecidas com os mesmos valores de camadas semirredutoras, segundo recomen- 
Tabela 7.1: Parâmetros de controle da simulação de Monte Carlo com código PENELOPE utilizados neste trabalho.

\begin{tabular}{cc}
\hline Parâmetro de Controle & Valor \\
\hline Energia de corte para fótons & $1 \mathrm{keV}$ \\
Energia de corte para $e^{+}$e $e^{-}$ & $1 \mathrm{keV}$ \\
$C_{1}$ & 0,05 \\
$C_{2}$ & 0,05 \\
$W_{\mathrm{CC}}$ & $0,1 \mathrm{keV}$ \\
$W_{\mathrm{CR}}$ & $1,0 \mathrm{keV}$ \\
Número de histórias simuladas & $10^{10}$ \\
\hline
\end{tabular}

Tabela 7.2: Fatores de correção experimentais e simulados da câmara de ionização L2 nas qualidades de radiação de $T C$.

\begin{tabular}{cccc}
\hline Qualidade & Fatores de & \multicolumn{2}{c}{ Simulação de Monte Carlo } \\
\cline { 3 - 4 } da & Correção & Espectro do & Espectro do \\
Radiação & (Experimental) & PTB & SpekCalc \\
\hline RQT8 & $0,979 \pm 0,021$ & $1,002 \pm 0,015$ & $1,008 \pm 0,015$ \\
RQT9 & $1,000 \pm 0,021$ & $1,000 \pm 0,015$ & $1,000 \pm 0,015$ \\
RQT10 & $1,026 \pm 0,019$ & $0,998 \pm 0,015$ & $1,001 \pm 0,015$ \\
\hline
\end{tabular}

dações da norma IEC 61267 [IEC (2005)], o espectro do PTB foi utilizado para analisar o efeito de alguns componentes das câmaras de ionização, caracterizadas neste trabalho, nas suas respostas.

As geometrias das câmaras de ionização L1 e L2 com todos os componentes são mostradas nas Figuras 7.1(a) e 7.2(a), respectivamente. Os componentes das câmaras de ionização L1 e L2 estudados foram: conector de BNC (Figuras 7.1(b) e 7.2(b)), eletrodo coletor (Figuras 7.1(c) e 7.2(c)), corpo de PMMA (Figuras 7.1(d) e 7.2(d)) e substituição do material da parede de PVC por PMMA. 

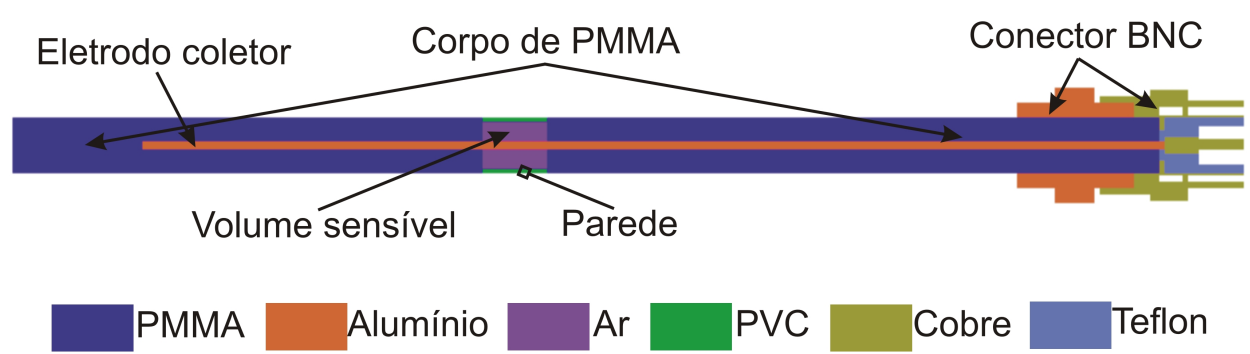

(a)
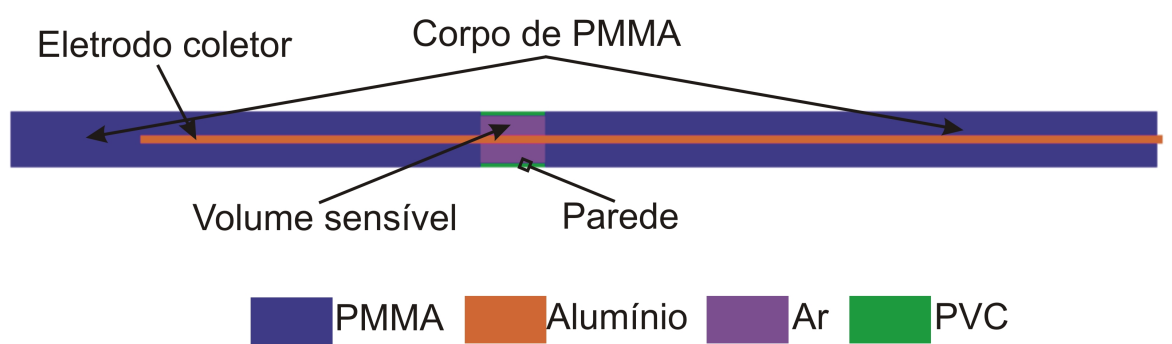

(b)
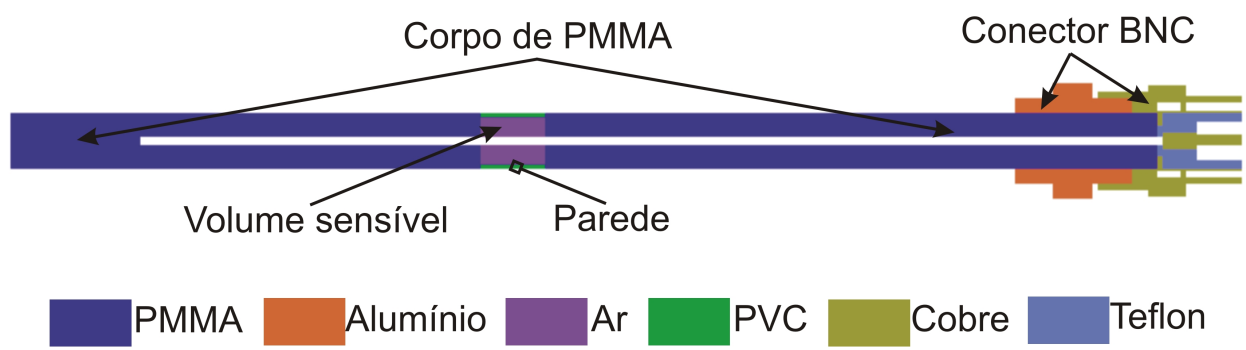

(c)

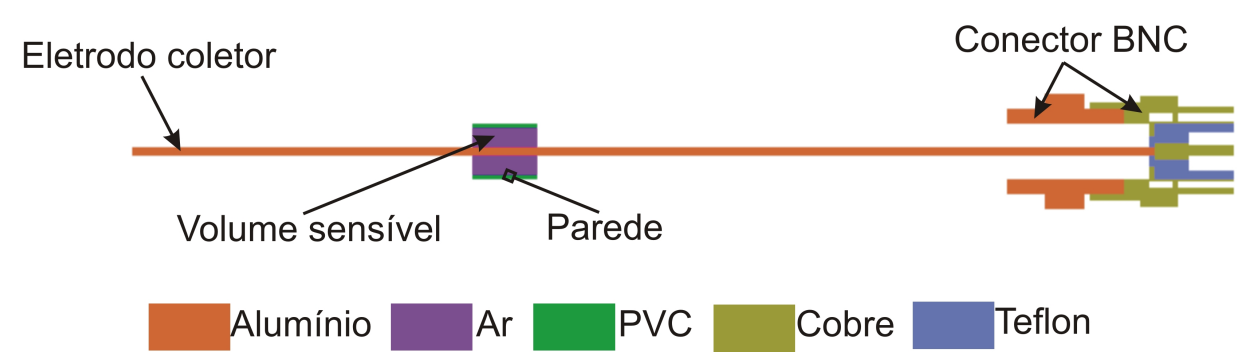

(d)

Figura 7.1: Geometria utilizada no arquivo de entrada nas simulações de Monte Carlo com o código PENELOPE da câmara de ionização L1 (a) completa, (b) sem o conector $B N C$, (c) sem o eletrodo coletor e (d) sem o corpo de PMMA. 


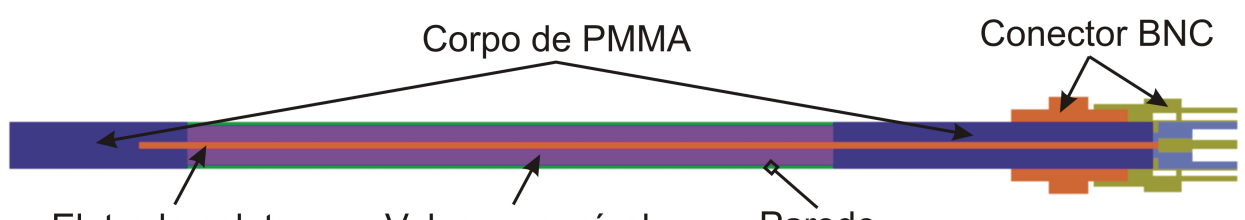

Eletrodo coletor Volume sensível Parede

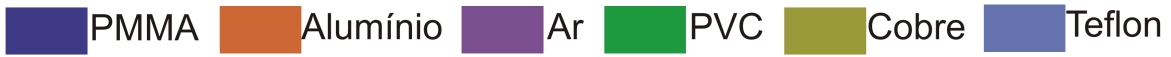

(a)

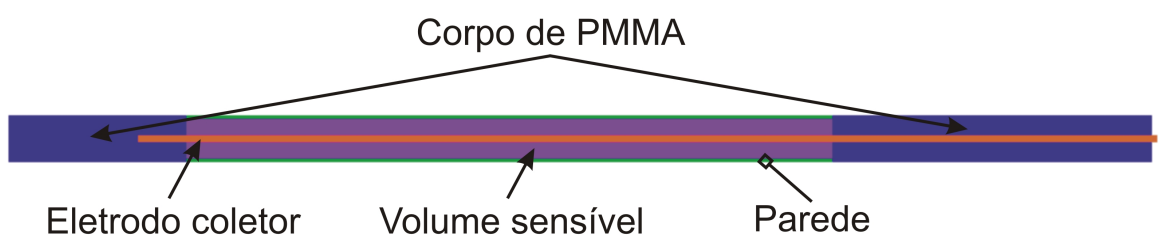

$\begin{array}{llll}\text { PMMA } & \text { Alumínio } \quad \text { Pr }\end{array}$

(b)

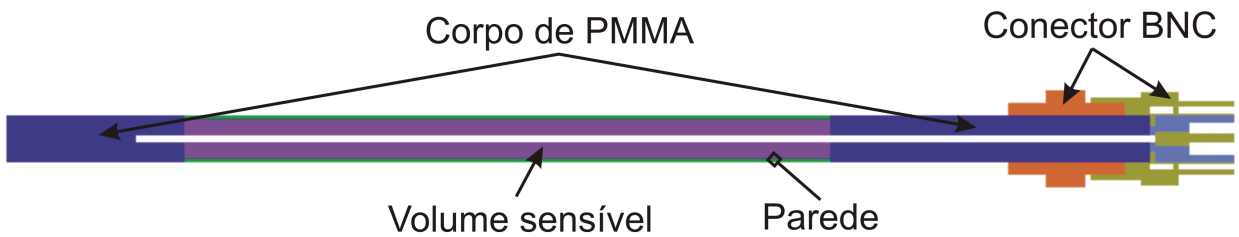

PMMA Alumínio Ar PVC Cobre Teflon

(c)
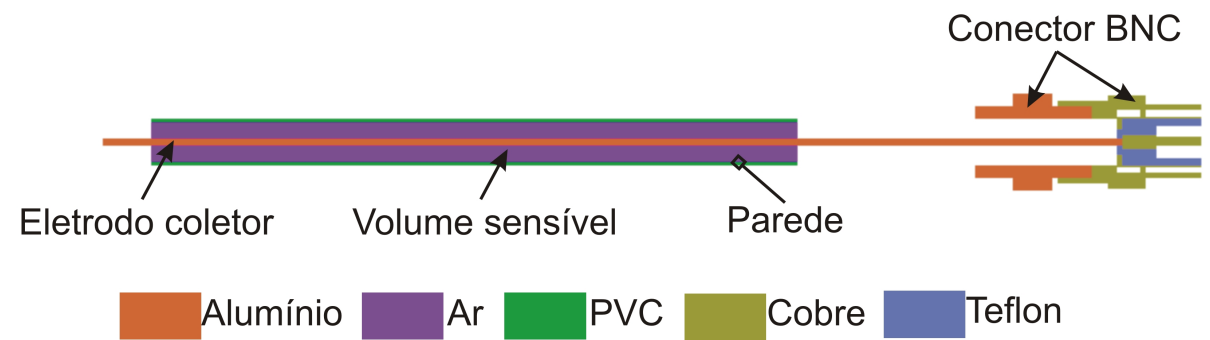

(d)

Figura 7.2: Geometria utilizada no arquivo de entrada nas simulações de Monte Carlo com o código PENELOPE da câmara de ionização L2 (a) completa, (b) sem o conector $B N C$, (c) sem o eletrodo coletor e (d) sem o corpo de PMMA.

Os componentes das câmaras de ionização L1 e L2 foram estudados para se avaliar suas respectivas influências sobre a energia depositada no volume sensível das câmaras de ionização, utilizando a qualidade de radiação RQT9. A Tabela 7.3 mostra os resultados obtidos. As razões entre as energias depositadas foram calculadas dividindo-se a resposta da câmara sem o componente em estudo e a resposta com a câmara completa, exceto para a parede de PMMA no lugar de PVC. Neste caso, a 
razão foi obtida pela divisão entre a resposta da câmara com parede de PMMA e a resposta com a parede de PVC. O material do componente em estudo foi substituído por ar (mesmo material em torno da câmara de ionização) durante as simulações.

Tabela 7.3: Influência dos componentes das câmaras de ionização L1 e L2 na energia depositada em seus volumes sensiveis para a qualidade de radiação RQT9.

\begin{tabular}{ccc}
\hline Componente Estudado & Razões entre as Energias & Depositadas \\
\cline { 2 - 3 } & L1 & L2 \\
\hline Conector BNC & $0,99 \pm 0,01$ & $1,00 \pm 0,01$ \\
Eletrodo coletor & $0,89 \pm 0,01$ & $0,91 \pm 0,01$ \\
Corpo de PMMA & $0,99 \pm 0,01$ & $1,00 \pm 0,01$ \\
PMMA no lugar de PVC & $0,53 \pm 0,01$ & $0,51 \pm 0,01$ \\
\hline
\end{tabular}

A partir dos resultados da Tabela 7.3, é possível observar que o conector BNC e o corpo de PMMA não têm influência significativa sobre as medições das câmaras de ionização L1 e L2. O estudo do conector foi importante, pois a sua posição (junto ao corpo da câmara de ionização) é diferente das demais câmaras de ionização comerciais onde o conector é ligado à câmara de ionização por meio de um cabo. Também pode-se observar que o eletrodo coletor de alumínio tem influência significativa na resposta das câmaras de ionização. Isto está relacionado ao fato de que os elétrons de recuo e os fotoelétrons, produzidos por interações de fótons com o eletrodo coletor de alumínio, contribuírem de forma significativa para a energia depositada em seus volumes sensíveis. É ainda possível verificar que a parede de PVC apresentou uma resposta maior em relação à parede de PMMA e isto se deve ao número atômico efetivo do PVC ser maior que o do PMMA.

\subsubsection{Estudo da Distribuição de Energia no Volume Sensí- vel da Câmara de Ionização CG e a Influência do seu Eletrodo Coletor nas suas Medições}

Para avaliar a nova configuração da câmara de ionização CG nas qualidades de diagnóstico convencional (eletrodo coletor no meio do volume sensível), algumas simulações foram feitas com a finalidade de se determinar a influência do eletrodo coletor da câmara de ionização na sua resposta. A geometria adotada durante as 
simulações com o código PENELOPE é apresentada na Figura 7.3. Foi também avaliada a distribuição de energia no volume sensível e para isso o volume sensível foi dividido em três partes, como mostra a Figura 7.3(a). As simulações foram realizadas utilizando-se os espectros das qualidades de radiação X do PTB [BÜERMANN (2012)].

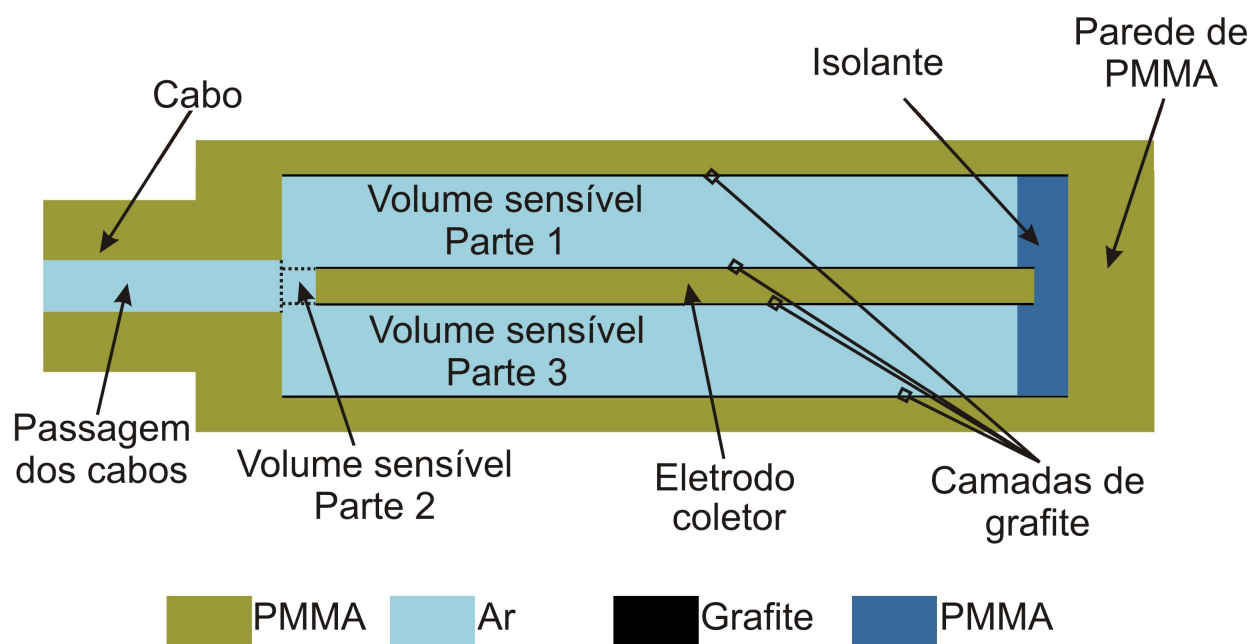

(a)

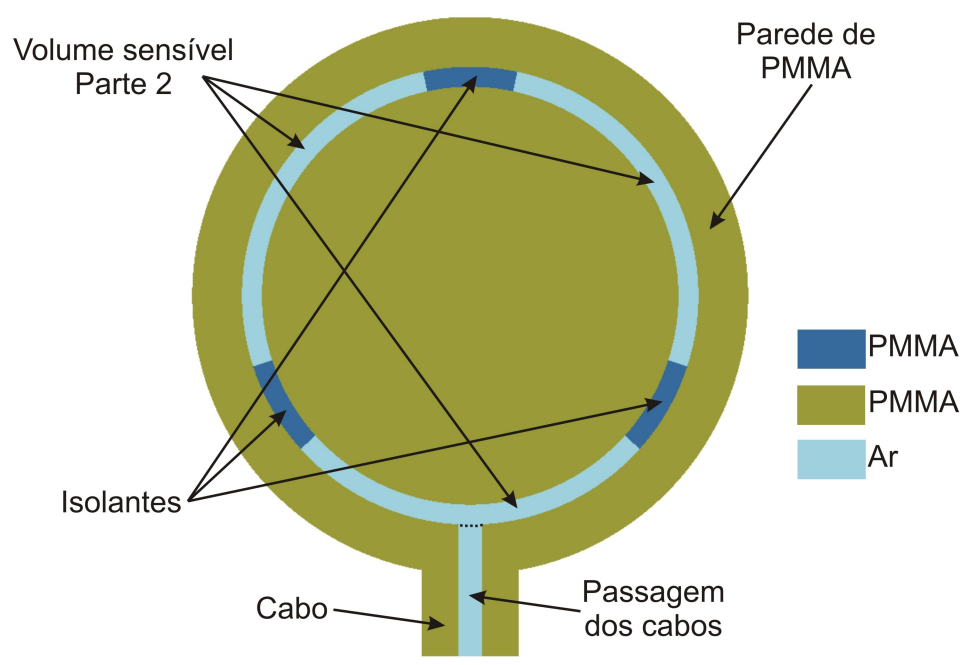

(b)

Figura 7.3: Geometria da câmara CG utilizada no arquivo de entrada nas simulaçôes de Monte Carlo com o código PENELOPE (a) corte axial e (b) visão frontal.

A Tabela 7.4 mostra os resultados obtidos, e é possível observar que a máxima diferença na energia depositada foi de 1,6\% entre as partes 1 e 3 do volume sensível nas qualidades de radiação RQR5, RQR8 e RQR10. É esperado que os valores de energia depositada nestas duas partes do volume sensível sejam o mais próximo 
possível, pois os volumes sensíveis são iguais. Diferenças significativas de energia depositada entre estas partes do volume sensível apontam para uma grande influência do eletrodo coletor. Também foi avaliado o efeito do eletrodo coletor para a qualidade de radiação RQR5. A Figura 7.4 mostra a geometria de Monte Carlo adotada para o estudo do eletrodo coletor. O efeito do eletrodo coletor obtido foi de apenas $0,34 \%$; isto se deve ao fato que uma câmara de ionização com uma construção homogênea, parede e eletrodo coletor de mesmo material apresentar a vantagem de não possuir uma influência significativa do eletrodo coletor nas suas medições [MUIR e ROGERS (2011)].

Tabela 7.4: Distribuição da energia depositada nas três partes distintas do volume sensivel da câmara de ionização $C G$ nas qualidades de radiação $R Q R$.

\begin{tabular}{cccc}
\hline $\begin{array}{c}\text { Qualidade } \\
\text { de }\end{array}$ & \multicolumn{3}{c}{$\begin{array}{c}\text { Fração da Energia Depositada em Cada } \\
\text { Parte do Volume Sensível (\%) }\end{array}$} \\
\cline { 2 - 4 } Radiação & Parte $\mathbf{1}$ & Parte 2 & Parte 3 \\
\hline RQR3 & 48,8 & 2,6 & 48,6 \\
RQR5 & 49,1 & 2,6 & 48,3 \\
RQR8 & 49,1 & 2,6 & 48,3 \\
RQR10 & 49,1 & 2,6 & 48,3 \\
\hline
\end{tabular}

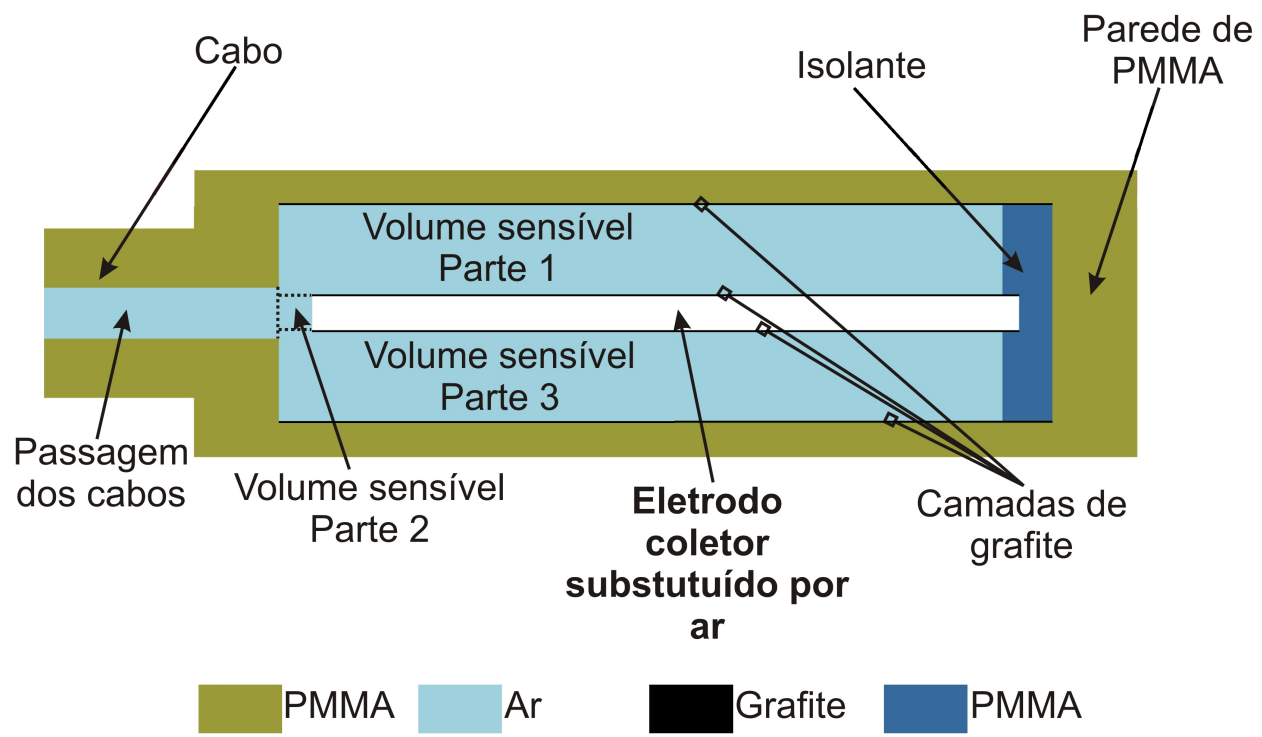

Figura 7.4: Geometria utilizada no arquivo de entrada nas simulações de Monte Carlo com o código PENELOPE da câmara de ionização CG sem o eletrodo coletor. 


\subsubsection{Estudo da Influência dos Componentes da Câmara de Ionização PPTC na sua Resposta}

A câmara de ionização PPTC apresenta diversas diferenças em relação às câmaras de ionização tipo lápis, normalmente utilizadas para dosimetria em TC. Com a impossibilidade de se avaliar estas diferenças experimentalmente, simulações de Monte Carlo com o código PENELOPE foram adotadas para se estudar a influência de alguns componentes na sua resposta, utilizando a qualidade de radiação RQT9. A geometria da câmara de ionização PPTC com todos os componentes adotada nas simulações com o código PENELOPE é apresentada na Figura 7.5. Os componentes estudados foram: cabos (Figura 7.6(a)), isolante (Figura 7.6(b)), corpo de PMMA (Figura 7.6(c)), eletrodo coletor (Figura 7.7(a)), anel de guarda (Figura 7.7(b)) e parafusos (Figura 7.7(c)). 

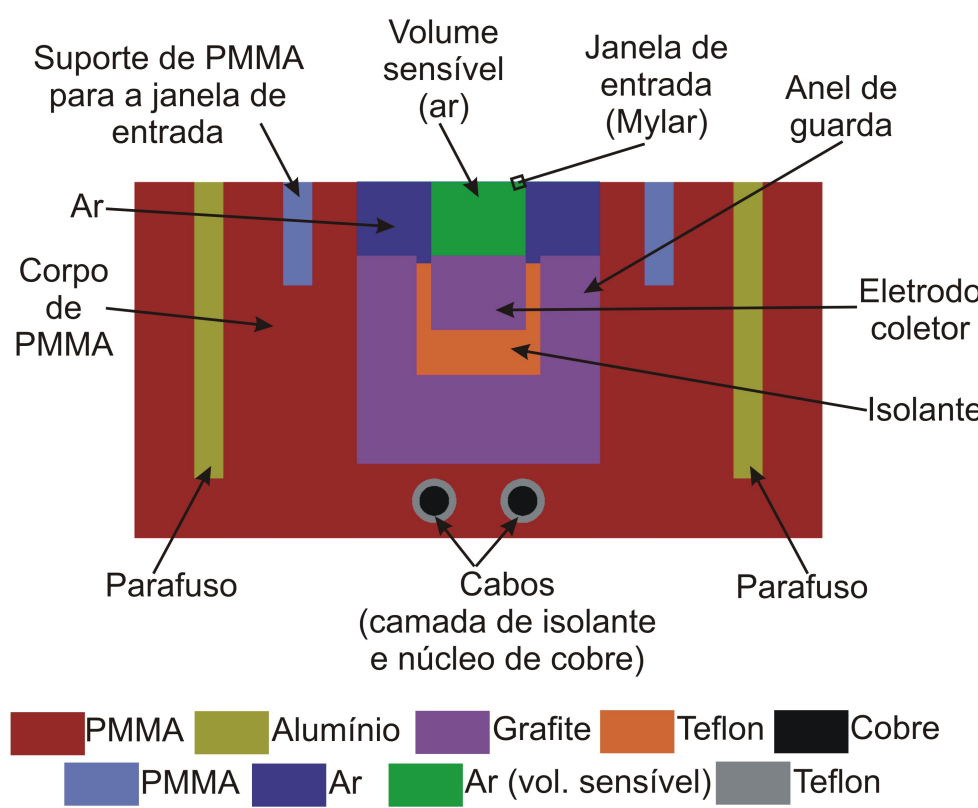

(a)

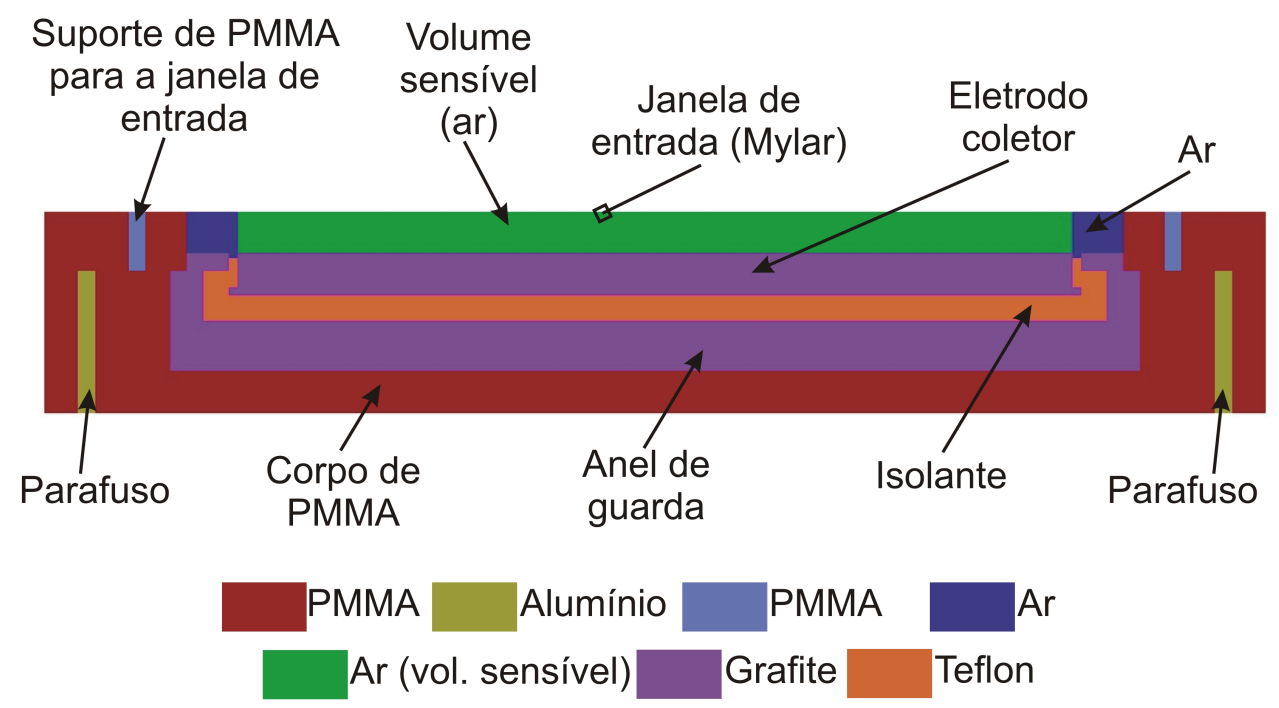

(b)

Figura 7.5: Geometria utilizada no arquivo de entrada nas simulações de Monte Carlo com o código PENELOPE da câmara de ionização PPTC com todos componentes (a) corte axial e (b) corte lateral. 


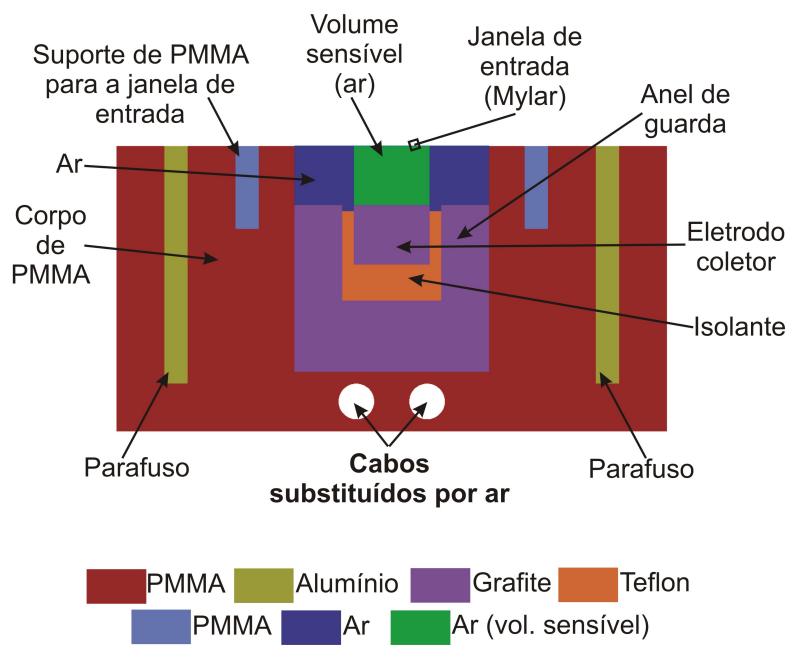

(a)

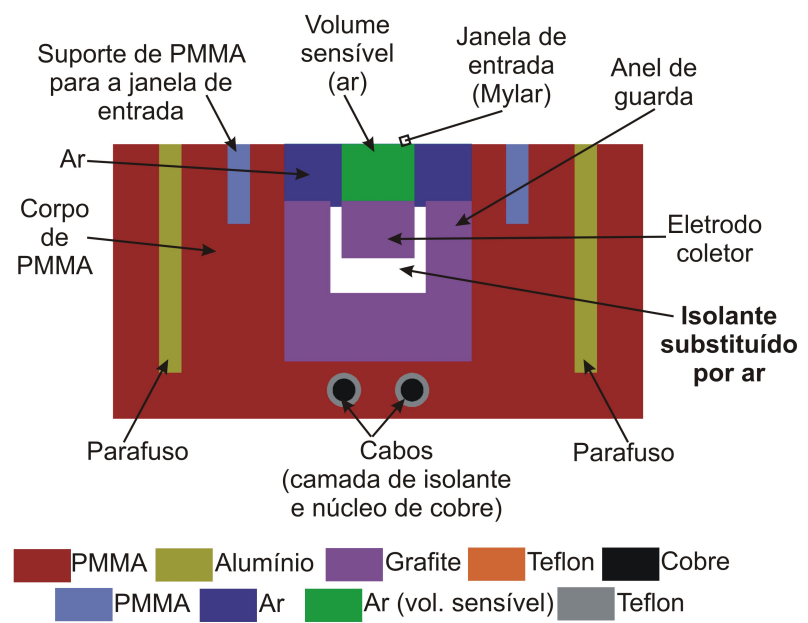

(b)

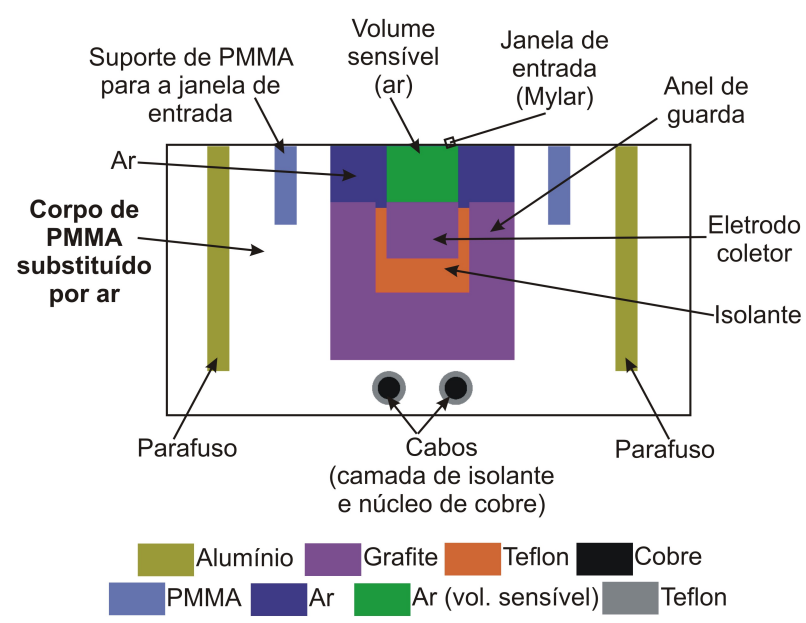

(c)

Figura 7.6: Geometria utilizada no arquivo de entrada nas simulações de Monte Carlo com o código PENELOPE da câmara de ionização PPTC (a) sem os cabos, (b) sem o isolante e (c) sem o corpo de PMMA. Os componentes em estudo foram destacados em negrito. 


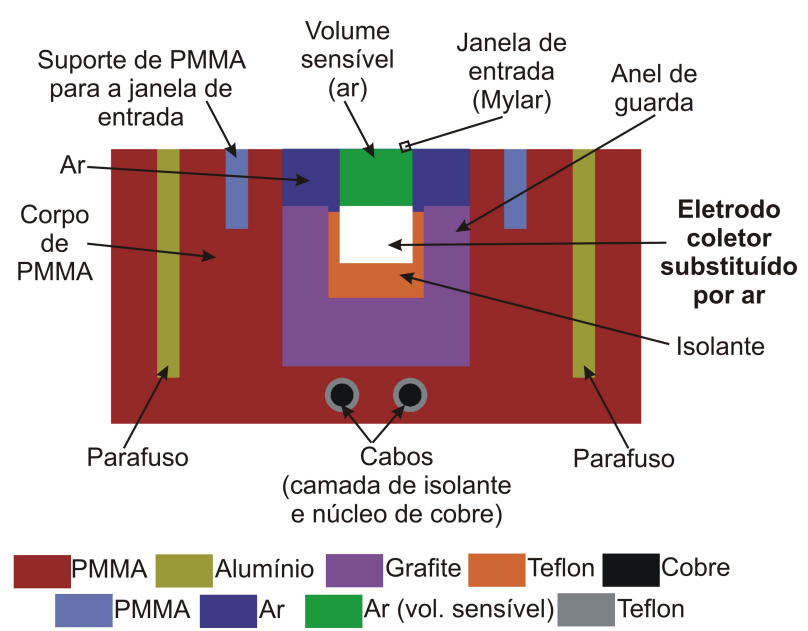

(a)

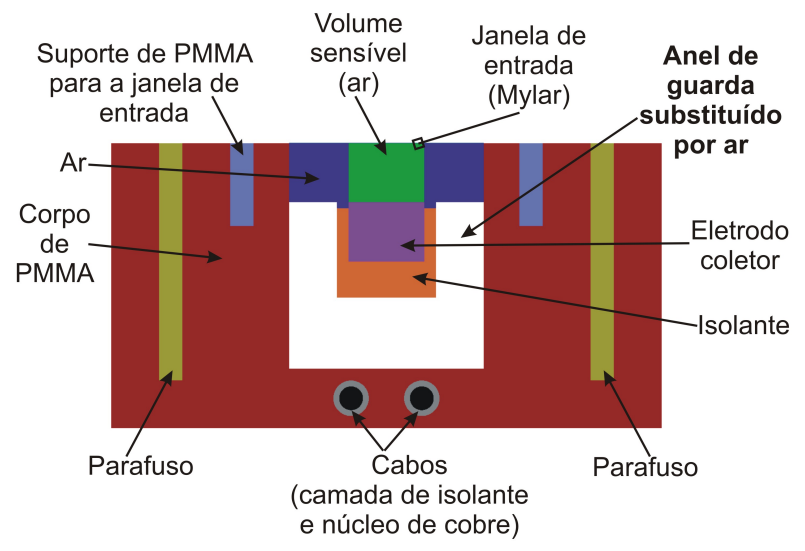

PMMA Alumínio Grafite Teflon Cobre

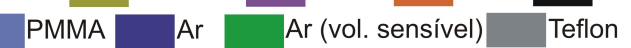

(b)

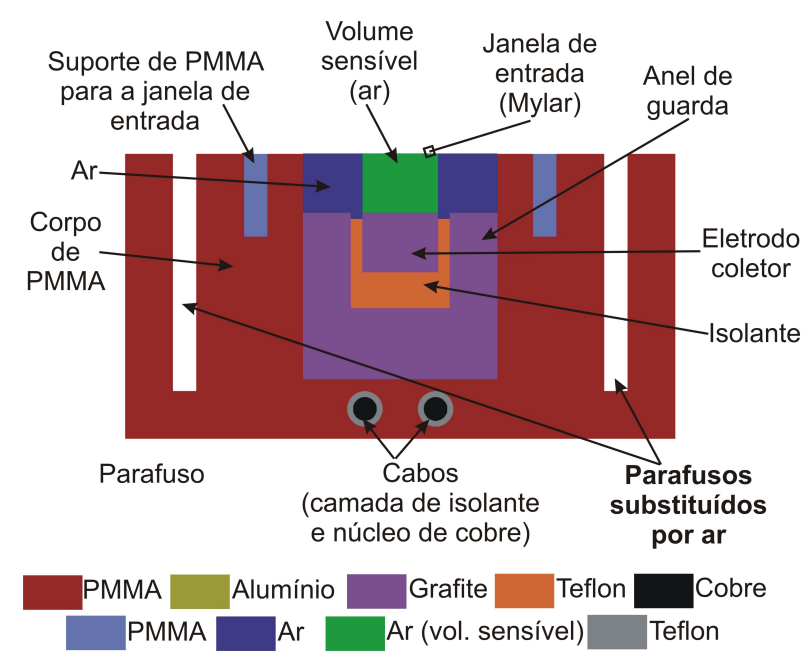

(c)

Figura 7.7: Geometria utilizada no arquivo de entrada nas simulações de Monte Carlo com o código PENELOPE da câmara de ionização PPTC (a) sem eletrodo coletor, (b) sem $o$ anel de guarda e (c) sem os parafusos. Os componentes em estudo foram destacados em negrito. 
Os resultados das influências dos componentes da câmara de ionização PPTC na sua resposta são listados na Tabela 7.5.

Tabela 7.5: Influência dos componentes da câmara de ionização PPTC na sua resposta utilizando a qualidade de radiação RQT9.

\begin{tabular}{cc}
\hline Componente Estudado & Influência (\%) \\
\hline Cabos & 0,4 \\
Isolante & 3,0 \\
Corpo de PMMA & 10,7 \\
Eletrodo coletor & 13,3 \\
Anel de guarda & 4,0 \\
Parafusos & 0,5 \\
\hline
\end{tabular}

O eletrodo coletor apresentou a maior influência (13,3\%) na resposta da câmara de ionização PPTC. Esta influência não é tão significativa quando comparada com a influência de um eletrodo de alumínio. O efeito do eletrodo coletor de alumínio pode chegar a 50\% em alguns casos [MUIR e ROGERS (2011)]. A influência do eletrodo coletor de 13,3\% na resposta da câmara de ionização se deve ao fato de ele ter um tamanho significativo, uma vez que ele cobre toda a área abaixo do volume sensível e sua influência é principalmente devido à radiação espalhada. Esta justificativa também se aplica para outros componentes que estão próximos ao volume sensível, como é o caso do isolante, corpo de PMMA e anel de guarda. Como os cabos e parafusos estão distantes do volume sensível suas influências na resposta da câmara de ionização foram muito pequenas.

Para estudar a influência de diferentes materiais da câmara de ionização PPTC na sua resposta, utilizou-se também a simulação de Monte Carlo, que foi empregada para avaliar o uso de alumínio como material do eletrodo coletor, baquelite e PMMA como material do isolante, alumínio como material da janela de entrada e PVC como material do corpo da câmara de ionização. Os resultados das influências dos componentes da câmara de ionização constituídos de materiais diferentes na sua resposta são apresentados na Tabela 7.6.

Os resultados da Tabela 7.6 mostram que a utilização de alumínio como mate- 
Tabela 7.6: Influência dos componentes da câmara de ionização PPTC constituídos de materiais diferentes na sua resposta.

\begin{tabular}{ccc}
\hline Material & Material Empregado & Influência \\
Modificado & no Protótipo PPTC & $(\boldsymbol{\%})$ \\
\hline Eletrodo coletor de alumínio & Grafite & 98,4 \\
Isolante de baquelite & Teflon & 1,1 \\
Isolante de PMMA & Teflon & 2,3 \\
Janela de entrada de alumínio & Mylar & 137,9 \\
Corpo de PVC & PMMA & 58,8 \\
\hline
\end{tabular}

rial do eletrodo coletor e da janela de entrada apresenta uma grande influência na resposta da câmara de ionização. Isto é causado principalmente pelos elétrons de recuo e os fotoelétrons, gerados pelas interações de fótons com o eletrodo coletor de alumínio, que contribuem de forma significativa para a energia depositada no volume sensível. Além disso, o eletrodo coletor da câmara de ionização não é apenas um fio, mas uma placa cobrindo toda parte inferior do volume sensível. Por isso, é esperado que a seleção do material apresente uma influência significativa na resposta da câmara de ionização. A mesma justificativa se aplica para o material da janela de entrada.

O corpo de PVC apresentou uma influência maior em relação ao corpo de PMMA na resposta da câmara de ionização. Isto se deve ao número atômico efetivo do PVC ser maior que o do PMMA para interações com fótons. A utilização de diferentes materiais isolantes não apresentou muita diferença em relação ao Teflon, mas é importante notar que Teflon é melhor isolante que o PMMA. O isolante de baquelite apresentou uma influência de apenas 1,1\% na resposta da câmara de ionização, menor que o isolante de Teflon, mas é mais difícil de ser usinado; sendo assim, para o projeto desta câmara de ionização o Teflon foi a escolha mais apropriada.

Para completar o estudo por meio de simulação de Monte Carlo, também foi estudada a influência de disposições geométricas diferentes do projeto original da câmara de ionização PPTC na sua resposta, como espessura do eletrodo coletor, do corpo de PMMA, dos isolantes e o número de cabos dentro da câmara de ionização. 
Os resultados são apresentados na Tabela 7.7.

Tabela 7.7: Influência de configurações geométricas diferentes da câmara de ionização PPTC na sua resposta.

\begin{tabular}{cccc}
\hline $\begin{array}{c}\text { Configuração } \\
\text { Geométrica } \\
\text { Estudada }\end{array}$ & $\begin{array}{c}\text { Geometria } \\
\text { Empregada no } \\
\text { Protótipo PPTC }\end{array}$ & $\begin{array}{c}\text { Modificação no } \\
\text { Protótipo PPTC }\end{array}$ & $\begin{array}{c}\text { Influência } \\
\mathbf{( \% )}\end{array}$ \\
\hline $\begin{array}{c}\text { Espessura do } \\
\text { eletrodo coletor } \\
\text { Comprimento lateral } \\
\text { do corpo de PMMA } \\
\text { Espessura }\end{array}$ & $5,0 \mathrm{~mm}$ & $2,5 \mathrm{~mm}$ & $-0,5$ \\
$\begin{array}{c}\text { do isolante } \\
\text { Número de cabos }\end{array}$ & $1,0 \mathrm{~mm}$ & $30,8 \mathrm{~mm}$ & $-4,3$ \\
\hline
\end{tabular}

A influência do tamanho do corpo de PMMA apresentou a maior influência na resposta da câmara de ionização entre as diferentes configurações geométricas estudadas. Como o feixe de radiação X irradia todo o dosímetro, a utilização de um corpo de PMMA menor reduziria a influência da radiação espalhada no volume sensível da câmara de ionização. Esta nova configuração poderá ser adotada para construção de novos protótipos.

A utilização de um eletrodo coletor de espessura menor que o utilizado na confecção da câmara de ionização levou a uma redução de apenas $0,5 \%$ do seu efeito na resposta da câmara de ionização. Além disso, um eletrodo de grafite com espessura menor que 5,0 mm deixa a câmara de ionização menos resistente, uma vez que o grafite é facilmente quebrável. A redução da espessura do isolante em torno do volume sensível também reduziu sua influência na resposta da câmara de ionização, mas um isolante de espessura de apenas $0,2 \mathrm{~mm}$ poderia aumentar a corrente de fuga. A utilização de 3 cabos ao invés de 2 não representou uma modificação significativa na resposta da câmara de ionização. Observa-se que a configuração da câmara de ionização com 3 cabos com conectores bananas no lugar de 2 cabos (1 cabo com conector BNC e 1 cabo com conector banana) apresentou uma maior influência na resposta da câmara de ionização, principalmente devido à maior quantidade de cobre. 


\subsection{Simulação de Monte Carlo das Câmaras de Io- nização CG, G1 e G2 em Feixes de ${ }^{60} \mathrm{Co}$}

Para avaliar a nova configuração da câmara de ionização CG nos feixes de ${ }^{60} \mathrm{Co}$, fez-se uso da simulação de Monte Carlo para estudar a influência de seus componentes nas suas medições. A simulação de Monte Carlo também foi empregada para determinar os fatores de correção das câmaras de ionização G1 e G2 com a finalidade de calcular a taxa de kerma no ar da fonte de ${ }^{60} \mathrm{Co}$ disponível no LCI.

\subsubsection{Simulação de Monte Carlo para Avaliação do Efeito de Alguns Componentes da Câmara de Ionização CG nas suas Medições}

Para avaliar a nova configuração da câmara de ionização CG nos feixes de ${ }^{60} \mathrm{Co}$, foram conduzidas simulações com o código PENELOPE para estudar a influência de alguns componentes da câmara de ionização na sua resposta. Foi também avaliada a distribuição de energia no volume sensível e para isso este foi dividido em três partes, como mostra a Figura 7.8: Partes 1, 2 e 3.

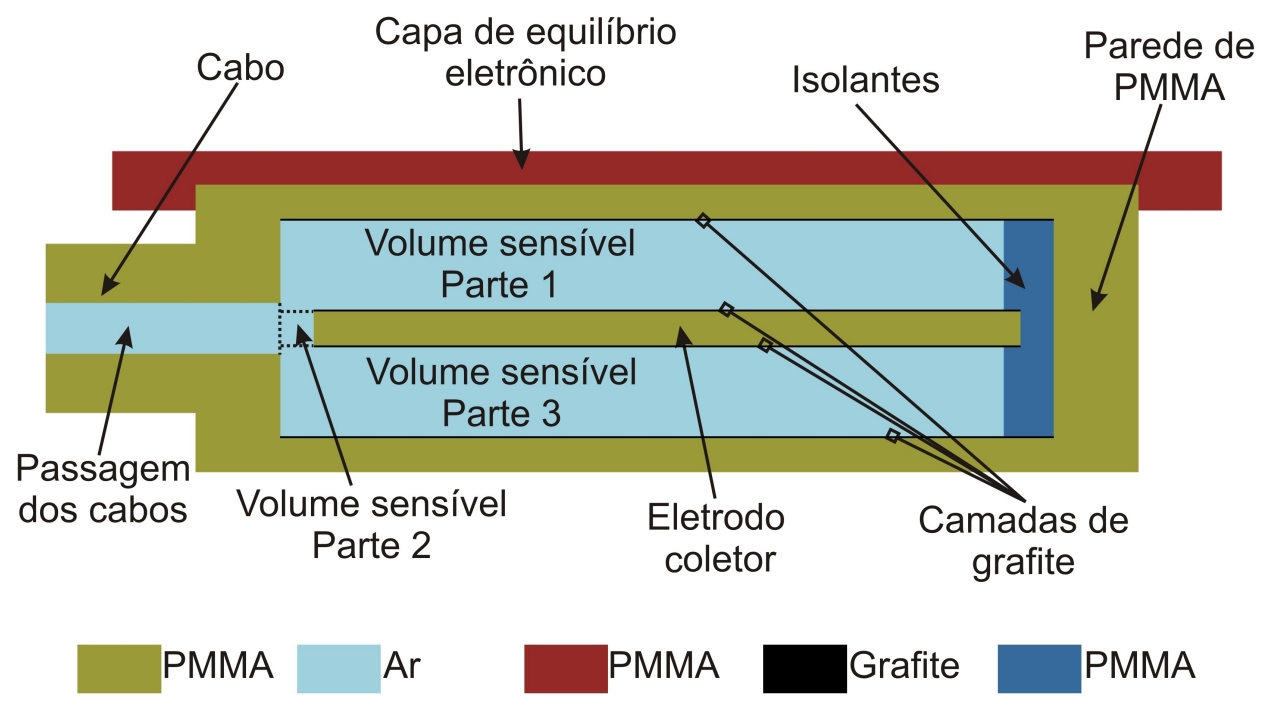

Figura 7.8: Corte axial da geometria da câmara CG utilizada no arquivo de entrada nas simulações de Monte Carlo com o código PENELOPE.

Durante estes estudos, foi utilizado o espectro de uma fonte de ${ }^{60} \mathrm{Co}$ [TEDGREN et al. (2010)]. O efeito de cada componente foi obtido como a razão entre a dose no volume sensível da câmara de ionização sem o componente estudado 
e a dose com a câmara completa. No feixe de ${ }^{60} \mathrm{Co}$, a influência dos componentes na resposta da câmara de ionização foi determinada nas três partes de volumes sensíveis. Os componentes da câmara CG analisados foram: eletrodo coletor (Figura 7.9(a)), isolantes (Figura 7.9(b)) e cabo (Figura 7.9(c)). 


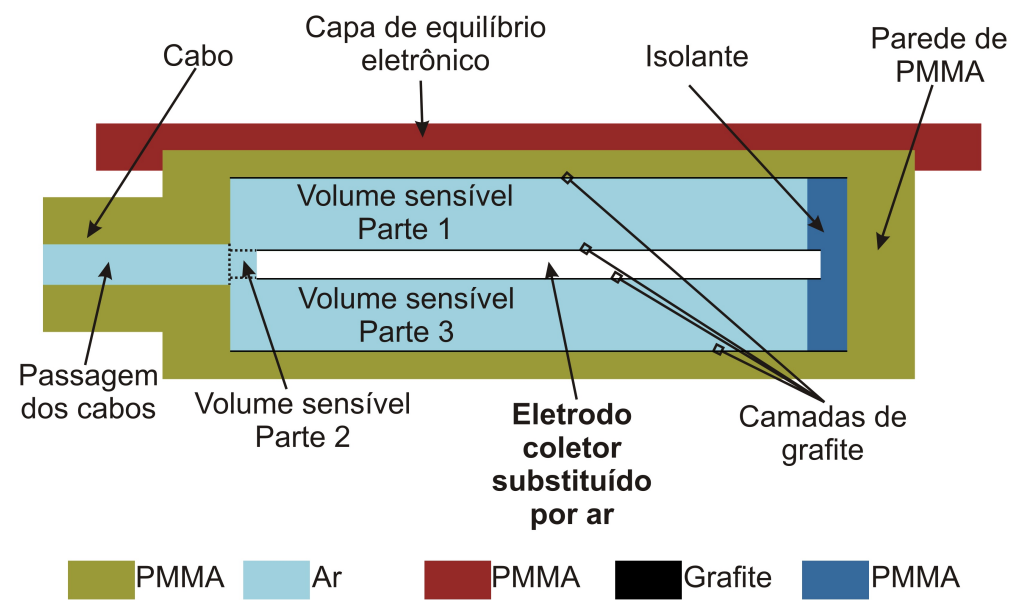

(a)

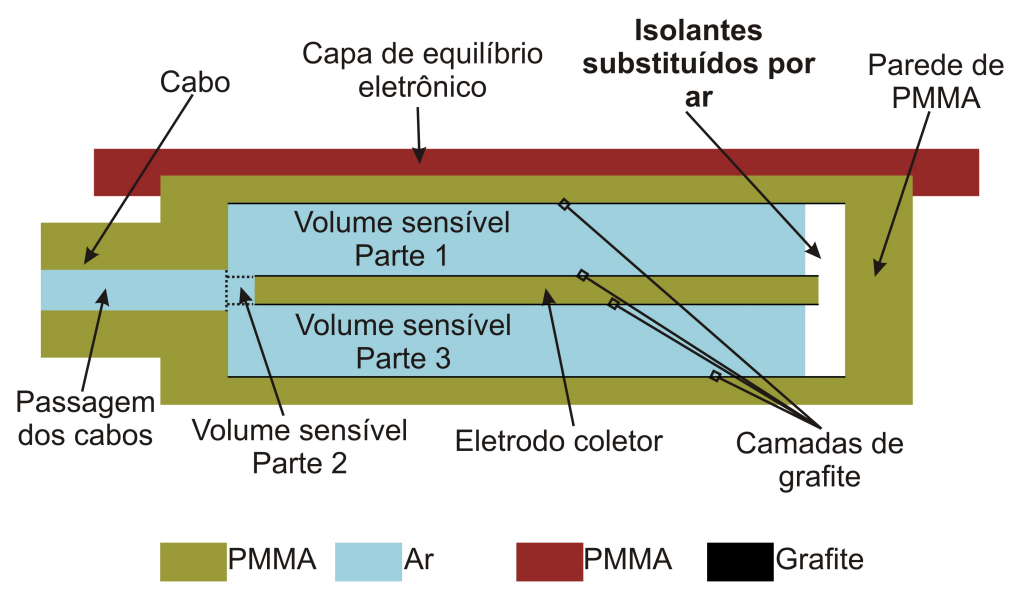

(b)

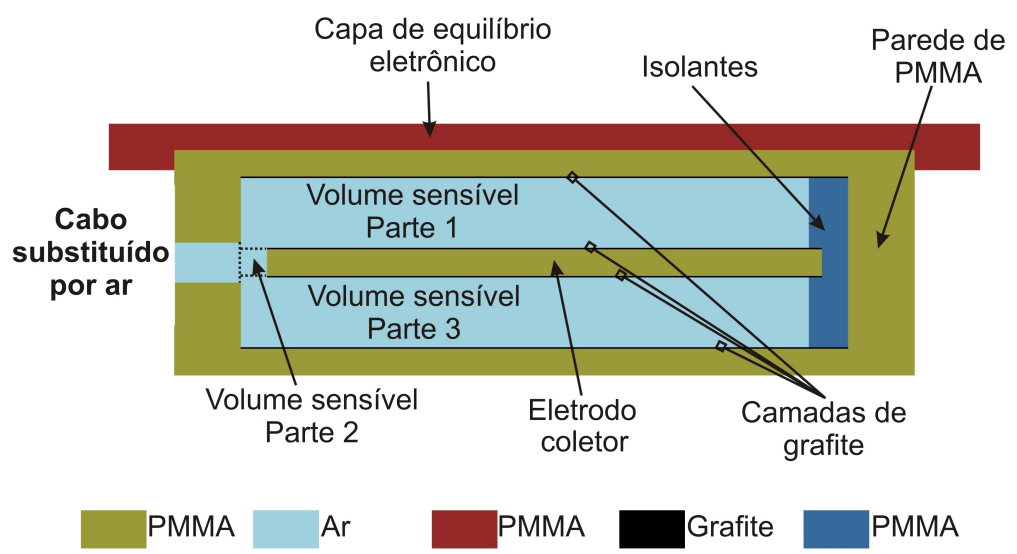

(c)

Figura 7.9: Geometria utilizada no arquivo de entrada nas simulações de Monte Carlo com o código PENELOPE da câmara de ionização CG (a) sem eletrodo coletor, (b) sem isolantes e (c) sem cabo. Os componentes estudados estão destacados em negrito.

Os resultados da influência dos componentes da câmara de ionização CG na sua resposta são mostrados na Tabela 7.8. É possível observar uma pequena influência do eletrodo coletor, e também foi observada uma diferença de apenas 0,06\% na 
distribuição de energia entre as partes 1 e 3 do volume sensível. Este resultado indica que a posição do eletrodo coletor, no meio do volume sensível, e o material (PMMA grafitado) não alteraram a energia depositada no volume sensível. Além disso, esta nova configuração do eletrodo coletor, melhorou o desempenho da câmara CG, pois o campo elétrico se tornou mais homogêneo no volume sensível.

Os isolantes apresentaram uma pequena influência na resposta da câmara de ionização. Isto se deve ao fato de eles serem muito pequenos e assim eles interferem pouco na resposta do detector. Como o cabo tem um tamanho considerável em relação ao tamanho da câmara de ionização, ele teve uma contribuição significativa sobre a sua resposta devido à radiação espalhada por ele, inviabilizando a sua utilização como um sistema padrão primário.

Tabela 7.8: Influência dos componentes da câmara de ionização CG na sua resposta, no feixe de ${ }^{60} \mathrm{Co}$, nas três partes distintas do volume sensivel.

\begin{tabular}{cccc}
\hline Componente & \multicolumn{3}{c}{ Influência (\%) } \\
\cline { 2 - 4 } Estudado & Parte & Parte & Parte $\mathbf{3}$ \\
\hline Eletrodo coletor & 2,5 & 2,7 & 2,2 \\
Isolantes & 0,1 & 0,7 & 0,2 \\
Cabo & 6,3 & 4,9 & 7,0 \\
\hline
\end{tabular}

\subsubsection{Determinação dos Fatores de Correção das Câmaras de Ionização G1 e G2 pelo Método de Monte Carlo para o Cálculo da Taxa de Kerma no Ar}

O cálculo de fatores de correção aplicados a câmaras de ionização é muito importante quando se necessita caracterizar uma câmara de ionização como um dosímetro padrão. Eles são parte fundamental na equação para determinação do kerma no ar $\left(K_{\mathrm{ar}}\right)$, como mostrado na Equação 4.9 .

Para determinar a taxa de kerma no ar (Equação 4.9) os fatores de correção foram calculados com o código de Monte Carlo EGSnrc, que é específico para determinação de fatores de correção para sistemas padrões primários. Os parâmetros de controle da simulação de Monte Carlo com código EGSnrc utilizados neste trabalho foram: energia de corte para partículas carregadas e para fótons igual a $512 \mathrm{keV}$ e 
número de partículas igual $1 \times 10^{9}$. O espectro da fonte de ${ }^{60}$ Co utilizado nas simulações foi fornecido por TEDGREN et al. (2010). Os fatores de correção do eletrodo coletor e do cabo foram calculados utilizando-se o código cavity/EGSnrc. A geometria da câmara de ionização com todos os componentes é mostrada na Figura 7.10(a) e dos componentes em estudo, eletrodo coletor e cabo, são apresentadas nas Figuras $7.10(\mathrm{~b})$ e $7.10(\mathrm{c})$, respectivamente. Os resultados obtidos nesta simulação são apresentados na Tabela 7.9.

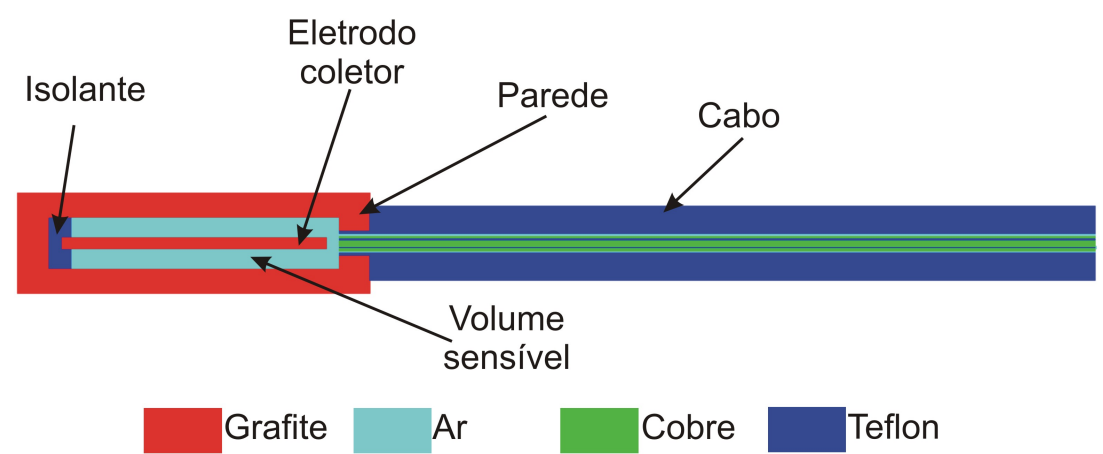

(a)

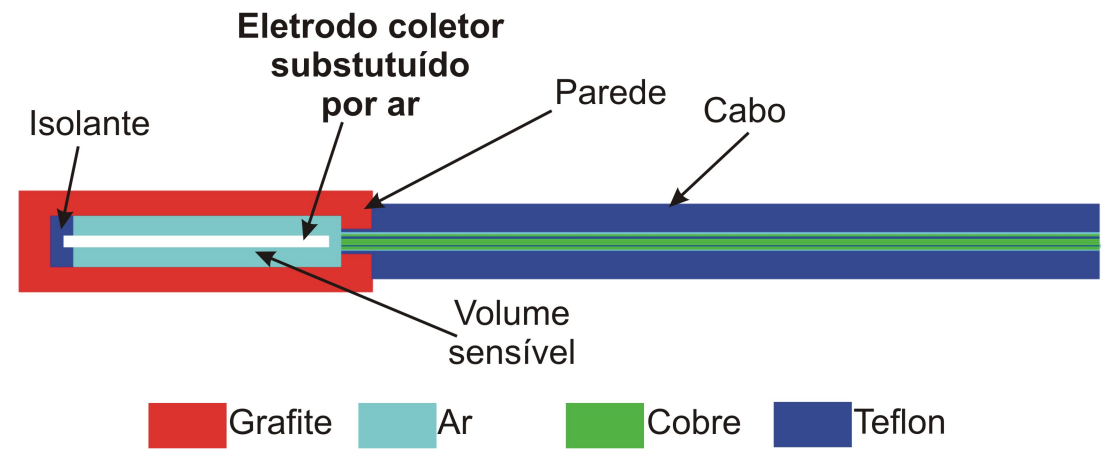

(b)

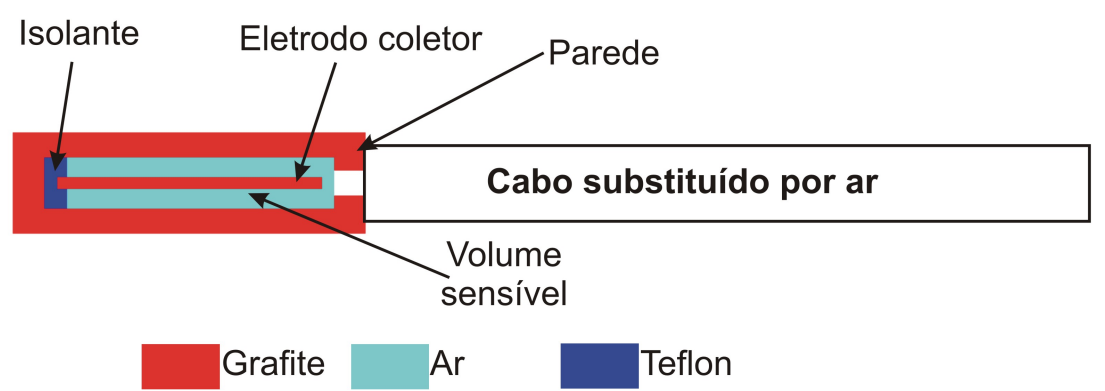

(c)

Figura 7.10: Geometria utilizada no arquivo de entrada nas simulações de Monte Carlo com o código EGSnrc da câmara de ionização G1 e G2 (a) completa, (b) sem eletrodo coletor e (c) sem cabo. Os componentes em estudo estão em negrito.

A partir dos dados apresentados na Tabela 7.9, é possível verificar que o eletrodo 
Tabela 7.9: Resultados da simulação de Monte Carlo para os termos envolvidos na determinação da taxa de kerma no ar

\begin{tabular}{ccc}
\hline Fator de & \multicolumn{2}{c}{ Câmara de Ionização } \\
\cline { 2 - 3 } Correção & G1 & G2 \\
\hline$\left(\bar{\mu}_{\text {en }} / \rho\right)_{\text {ar }}^{\text {parede }}$ & $0,9994 \pm 0,0014$ & $0,9994 \pm 0,0014$ \\
$\left(1-\bar{g}_{\text {ar }}\right)^{-1}$ & $1,0024 \pm 0,0004$ & $1,0024 \pm 0,0004$ \\
$(\bar{L} / \rho)_{\text {ar }}^{\text {parede }}$ & $1,0017 \pm 0,0003$ & $1,0018 \pm 0,0002$ \\
$k_{\text {an }}$ & $1,0015 \pm 0,0021$ & $0,9978 \pm 0,0017$ \\
$k_{\text {parede }}$ & $1,0051 \pm 0,0002$ & $1,0051 \pm 0,0001$ \\
$k_{\text {elec }}$ & $1,0015 \pm 0,0011$ & $0,9998 \pm 0,0008$ \\
$k_{\text {cabo }}$ & $1,0013 \pm 0,0044$ & $0,9993 \pm 0,0024$ \\
\hline
\end{tabular}

coletor $\left(k_{\text {elec }}\right)$ tem uma influência muito pequena sobre a resposta das câmaras de ionização G1 e G2, e isto se deve ao fato do eletrodo coletor e a parede serem feitos de mesmo material [MUIR e ROGERS (2011)]. Além do eletrodo coletor, a parede $\left(k_{\text {parede }}\right)$ também tem uma pequena influência sobre as respostas das novas câmaras de ionização. Portanto, estes dosímetros possuem espessura das paredes suficiente para excluir as partículas secundárias com energias mais altas produzidas pela interação da radiação com outro meio, e, além disso, esta espessura é suficiente para a obtenção de equilíbrio eletrônico, com um efeito muito pequeno nas medições das câmaras de ionização. O cabo também apresentou um efeito insignificante nas medições das câmaras de ionização; isto é esperado, pois o cabo foi feito de Teflon, que apresentou uma contribuição máxima de 0,13\% (G1).

Os resultados dos parâmetros envolvidos na determinação da taxa de kerma no ar foram comparados com os parâmetros determinados por dois laboratórios padrões primários (BIPM e PTB). Para esta comparação foram utilizadas as câmaras de ionização G1 e G2, desenvolvidas neste trabalho, e as câmaras de ionização de placas paralelas de grafite desenvolvidas pelo PTB e pelo BIPM [ALLISY-ROBERTS et al. (2005)]. A câmara de ionização do BIPM apresenta um volume sensível de $6,8344 \mathrm{~cm}^{3}$ e a câmara de ionização do PTB apresenta um volume sensível de $6,138 \mathrm{~cm}^{3}$. Os resultados obtidos da comparação dos parâmetros determinados neste trabalho (Tabela 7.9) e os obtidos nos laboratórios BIPM e PTB [ALLISY-ROBERTS et al. 
(2005)], utilizados na determinação da taxa de kerma no ar, são apresentados na Tabela 7.10 e Tabela 7.11, respectivamente.

Tabela 7.10: Comparação entre os parâmetros utilizados na determinação da taxa de kerma no ar dos protótipos G1 e G2 e da câmara de ionização do BIPM.

\begin{tabular}{cccc}
\hline & Valor & \multicolumn{2}{c}{$\begin{array}{c}\text { Diferença dos fatores de } \\
\text { correção dos protótipos }\end{array}$} \\
Fator de & BIPM & G1 & Gesenvolvidos neste projeto $(\%)$ \\
\cline { 2 - 4 } Correção & $0,9985 \pm 0,0010$ & 0,1 & 0,1 \\
\hline$\left(\bar{\mu}_{\text {en }} / \rho\right)_{\text {ar }}^{\text {parede }}$ & $1,0032 \pm 0,0004$ & 0,1 & 0,1 \\
$\left(1-\bar{g}_{\text {ar }}\right)^{-1}$ & $1,0010 \pm 0,0022$ & 0,1 & 0,1 \\
$(\bar{L} / \rho)_{\text {ar }}^{\text {parede }}$ & $0,9964 \pm 0,0014$ & 0,5 & 0,1 \\
$k_{\text {an }}$ & $1,0107 \pm 0,0014$ & 0,6 & 0,6 \\
$k_{\text {parede }}$ & $1,0000^{\dagger}$ & 0,1 & 0,0 \\
$k_{\text {elec }}$ & $1,000 \pm 0,0002$ & 0,1 & 0,1 \\
$k_{\text {cabo }}$ & ${ }^{\dagger}$ Este fator de correção foi considerado unitário pelo BIPM. &
\end{tabular}

Tabela 7.11: Comparação entre os parâmetros utilizados na determinação da taxa de kerma no ar dos protótipos G1 e G2 e da câmara de ionização do PTB.

\begin{tabular}{cccc}
\hline & Valor & \multicolumn{2}{c}{$\begin{array}{c}\text { Diferença dos fatores de } \\
\text { correção dos protótipos }\end{array}$} \\
Fator de & PTB & G1 & G2 \\
\cline { 3 - 4 } Correção & $0,9985 \pm 0,0010$ & 0,1 & 0,1 \\
\hline$\left(\bar{\mu}_{\text {en }} / \rho\right)_{\text {ar }}^{\text {parede }}$ & $1,0032 \pm 0,0004$ & 0,1 & 0,1 \\
$\left(1-\bar{g}_{\text {ar }}\right)^{-1}$ & $1,0010 \pm 0,0022$ & 0,1 & 0,1 \\
$(\bar{L} / \rho)_{\text {ar }}^{\text {parede }}$ & $1,0015 \pm 0,0012$ & 0,0 & 0,4 \\
$k_{\text {an }}$ & $1,0004 \pm 0,0010$ & 0,5 & 0,5 \\
$k_{\text {parede }}$ & $1,0000^{\dagger}$ & 0,1 & 0,0 \\
$k_{\text {elec }}$ & $0,9992 \pm 0,0010$ & 0,2 & 0,0 \\
$k_{\text {cabo }}$ & ${ }^{\dagger}$ Este fator de correção foi considerado unitário pelo PTB. &
\end{tabular}

Os resultados listados na Tabela 7.10 mostram que a a maior diferença entre os valores de fatores de correção, determinados com o código de Monte Carlo EGSnrc, das câmaras de ionização G1 e G2 em relação aos valores obtidos para a câmara de ionização do BIPM foi de apenas 0,6\%, para o fator de correção da parede. No caso 
da comparação dos valores de fatores de correção das câmaras de ionização G1 e G2 com os valores de fatores de correção da câmara de ionização do PTB, também foi possível observar que o fator de correção da parede apresentou a maior diferença, de apenas 0,5\% entre os valores comparados, como mostra a Tabela 7.11.

A taxa de kerma no ar para o feixe de ${ }^{60}$ Co do LCI foi determinada, no dia 05/03/2013, com as duas câmaras de ionização de placas paralelas de grafite e comparadas com a taxa de kerma no ar obtida com a câmara de referência para a fonte de ${ }^{60}$ Co do LCI (PTW, modelo TN30002, série 272). Os valores de taxa de kerma obtidos são listados na Tabela 7.12. Os resultados apresentados nesta tabela não apresentam diferenças estatísticas.

Tabela 7.12: Valores da taxa de kerma no ar da fonte de ${ }^{60}$ Co do LCI determinados com as câmaras de ionização G1, G2 e PTW.

\begin{tabular}{cc}
\hline $\begin{array}{c}\text { Câmara } \\
\text { de }\end{array}$ & $\begin{array}{c}\text { Taxa de Kerma } \\
\text { no Ar } \\
\text { Ionização }\end{array}$ \\
\hline G1 & $0,599 \pm 0,012$ \\
G2 & $0,596 \pm 0,012$ \\
PTW & $0,589 \pm 0,018$ \\
\hline
\end{tabular}

Por meio da pequena diferença encontrada entre os valores de taxa de kerma obtidos com as câmaras de ionização G1 e G2 em relação à câmara padrão de referência do LCI (Tabela 7.12), e também devido ao fato dos fatores de correção das câmaras de ionização G1 e G2 estarem muito próximos aos valores dos fatores de correção das câmaras de ionização de laboratórios padrões primários [ALLISY-ROBERTS et al. (2005)], é possível afirmar que elas apresentam qualidade metrológica para serem aplicadas como sistemas padrões primários. 


\section{Capítulo 8}

\section{Conclusões}

Os objetivos propostos neste projeto foram alcançados. Foram desenvolvidos e caracterizados diferentes tipos de câmaras de ionização como sistemas padrões em diagnóstico convencional e tomografia computadorizada, e em feixes de ${ }^{60} \mathrm{Co}$. O projeto das câmaras de ionização levou em consideração o desenvolvimento de detectores com diferentes características relacionadas à sua configuração que os diferencia das câmaras de ionização já existentes no mercado. Outra característica que também foi levada em conta está relacionada ao processo de confecção das câmaras de ionização ser simples, utilizando-se somente materiais disponíveis no mercado nacional, de custo baixo.

As câmaras de ionização desenvolvidas e utilizadas neste trabalho foram submetidas aos testes de caracterização recomendados por normas internacionais, para determinar suas principais características: saturação da corrente de ionização, efeito de polaridade, eficiência de coleção de íons, linearidade de resposta, tempo de estabilização, estabilidade de resposta, corrente de fuga, dependência angular e energética.

As três câmaras de ionização CG, CMETG e CMETA, construídas e caracterizadas em feixes padronizados de radiação X convencional no LCI, apresentaram um desempenho muito bom nos testes de caracterização, com todos os resultados dentro dos limites das normas internacionais. A câmara de ionização que mostrou o melhor desempenho, com uma dependência energética menor nas qualidades RQR e RQA, foi a câmara CMETG. Isto pode ser justificado pelo fato de ela ter a parede e 
o eletrodo coletor feitos de material equivalente ao tecido, simulando melhor a dose recebida pelo paciente.

As câmaras tipo lápis L1 e L2 caracterizadas neste trabalho apresentaram um excelente desempenho nos testes de caracterização. A câmara de ionização L1, quando comparada com a câmara de ionização Farmer, para mapeamento de campo de radiação, apresentou uma diferença máxima de 1,25\% entre seus resultados, indicando uma aplicação nova para este tipo de câmara de ionização, visto que o comprimento do seu volume sensível é de apenas 1,0 cm. Para determinar algumas diferenças das câmaras de ionização L1 e L2 em relação às demais câmaras de ionização tipo lápis encontradas comercialmente, foram feitas algumas simulações de Monte Carlo. Estas simulações das câmaras de ionização L1 e L2 mostraram que o conector BNC, junto ao corpo das câmaras de ionização, não modificou as suas respostas e as influências do eletrodo de alumínio foram de 11,0\% e 9,0\% para as câmaras de ionização L1 e L2, respectivamente. Segundo alguns estudos na literatura [MUIR e ROGERS (2011)], o efeito do eletrodo coletor pode ser de até 50,0\% na resposta da câmara de ionização em alguns casos. Portanto, os valores obtidos neste trabalho são aceitáveis, e não comprometem o desempenho destas câmaras de ionização.

A câmara de ionização de placas paralelas PPTC, caracterizada em feixes padrões de TC, também obedeceu a todos os limites requeridos nos testes de caracterização. De acordo com a simulação de Monte Carlo, no estudo da influência dos componentes da câmara de ionização PPTC na sua resposta, pôde-se observar que o eletrodo coletor de grafite apresentou a maior influência (13,3\%) na sua resposta. Além disso, os resultados advindos da simulação mostraram que a escolha dos materiais e das dimensões da câmara de ionização PPTC foi adequada para sua construção, pois esta câmara de ionização é robusta e eficiente para aplicação como um sistema padrão de trabalho para dosimetria de feixes de TC em laboratórios de calibração.

As câmaras de ionização de placas paralelas caracterizadas no feixe de ${ }^{60} \mathrm{Co}$ apresentaram resultados experimentais muito promissores em todos os testes de caracterização. Embora os resultados experimentais da câmara de ionização CG 
sejam satisfatórios, ela não foi caracterizada como um sistema de referência, pois a influência do eletrodo coletor e do cabo não foi pequena o suficiente. O ideal para uma câmara de ionização ser caracterizada como um sistema de referência é ela possuir cada um de seus fatores de correção o mais próximo possível de 1,000. Sendo assim, somente as câmaras de ionização de placas paralelas de grafite G1 e G2 possuem qualidade metrológica para atuação como sistemas primários de referência.

Por meio da caracterização experimental e pela determinação dos fatores de correção das câmaras de ionização de grafite G1 e G2, foi possível determinar a taxa de kerma no ar para a fonte de ${ }^{60} \mathrm{Co}$ do LCI, que foi um dos objetivos principais desta tese de doutorado. A taxa de kerma no ar obtida com as câmaras de ionização de grafite G1 e G2 foi comprada com a taxa de kerma no ar obtida com o padrão de referência do LCI (PTW, modelo TN30002). A máxima diferença encontrada foi de apenas $1,7 \%$ entre a câmara padrão de referência do LCI e a câmara de ionização G1. Portanto, tanto os resultados experimentais quanto os resultados da simulação de Monte Carlo, responsável pela determinação dos fatores de correção, indicaram que as câmaras de ionização de grafite têm potencial para aplicação como sistemas padrões primários em feixes de ${ }^{60} \mathrm{Co}$. 


\section{Apêndice A}

\section{Lista de Publicações em Periódicos Decorrentes desta Tese}

\section{A.1 Artigos Publicados em Periódicos}

1. PERINI, A.P.; NEVES, L.P.; FERNÁNDEZ-VAREA, J.M.; BÜERMANN, L.; CALDAS, L.V.E. Evaluation and simulation of a new ionization chamber design for use in computed tomography beams. IEEE Transactions on Nuclear Science, v.60, p.768-773, 2013.

2. PERINI, A.P.; NEVES, L.P.; XAVIER, M.; KHOURY, H.J.; CALDAS, L.V.E. Evaluation of linearity of response and angular dependence of an ionization chamber for dosimetry in computed tomography. Radioprotecção (S. João da Talha), v.2, p.25-30, 2012.

3. PERINI, A.P.; NEVES, L.P.; VIVOLO, V.; XAVIER, M.; KHOURY, H.J.; CALDAS, L.V.E. Characterization of a CT ionization chamber for radiation field mapping. Applied Radiation and Isotopes, v.70, p.1300-1303, 2012.

4. NEVES, L.P.; PERINI, A.P.; FERNÁNDEZ-VAREA, J.M.; CALDAS, L.V.E. Application of a pencil ionization chamber $\left(0.34 \mathrm{~cm}^{3}\right.$ Volume $)$ for ${ }^{60} \mathrm{Co}$ beams: experimental and Monte Carlo results. IEEE Transactions on Nuclear Science, v.60, p.746-750, 2013.

5. NEVES, L.P.; PERINI, A.P.; CALDAS, L.V.E. Development and characterization of a new cylindrical ionization chamber for dosimetry of ${ }^{60}$ Co beams. 
IEEE Transactions on Nuclear Science, v.60, p.712-715, 2013.

6. NEVES, L.P.; PERINI, A.P.; XAVIER, M.; KHOURY, H.J.; CALDAS, L.V.E. Pre-evaluation of an ionization chamber for clinical radiotherapy dosimetry. Radioprotecção (S. João da Talha), v.2, p.133-138, 2012.

7. NEVES, L.P.; SILVA, E.A.B.; PERINI, A.P.; MAIDANA, N.L.; CALDAS, L.V.E. Characterization of an extrapolation chamber for low-energy X-rays: Experimental and Monte Carlo preliminary results. Applied Radiation and Isotopes, v.70, p.1388-1391, 2012.

8. NEVES, L.P.; PERINI, A.P.; DOS SANTOS, G.P.; XAVIER, M.; KHOURY, H.J.; CALDAS, L.V.E. Characterization of a homemade ionization chamber for radiotherapy beams. Applied Radiation and Isotopes, v.70, p.12911295, 2012.

9. VIVOlO, V.; NEVES, L.P.; PERINI, A.P.; SIlVA, J.O.; LUCENA, R.F.; POTIENS, M.P.A.; CALDAS, L.V.E. Evaluation of the voltage quantities measured with different noninvasive meters for quality control at a calibration laboratory. Applied Radiation and Isotopes, v.70, p.1429-1431, 2012.

\section{A.2 Artigos Aceitos para Publicação}

1. PERINI, A.P.; NEVES, L.P.; MAIA, A.F.; CALDAS, L.V.E. Characterization and simulation of a new design parallel-plate ionization chamber for CT dosimetry at calibration laboratories. IEEE Transactions on Nuclear Science, 2014 .

2. PERINI, A.P.; NEVES, L.P.; FERNÁNDEZ-VAREA, J.M.; CASSOLA, V.; KRAMER, R.; KHOURY, H.J.; CALDAS, L.V.E. A new parallel-plate graphite ionization chamber as a ${ }^{60} \mathrm{Co}$ gamma radiation reference instrument. Radiation Physics and Chemistry, 2013. 
3. PERINI, A.P.; NEVES, L.P.; CALDAS, L.V.E. Investigation of the applicability of a special parallel-plate ionization chamber for x-ray beam dosimetry. Radiation Physics and Chemistry, 2013.

4. NEVES, L.P.; PERINI, A.P.; FERnÁNDEZ-VAREA, J.M.; CASSOLA, V.; KRAMER, R.; KHOURY, H.J.; CALDAS, L.V.E. Dosimetric application of a special pencil ionization chamber in radiotherapy x-ray beams. Radiation Physics and Chemistry, 2012. 


\section{Apêndice B}

\section{Lista de Trabalhos Completos Publicados em Anais de Congressos Decorrentes desta Tese}

1. PERINI, A.P.; PASCHOAL, C.M.M.; NEVES, L.P.; SANTOS, L.A.P.; SOUZA, D.N.; CALDAS, L.V.E. Comparison between two homemade dosimeters for computed tomography: an ionization chamber and a semiconductor detector. In: International Nuclear Atlantic Conference - INAC 2011, Belo Horizonte. Proceedings INAC, 2011.

2. PERINI, A.P.; NEVES, L.P.; CALDAS, L.V.E. Stability and angular dependence of a homemade ionization chamber ${ }^{60} \mathrm{Co}$ beams. In: $\mathbf{6}^{\circ}$ Congresso Brasileiro de Metrologia, 2011, Natal. CD Proceedings, 2011.

3. PERINI, A.P.; NEVES, L.P.; CALDAS, L.V.E. Performance of a Roos ionization chamber in gamma radiation beams $\left({ }^{60} \mathrm{Co}\right)$. In: International Nuclear Atlantic Conference - INAC 2011, Belo Horizonte. Proceedings INAC, 2011.

4. Alvarenga, T.S.; NEVES, L.P.; PERINI, A.P.; SANCHES, M.P.; FEDERICO, C.A.; CALDAS, L.V.E. Determinação da radiação espalhada no projeto de um laboratório de calibração com nêutrons. In: Congresso Brasileiro de Física Médica (CBFM), 2013, São Pedro. Anais do Congresso Brasileiro de Física Médica, 2013. 
5. VIVOLO, V.; NEVES, L.P.; PERINI, A.P.; CALDAS, L.V.E. Establishment of the practical peak voltage for standard computed tomography radiation qualities at a Calibration Laboratory. In: 13th International Congress of the International Radiation Protection Association (IRPA), 2012, Glasgow. IRPA 13 Proceedings, 2012.

6. NEVES, L.P.; PERINI, A.P.; CALDAS, L.V.E. Energy dependence of a homemade ionization chamber designed for $\mathrm{X}$ radiation field mapping. In: $\mathbf{6}^{\circ}$ Congresso Brasileiro de Metrologia, 2011, Natal. CD Proceedings, 2011.

7. NEVES, L.P.; PERINI, A.P.; CALDAS, L.V.E. Comparison between a commercial and a homemade ionization chambers for dosimetry of ${ }^{60} \mathrm{Co}$ beams. In: International Nuclear Atlantic Conference - INAC 2011, Belo Horizonte. Proceedings INAC, 2011. 


\section{Apêndice C}

\section{Lista de Resumos Publicados em Anais de Congressos Decorrentes desta Tese}

1. PERINI, A.P.; NEVES, L.P.; CALDAS, L.V.E. Development and characterization of a graphite-walled ionization chamber as a reference dosimeter for ${ }^{60} \mathrm{Co}$ beams. In: 1st International Conference on Dosimetry and its Applications, Praga. Book of Abstracts. Praga: České vysoké učení technické v Praze, 2013. v.1. pp.114-114.

2. PERINI, A.P.; NEVES, L.P.; CALDAS, L.V.E. Response of a PMMA graphite coated parallel-plate ionization chamber in ${ }^{60} \mathrm{Co}$ beams. In: 1st International Conference on Dosimetry and its Applications, Praga. Book of Abstracts. Praga: České vysoké učení technické v Praze, 2013. v.1 pp.115-115.

3. PERINI, A.P.; NEVES, L.P.; GUIMARAES, M.; OLIVEIRA, P.; VIVOLO, V.; SILVA, T.; CALDAS, L.V.E. Comparison between two calibration systems for direct and attenuated radiation qualities, diagnostic radiology level. In: 1st International Conference on Dosimetry and its Applications, Praga. Book of Abstracts. Praga: České vysoké učení technické v Praze, 2013. v.1 pp. 116-116.

4. PERINI, A.P.; NEVES, L.P.; CALDAS, L.V.E. Assembling and study of a plane-parallel ionization chamber in low-energy X-ray qualities for radiothe- 
rapy. In: 2012 IEEE Symposium on Radiation Measurements and Applications, Oakland. Sorma West 2012 Proceedings.

5. PERINI, A.P.; NEVES, L.P.; FERNÁNDEZ-VAREA, J.M.; CALDAS, L.V.E. Evaluation and simulation study of a homemade ionization chamber for use in computed tomography beams. In: 2012 IEEE Symposium on Radiation Measurements and Applications, 2012, Oakland. Sorma West 2012 Proceedings.

6. PERINI, A.P.; NEVES, L.P.; FERNÁNDEZ-VAREA, J.M.; CASSOLA, V.; KRAMER, R.; KHOURY, H.J.; CALDAS, L.V.E. A new parallel plate graphite ionization chamber as a ${ }^{60} \mathrm{Co}$ gamma radiation standard. In: 12th International Symposium on Radiation Physics, 2012, Rio de Janeiro. Book of Abstracts.

7. PERINI, A.P.; NEVES, L.P.; CALDAS, L.V.E. Investigation of the aplicability of a special parallel ionization chamber for x-ray beam dosimetry. In: 12th International Symposium on Radiation Physics, 2012, Rio de Janeiro. Book of Abstracts.

8. PERINI, A.P.; NEVES, L.P.; XAVIER, M.; KHOURY, H.J.; CALDAS, L.V.E. Evaluation of linearity of response and angular dependence of an ionization chamber for dosimetry in computed tomography. In: International Joint Conference - RADIO, 2011, Recife. Book of Abstracts.

9. PERINI, A.P.; NEVES, L.P.; CALDAS, L.V.E. Estudo de uma câmara de ionização cilíndrica em feixe de ${ }^{60}$ Co. In: I WORKSHOP DO INCT METROLOGIA DAS RADIAÇÕES NA MEDICINA, 2011, Recife. CD de Posteres do I Workshop do INCT MRM.

10. PERINI, A.P.; NEVES, L.P.; XAVIER, M.; KHOURY, H.J.; CALDAS, L.V.E. Preliminary characterization of a homemade ionization chamber for use in computed tomography. In: 18th International Conference on Me- 
dical Physics, 2011, Porto Alegre. Brazilian Journal of Medical Physics. São Paulo: Zeppelini Editorial, 2011. v.5. p.131-131.

11. PERINI, A.P.; NEVES, L.P.; VIVOLO, V.; XAVIER, M.; KHOURY, H.J.; CALDAS, L.V.E. Characterization of a CT ionization chamber for radiation field mapping. In: Industrial Radiation and Radioisotope Measurement Applications, 2011, Kansas City. Book of Abstracts.

12. PERINI, A.P.; NEVES, L.P.; COSTA, P.R.; FRIMAIO, A.; CALDAS, L.V.E. Development and evaluation of a tissue equivalent ionization chamber. In: IRRMA 8 - Industrial Radiation and Radioisotope Measurement Applications, 2011, Kansas City. Book of Abstracts.

13. NEVES, L.P.; GORSKI, R.; PERINI, A.P.; SANTOS, W.S.; MAIA, A.F.; CALDAS, L.V.E.; ORENGO, G. Dosimetric study of a brachytherapy treatment of esophagus with Brazilian ${ }^{192}$ Ir sources using anthropomorphic phantoms. In: 1st International Conference on Dosimetry and its Applications, Praga. Book of Abstracts. Praga: České vysoké učení technické v Praze, 2013. v.1. pp.113-113.

14. NEVES, L.P.; PERINI, A.P.; CALDAS, L.V.E. A new standard cylindrical graphite-walled ionization chamber for dosimetry in ${ }^{60} \mathrm{Co}$ beams at calibration laboratories. In: 1st International Conference on Dosimetry and its Applications, Praga. Book of Abstracts. Praga: České vysoké učení technické v Praze, 2013. v.1 pp. 112-112.

15. NEVES, L.P.; PERINI, A.P.; CALDAS, L.V.E. Development and Characterization of a New Cylindrical Ionization Chamber for Dosimetry of ${ }^{60} \mathrm{Co}$ Beams. In: 2012 IEEE Symposium on Radiation Measurements and Applications, Oakland. Sorma West 2012 Proceedings.

16. NEVES, L.P.; PERINI, A.P.; FERNÁNDEZ-VAREA, J.M.; CALDAS, L.V.E. Application of a pencil ionization chamber with a $0.34 \mathrm{~cm}^{3}$ volume for 
${ }^{60}$ Co beams: experimental and Monte Carlo results. In: 2012 IEEE Symposium on Radiation Measurements and Applications, Oakland. Sorma West 2012 Proceedings.

17. NEVES, L.P.; PERINI, A.P.; CASSOLA, V.; KRAMER, R.; KHOURY, H.J.; CALDAS, L.V.E. Using a graphite ionization chamber in medium-energy x-ray beams. In: 12th International Symposium on Radiation Physics, 2012, Rio de Janeiro. Book of Abstracts.

18. NEVES, L.P.; PERINI, A.P.; FFERNÁNDEZ-VAREA, J.M.; CASSOLA, V.; KRAMER, R.; KHOURY, H.J.; CALDAS, L.V.E. Dosimetric application of a pencil ionization chamber in radiotherapy X-ray beams. In: 12th International Symposium on Radiation Physics, 2012, Rio de Janeiro. Book of Abstracts.

19. NEVES, L.P.; PERINI, A.P.; CALDAS, L.V.E. Simulação de câmaras de ionização pelo método de Monte Carlo. In: I WORKSHOP DO INCT METROLOGIA DAS RADIAÇÕES NA MEDICINA, 2011, Recife. CD de Posteres do I Wrokshop do INCT MRM.

20. NEVES, L.P.; PERINI, A.P.; XAVIER, M.; KHOURY, H.J.; CALDAS, L.V.E. Angular dependence tests of an ionization chamber developed for determining the $\mathrm{X}$ radiation field homogeneity. In: 18th International Conference on Medical Physics, 2011, Porto Alegre. Brazilian Journal of Medical Physics. São Paulo: Zeppelini Editorial, 2011. v.5. p.131-131.

21. NEVES, L.P.; PERINI, A.P.; DOS SANTOS, G.P.; XAVIER, M.; KHOURY, H.J.; CALDAS, L.V.E. Characterization of a homemade ionization chamber for radiotherapy beams. In: Industrial Radiation and Radioisotope Measurement Applications, 2011, Kansas City. Book of Abstracts.

22. NEVES, L.P.; SILVA, E.A.B.; PERINI, A.P.; MAIDANA, N.L.; CALDAS, L.V.E. Characterization of an extrapolation chamber for low energy X rays: 
Experimental and Monte Carlo preliminary results. In: Industrial Radiation and Radioisotope Measurement Application, 2011, Kansas City. Book of Abstracts.

23. VIVOlO, V.; NEVES, L.P.; PERINI, A.P.; SILVA, J.O.; LUCENA, R.F.; POTIENS, M.P.A.; CALDAS, L.V.E. Evaluation of the voltage quantities measured with different noninvasive meters for quality control at a calibration laboratory. In: International Radiation and Radioisotope Measurement Applications, 2011, Kansas City. Book of Abstracts.

24. NEVES, L.P.; PERINI, A.P.; XAVIER, M.; KHOURY, H.J.; CALDAS, L.V.E. Pre-evaluation of an ionization chamber for clinical radiotherapy dosimetry. In: International Joint Conference - RADIO, 2011, Recife. Book of Abstracts. 


\section{Apêndice D}

\section{Estimativa do custo de confecção das câmaras de ionização desenvolvidas neste projeto}

Foi feito um levantamento dos gastos para confecção das câmaras de ionização desenvolvidas neste projeto. A Tabela D.1 apresenta o custo estimado da confecção da câmara de ionização de placas paralelas CG, a Tabela D.2 apresenta o custo estimado de confecção das câmaras de ionização de placas paralelas CMETG e CMETA e a Tabela D.3 mostra os valores gastos para a confecção das câmaras de ionização de grafite de placas paralelas G1 e G2. Estes valores são referentes à época em que as câmaras de ionização foram desenvolvidas.

Tabela D.1: Estimativa de custo de confecção da câmara de ionização CG.

\begin{tabular}{cc}
\hline Item & Valor $(\mathbf{R} \$)$ \\
\hline $\begin{array}{c}\text { Peças usinadas de PMMA, incluindo a } \\
\text { mão de obra }\end{array}$ & 300,00 \\
\hline $\begin{array}{c}\text { Spray de grafite Aerodag } \mathrm{G}^{\circledR} \text { para } \\
\text { o eletrodo coletor e parede interna de grafite }\end{array}$ & 50,00 \\
\hline Cabo coaxial RG 174 $(1 \mathrm{~m})$ & 5,00 \\
\hline Conector BNC para cabo & 10,00 \\
\hline TOTAL & $\mathbf{3 6 5 , 0 0}$ \\
\hline
\end{tabular}


Tabela D.2: Estimativa de custo de confeç̧ão das câmaras de ionização CMETG e CMETA.

\begin{tabular}{ccc}
\hline \multirow{2}{*}{ Item } & \multicolumn{2}{c}{ Valor (R\$) } \\
\cline { 2 - 3 } & CMETG & CMETA \\
\hline $\begin{array}{c}\text { Peças usinadas de material equivalente } \\
\text { ao tecido, incluindo mão de obra }\end{array}$ & 200,00 & 200,00 \\
\hline $\begin{array}{c}\text { Peça usinada de alumínio para o eletrodo } \\
\text { coletor, incluindo mão de obra para a CMETA }\end{array}$ & - & 100,00 \\
\hline $\begin{array}{c}\text { Spray de grafite Aerodag G }{ }^{\circledR} \text { para o eletrodo } \\
\text { coletor da CMETG e parede interna }\end{array}$ & 50,00 & 50,00 \\
$\quad$ das CMETA e CMETG & & \\
\hline $\begin{array}{c}\text { Peças usinadas de Teflon para confeç̧ão das } \\
\text { hastes e dos isolantes das câmaras }\end{array}$ & 200,00 & 200,00 \\
de ionização, incluindo mão de obra & 5,00 & 5,00 \\
\hline Cabos coaxiais RG 174 (1 m) & 10,00 & 10,00 \\
\hline Conectores BNC & $\mathbf{4 6 5 , 0 0}$ & $\mathbf{5 6 5 , 0 0}$ \\
\hline TOTAL
\end{tabular}

Tabela D.3: Estimativa de custo de confecção das câmaras de ionização G1 e G2.

\begin{tabular}{ccc}
\hline \multirow{2}{*}{ Item } & \multicolumn{2}{c}{ Valor (R\$) } \\
\cline { 2 - 3 } & $\mathbf{G 1}$ & $\mathbf{G 2}$ \\
\hline $\begin{array}{c}\text { Peças usinadas de grafite com pureza } \\
\text { de 99,5\%, incluindo mão de obra }\end{array}$ & $2.500,00$ & $2.500,00$ \\
\hline $\begin{array}{c}\text { Peças usinadas de Teflon para confecção } \\
\text { das hastes e dos isolantes das câmaras de } \\
\text { ionização, incluindo mão de obra }\end{array}$ & 200,00 & 200,00 \\
\hline Cabos coaxiais RG 174 (1 m) & 5,00 & 5,00 \\
\hline Conectores BNC & 10,00 & 10,00 \\
\hline TOTAL & $\mathbf{2 . 7 1 5 , 0 0}$ & $\mathbf{2 . 7 1 5 , 0 0}$ \\
\hline
\end{tabular}




\section{Referências Bibliográficas}

ABNT (2003) ABNT. ASSOCIAÇ $\widetilde{O}$ BRASILEIRA DE NORMAS TÉCNICAS, INSTITUTO NACIONAL DE METROLOGIA, NORMALIZAÇÃO E QUALIDADE INDUSTRIAL: Guia para expressão da incerteza de medição, Julho 2003. $3^{a}$ Edição Brasileira, Rio de Janeiro. Citado na pág. 62

ALBUQUERQUE (1990) M.P.P. ALBUQUERQUE. Projeto, Construção e Calibração de Câmaras de Ionização de Placas Paralelas para RadiaçãoX. Dissertação de Mestrado, Instituto de Pesquisas Energéticas e Nucleares, Universidade de São Paulo, Brasil. Citado na pág. 32

ALBUQUERQUE e CALDAS (1989) M.P.P. ALBUQUERQUE e L.V.E. CALDAS. New ionization chambers for beta and X-radiation. Nuclear Instruments and Methods in Physics Research Section A: Accelerators, Spectrometers, Detectors and Associated Equipment, 280(2-3):310-313. doi: 10.1016/0168-9002(89)90924-8. Citado na pág. 9

ALLISY-ROBERTS et al. (2005) P.J. ALLISY-ROBERTS, D.T. BURNS, L. BÜERMANN e H.-M. KRAMER. Comparisons of the standards for air kerma of the PTB and the BIPM for ${ }^{60} \mathrm{Co}$ and ${ }^{137} \mathrm{Cs}$ gamma radiation. Relatório técnico, BUREAU INTERNATIONAL DES POIDS ET MESURES, Sévres. Citado na pág. 93, 124, 126

ALMOND et al. (1999) P.R. ALMOND, P.J. BIGGS, B.M. COURSEY, W.F. HANSON, M. SAIFUL HUQ, R. NATH e D.W.O. ROGERS. AAPM's TG51 Protocol for clinical reference dosimetry of high-energy photon and electron beams. Medical Physics, 26(9):1847-1869. doi: 10.1118/1.598691. Citado na pág. 30

ARPANSA (2013) ARPANSA. AUSTRALIAN RADIATION PROTECTION AND NUCLEAR SAFETY AGENCY: Radiotherapy calibrations. http:// www.arpansa.gov.au/services/calibration/radiotherapy.cfm, 2013. Último acesso em 31/08/2013. Citado na pág. 50

ATTIX (2004) F.H. ATTIX. Introduction to Radiological Physics and Radiation Dosimetry. Wiley, New York, $2^{a}$ ed. Citado na pág. xi, 11, 16, 17, 18, 20, $22,24,25,27,31,34$

BACELAR et al. (2011) A. BACELAR, J.R.M. ANDRADE, A.C.S. FISCHER, A.C. ACCURSO e G. HOFF. Mapeamento de curvas de isoexposição para avaliação de equivalente de dose ambiente para equipamentos móveis de radiodiagnóstico. Em Proceedings II Congresso Brasileiro de Proteção Radiológica, Recife. Anais do II CBRP, páginas 1-10. Citado na pág. 2 
BIELAJEW (1990) A. F. BIELAJEW. An analytic theory of the pointsource non-uniformity correction factor for thick-walled ionisation chambers in photon beams. Physics in Medicine and Biology, 35(4):517-538. doi: 10.1088/0031-9155/35/4/004. Citado na pág. 36

BIPM (2013) BIPM. Bureau international des poids et mesures. The Metre Convention. http://www.bipm.org/en/convention/, 2013. Último acesso em 31/08/2013. Citado na pág. 49

BOGDANICH (2009a) W. BOGDANICH. Radiation overdoses point up dangers of CT scans. http://www.nytimes.com/2009/10/16/us/16radiation. html, 2009a. Último acesso em 31/08/2013. Citado na pág. 1

BOGDANICH (2009b) W. BOGDANICH. After stroke scans, patients face serious health risks. http://www.nytimes.com/2010/08/01/ health/01radiation.html?ref=radiation_boomAcesso, 2009b. Último acesso em 31/08/2013. Citado na pág. 1

BOUTILLON e NIATEL (1973) M. BOUTILLON e M.T.A. NIATEL. Study of a graphite cavity ionization chamber for absolute exposure measurements of ${ }^{60}$ Co gamma rays. Metrologia, 9(4):139-146. doi: 10.1088/0026-1394/9/4/001. Citado na pág. 13, 35

BÜERMANN (2012) L. BÜERMANN. PTB Radiation qualities for calibration of secondary standards. http://www.ptb.de/en/org/6/62/625/pdf/ strhlq.pdf, 2012. Último acesso em 25/01/2012. Citado na pág. 59, 105, 110

BÜERMANN e BURNS (2009) L. BÜERMANN e D. T. BURNS. Air-kerma cavity standards. Metrologia, 46(2):S24-S38. doi: 10.1088/0026-1394/46/2/S03. Citado na pág. 3, 34, 36

BÜERMANN e BURNS (2007) L. BÜERMANN e G. D. T. BURNS. Significant discrepancies in air kerma rates measured with free-air and cavity ionization chambers. Nuclear Instruments and Methods in Physics Research A, 580 (1):477-480. doi: doi:10.1016/j.nima.2007.05.144. Citado na pág. 14

BÜERMANN e CSETE (2003) L. BÜERMANN e I. CSETE. Recent developments and current status of air kerma standards. Em Proceedings of the International Symposium Standards and Codes of Practice in Medical Radiation Dosimetry, páginas 125-138. IAEA, Vienna. Citado na pág. 12

BÜERMANN et al. (2003) L. BÜERMANN, H.M. KRAMER e I. CSETE. Results supporting calculated wall correction factors for cavity chambers. Physics in Medicine and Biology, 48(21):3581-3594. doi: 10.1088/0031-9155/48/21/ 009. Citado na pág. 41

BURNS (2006) D. T. BURNS. A new approach to the determination of air kerma using primary-standard cavity ionization chambers. Physics in Medicine and Biology, 51(4):929-942. doi: doi:10.1088/0031-9155/51/4/012. Citado na pág. 13

BURNS e BÜERMANN (2009) D.T. BURNS e L. BÜERMANN. Free-air ionization chambers. Metrologia, 46(2):S9-S23. doi: doi:10.1088/0026-1394/46/ 2/S02. Citado na pág. xi, 26 
BURNS et al. (2007) D.T. BURNS, P.J. ALLISY e C. KESSLER. Re-evaluation of the bipm international standard for air kerma in ${ }^{60}$ co gamma radiation. Metrologia, 44(6):L53-L56. doi: doi:10.1088/0026-1394/44/6/N02. Citado na pág. 3

CALDAS (1991) L.V.E. CALDAS. A sequential Tandem system of ionization chambers for effective energy determination of X-radiation fields. Radiation Protection Dosimetry, 36(1):47-50. Citado na pág. 9

CAMPOS (1982) A.A.L. CAMPOS. Construção, Calibração e Teste de uma Câmara de Ionização para Medidas de Exposição de Raios X e Gama na Região de $40 \mathrm{keV}$ até $1250 \mathrm{keV}$. Dissertação de Mestrado, Universidade do Estado do Rio de Janeiro. Citado na pág. 29

CARRIER et al. (2004) J.F. CARRIER, L. ARCHAMBAULT, L. BEAULIEU e R. ROY. Validation of GEANT4, an object-oriented Monte Carlo toolkit, for simulations in medical physics. Medical Physics, 31(3):484-492. doi: doi:10. 1118/1.1644532. Citado na pág. 40

CHERY e DUXBURY (2009) P. CHERY e A. DUXBURY. Practical Radiotherapy Physics and Equipments. John Wiley \& Sons, Nova York, $2^{a}$ ed. Citado na pág. xi, 28, 29

COSTA (2003) A.M. COSTA. Desenvolvimento de Câmaras de Ionização Tandem para Utilização em Programas de Controle da Qualidade em Radioterapia e Radiodiagnóstico. Tese de Doutorado, Instituto de Pesquisas Energéticas e Nucleares, Universidade de São Paulo. Citado na pág. 32

COSTA e CALDAS (2003) A.M. COSTA e L.V.E. CALDAS. A special ionization chamber for quality control of diagnostic and mammography X-ray equipment. Radiation Protection Dosimetry, 104(1):41-45. doi: rpd.oxfordjournals.org/ content/104/1/41.long. Citado na pág. 9

COSTA (2012) PAULO ROBERTO COSTA. Comunicação Privada, 2012. Citado na pág. 65,70

CYGLER et al. (2004) J.E. CYGLER, G.M. DASKALOV G.H. CHAN e G.X. DING. Evaluation of the first commercial Monte Carlo dose calculation engine for electron beam treatment planning. Physics in Medicine and Biology, 31 (1):142-153. doi: doi:10.1118/1.1633105. Citado na pág. 37

DeWERD e WAGNER (1999) L.A. DeWERD e L.K. WAGNER. Characteristics of radiation detectors for diagnostic radiology. Applied Radiation and Isotopes, 50(1):125-136. doi: doi:10.1016/S0969-8043(98)00044-X. Citado na pág. xi, $2,3,8,30$

ERAZO e LALLENA (2013) F. ERAZO e A.M. LALLENA. Calculation of beam quality correction factors for various thimble ionization chambers using the Monte Carlo PENELOPE. Physica Medica, 29(2):163-170. doi: doi:10.1016/j. ejmp.2012.01.001. Citado na pág. 14

FALLONE e PODGOSRSAK (1983) B.G. FALLONE e E.B. PODGOSRSAK. Saturation curves of parallel-plate ionization chambers. Medical Physics, 10(2): 191-196. doi: doi:10.1118/1.595292. Citado na pág. 9 
GORBICS e ATTIX (1968) S.G. GORBICS e F.H. ATTIX. LiF and $\mathrm{CaF}_{2}: \mathrm{Mn}$ thermoluminescent dosimeters in tandem. International Journal of Applied Radiation and Isotopes, 19(1):81-89. doi: doi:10.1016/0020-708X(68)90074-4. Citado na pág. 32

GRAY (1936) L.H. GRAY. An ionization method for the absolute measurement of $\gamma$-ray energy. Em Proceedings of the Royal Society, volume 156, páginas 578-596. doi: doi:10.1098/rspa.1936.0169. Citado na pág. 11

GREENING e INST (1964) J.R. GREENING e F.P. INST. Saturation characteristics of parallel-plate ionization chambers. Physics in Medicine and Biology, 9(2):143-154. doi: doi:10.1088/0031-9155/9/2/302. Citado na pág. 9

GUNN (1964) S.R. GUNN. Radiometric calorimetry: A review. Nuclear Instruments and Methods, 29(1):1-24. doi: doi:10.1016/0029-554X(64)90002-3. Citado na pág. 12

HERMANN et al. (1985) K.P. HERMANN, L. GEWORSKI, M. MUTH e D. HARDER. Polyethylene-based water-equivalent phantom material for x-ray dosimetry at tube voltages from 10 to $100 \mathrm{kV}$. Physics in Medicine and Biology, 30(11):1195-1200. doi: doi:10.1088/0031-9155/30/11/002. Citado na pág. 69

HERMANN et al. (1986) K.P. HERMANN, L. GEWORSKI, T. HATZKY, R. LIETZ e D. HARDER. Muscle and fat-equivalent polyethylene-based phantom materials for x-ray dosimetry at tube voltages below $100 \mathrm{kV}$. Physics in Medicine and Biology, 31(9):1041-1046. doi: doi:10.1088/0031-9155/31/9/009. Citado na pág. 69

HOFF et al. (2011) G. HOFF, J.R.M. ANDRADE, A.C.S. FISCHER, A.C. ACCURSO e A. BACELAR. Mapeamento de curvas de isoexposição geradas por equipamentos de radiodiagnostico móveis convencionais e dose em pacientes hospitalizados. Em Proceedings II Congresso Brasileiro de Proteção Radiológica, 2011, Recife. Anais do II CBPR, páginas 1-10. Citado na pág. 2

HUBBELL (2006) J.H. HUBBELL. Review and history of photon cross section calculations. Physics in Medicine and Biology, 51(13):R245-R262. doi: doi: 10.1088/0031-9155/51/13/R15. Citado na pág. 63

IAEA (2000) IAEA. INTERNATIONAL ATOMIC ENERGY AGENCY. Calibration of radiation protection monitoring instruments. Relatório Técnico IAEA SRS 16, IAEA, Vienna. Citado na pág. 45

IAEA (1994) IAEA. INTERNATIONAL ATOMIC ENERGY AGENCY. Calibration of dosemeters used in radiotherapy. Relatório Técnico IAEA TRS 374, IAEA, Vienna. Citado na pág. 45, 48

IAEA (1997) IAEA. INTERNATIONAL ATOMIC ENERGY AGENCY. The use of plane parallel ionization chambers in high energy electron and photon beams: an international code of practice for dosimetry. Relatório Técnico IAEA TRS 381, IAEA, Vienna. Citado na pág. 30 
IAEA (2004) IAEA. INTERNATIONAL ATOMIC ENERGY AGENCY. Absorbed dose determination in external beam radiotherapy: an international code of practice for dosimetry based on standards of absorbed dose to water. Relatório Técnico IAEA TRS 398 (v.11b), IAEA, Vienna. Citado na pág. 2, 30,57

IAEA (2007) IAEA. INTERNATIONAL ATOMIC ENERGY AGENCY. Dosimetry in diagnostic radiology: an international code of practice. Relatório Técnico IAEA TRS 457, IAEA, Vienna. Citado na pág. 59

ICRU (1964) ICRU. INTERNATIONAL COMMISSION ON RADIATION UNITS AND MEASUREMENTS. Physical aspects of irradiation. Relatório Técnico ICRU Report 10b, ICRU, Bethesda, Maryland. Citado na pág. 11

ICRU (1980) ICRU. INTERNATIONAL COMMISSION ON RADIATION UNITS AND MEASUREMENTS. Radiation quantities and units. Relatório Técnico ICRU Report 33, ICRU, Bethesda, Maryland. Citado na pág. 20

ICRU (1998) ICRU. INTERNATIONAL COMMISSION ON RADIATION UNITS AND MEASUREMENTS. Fundamental quantities and units for ionizing radiation. Relatório Técnico ICRU Report 60, ICRU, Bethesda, Maryland. Citado na pág. 18, 19

IEC (2011) IEC. INTERNATIONAL ELECTROTECHNICAL COMMISSION. Medical electrical equipment-dosemeters with ionization chambers as used in radiotherapy. Relatório Técnico IEC 60731, IEC, Genéve. Citado na pág. xiii, 30, 55, 56, 57, 58, 64, 72, 82, 98, 100, 101, 102, 103

IEC (2005) IEC. INTERNATIONAL ELECTROTECHNICAL COMMISSION. Medical diagnostic X-ray equipment - Radiation conditions for use in the determination of characteristics. Relatório Técnico IEC 61267, IEC, Genéve. Citado na pág. xv, 52, 53, 60, 81, 106

IEC (1994) IEC. INTERNATIONAL ELECTROTECHNICAL COMMISSION. Medical diagnostic X-ray equipment - Radiation conditions for use in determination of characteristics. Relatório Técnico IEC 61267, IEC, Genéve. Citado na pág. 81

IEC (1997) IEC. INTERNATIONAL ELECTROTECHNICAL COMMISSION. Medical electrical equipment-dosimeters with ionization chambers and/or semi-conductor detectors as used in x-ray diagnostic imaging. Relatório Técnico IEC 61674, IEC, Genéve. Citado na pág. xii, 30, 55, 56, 57, 58, 64, $71,73,74,75,76,77,78,84,85,86,87,88,90$

INMETRO (2012) INMETRO. INSTITUTO NACIONAL DE METROLOGIA, QUALIDADE e TECNOLOGIA: Vocabulário Internacional de Metrologia: Conceitos Fundamentais e Gerais e Termos Associados (VIM 2012). INMETRO, $1^{a}$ luso-brasileira ed. Citado na pág. 30, 46, 62

ISO (1995) ISO. INTERNATIONAL ORGANIZATION FOR STANDARDIZATION: Guide to expression of uncertainty in measurement. Relatório Técnico 1, ISO, Geneva. Citado na pág. 62 
ISO (1996) ISO. INTERNATIONAL ORGANIZATION FOR STANDARDIZATION: $\mathrm{X}$ and gamma reference radiation for calibrating dosimeters and dose rate meters and for determining their response as a function of photon energy - Part 1: Radiation characteristics and production methods. Relatório Técnico ISO 4037-1, ISO, Geneva. Citado na pág. 91

JAN et al. (2004) S. JAN, G. SANTIN, D. STRUL, S. STAELENS, K. ASSIÉ, D. AUTRET, S. AVNER, R. BARBIER, M. BARDIES, P.M. BLOOMFIELD, D. BRASSE, V. BRETON, P. BRUYNDONCKX, I. BUVAT, A.F. CHATZIIOANNOU, Y. CHOI, Y.H. CHUNG, C. COMTAT, D. DONNARIEIX, L. FERRER, S.J. GLICK, C.J. GROISELLE, D. GUEZ, P.-F. HONORE, S. KERHOASCAVATA, A.S. KIROV, V. KOHLI, M. KOOLE, M. KRIEGUER, D.J. VAN DER LAAN, F. LAMARE, G. LARGERON, C. LARTIZIEN, D. LAZARO, M.C. MAAS, L. MAIGNE, F. MAYET, F. MELOT, C. MERHEB, E. PENNACCHIO, J. PEREZ, U. PIETRZYK, F.R. RANNOU, M. REY, D.R. SCHAART, C.R. SCHMIDTLEIN, L. SIMON, T.Y. SONG, J.-M. VIEIRA, D. VISVIKIS, R. VAN DE WALLE, E WIEËRS e C. MOREL. GATE: a simulation toolkit for PET and SPECT. Physics in Medicine and Biology, 49(19):4543-4561. doi: doi:10.1088/0031-9155/49/19/007. Citado na pág. 40

JOHNS e CUNNINGHAM (1983) P.C. JOHNS e J.R. CUNNINGHAM. The Physics of Radiology. Charles C. Thomas Pub. Ltd, Springfield, $4^{a}$ ed. Citado na pág. 17

JUCIUS e KAMBIC (1977) R.A. JUCIUS e G.X. KAMBIC. Radiation dosimetry in computed tomography (CT). Em SPIE Proceedings, Application of Optical Instrumentation in Medicine VI, v. 127, páginas 286-295. SPIE. doi: doi:10.1117/12.955952. Citado na pág. 10

KASE et al. (1986) K.R. KASE, B.E. BJAERNGARD e F.H. ATTIX. The Dosimetry of Ionizing Radiation. Academic Press, New York, $1^{a}$ ed. Citado na pág. 28,31

KEMP (1977) L.A.W. KEMP. Intercomparison of the primary exposure standards. Em E. CASNATI, editor, Ionizing Radiation Metrology, páginas 213225. Editrice Compositari, Bologna, Itália, 1 ed. Citado na pág. 12

KENNEY e CAMERON (1963) G.N. KENNEY e J.R. CAMERON. X-ray beam quality measurements utilizing TL dosemeters. Relatório Técnico TID-19112, Wisconsin Univ., Madison, AEC Contract AT 11-1-1105, US. Citado na pág. 32

KHAN (2009) F.M. KHAN. The Physics of Radiation Therapy. Lippincott Williams \& Wilkins, Philadelphia, $4^{a}$ ed. Citado na pág. 24

KIMURA et al. (2011) B.H. KIMURA, A. FRIMAIO e P.R. COSTA. Development of tissue equivalent polymeric composites: preliminary results. Em Anals of the International Conference on Medical Physics, Porto Alegre. Citado na pág. 70

KRISTENSEN (1983) M. KRISTENSEN. Measured influence of central electrode diameter and material on the response of a graphite ionization chamber to 
${ }^{60}$ Co gamma-rays. Physics in Medicine and Biology, 28(11):1269-1278. doi: doi:10.1088/0031-9155/28/11/007. Citado na pág. 36

LAITANO (1998) R.F. LAITANO. Comparison of the NIST and the ENEA air kerma standards. Journal of Research of the National Institute of Standards and Technology, 103(4):365-378. Citado na pág. 49

LOEVINGER (1977) R. LOEVINGER. Realization of the unit of exposure: cavity chambers. Em E. CASNATI, editor, Ionizing Radiation Metrology, página 103. Editrice Compositari, Bologna, Itália, 1 ed. Citado na pág. 12

MA e NAHUM (1993) C. MA e A.E. NAHUM. Effect of size and composition of the central electrode on the response of cylindrical ionization chambers in highenergy photon and electron beams. Physics in Medicine and Biology, 38(2): 267-290. doi: doi:10.1088/0031-9155/38/2/005. Citado na pág. 37

MA et al. (2001) C.-M. MA, C.W. COFFEY, L.A. DEWERD, C. LIU, R. NATH, S.M. SELTZER e J.P. SEUNTJENS. AAPM protocol for 40-300 kV X-ray beam dosimetry in radiotherapy and radiobiology. Medical Physics, 28(6):868-892. doi: doi:10.1118/1.1374247. Citado na pág. 30

MAIA (2005) A.F. MAIA. Padronização de Feixes e Metodologia Dosimétrica em Tomografia Computadorizada. Tese de Doutorado, Instituto de Pesquisas Energéticas e Nucleares, Universidade de São Paulo. Citado na pág. 32

MAIA e CALDAS (2005) A.F. MAIA e L.V.E. CALDAS. A new extendedlength parallel-plate ionization chamber. Physics in Medicine and Biology, 50(16):3837-3847. doi: doi:10.1088/0031-9155/50/16/012. Citado na pág. 10, 80, 81

MEGHZIFENE e SHORTT (2002) A. MEGHZIFENE e K.R. SHORTT. Calibration factor or calibration coefficient? SSDL Newsletter, 46(1):33-33. Citado na pág. 58

MINNITI e CZAP (2011) R. MINNITI e L. CZAP. Comparison of the air kerma standards for ${ }^{137} \mathrm{Cs}$ and ${ }^{60} \mathrm{Co}$ gamma-ray beams between the IAEA and the NIST. Metrologia, 48(06005):1-8. doi: doi:10.1088/0026-1394/48/1A/06005. Citado na pág. 3

MUIR e ROGERS (2011) R. MUIR e D.W.O. ROGERS. The central electrode correction factor for high-Z electrodes in small ionization chambers. Medical Physics, 38(2):1081-1088. doi: 10.1118/1.3532818. Citado na pág. 37, 111, 116, 124, 128

NATH e SCHULZ (1981) R. NATH e R.J. SCHULZ. Calculated response and wall correction factors for ionization chambers exposed to ${ }^{60} \mathrm{Co}$ gamma-rays. $\mathrm{Me}$ dical Physics, 8(6):85-93. doi: 10.1118/1.595205. Citado na pág. 13, 41

NEVES et al. (2013) L.P. NEVES, A.P. PERINI, J.M. FERNÁNDEZ-VAREA e L.V.E. CALDAS. Application of a pencil ionization chamber $\left(0.34 \mathrm{~cm}^{3}\right.$ volume $)$ for ${ }^{60}$ Co beams: experimental and Monte Carlo results. IEEE Transactions on Nuclear Science, 60(2):746-750. doi: 10.1109/TNS.2012.2229294. Citado na pág. 60 
NIATEL et al. (1975) M.T. NIATEL, T.P. LOFTUS e W. OETZMAN. Comparison of exposure standards for ${ }^{60} \mathrm{Co}$ gamma rays. Metrologia, 11(1):17-23. doi: doi:10.1088/0026-1394/11/1/005. Citado na pág. 12

NIST (2013) NIST. NATIONAL INSTITUTE OF STANDARDS AND TECHNOLOGY, XCOM: Photon Cross Sections Database. http://physics.nist. gov/PhysRefData/Xcom/Text/XCOM.html, 2013. Último acesso em 31/08/2013. Citado na pág. 70

NPL (2013) NPL. NATIONAL PHYSICAL LABORATORY, Changes to the NPL air kerma standard for ${ }^{137} \mathrm{Cs}$ and ${ }^{60} \mathrm{Co}$. http://www.npl.co.uk/ content/ConPublication/4325/, 2013. Último acesso em 31/08/2013. Citado na pág. 50

NRC (2013) NRC. NATIONAL RESEARCH COUNCIL CANADA, Ionizing radiation standards. http://www.nrc-cnrc.gc.ca/eng/services/inms/ calibration-services/ionizing-radiation.html, 2013. Último acesso em 31/08/2013. Citado na pág. 50

O'BRIEN e LAMPERTI (2000) M. O'BRIEN e P. LAMPERTI. Comparison of the NIST and NPL air kerma standards used for X-ray measurements between $10 \mathrm{kV}$ and $80 \mathrm{kV}$. Journal of Research of the National Institute of Standards and Technology, 105(5):701-707. doi: doi:jresv105n5p701. Citado na pág. 49, 50

PAVLICEK et al. (1979) W. PAVLICEK, J. HORTON e R. TURCO. Evaluation of the MDH Industries Inc. pencil ionization chamber for direct beam CT measurements. Health Physics, 37(6):773-774. Citado na pág. 10

PERINI et al. (2013) A.P. PERINI, L.P. NEVES, J.M. FERNÁNDEZ-VAREA, L. BÜERMANN e L.V.E. CALDAS. Evaluation and simulation of a new ionization chamber design for use in computed tomography beams. IEEE Transactions on Nuclear Science, 60(2):768-773. doi: 10.1109/TNS.2012.2233752. Citado na pág. 63

PODGORSAK (2005) E.B. PODGORSAK. Radiation Oncology Physics: A Handbook for Teachers and Students. Relatório técnico, International Atomic Energy Agency, Vienna. Citado na pág. 2, 3, 20, 21, 23, 24, 27, 29

POLUDNIOWSKI et al. (2009) G. POLUDNIOWSKI, G. LANDRY, F. DEBLOIS, P.M. EVANS e F. VERHAEGEN. Spekcalc: A program to calculate photons spectra from tungsten anode x-ray tubes. Physics in Medicine and Biology, 54(19):N433-N438. doi: doi:10.1088/0031-9155/54/19/N01. Citado na pág. 105

POTIENS (1999) M.P.A. POTIENS. Metodologia Dosimétrica e Sistema de Referência para Radiação X Nivel Diagnóstico. Tese de Doutorado, Instituto de Pesquisas Energéticas e Nucleares, Universidade de São Paulo, Brasil. Citado na pág. 32 
PTB (2013) PTB. PHYSIKALISCH-TECHNISCHE BUNDESANSTALTPrimary Standards. http://www.ptb.de/en/org/6/62/625/luftkermastan.htm, 2013. Último acesso em 31/08/2013. Citado na pág. 49

RAESIDE (1976) D.E. RAESIDE. Monte Carlo principles and applications. Physics in Medicine and Biology, 21(2):181-197. doi: 10.1088/0031-9155/21/2/ 001. Citado na pág. 37

ROGERS (2006) D.W.O. ROGERS. Fifty years of Monte Carlo simulations for medical physics. Physics in Medicine and Biology, 51(13):R287-R301. doi: 10.1088/0031-9155/51/13/R17. Citado na pág. 13, 37, 39, 40

ROGERS e KAWRAKOW (2003) D.W.O. ROGERS e I. KAWRAKOW. Monte Carlo calculated correction factors for primary standards of air kerma. Medical Physics, 30(4):521-532. doi: 10.1118/1.1563663. Citado na pág. 13, 33, 34, 36

ROGERS et al. (2011) D.W.O. ROGERS, I. KAWRAKOW, J.P. SEUNTJENS, B.R.B. WALTERS e E. MAINEGRA-HING. NRC User Codes for EGSnrc. Relatório Técnico PIRS-702 (revC), National Research Council of Canada, Ottawa, Canada. Citado na pág. 35, 43, 44

ROOS e KLASSEN (1996) C.K. ROOS e N.V. KLASSEN. Water calorimetry for radiation dosimetry. Physics in Medicine and Biology, 41(1):1-29. doi: 10.1088/0031-9155/41/1/002. Citado na pág. 12

ROSA (1981) L.A.R. DA ROSA. Utilização de Dosímetros Termoluminescentes para Determinação da Exposição ou Dose Absorvida em Campos de Radiação Gama ou X com Distribuição Espectral Desconhecida. Tese de Doutorado, Universidade Federal do Rio de Janeiroo. Citado na pág. 32

ROSA e NETTE (1988) L.A.R. DA ROSA e H.P. NETTE. Thermoluminescent dosimeters for exposure assessment in gamma or X radiation fields with unknown spectral distribution. Applied Radiation and Isotopes, 39(3):191-197. doi: 10.1016/0883-2889(88)90171-2. Citado na pág. 32

RUSSA et al. (2007) D.J. LA RUSSA, M. MCEWEN e D.W.O. ROGERS. An experimental and computational investigation of the standard temperature-pressure correction factor for ion chambers in kilovoltage x rays. Medical Physics, 34 (12):4690-4699. doi: doi:10.1118/1.2799580. Citado na pág. 9

SALVAT et al. (2003) F. SALVAT, J.M. FERNÁNDEZ-VAREA e J. SEMPAU. PENELOPE - A code system for Monte Carlo simulation of electron and photon transport. Relatório técnico, OECD Nuclear Energy Agency, Issyles-Moulineaux, France. Citado na pág. 38, 40, 42

SALVAT et al. (2008) F. SALVAT, J.M. FERNÁNDEZ-VAREA e J. SEMPAU. Proceedings of the penelope-2008 workshop. Em PENELOPE-2008: A code system for Monte Carlo simulation of electron and photon transport, Spain. 30 June-3 July. Citado na pág. 42 
SELTZER e BERGSTROM (2003) S.M. SELTZER e P.M. BERGSTROM. Changes in the U.S. primary standards for the air kerma from gamma-ray beams. Journal of Research of National Institute of Standards and Technology, 108(5):359-381. Citado na pág. 49

SEMPAU e ANDREO (2006) J. SEMPAU e P. ANDREO. Configuration of the electron transport algorithm of PENELOPE to simulate ion chambers. Physics in Medicine and Biology, 51(14):3533-3548. doi: 10.1088/0031-9155/51/14/ 017. Citado na pág. 13

SEMPAU et al. (2006) J. SEMPAU, P. ANDREO, J. ALDANA, J. MAZURIER e F. SALVAT. Electron beam quality correction factors for plane-parallel ionization chambers: Monte Carlo calculations using the PENELOPE system. Physics in Medicine and Biology, 48(18):4427-4444. doi: 10.1088/0031-9155/49/18/016. Citado na pág. 13

SEUNTJENS e PALMANS (1999) J. SEUNTJENS e H. PALMANS. Correction factors and performance of a $4^{\circ} \mathrm{c}$ sealed water calorimeter. Physics in Medicine and Biology, 44(3):627-646. doi: 10.1088/0031-9155/44/3/001. Citado na pág. 12

SHANI (2001) G. SHANI. Radiation Dosimetry Instrumentation and Methods. CRC Press, New York, $2^{a}$ ed. Citado na pág. 34

SPURNY et al. (1973) Z. SPURNY, C. MILU e N. RACOVEANU. Comparison of X-ray beams using thermoluminescent dosemeters. Physics in Medicine and Biology, 18(2):276-278. doi: 10.1088/0031-9155/18/2/012. Citado na pág. 32

TAUHATA et al. (2003) L. TAUHATA, I.P. SALATI e A.R. DI PRINZIO. $\boldsymbol{R} \boldsymbol{a}$ dioproteção e Dosimetria: Fundamentos. Instituto de Radioproteção e Dosimetria (IRD) - CNEN. Citado na pág. xi, 16, 17

TEDGREN et al. (2010) A.C. TEDGREN, S. LUELMO e J.E. GRINDBORG. Characterization of a ${ }^{60} \mathrm{Co}$ unit at a secondary standard dosimetry laboratory: Monte Carlo simulations compared to measurements and results from the literature. Medical Physics, 37(6):2777-2786. doi: 10.1118/1.3392198. Citado na pág. 60, 119,123

UNSCEAR (2008) UNSCEAR. UNITED NATIONS SCIENTIFIC COMMITTEE ON THE EFFECTS OF ATOMIC RADIATION. Sources and effects of ionizing radiation. Relatório Técnico UNSCEAR 2008 Report, UNSCEAR, New York. Citado na pág. 1

VIVOLO (2006) V. VIVOLO. Desenvolvimento de um Sistema de Referência para Determinação do Equivalente de Dose Pessoal e da Constância de Feixes de Radiação $\boldsymbol{X}$. Tese de Doutorado, Instituto de Pesquisas Energéticas e Nucleares, Universidade de São Paulo, Brasil. Citado na pág. 32

WULFF et al. (2008) J. WULFF, J.T. HEVERHAGEN e K. ZINK. Monte-Carlobased perturbation and beam quality correction factors for thimble ionization chambers in high-energy photon beams. Physics in Medicine and Biology, 53(11):2823-2836. doi: 10.1088/0031-9155/53/11/005. Citado na pág. 14 
WYCKOFF (1960) H.O. WYCKOFF. Measurement of Cobalt-60 and Caesium137 gama rays with a free-air chamber. Journal of Research of the National Bureau of Standards C, 64(2):87-97. doi: http://archive.org/details/ jresv64Cn2p87. Citado na pág. 11

YORIAZ (2009) H. YORIAZ. Método de Monte Carlo: Princípios e aplicações em física médica. Revista Brasileira de Fisica Médica, 31(1):141-149. doi: http://www.abfm.org.br/rbfm/publicado/rbfm_v3n1_141-9.pdf. Citado na pág. 38, 39 